\author{
UNIVERSIDADE DE SÃO PAULO \\ ESCOLA DE ENGENHARIA DE SÃO CARLOS
}

JANISON RODRIGUES DE CARVALHO

\title{
Estatísticas de Ordem Superior e Redes Neurais Artificiais Aplicadas à Proteção de Linhas de Transmissão
}

São Carlos, SP

2013 



\section{Estatísticas de Ordem Superior e Redes Neurais Artificiais Aplicadas à Proteção de Linhas de Transmissão}

Tese de Doutorado apresentada à Escola de Engenharia de São Carlos da Universidade de São Paulo, como parte dos requisitos para obtenção do título de Doutor em Ciências, Programa de Engenharia Elétrica.

Área de Concentração: Sistemas Elétricos de Potência

Orientador: Prof. Tit. Denis Vinicius Coury

São Carlos - SP 2013 
AUTORIZO A REPRODUÇÃO TOTAL OU PARCIAL DESTE TRABALHO, POR QUALQUER MEIO CONVENCIONAL OU ELETRONNICO, PARA FINS DE ESTUDO E PESQUISA, DESDE QUE CITADA A FONTE.

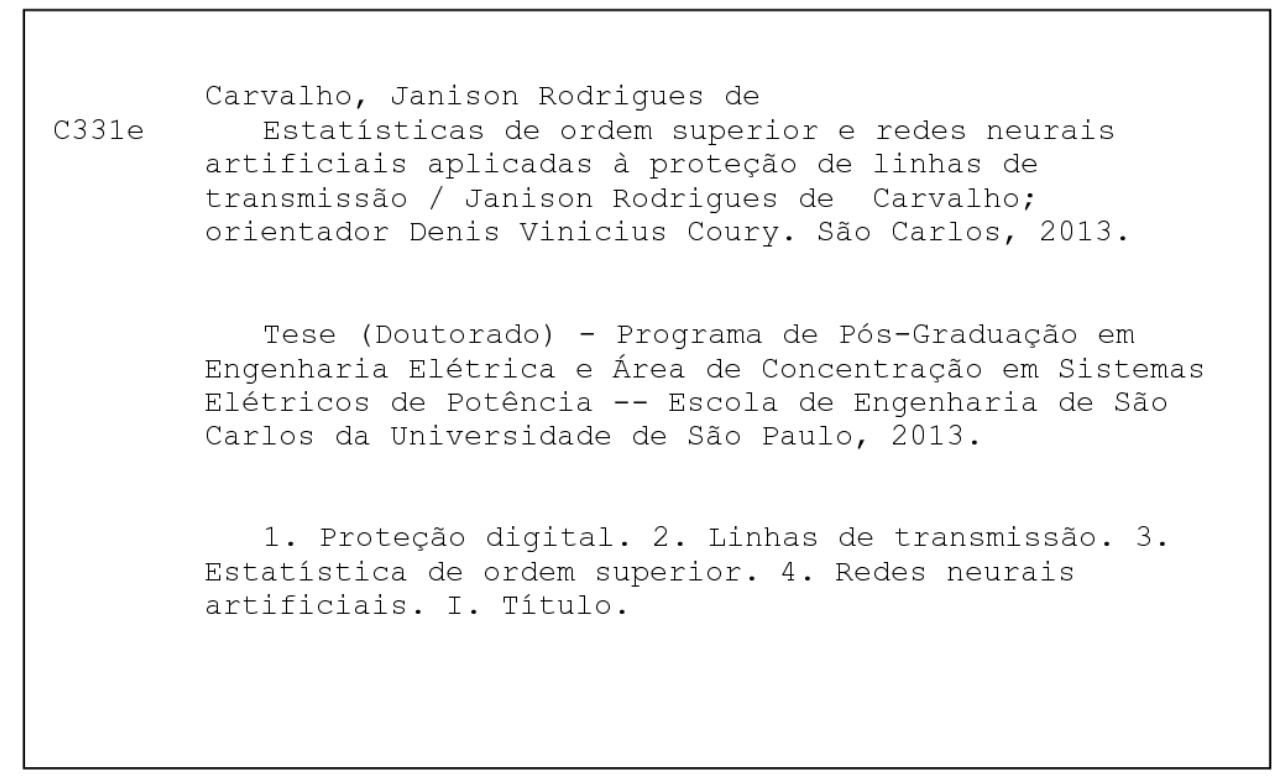




\section{FOLHA DE JULGAMENTO}

\section{Candidato: Engenheiro JANISON RODRIGUES DE CARVALHO.}

Título da tese: "Estatísticas de ordem superior e redes neurais artificiais aplicadas à proteção digital de linhas de transmissão ".

Data da defesa: 02/04/2013

\section{Comissão Julgadora:}

Prof. Titular Denis Vinicius Coury (Orientador)

(Escola de Engenharia de São Carlos/EESC)

Prof. Dr. Mário Oleskovicz

(Escola de Engenharia de São Carlos/EESC)

Prof. Dr. Fernando Augusto Moreira

(Universidade Federal da Bahia/UFBA)

Prof. Dr. Ghendy Cardoso Junior

(Universidade Federal de Santa Maria/UFSM)

Prof. Dr. Carlos Augusto Duque

(Universidade Federal de Juiz de Fora/UFJF)
Resultado:
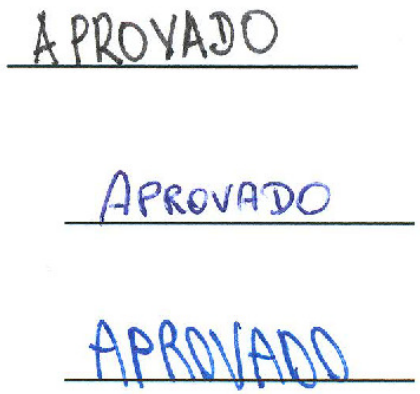

APROVADO

APROVADO

Coordenador do Programa de Pós-Graduação em Engenharia Elétrica e Presidente da Comissão de Pós-Graduação:

Prof. Titular Denis Vinicius Coury 

A esta mulher incrível, minha esposa, Lígia. 



\section{Agradecimentos}

Agradeço ao povo brasileiro.

Agradeço a minha esposa, Lígia Antonucci Forny, por seu apoio incondicional, por seu amor e por proporcionar, neste momento, uma alegria incomensurável na vida do futuro papai. Seja bem-vinda, Stela, minha filha!

Agradeço ao meu orientador, Prof. Denis Vinicius Coury, por confiar no meu trabalho e na minha dedicação, proporcionando uma grandiosa e valiosa experiência de vida pela qual passei nestes últimos anos na Universidade de São Paulo.

A meus pais, Jacimar e Marlene, e ao meu irmão, Rafael, minha eterna gratidão pelo apoio de sempre. Aos meus tios Ademir e Nena, e primos Anderson, André, Andréa, Vivi, Ana Clara e Gui, um especial agradecimento pela acolhida carinhosa no estado de São Paulo, fazendo de suas casas o meu segundo lar.

A todos os amigos do LSEE, da USP e de São Carlos, meus agradecimentos pela troca de experiências, pelos momentos de descontração e pela valiosa amizade. Marcelo, Tatiana, Silvio, Eugênia, Serjão, Monaro, Arthur, Hermes, e cia., um grande abraço e muito obrigado por tudo!

Ao professor David Calhau Jorge, minha gratidão pelo suporte nas minhas atividades de pesquisa, com discussões primorosas sobre o tema proteção. Ao professor José Antônio Pinto, meus sinceros agradecimentos pelo convite para integrar o corpo docente do CEFET-MG. A esta querida instituição, agradeço pelo apoio financeiro.

Agradeço imensamente à Coordenação de Aperfeiçoamento de Pessoal de Nível Superior pelo suporte financeiro que remonta ao período do mestrado na UFJF.

Finalmente, deixo o meu muito obrigado ao Departamento de Engenharia Elétrica da Escola de Engenharia de São Carlos e à Universidade de São Paulo. 

"Esta circulação interminável de fluido elétrico pode parecer um contrassenso, no entanto ela é verdadeira e real, e você pode senti-la com suas mãos."

Alessandro Volta 



\section{Resumo}

Carvalho, J. R. Estatísticas de Ordem Superior e Redes Neurais Artificiais Aplicadas à Proteção Digital de Linhas de Transmissão. 2013. 261 p. Tese (Doutorado) - Escola de Engenharia de São Carlos, Universidade de São Paulo, São Carlos, 2013.

Neste trabalho, é apresentado e discutido um novo modelo para proteção de Linhas de Transmissão. O sistema proposto executa, individualmente, as etapas tradicionais da filosofia de proteção de distância: detecção, classificação e localização. Este modelo emprega Estatísticas de Ordem Superior (EOS) como ferramenta de extração de características, para posterior aplicação das Redes Neurais Artificiais (RNAs). As RNAs são responsáveis pelas tomadas de decisões do sistema, no sentido de identificar a ocorrência da falta e o tipo da mesma, além de localizar a falta no que tange às zonas de proteção consideradas. O processamento com tais estatísticas é responsável pela transformação dos dados para um domínio onde as diferentes faltas são evidenciadas através de agrupamentos de dados (padrões). O banco de dados disponível com sinais elétricos de LTs em condições de falta é utilizado para cálculo das estatísticas e o posterior treinamento supervisionado (e validação) das redes. A junção das etapas de proteção em um único modelo permitiu o desenvolvimento de um protótipo de relé, sendo executada uma bateria extensiva de testes, com as mais diversas condições de faltas possíveis. Apesar de operar apenas com sinais de corrente, o método proposto alcançou resultados que, em comparação com a técnica tradicional de proteção de distância, baseada na impedância aparente, aumenta consideravelmente o desempenho da proteção de LTs. Especialmente para as faltas monofásicas, de ocorrência mais comum, o desempenho obtido com o algoritmo proposto é largamente superior ao obtido com um relé de distância tradicional normalmente empregado em proteção de LTs, evidenciando a relevância da técnica empregada em aplicações de proteção.

Palavras-chave: Proteção digital, Linhas de transmissão, Redes Neurais Artificiais, Estatísticas de Ordem Superior. 



\section{Abstract}

Carvalho, J. R. Higher-Order Statistics and Artificial Neural Networks Applied to Transmission Line Protection. 2013. 261 p. Ph.D. Thesis - Engineering School of São Carlos, University of São Paulo, São Carlos, 2013.

A novel method of Transmission Lines (TLs) protection is presented and discussed in this work. The proposed algorithm performs the traditional steps of distance relaying, such as: fault detection, classification and location. The new method applies the Higher Order Statistics (HOS), also known as cumulants, as a tool for feature extraction in order to apply Artificial Neural Networks (ANN) for pattern classification. These networks are responsible for the processing of information, identifying a possible fault condition, the type of fault and, finally, its location in terms of fault zones considered for the problem. The application of HOS in a protection scheme is responsible for the transformation of electrical data, such as current signals, to a different domain where the different types of faults are highlighted by different classes of samples. The available database was obtained by simulating an Electric Power System and it is used for computing the statistics and training/validating the distinct neural networks of each step of the distance protection. A relay prototype is obtained by combining these steps in a synchronized operation. This prototype allowed the execution of extensive tests, simulating the operation of a protective system in real-time. Despite the use of currents signals only, the proposed method provided efficient protection for the EPS under study. In fact, comparing the results with a traditional method applied to distance protection, based on apparent impedance, an improvement of the protection performance was demonstrated. Especially for faults involving one phase and the ground, the most common in power systems, the results of the new methodology was significantly superior to that of the conventional relay. It can be concluded that the technique presents a high relevance for applications in transmission line protection.

Keywords: Digital Protection, Transmission Lines, Artificial Neural Networks, HigherOrder Statistics. 



\section{Lista de Figuras}

Figura 1. Um sistema de proteção típico para um trecho de um sistema de transmissão, com as zonas de atuação para o relé $R_{d e}$

Figura 2. Componentes típicos de um sistema de proteção.

Figura 3. Princípio de medição dos relés de distância. 53

Figura 4. Detecção de distúrbios de QEE com a utilização de cumulantes. 54

Figura 5. Deteç̧ão de faltas pela comparação ciclo-a-ciclo: (a) sinal elétrico e; (b) índice $s_{c}$.

Figura 6. Exemplo de classificação de faltas pelo método das correntes superpostas: (a) falta A-T; (b) falta A-B; (c) falta A-B-T e (d) falta A-B-C.

Figura 7. Tipos de características funcionais de relés de distância: (a) região de proteção circular e (b) região de proteção quadrilateral.

Figura 8. Cálculo de cumulantes para janelas deslizantes de sinais elétricos.

Figura 9. Modelo de um neurônio artificial. 88

Figura 10. Perceptron Multicamadas (2 camadas neurais).

Figura 11. O princípio de operação adotado para o sistema proposto: três sistemas distintos responsáveis pelas operações de deteç̧ão, classificação e localização de faltas em LTs.

Figura 12. Diagrama funcional generalizado para as etapas de deteç̧ão, classificação e localização de faltas do sistema de proteção proposto.

Figura 13. Diagrama funcional do sistema de proteção proposto. 95

Figura 14. Representação do problema de separação de classes: (a) médias próximas com baixa variância; (b) médias afastadas com variância elevada e; (c) médias afastadas e baixa variância. 98

Figura 15. Representação do processo de medição de sinais elétricos nos relés digitais. 
Figura 16. Representação dos espectros dos sinais: (a) analógico; (b) discreto com frequência de amostragem adequada e; (c) discreto com frequência de amostragem inadequada.

Figura 17. Resposta em módulo de um filtro ideal e do filtro Butterworth de várias ordens.

Figura 18. Exemplo de filtragem de um sinal elétrico por um filtro anti-aliasing........ 104

Figura 19. Modelo simplificado de um conversor A/D.......................................... 105

Figura 20. Relação entrada/saída típica de um CAD.................................................. 106

Figura 21. Exemplo do processo de conversão A/D de um sinal elétrico. .................... 107

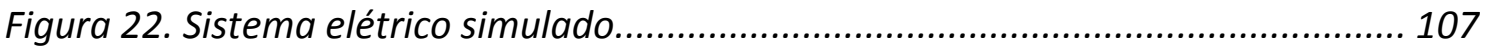

Figura 23. Arranjo das resistências para simulações das faltas: (a) fase-terra; (b) fase-

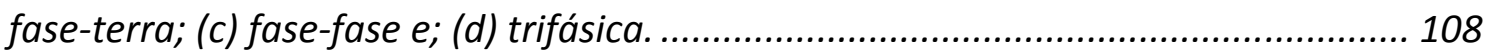

Figura 24. Estrutura da torre de transmissão com as disposições geométrica dos condutores.

Figura 25. Modelagem do SEP estudado no Simulink ${ }^{\circledR}$.

Figura 26. Exemplo de simulação do modelo: em (a) sinais de tensão e em (b) sinais de corrente para uma falta A-T a $65 \mathrm{~km}$ do relé, com incidência de $90^{\circ}$ e resistência de falta $R_{t}=25 \Omega$.

Figura 27. Intervalos de tempo utilizados para geração dos padrões do problema de deteç̧ão.

Figura 28. Fisher Discriminant Ratio para o problema de deteç̧ão: (a) cumulantes de $2 \underline{a}$ ordem; (b) cumulantes de $3 \underline{a}$ ordem e; (c) cumulantes de $4 \underline{a}$ ordem.

Figura 29. Padrões de regime pré- e pós-falta gerados para o problema de detecção.

Figura 30. Representação da rede neural utilizada para deteç̧ão de falta.

Figura 31. Resultados obtidos para a RNA de detecção: (a) evolução do EQM no treinamento e; (b) validação.

Figura 32. Simulação de falta $A-T$ na linha $L T 2$ a $85 \mathrm{~km}$ do barramento $E$, com $R_{t}=100 \Omega$ e $\phi=90^{\circ}$. Sinais: (a) correntes; (b) saídas do filtro notch; (c) cumulantes e; (d) saída da rede de detecção. 
Figura 33. Resultados de detecção para simulações de faltas na linha $L T 2 \mathrm{com} d=10 \mathrm{~km}$, $R_{t}=10 \Omega, R_{f}=2 \Omega$ e $\phi=0^{\circ}$

Figura 34. Resultados de detecção para simulações de faltas na linha LT2 com d=130

$k m, R_{t}=1 \Omega, R_{f}=1 \Omega$ e $\phi=90^{\circ}$.

Figura 35. Resultados de detecção para simulações de faltas na linha LT3 com $d=200$

$\mathrm{km}, R_{t}=10 \Omega, R_{f}=4 \Omega$ e $\phi=150^{\circ}$. 126

Figura 36. Intervalo de tempo utilizado para geração dos padrões do problema de classificação.

Figura 37. Fisher Discriminant Ratio para o problema de classificação (a) cumulantes de

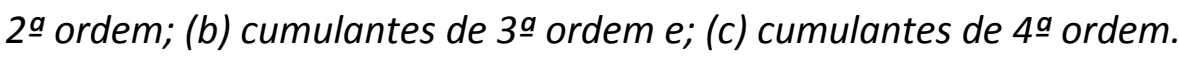

Figura 38. Padrões gerados para o problema de classificação quanto ao envolvimento da fase monitorada na falta ocorrida: caso do monitoramento da fase A.

Figura 39. Representação da rede neural utilizada para classificação de falta.

Figura 40. Resultados obtidos para a RNA de classificação: (a) evolução do EQM no treinamento e; (b) validação.

Figura 41. Simulação de falta A-T a $50 \mathrm{~km}$ do relé, com $R_{t}=100 \Omega$ e $\phi=150^{\circ}$. Sinais: (a) correntes; (b) saídas do filtro notch; (c) cumulantes e; (d) saída da rede de classificação correspondente à Fase $A$.

Figura 42. Simulação de falta $C-T$ a $50 \mathrm{~km}$ do relé, com $R_{t}=100 \Omega$ e $\phi=150^{\circ}$. Sinais: (a) correntes; (b) saídas do filtro notch; (c) cumulantes e; (d) saída da rede de classificação correspondente à Fase A.

Figura 43. Distribuição amostral do cumulante de $2 \underline{a}$ ordem com lag $\tau=0$, para as classes $C_{1}$ e $C_{2}$, associadas ao problema de identificação da terra na falta.

Figura 44. Simulação de falta A-T a $50 \mathrm{~km}$ do relé, com $R_{t}=100 \Omega$ e $\phi=150^{\circ}$. Sinais: (a) correntes; (b) corrente de sequência zero; (c) cumulante e; (d) saída de classificação de terra.

Figura 45. Resultados de classificação para simulações de faltas na linha LT2 com $d=10$ $k m, R_{t}=0 \Omega, R_{f}=10 \Omega$ e $\phi=60^{\circ}$. Saídas do módulo de classificação: (a) fase $A$; (b) fase $B$; (c) fase C; e (d) terra.

Figura 46. Resultados de classificação para simulações de faltas na linha LT2 com $d=115 \mathrm{~km}, R_{t}=75 \Omega, R_{f}=1 \Omega$ e $\phi=0^{\circ}$. Saídas do módulo de classificação: (a) fase $A$; (b) fase $B$; (c) fase $C$; e (d) terra. 
Figura 47. Resultados de classificação para simulações de faltas na linha LT3 com $d=220 \mathrm{~km}, R_{t}=25 \Omega, R_{f}=4 \Omega$ e $\phi=90^{\circ}$. Saídas do módulo de classificação: (a) fase $A$; (b) fase $B$; (c) fase $C$; e (d) terra.

Figura 48. Intervalo de tempo utilizado para geração dos padrões do problema de localização.

Figura 49. Definição das zonas de proteção para o SEP simulado.

Figura 50. Fisher Discriminant Ratio para o problema de localização de faltas F-T (fase em falta): (a) cumulantes de 2a ordem; (b) cumulantes de $3 \underline{a}$ ordem e; (c) cumulantes de $4 \underline{a}$ ordem. 144

Figura 51. Fisher Discriminant Ratio para o problema de localização de faltas F-T (fase não faltosa): (a) cumulantes de $2^{a}$ ordem; (b) cumulantes de $3^{\underline{a}}$ ordem e; (c) cumulantes de $4 \underline{a}$ ordem.

Figura 52. Padrões gerados para o problema de localização de faltas do tipo fase-terra.

Figura 53. Representação da rede neural utilizada no problema de localização de faltas F-T.

Figura 54. Resultados obtidos para a RNA de localização (faltas do tipo F-T): (a) evolução do EQM no treinamento e; validação da rede: (b) saída $y_{1 ;}$ (c) saída $y_{2}$ e (d) saída $y_{3}$

Figura 55. Simulação de falta A-T a $110 \mathrm{~km}$ do relé, com $R_{t}=10 \Omega$ e $\phi=30^{\circ}$. Sinais: (a) correntes; (b) saídas do filtro notch; (c) cumulantes e; (d) saídas da rede de localização para faltas $F-T$.

Figura 56. Resultados de localização para simulações de faltas fase-terra na linha LT2 com $d=25 \mathrm{~km}, R_{t}=75 \Omega$ e $\phi=30^{\circ}$.

Figura 57. Resultados de localização para simulações de faltas fase-terra na linha LT2 com $d=140 \mathrm{~km}, R_{t}=1 \Omega$ e $\phi=90^{\circ}$.....

Figura 58. Resultados de localização para simulações de faltas fase-terra na linha LT3 com $d=200 \mathrm{~km}, R_{t}=10 \Omega$ e $\phi=120^{\circ}$.

Figura 59. Fisher Discriminant Ratio para o problema de localização de faltas F-F-T (fase em falta): (a) cumulantes de $2^{a}$ ordem; (b) cumulantes de $3^{\underline{a}}$ ordem e; (c) cumulantes de $4 \underline{a}$ ordem. 
Figura 60. Fisher Discriminant Ratio para o problema de localização de faltas F-F-T (fase não faltosa): (a) cumulantes de $2^{\underline{a}}$ ordem; (b) cumulantes de $3 \underline{a}$ ordem e; (c) cumulantes de $4 \underline{a}$ ordem.

Figura 61. Padrões gerados para solução do problema de localização de faltas do tipo fase-fase-terra.

Figura 62. Resultados obtidos para a RNA de localização (faltas do tipo F-F-T): (a) evolução do EQM no treinamento e; validação da rede: (b) saída $y_{1 ;}$ (c) saída $y_{2}$; e (d) saída $y_{3}$

Figura 63. Simulação de falta $A-B-T$ a $140 \mathrm{~km}$ do relé, com $R_{t}=10 \Omega$ e $\phi=90^{\circ}$. Sinais: (a) correntes; (b) saídas do filtro notch; (c) cumulantes e; (d) saídas da rede de localização para faltas F-F-T.

Figura 64. Resultados de localização para simulações de faltas fase-fase-terra na linha $L T 2$ com $d=15 \mathrm{~km}, R_{t}=100 \Omega$ e $\phi=90^{\circ}$

Figura 65. Resultados de localização para simulações de faltas fase-fase-terra na linha $L T 3$ com $d=130 \mathrm{~km}, R_{t}=10 \Omega$ e $\phi=150^{\circ}$.

Figura 66. Resultados de localização para simulações de faltas fase-fase-terra na linha LT3 com $d=215 \mathrm{~km}, R_{t}=1 \Omega$ e $\phi=0^{\circ}$

Figura 67. Fisher Discriminant Ratio para o problema de localização de faltas $F-F$ (fase em falta): (a) cumulantes de 2a ordem; (b) cumulantes de $3 \underline{a}$ ordem $e$; (c) cumulantes de $4 \underline{a}$ ordem 160

Figura 68. Fisher Discriminant Ratio para o problema de localização de faltas $F-F$ (fase não faltosa): (a) cumulantes de $2^{a}$ ordem; (b) cumulantes de ${ }^{\underline{a}}$ ordem e; (c) cumulantes de $4 \underline{a}$ ordem.

Figura 69. Padrões gerados para solução do problema de localização de faltas do tipo fase-fase.

Figura 70. Resultados obtidos para a RNA de localização (faltas do tipo F-F): (a) evolução do EQM no treinamento e; validação da rede: (b) saída $y_{1}$; (c) saída $y_{2}$; e (d) saída $y_{3}$.

Figura 71. Simulação de falta $A-B$ a $85 \mathrm{~km}$ do relé, com $R_{f}=5 \Omega$ e $\phi=60^{\circ}$. Sinais: (a) correntes; (b) saídas do filtro notch; (c) cumulantes e; (d) saídas da rede de localização para faltas $F-F$. 
Figura 72. Resultados de localização para simulações de faltas fase-fase na linha LT2 com $d=35 \mathrm{~km}, R_{f}=0 \Omega$ e $\phi=30^{\circ}$.

Figura 73. Resultados de localização para simulações de faltas fase-fase na linha LT3 com $d=155 \mathrm{~km}, R_{f}=2 \Omega$ e $\phi=90^{\circ}$.

Figura 74. Resultados de localização para simulações de faltas fase-fase na linha LT3 com $d=240 \mathrm{~km}, R_{f}=0,5 \Omega$ e $\phi=0^{\circ}$.. 166

Figura 75. Fisher Discriminant Ratio para o problema de localização de faltas F-F-F: (a) cumulantes de $2 \underline{a}$ ordem; (b) cumulantes de $3 \underline{a}$ ordem e; (c) cumulantes de $4 \underline{a}$ ordem.

Figura 76. Padrões gerados para solução do problema de localização de faltas do tipo fase-fase-fase.

Figura 77. Resultados obtidos para a RNA de localização (faltas do tipo F-F-F): (a) evolução do EQM no treinamento e; validação da rede: (b) saída $y_{1}$; (c) saída $y_{2}$ e (d) saída $y_{3}$.

Figura 78. Simulação de falta $A-B-C$ a $100 \mathrm{~km}$ do relé, com $R_{f}=5 \Omega$ e $\phi=60^{\circ}$. Sinais: (a) correntes; (b) saídas do filtro notch; (c) cumulantes $e$; (d) saídas da rede de localização para faltas F-F-F.

Figura 79. Resultados de localização para simulações de faltas nas linhas LT2 e LT3 referentes aos casos 1, 2 e 3 de faltas trifásicas.

Figura 80. Estruturas das etapas de deteç̧ão, classificação e localização.

Figura 81. Protótipo de relé digital baseado na metodologia proposta. 174

Figura 82. Representação detalhada da etapa de condicionamento de sinais. 174

Figura 83. Representação da operação do controle de temporização do relé proposto.

Figura 84. Distribuições de probabilidades para geração dos parâmetros de faltas... 178

Figura 85. Diagrama funcional da metodologia de direcionalidade. 179

Figura 86. Combinações de simulações referentes a dez experimentos de faltas F-T. 181

Figura 87. Resultados de operação do sistema de proteção proposto para dez experimentos distintos de faltas F-T: saídas inativas em cor preta e ativas em cor branca 
Figura 88. Resultados de operação do método de proteção tradicional para dez experimentos distintos de faltas F-T: saídas inativas em cor preta e ativas em cor branca.

Figura 89. Parâmetros de faltas F-T associados a erros de localização na Zona 1 (LT2): Operação sem pré-processamento em (a), (b) e (c) e com pré-processamento em (d), (e) $e(f)$.

Figura 90. Distribuição dos parâmetros de faltas F-T associados a erros de localização na Zona 1 (LT2): Operação sem pré-processamento em (a), (b) e (c) e com préprocessamento em (d), (e) e (f). 189

Figura 91. Parâmetros de faltas F-T associados a erros de localização na Zona 2 (LT2): Operação sem pré-processamento em (a), (b) e (c) e com pré-processamento em (d), (e) $e(f)$.

Figura 92. Distribuição dos parâmetros de faltas F-T associados a erros de localização na Zona 2 (LT2): Operação sem pré-processamento em (a), (b) e (c) e com préprocessamento em (d), (e) e (f).

Figura 93. Parâmetros de faltas F-T associados a erros de localização na Zona 2 (LT3): Operação sem pré-processamento em (a), (b) e (c) e com pré-processamento em (d), (e) $e(f)$.

Figura 94. Parâmetros de faltas F-T associados a erros de localização na Zona 3 (LT3): Operação sem pré-processamento em (a), (b) e (c) e com pré-processamento em (d), (e) $e(f)$.

Figura 95. Distribuição dos parâmetros de faltas F-T associados a erros de localização na Zona 3 (LT3): Operação sem pré-processamento em (a), (b) e (c) e com préprocessamento em (d), (e) e (f).

Figura 96. Resumo do resultado de localização (taxa de acerto) para faltas F-T: (a) metodologia proposta e; (b) metodologia tradicional.

Figura 97. Lugar geométrico das impedâncias referentes às faltas monofásicas na zona 1. 204

Figura 98. Parâmetros de faltas F-F-T associados a erros de localização na Zona 1 (LT2): Operação sem pré-processamento em (a), (b) e (c) e com pré-processamento em (d), (e) $e(f)$. 207 
Figura 99. Parâmetros de faltas F-F-T associados a erros de localização na Zona 2 (LT2): Operação sem pré-processamento em (a), (b) e (c) e com pré-processamento em (d), (e) $e(f)$. 210

Figura 100. Distribuição dos parâmetros de falta F-F-T associados a erros de localização na Zona 2 (LT2): Operação sem pré-processamento em (a), (b) e (c) e com préprocessamento em (d), (e) e (f).

Figura 101. Parâmetros de faltas F-F-T associados a erros de localização na Zona 2 (LT3): Operação sem pré-processamento em (a), (b) e (c) e com pré-processamento em (d), (e) e (f).

Figura 102. Parâmetros de faltas F-F-T associados a erros de localização na Zona 3 (LT3): Operação sem pré-processamento em (a), (b) e (c) e com pré-processamento em (d), (e) e (f).

Figura 103. Distribuição de parâmetros de faltas F-F-T associados a erros de localização na Zona 3 (LT3): Operação sem pré-processamento em (a), (b) e (c) e com préprocessamento em (d), (e) e (f).

Figura 104. Resumo do resultado de localização (taxa de acerto) para faltas F-F-T: (a) metodologia proposta e; (b) metodologia tradicional.

Figura 105. Parâmetros de faltas F-F associados a erros de localização na Zona 1 (LT2): Operação sem pré-processamento em (a), (b) e (c) e com pré-processamento em (d), (e) $e(f)$.

Figura 106. Distribuição dos parâmetros de faltas F-F associados a erros de localização na Zona 1 (LT2): Operação sem pré-processamento em (a), (b) e (c) e com préprocessamento em (d), (e) e (f).

Figura 107. Parâmetros de faltas F-F associados a erros de localização na Zona 2 (LT2): Operação sem pré-processamento em (a), (b) e (c) e com pré-processamento em (d), (e) $e(f)$.

Figura 108. Parâmetros de faltas F-F associados a erros de localização na Zona 2 (LT3): Operação sem pré-processamento em (a), (b) e (c) e com pré-processamento em (d), (e) $e(f)$. 228

Figura 109. Distribuição dos parâmetros de faltas F-F associados a erros de localização na Zona 2 (LT3): Operação sem pré-processamento em (a), (b) e (c) e com préprocessamento em (d), (e) e (f). 
Figura 110. Parâmetros de faltas F-F associados a erros de localização na Zona 3 (LT3):

Operação sem pré-processamento em (a), (b) e (c) e com pré-processamento em (d), (e)

$e(f)$.

Figura 111. Resumo do resultado de localização (taxa de acerto) para faltas F-F: (a) metodologia proposta e; (b) metodologia tradicional.

Figura 112. Parâmetros de faltas F-F-F associados a erros de localização na Zona 1 (LT2): Operação sem pré-processamento em (a), (b) e (c) e com pré-processamento em (d), (e) e (f).

Figura 113. Parâmetros de faltas F-F-F associados a erros de localização na Zona 2 (LT2): Operação sem pré-processamento em (a), (b) e (c) e com pré-processamento em (d), (e) e (f).

Figura 114. Distribuição dos parâmetros de faltas F-F-F associados a erros de localização na Zona 2 (LT2): Operação sem pré-processamento em (a), (b) e (c) e com pré-processamento em (d), (e) e (f).

Figura 115. Parâmetros de faltas F-F-F associados a erros de localização na Zona 2 (LT3): Operação sem pré-processamento em (a), (b) e (c) e com pré-processamento em (d), (e) e (f).

Figura 116. Parâmetros de faltas F-F-F associados a erros de localização na Zona 3 (LT3): Operação sem pré-processamento em (a), (b) e (c) e com pré-processamento em (d), (e) e (f).

Figura 117. Distribuição dos parâmetros de faltas F-F-F associados a erros de localização na Zona 3 (LT3): Operação sem pré-processamento em (a), (b) e (c) e com pré-processamento em (d), (e) e (f).

Figura 118. Resumo do resultado de localização (taxa de acerto) para faltas F-F-F: (a) metodologia proposta e; (b) metodologia tradicional. 



\section{Lista de Tabelas}

Tabela 4-1. Especificação dos condutores do sistema elétrico simulado 108

Tabela 4-2. Demais parâmetros da $L T$ 109

Tabela 4-3. Parâmetros elétricos da LT simulada 110

Tabela 4-4. Parâmetros elétricos da geração nas barras $D$ e $G$ 110

Tabela 4-5. Conjunto de parâmetros de condições de faltas simuladas para LT1 112

Tabela 4-6. Conjunto de parâmetros de condições de faltas simuladas para LT2 112

Tabela 4-7. Conjunto de parâmetros de condições de faltas simuladas para LT3 112

Tabela 5-1. Conjunto de parâmetros de falta utilizados para geração de padrões de treinamento e validação da rede neural de detecção

Tabela 5-2. Conjunto de parâmetros de falta utilizados para geração de padrões de treinamento e validação da rede neural de classificação

Tabela 5-3. Conjunto de parâmetros de falta utilizados para geração de padrões de treinamento e validação das redes neurais de localização. 145

Tabela 6-1. Constantes utilizadas para validação das indicações de detecção, classificação e localização do relé proposto.

Tabela 6-2. Caso especial de validação do resultado de classificação. 177

Tabela 6-3. Casos especiais de validação do resultado de localização. 177

Tabela 6-4. Resultados de detecção para faltas F-T na Zona 1, linha LT2. 185

Tabela 6-5. Resultados de classificação para faltas F-T na Zona 1, linha LT2. 186

Tabela 6-6. Resultados de localização para faltas F-T na Zona 1, linha LT2. 186

Tabela 6-7. Taxa de acerto de localização para faltas F-T na Zona 1 (LT2), em função da distância da falta. 190

Tabela 6-8. Resultados de detecção para faltas F-T na Zona 2, linha LT2 190

Tabela 6-9. Resultados de classificação para faltas F-T na Zona 2, linha LT2. 191

Tabela 6-10. Resultados de localização para faltas F-T na Zona 2, linha LT2. 191 
Tabela 6-11. Taxa de acerto de localização para faltas F-T na Zona 2 (LT2), em função da distância da falta. 194

Tabela 6-12. Resultados de detecção para faltas F-T na Zona 2, linha LT3. 195

Tabela 6-13. Resultados de classificação para faltas F-T na Zona 2, linha LT3. 195

Tabela 6-14. Resultados de localização para faltas F-T na Zona 2, linha LT3. 196

Tabela 6-15. Taxa de acerto de localização para faltas F-T na Zona 2 (LT3), em função da distância da falta. 198

Tabela 6-16. Resultados de detecção para faltas F-T na Zona 3, linha LT3 199

Tabela 6-17. Resultados de classificação para faltas F-T na Zona 3, linha LT3. 199

Tabela 6-18. Resultados de localização para faltas F-T na Zona 3, linha LT3. 199

Tabela 6-19. Taxa de acerto de localização para faltas F-T na Zona 3 (LT3), em função da distância da falta. 202

Tabela 6-20. Resultados de detecção para faltas F-F-T na Zona 1, linha LT2 205

Tabela 6-21. Resultados de classificação para faltas F-F-T na Zona 1, linha LT2. 205

Tabela 6-22. Resultados de localização para faltas F-F-T na Zona 1, linha LT2. 205

Tabela 6-23. Taxa de acerto de localização para faltas F-F-T na Zona 1 (LT2), em função da distância da falta. 207

Tabela 6-24. Resultados de detecção para faltas F-F-T na Zona 2, linha LT2 208

Tabela 6-25. Resultados de classificação para faltas F-F-T na Zona 2, linha LT2. 208 Tabela 6-26. Resultados de localização para faltas F-F-T na Zona 2, linha LT2. 209

Tabela 6-27. Taxa de acerto de localização para faltas F-F-T na Zona 2 (LT2), em função da distância da falta. 211

Tabela 6-28. Resultados de detecção para faltas F-F-T na Zona 2, linha LT3 212

Tabela 6-29. Resultados de classificação para faltas F-F-T na Zona 2, linha LT3. 212 Tabela 6-30. Resultados de localização para faltas F-F-T na Zona 2, linha LT3. 212

Tabela 6-31. Taxa de acerto de localização para faltas F-F-T na Zona 2 (LT3), em função da distância da falta. 214 
Tabela 6-32. Resultados de deteç̧ão para faltas F-F-T na Zona 3, linha LT3 215

Tabela 6-33. Resultados de classificação para faltas F-F-T na Zona 3, linha LT3. 215

Tabela 6-34. Resultados de localização para faltas F-F-T na Zona 3, linha LT3. 215

Tabela 6-35. Taxa de acerto de localização para faltas F-F-T na Zona 3 (LT3), em função da distância da falta. 218

Tabela 6-36. Resultados de detecção para faltas F-F na Zona 1, linha LT2 220

Tabela 6-37. Resultados de classificação para faltas F-F na Zona 1, linha LT2. 220

Tabela 6-38. Resultados de localização para faltas F-F na Zona 1, linha LT2. 220

Tabela 6-39. Taxa de acerto de localização para faltas F-F na Zona 1 (LT2), em função da distância da falta. 223

Tabela 6-40. Resultados de detecção para faltas F-F na Zona 2, linha LT2 223

Tabela 6-41. Resultados de classificação para faltas F-F na Zona 2, linha LT2. 223

Tabela 6-42. Resultados de localização para faltas F-F na Zona 2, linha LT2. 224

Tabela 6-43. Taxa de acerto de localização para faltas F-F na Zona 2 (LT2), em função da distância da falta. 225

Tabela 6-44. Resultados de deteç̧ão para faltas F-F na Zona 2, linha LT3 226

Tabela 6-45. Resultados de classificação para faltas F-F na Zona 2, linha LT3 226

Tabela 6-46. Resultados de localização para faltas F-F na Zona 2, linha LT3. 226

Tabela 6-47. Taxa de acerto de localização para faltas F-F na Zona 2 (LT3), em função da distância da falta. 229

Tabela 6-48. Resultados de detecção para faltas F-F na Zona 3, linha LT3 229

Tabela 6-49. Resultados de classificação para faltas F-F na Zona 3, linha LT3 230 Tabela 6-50. Resultados de localização para faltas F-F na Zona 3, linha LT3 230

Tabela 6-51. Taxa de acerto de localização para faltas F-F na Zona 3 (LT3), em função da distância da falta. 231

Tabela 6-52. Resultados de detecção para faltas F-F-F na Zona 1, linha LT2 234 
Tabela 6-53. Resultados de classificação para faltas F-F-F na Zona 1, linha LT2. 234

Tabela 6-54. Resultados de localização para faltas F-F-F na Zona 1, linha LT2. 234

Tabela 6-55. Taxa de acerto de localização para faltas F-F-F na Zona 1 (LT2), em função da distância da falta. 236

Tabela 6-56. Resultados de detecção para faltas F-F-F na Zona 2, linha LT2 236

Tabela 6-57. Resultados de classificação para faltas F-F-F na Zona 2, linha LT2. 237

Tabela 6-58. Resultados de localização para faltas F-F-F na Zona 2, linha LT2. 237

Tabela 6-59. Taxa de acerto de localização para faltas F-F-F na Zona 2 (LT2), em função da distância da falta. 239

Tabela 6-60. Resultados de detecção para faltas F-F-F na Zona 2, linha LT3 240

Tabela 6-61. Resultados de classificação para faltas F-F-F na Zona 2, linha LT3 240

Tabela 6-62. Resultados de localização para faltas F-F-F na Zona 2, linha LT3. 240

Tabela 6-63. Taxa de acerto de localização para faltas F-F-F na Zona 2 (LT3), em função da distância da falta. 242

Tabela 6-64. Resultados de detecção para faltas F-F-F na Zona 3, linha LT3 243

Tabela 6-65. Resultados de classificação para faltas F-F-F na Zona 3, linha LT3 243

Tabela 6-66. Resultados de localização para faltas F-F-F na Zona 3, linha LT3 243

Tabela 6-67. Taxa de acerto de localização para faltas F-F-F na Zona 3 (LT3), em função da distância da falta. 246 


\section{Lista de Abreviaturas e Siglas}

$\mathrm{A} / \mathrm{D}$

ABNT

AG

ART

ATP

Bit

CA

CAD

$\mathrm{CC}$

CESP

CPU

DFT

DSP

EOS

EQM

F-F

F-F-F

F-F-T

F-T

FDR

FFT

IEEE

IIR

LT

MODWT

P-B

PDS

PMC

$\mathrm{R}-\mathrm{X}$

RNA

$\mathrm{S} / \mathrm{H}$
Analógico/Digital

Associação Brasileira de Normas Técnicas

Algoritmo Genético

Adaptive Ressonance Theory

Alternative Transient Program

Binary Digit

Corrente Alternada

Conversor Analógico/Digital

Corrente Contínua

Companhia Energética de São Paulo

Central Processing Unit

Discrete Fourier Transform

Digital Signal Processing

Estatísticas de Ordem Superior

Erro Quadrático Médio

Fase-Fase (falta)

Fase-Fase-Fase (falta)

Fase-Fase-Terra (falta)

Fase-Terra (falta)

Fisher Discriminant Ratio

Fast Fourier Transform

Institute of Electrical and Electronic Engineers

Infinite Impulse Response

Linha de Transmissão

Maximal Overlap Discrete Wavelet Transform

Passa-Baixas

Processamento Digital de Sinais

Perceptron Multicamadas

Resistência-Reatância

Redes Neurais Artificiais

Sample-and-Hold 
SEP Sistema Elétrico de Potência

SNR Signal-to-Noise Ratio

TC Transformador de Corrente

TP Transformador de Potencial

TRAFO Transformador

TRF Transformada Rápida de Fourier

XOR Exclusive Or 


\section{Lista de Símbolos}

\begin{tabular}{|c|c|}
\hline GW & Gigawatt \\
\hline $\mathrm{R}_{\mathrm{xy}}$ & Relé de proteção para o trecho entre $\mathrm{x}$ e y \\
\hline $\mathrm{A}, \mathrm{B}, \mathrm{C}$ & Fases do Sistema Elétrico de Potência \\
\hline $\mathrm{D}, \mathrm{E}, \mathrm{F}, \mathrm{G}$ & Barramentos no Sistema Elétrico de Potência \\
\hline$d$ & Distância da falta em relação ao relé \\
\hline$R$ & Resistência de falta monofásica \\
\hline$x[n]$ & Sinal de tempo discreto \\
\hline$X_{h}$ & Fasor do $h$-ésimo componente harmônico de um sinal discreto \\
\hline$N$ & Número de pontos por ciclo/ Número de entradas de uma rede neural \\
\hline $\operatorname{Re}$ & Parte real de um número complexo \\
\hline $\operatorname{Im}$ & Parte imaginária de um número complexo \\
\hline$s_{c}$ & Índice de detecção de falta pelo método de comparação ciclo-a-ciclo \\
\hline$h$ & Limiar para detecção de falta (threshold) \\
\hline $\mathrm{pu}$ & por unidade \\
\hline$I_{x}^{\text {sup }}$ & Corrente superposta da fase $x$ \\
\hline$I_{\min }$ & Corrente de limiar para identificação da terra na falta \\
\hline$Z_{a p}$ & Impedância aparente vista pelo relé \\
\hline $\boldsymbol{V}_{x}$ & Fasor de tensão da fase $x$ \\
\hline $\boldsymbol{I}_{x}$ & Fasor de corrente da fase $x$ \\
\hline$k_{0}$ & Fator de compensação de correntes de sequência zero \\
\hline$I_{0}$ & Fasor de corrente de sequência zero \\
\hline$\mu \mathrm{P}$ & Microprocessador \\
\hline$X$ & Processo aleatório \\
\hline$x_{1}(t), x_{2}(t), \ldots$ & Variáveis aleatórias \\
\hline $\operatorname{cum}()$. & Operador cumulante \\
\hline$E()$. & Operador expectância ou valor esperado \\
\hline$x(t)$ & Sinal de tempo contínuo/variável aleatória \\
\hline$C_{2}, C_{3}, C_{4}$ & Cumulantes de $2^{\mathrm{a}}, 3^{\mathrm{a}}$ e $4^{\mathrm{a}}$ ordens \\
\hline $\bmod ()$. & Operador resto da divisão inteira \\
\hline$n_{0}$ & Instante de tempo discreto qualquer \\
\hline$\tau$ & Lag do cumulante \\
\hline
\end{tabular}




\begin{tabular}{|c|c|}
\hline$x_{1}, x_{2}, \ldots, x_{N}$ & Entradas de uma rede neural perceptron \\
\hline$w_{1}, w_{2}, \ldots, w_{N}$ & Pesos de uma rede neural perceptron \\
\hline$\theta$ & Limiar de uma rede neural perceptron \\
\hline $\mathrm{u}$ & Saída do combinador linear de uma rede neural perceptron \\
\hline $\mathrm{g}()$. & Função de ativação de uma rede neural perceptron \\
\hline$W_{i}$ & Matriz de pesos da $i$-ésima camada de um PMC \\
\hline$N_{i}$ & Número de neurônios da $i$-ésima camada de um PMC \\
\hline$d_{j}(k)$ & Saída do j-ésimo neurônio de um PMC para o padrão $k$ \\
\hline$\varepsilon(k)$ & Erro quadrático relativo ao $k$-ésimo padrão \\
\hline$\beta$ & Fator da função de ativação \\
\hline$\eta$ & Taxa de aprendizado do algoritmo backpropagation \\
\hline$\delta_{j}$ & Gradiente local do erro no $j$-ésimo neurônio \\
\hline$y_{i}$ & Saída do $i$-ésimo neurônio \\
\hline$\alpha_{R N A}$ & Fator de momentum do algoritmo de aprendizado do PMC \\
\hline$H(z)$ & Função de transferência de um filtro digital \\
\hline$\alpha, \beta$ & Parâmetros do filtro notch \\
\hline$H_{0}$ & Hipótese nula \\
\hline$H_{1}$ & Hipótese alternativa \\
\hline$e_{\mathrm{x}}[n]$ & Sinal de erro da fase $x$ \\
\hline$r_{\mathrm{x}}[n]$ & Sinal de ruído da fase $\mathrm{x}$ \\
\hline$t_{\mathrm{x}}[n]$ & Sinal de transitório da fase $\mathrm{x}$ \\
\hline$C_{1}, C_{2}, C_{3}, \ldots$ & Classes de um problema de identificação de padrões \\
\hline$x, y, z$ & Variáveis relacionadas a um padrão pertencente a uma classe \\
\hline$\mu$ & Valor médio \\
\hline$\sigma^{2}$ & Variância \\
\hline$G_{1}, G_{2}$ & Unidades de geração equivalente em um modelo de SEP \\
\hline$L$ & Comprimento de uma linha de transmissão \\
\hline$f_{S}$ & Frequência de amostragem \\
\hline$\omega$ & Frequência angular \\
\hline$T_{S}$ & Período de amostragem \\
\hline$H_{B}(j \omega)$ & Resposta em frequência do filtro Butterworth \\
\hline$\omega_{C}, f_{C}$ & Frequência de corte \\
\hline $\mathrm{Hz}$ & Hertz \\
\hline
\end{tabular}




$\begin{array}{ll}B_{i} & i \text {-ésimo bit de uma palavra binária } \\ \delta & \text { Resolução de um conversor A/D } \\ \mathrm{km} & \text { Quilômetro } \\ R_{f} & \text { Resistência de falta entre fases } \\ R_{t} & \text { Resistência de falta entre fase e terra } \\ \mathrm{kV} & \text { Quilovolt } \\ R^{+}, R^{0} & \text { Resistências de sequência positiva e zero do modelo da LT } \\ L^{+}, L^{0} & \text { Indutânicas de sequência positiva e zero do modelo da LT } \\ C^{+}, C^{0} & \text { Capacitâncias de sequência positiva e zero do modelo da LT } \\ \mathrm{GVA} & \text { Giga volt-ampère } \\ { }^{\circledR} & \text { Marca registrada } \\ \mathrm{TM} & \text { Trademark } \\ \text { LT1, LT2, LT3 } & \text { Linhas de Transmissão } \\ M & \text { Fator de downsample } \\ \mathrm{dB} & \text { Decibel } \\ y_{\text {det }} & \text { Saída da rede neural de detecção } \\ y_{\text {class }} & \text { Saída da rede neural de classificação } \\ y_{1}, y_{2}, y_{3} & \text { Saídas das redes neurais de localização }\end{array}$





\section{SUMÁRIO}

1. INTRODUÇÃO

1.1. ProteçÃo de Sistemas ElÉtRICOS de PotêNCIA 43

1.2. RELÉS DE PROTEÇÃO 46

1.2.1. Relés Digitais e Breve Histórico da Tecnologia de Relés.. 46

1.2.2. Benefícios dos Relés Digitais. 48

1.2.3. Classificação de Relés 49

1.2.4. Características Funcionais dos Relés 50

1.3. Fundamentos da PRoteção de Distância 52

1.4. JUSTIFICATIVA E CONTRIBUIÇÕES DA PESQUISA 53

1.5. ORGANIZAÇÃO GERAL DA TESE ..... 55

2. LEVANTAMENTO BIBLIOGRÁFICO. 57

2.1. Um Sistema Tradicional Completo para Proteção Digital de Distância ....... 57

2.1.1. Extração de fasores com a Transformada Discreta de Fourier 58

2.1.2. Detecção de faltas pelo método de comparação de amostras 59

2.1.3. Classificação de faltas pelo método das correntes superpostas. 61

2.1.4. Localização de faltas pelo método da Impedância Aparente 63

2.1.5. Aspectos negativos para o desempenho do relé tradicional.. 65

2.2. AVANÇOS NA PROTEÇÃO DE DISTÂNCIA: TÉCNICAS BASEADAS NA IMPEDÂNCIA APARENTE. 66

2.2.1. Ajuste de Mínimos Quadrados . 66

2.2.2. Transformada Discreta de Fourier. 67

2.2.3. Filtros de Kalman 69

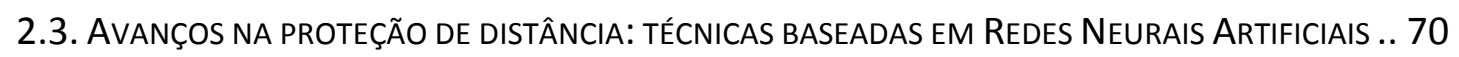

2.4. OUTRAS TÉCNICAS AVANÇADAS DE PROTEÇÃO DE DISTÂNCIA 73 


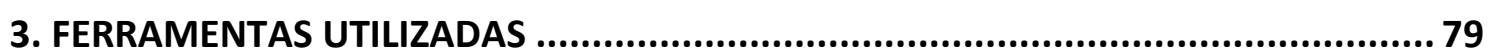

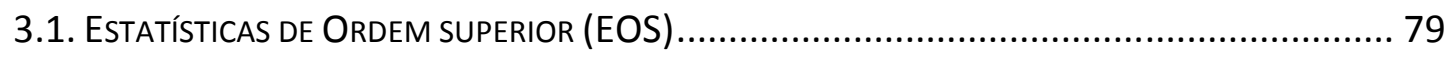

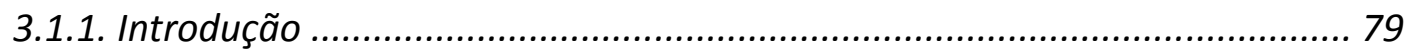

3.1.2. Fundamentos matemáticos........................................................... 81

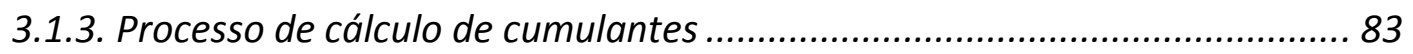

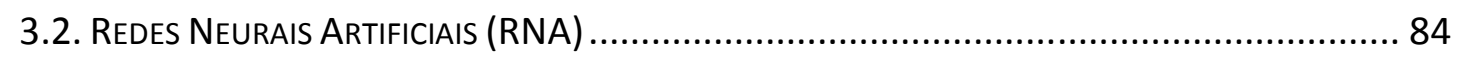

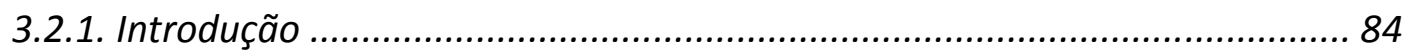

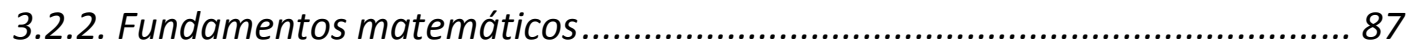

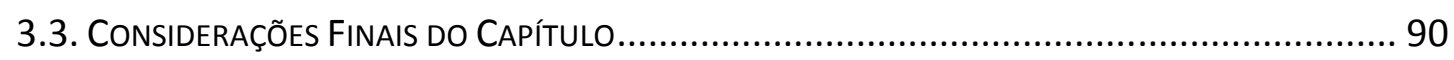

4. NOVO MÉTODO DE PROTEÇÃO COM EOS E RNA ............................................ 91

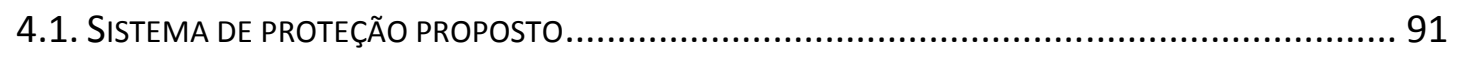

4.1.1. Descrição dos componentes do sistema .............................................. 91

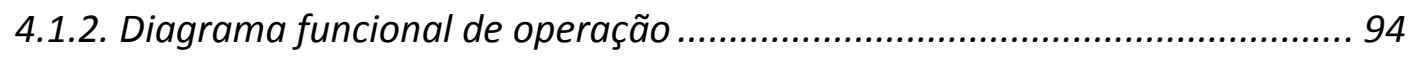

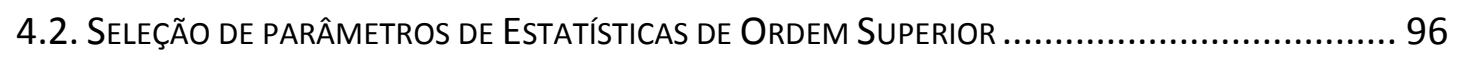

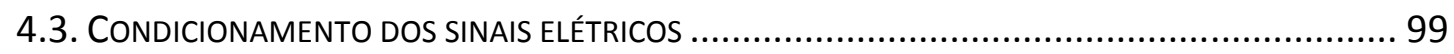

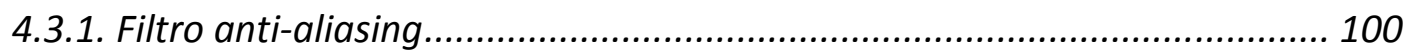

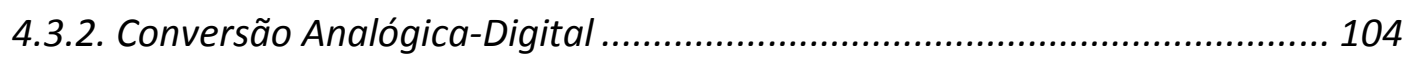

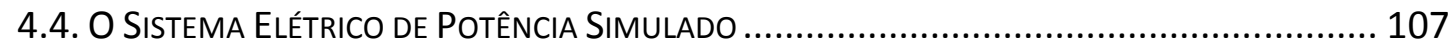

4.4.1. Especificação de torres e cabos .......................................................... 108

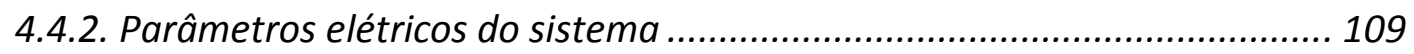

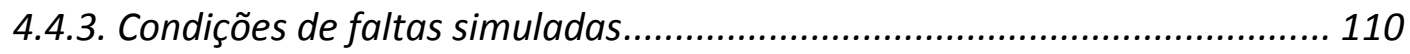

4.4.4. Modelagem do sistema no Simulink ${ }^{\circledR}$............................................... 113

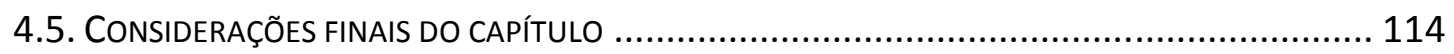




\section{RESULTADOS OBTIDOS PARA OS MÓDULOS DE DETECÇÃO, CLASSIFICAÇÃO E LOCALIZAÇÃO.}

5.1. DETECÇÃO DA FALTA

5.2. Classificação da Falta

5.2.1. Identificação do envolvimento da fase monitorada na falta

5.2.2. Identificação do envolvimento da terra na falta 133

5.3. LOCALIZAÇÃO DA FALTA 140

5.3.1. Faltas envolvendo uma fase e a terra (F-T). 143

5.3.2. Faltas envolvendo duas fases e a terra (F-F-T). 152

5.3.3. Faltas envolvendo duas fases (F-F). 159

5.3.4. Faltas envolvendo as três fases (F-F-F)... 166

5.4. ESQUEMÁTICO DAS ESTRUTURAS DE DETECÇÃO, CLASSIFICAÇÃO E LOCALIZAÇÃO...... 171

5.5. CONSIDERAÇÕES FINAIS DO CAPÍTULO 172

6. SIMULAÇÃO DE OPERAÇÃO DA PROTEÇÃO DE DISTÂNCIA PROPOSTA 173

6.1. PROTÓTIPO DE RELÉ DESENVOLVIDO. 173

6.2. GERAÇÃO DE PARÂMETROS DE SIMULAÇÃO 177

6.3. ASPECTOS RELACIONADOS À DIRECIONALIDADE DA FALTA E À COMPARAÇÃO DE RESULTADOS.. 178

6.4. OPERAÇÃo DA PROTEÇÃo PARA FALTAS DO TIPO F-T. 181

6.4.1. Resultados para faltas monofásicas na linha $L T 2$ 185

6.4.1.1. Faltas F-T na Zona 1 de proteção 185

6.4.1.2. Avaliação dos efeitos dos parâmetros de faltas F-T na Zona 1 186

6.4.1.3. Faltas F-T na Zona 2 de proteção 190

6.4.1.4. Avaliação dos efeitos dos parâmetros de faltas F-T na Zona 2 191

6.4.2. Resultados para faltas monofásicas na linha $L T 3$ 194

6.4.2.1. Faltas F-T na Zona 2 de proteção 194 
6.4.2.2. Avaliação dos efeitos dos parâmetros de faltas F-T na Zona 2

6.4.2.3. Faltas F-T na Zona 3 de proteção 198

6.4.2.4. Avaliação dos efeitos dos parâmetros de faltas F-T na Zona 3 . 199

6.4.3. Resumo da avaliação de desempenho para faltas F-T 202

6.5. OPERAÇÃO DA PROTEÇÃO PARA FALTAS DO TIPO F-F-T 204

6.5.1. Resultados para faltas bifásicas com terra na linha LT2. 205

6.5.1.1. Faltas F-F-T na Zona 1 de proteção 205

6.5.1.2. Avaliação dos efeitos dos parâmetros de faltas F-F-T na Zona 1 206

6.5.1.3. Faltas F-F-T na Zona 2 de proteção 208

6.5.1.4. Avaliação dos efeitos dos parâmetros de faltas F-F-T na Zona 2 209

6.5.2. Resultados para faltas bifásicas com terra na linha LT3. 211

6.5.2.1. Faltas F-F-T na Zona 2 de proteção 211

6.5.2.2. Avaliação dos efeitos dos parâmetros de faltas F-F-T na Zona 2 213

6.5.2.3. Faltas F-F-T na Zona 3 de proteção 214

6.5.2.4. Avaliação dos efeitos dos parâmetros de faltas F-F-T na Zona 3 216

6.5.3. Resumo da avaliação de desempenho para faltas F-F-T. 218

6.6. OPERAÇÃO DA PROTEÇÃO PARA FALTAS DO TIPO F-F.... 219

6.6.1. Resultados para faltas bifásicas na linha $L T 2$. 219

6.6.1.1. Faltas F-F na Zona 1 de proteção 219

6.6.1.2. Avaliação dos efeitos dos parâmetros de faltas F-F na Zona 1 221

6.6.1.3. Faltas F-F na Zona 2 de proteção 223

6.6.1.4. Avaliação dos efeitos dos parâmetros de faltas F-F na Zona 2 224

6.6.2. Resultados para faltas bifásicas na linha LT3 225

6.6.2.1. Faltas F-F na Zona 2 de proteção 225

6.6.2.2. Avaliação dos efeitos dos parâmetros de faltas F-F na Zona 2 . 227 
6.6.2.3. Faltas F-F na Zona 3 de proteção

6.6.2.4. Avaliação dos efeitos dos parâmetros de faltas F-F na Zona 3 ........................ 230

6.6.3. Resumo da avaliação de desempenho para faltas F-F........................... 232

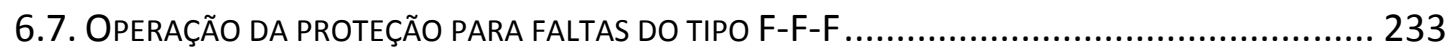

6.7.1. Resultados para faltas trifásicas na linha $L T 2$..................................... 233

6.7.1.1. Faltas F-F-F na Zona 1 de proteção ............................................................ 233

6.7.1.2. Avaliação dos efeitos dos parâmetros de faltas F-F-F na Zona 1 .................... 234

6.7.1.3. Faltas F-F-F na Zona 2 de proteção ................................................................. 236

6.7.1.4. Avaliação dos efeitos dos parâmetros de faltas F-F-F na Zona 2 ..................... 237

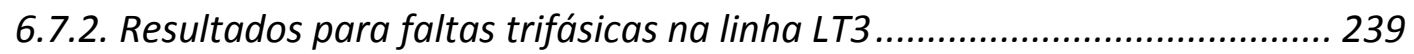

6.7.2.1. Faltas F-F-F na Zona 2 de proteção ............................................................. 239

6.7.2.2. Avaliação dos efeitos dos parâmetros de faltas F-F-F na Zona 2 .................... 241

6.7.2.3. Faltas F-F-F na Zona 3 de proteção ................................................................ 242

6.7.2.4. Avaliação dos efeitos dos parâmetros de faltas F-F-F na Zona 3 ..................... 244

6.7.3. Resumo da avaliação de desempenho para faltas F-F-F......................... 246

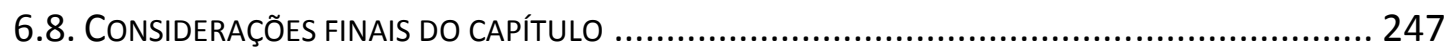

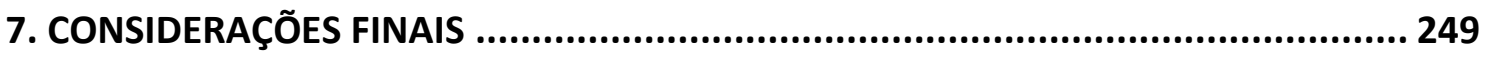

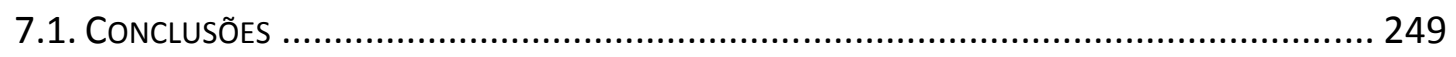

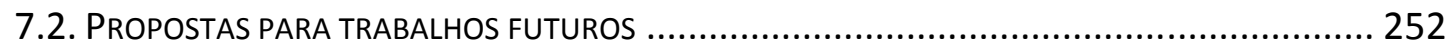

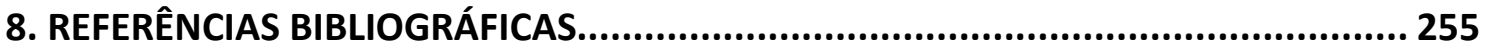

APÊNDICE A - PUBLICAÇÕES RELATIVAS À PESQUISA ................................... 261

A.1 CONGRESSOS:

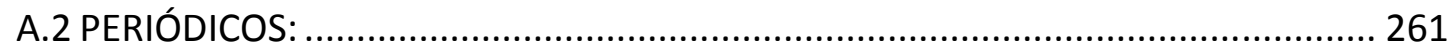





\section{INTRODUÇÃO}

A energia desempenha um papel fundamental no desenvolvimento de um país. De fato, conforme coloca Stevenson [1]: “O progresso industrial de uma nação pode ser medido pelo grau de aproveitamento de suas fontes de energia”. Ainda, de acordo com Camargo [2]: "Em um mundo altamente competitivo e submetido à globalização dos mercados, a energia passa a ser uma variável estratégica de desenvolvimento sobre a qual os planejadores podem e devem atuar no sentido de moldar o estilo de crescimento pretendido".

Um Sistema Elétrico de Potência (SEP) consiste em um sistema utilizado para a conversão e transporte de energia - neste caso, energia elétrica [1]. Os SEPs são constituídos basicamente por três componentes: as estações geradoras, as Linhas de Transmissão (LTs) e os sistemas de distribuição. As estações geradoras são responsáveis por converter a energia de origem hidráulica, térmica e nuclear, dentre outras, em energia elétrica. Os sistemas de distribuição disponibilizam a energia elétrica diretamente aos consumidores, sejam residenciais, comerciais ou industriais. Já as linhas de transmissão realizam a conexão entre as unidades geradoras e os sistemas de distribuição.

Um SEP é particularmente vantajoso quando a fonte primária de energia é hidráulica [1]. Apesar dos altos custos iniciais e custos de manutenção, o custo com o “combustível” - a água - é nulo. A energia hidráulica é convertida para elétrica por meios de conjuntos turbina-gerador no próprio local em que se encontram e o sistema de transmissão viabiliza o transporte até os pontos de consumo, normalmente distantes do local de origem. Neste cenário, o Brasil se destaca devido ao seu enorme potencial hidráulico, proporcionado pelas condições favoráveis à instalação de usinas hidrelétricas. Segundo dados divulgados no Atlas da Energia Elétrica do Brasil [3], tal 
potencial situa-se nas proximidades de $250 \mathrm{GW}$ e, em novembro de 2008 , as usinas hidrelétricas respondiam por aproximadamente $76 \%$ da potência total instalada no país. Adicionalmente, há de se destacar ainda que o potencial hidráulico pode ser intensamente explorado, haja vista que o grau de aproveitamento do mesmo é da ordem de apenas 30\%, de acordo com a mesma fonte.

Sob a forma de eletricidade, a única maneira de transporte de energia se dá por meio das linhas de transmissão. As LTs não podem armazenar energia e, portanto, com exceção às perdas inerentes ao sistema, toda a energia produzida é convertida simultaneamente em carga. Devido às suas enormes extensões, a maioria das falhas que ocorrem em um SEP envolve as linhas de transmissão [4].

Conforme coloca Stevenson [1], uma falta em um fio ou cabo é definida como uma falha total ou parcial na sua isolação ou na sua continuidade. As faltas são descritas como um curto-circuito na maioria das vezes e consistem em eventos de caráter aleatório [5]. Um evento destes tem como consequências o aumento das correntes e a diminuição das tensões do sistema nas fases faltosas [6]. A maioria das faltas que ocorrem em uma LT é causada por raios, os quais levam a descargas nos isoladores alojados nas torres do sistema de transmissão. Assim como os raios, são responsáveis por faltas em LTs os problemas de isolação, queimadas próximas às linhas, contato entre cabos ocasionado por agente externo, entre outros.

A experiência demonstra que um índice de $70 \%$ a $80 \%$ de faltas que ocorrem em uma LT são do tipo que envolve apenas uma das fases e a terra (faltas F-T ou monofásicas) [1]. Apenas cerca de 5\% envolvem as três fases simultaneamente, as faltas trifásicas (faltas F-F-F). Os demais tipos de falta são as envolvendo duas fases (faltas FF ou bifásicas) e duas fases mais a terra (faltas F-F-T ou bifásicas com terra). 


\subsection{Proteção de Sistemas Elétricos de Potência}

Mostrando-se evidente e clara a importância de um SEP, surge então a necessidade do projeto de esquemas de proteção para o mesmo, a fim de resguardá-lo dos efeitos danosos da ocorrência de faltas e de manter sua integridade para o fornecimento contínuo e econômico da energia. Com efeito, o não isolamento rápido de um componente em situação de falta (linha de transmissão, transformadores, barramento, etc.) pode levar o sistema elétrico à condição de instabilidade ou até mesmo desencadear a atuação de vários sistemas de proteção (efeito cascata), desligando grande parcela do SEP. Ademais, a continuidade da condição de falta pode ocasionar danos aos equipamentos próximos ao elemento faltoso, seja pelas elevadas correntes, pelas baixas tensões ou pelo desequilíbrio das correntes [7].

Conforme destaca Caminha [8], há dois princípios gerais que equipamentos de proteção devem obedecer, em sequência:

1. Em hipótese alguma, a proteção deve dar ordens se não existir defeito na sua zona de atuação;

2. Se existe defeito na zona de atuação de um equipamento de proteção, as ordens do mesmo devem corresponder exatamente àquilo que se espera da sua operação.

O conceito de zona de atuação ou zona de proteção pode ser facilmente entendido com o auxílio da Figura 1, onde o mesmo é abordado com o foco na proteção de LTs. As zonas de proteção consistem em áreas delimitadas no diagrama unifilar de um trecho de um SEP, que indicam os componentes a serem protegidos por um determinado 
sistema de proteção. Para o caso do relé $R_{\text {de }}$ desta figura, alocado junto ao barramento D, a zona de proteção primária consiste na região definida como Zona 1, a qual toma quase toda a linha de transmissão entre os barramentos D e E. Já as demais zonas Zona 2 e Zona 3 - são denominadas zonas secundária e terciária, respectivamente. Vale ressaltar que, considerando os demais dispositivos de proteção, como os relés $R_{e d}$, $R_{\mathrm{ef}} \mathrm{e} \mathrm{R}_{\mathrm{fe}}$ desta figura, outras zonas de proteção devem constar no diagrama, correspondendo às suas respectivas áreas de atuação. No entanto, não são demarcadas essas zonas visando à simplificação desta análise. Os dispositivos de proteção devem ser ajustados, então, de forma a operarem coordenadamente.

A atuação de um relé na sua zona primária é instantânea e nas demais a atuação é temporizada. Desta forma, havendo uma falta na linha entre os barramentos E e F, na localização $F_{2}$ (Figura 1), se o relé $R_{\text {ef }}$ falhar na proteção desta linha, visto que esta constitui sua zona primária, então o relé $\mathrm{R}_{\text {de }}$ deve prover atuação temporizada isolando o componente faltoso. Esta proteção é denominada proteção de retaguarda remota.

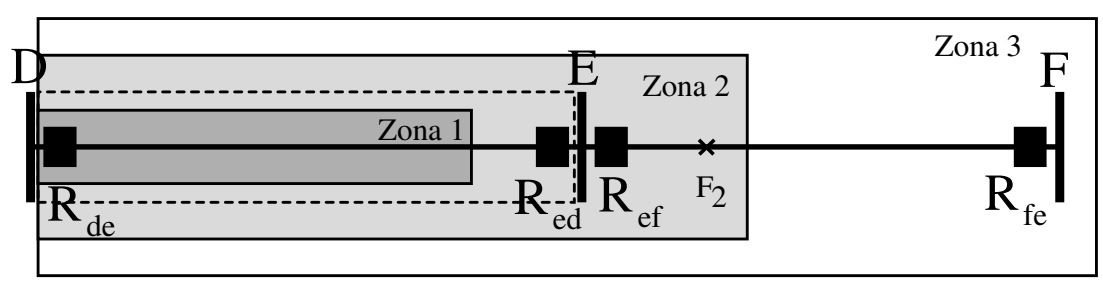

Figura 1. Um sistema de proteção típico para um trecho de um sistema de transmissão, com as zonas de atuação para o relé $\mathbf{R}_{\text {de }}$

Apesar de um sistema de proteção estar normalmente associado à figura de um relé de proteção, tal sistema consiste também de outros elementos que atuam no processo de remoção da falta, como demonstra o esquema apresentado na Figura 2. 


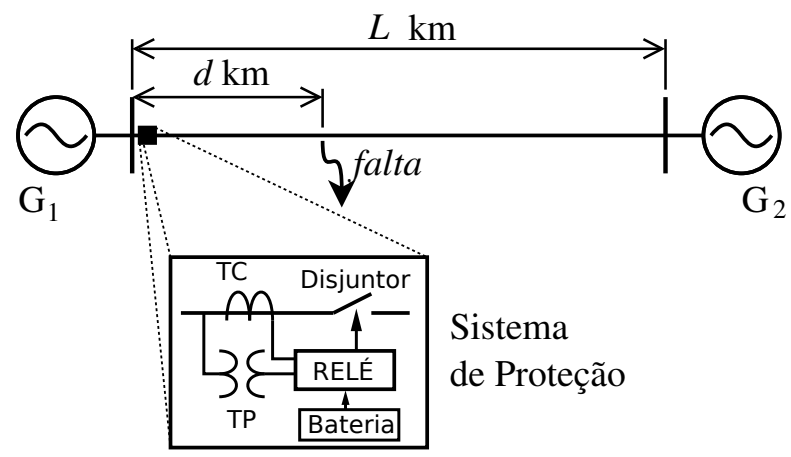

Figura 2. Componentes típicos de um sistema de proteção.

Conforme colocado por Coury, Oleskovicz e Giovanini [9], destacam-se os elementos:

- Disjuntores: são os componentes que têm como objetivo isolar o elemento em falta. Eles devem interromper a corrente quando a mesma se aproxima de zero e são operados através da energização de suas bobinas de ação.

- Transdutores: os Transformadores de Potencial (TPs) e Transformadores de Corrente (TCs) são os transdutores responsáveis pela transformação dos níveis de tensão e corrente, respectivamente, para níveis de tensão mais baixos, os quais são adequados para o tratamento do sistema de proteção. A reprodução das formas de onda de tensões e correntes é fiel, dentro de certos limites.

- Relés: estes componentes são responsáveis pela parte lógica da filosofia de proteção e serão abordados na subseção a seguir.

Por fim, pode-se colocar como sendo duas as funções de um sistema de proteção por meio de relés, conforme estabelece Caminha [8]: 
- Função Principal: consiste em promover uma rápida retirada de serviço de um elemento do sistema, quando este sofre um curto-circuito, ou quando ele começa a operar de modo anormal podendo causar danos ou, de outro modo, interferir com a correta operação do resto do sistema.

- Função Secundária: consiste em promover a indicação da localização e do tipo de defeito, visando à mais rápida reparação do mesmo e possibilidade da análise da eficiência e características de mitigação da proteção adotada.

\subsection{Relés de proteção}

Os relés de proteção, ou simplesmente relés, têm como objetivo operar corretamente os disjuntores de forma a desconectar do sistema elétrico apenas o equipamento em situação de falta, tão rápido quanto possível. Desta forma, minimizamse os problemas e defeitos quando da ocorrência das faltas [6]. Formalmente, a ABNT (Associação Brasileira de Normas Técnicas) define um relé como: "O relé é um dispositivo por meio do qual um equipamento elétrico é operado quando se produzem variações nas condições deste equipamento ou do circuito em que ele está ligado, ou em outro equipamento ou circuito associado" [8]. Os relés constituem certamente a ferramenta mais poderosa do engenheiro de proteção.

\subsubsection{Relés Digitais e Breve Histórico da Tecnologia de Relés}

Os primeiros relés projetados eram dispositivos com tecnologia eletromecânica [9]. O princípio de funcionamento destes relés é baseado na interação entre correntes e fluxos que dão lugar a forças responsáveis pela operação destes componentes. A natureza mecânica destes dispositivos é fator limitador e prejudica o desempenho dos 
mesmos. Com a evolução e expansão dos SEPs surgiu então a necessidade de esquemas de proteção com alto desempenho e mais confiáveis.

Neste contexto, surgem os relés de estado sólido, também conhecidos como relés estáticos. O termo estático se deve à ausência de movimentos mecânicos, presentes nos relés eletromecânicos. Estes relés possuem, como componentes básicos, os dispositivos semicondutores que necessitam de baixa potência para operação. Em contrapartida, os relés estáticos possuem limitações no que tange ao uso em ambientes com temperaturas extremas e umidade [9].

Na década de 1960, teve início, portanto, o desenvolvimento de uma nova tecnologia de relés: a tecnologia digital. Os relés digitais tiveram inicialmente o seu uso restrito, considerando o seu alto custo e as restrições operacionais dos primeiros computadores digitais. No entanto, o desenvolvimento da tecnologia de sistemas digitais viabilizou nos anos seguintes o uso de técnicas digitais na proteção de sistemas elétricos. Atualmente, os projetos de novas subestações de energia elétrica fazem uso exclusivo da tecnologia dos relés de proteção digitais [9]. Ademais, os relés eletromecânicos e de estado sólido que ainda estão instalados em subestações antigas têm sido gradualmente substituídos por relés digitais.

Um relé digital é um dispositivo gerenciado por uma unidade de processamento ou micropocessador específico. Ele é controlado, portanto, por um software que faz o processamento dos sinais de entrada do relé para a tomada de decisão. Esta característica construtiva impõe uma grande disparidade entre os relés convencionais eletromecânicos e de estados sólidos - e os relés digitais, com importantes fatores e aspectos positivos relacionados aos últimos. 


\subsubsection{Benefícios dos Relés Digitais}

Conforme colocado anteriormente, a tecnologia digital trouxe consigo uma série de aspectos positivos para esquemas de proteção. Phadke e Thorp [7] enumeram os seguintes benefícios da utilização de relés digitais:

- Custo: inicialmente os relés digitais tinham custo entre 10 a 20 vezes maior que o custo de um relé convencional de estado sólido. Este custo foi reduzido nos anos seguintes ao mesmo tempo em que houve aumento em capacidade de processamento. Contrariamente, os relés convencionais tiveram aumento de custo devido às modificações em seus projetos para melhoria de desempenho, entre outros aspectos.

- Possibilidade de auto-diagnose: O relé digital pode ser programado de forma a monitorar constantemente o funcionamento de seu hardware e software detectando, portanto, qualquer defeito que possa ocorrer. Se encontrado algum defeito no seu funcionamento, ele pode ser programado para desligar-se do serviço, sem interromper o SEP, e enviar uma informação de seu estado ao centro de operações. Esta característica diz respeito à confiabilidade destes relés e é um dos mais importantes aspectos técnicos favoráveis a estes dispositivos.

- Integração digital no SEP: Tendo os microcomputadores e os sistemas digitais se transformado na tecnologia base das subestações (telemetria, medições, comunicação, controle, etc.), o uso de relés digitais só tem a favorecer a interação com estes sistemas. 
- Flexibilidade quanto à função: Um relé digital pode ser programado para executar diversas funções, visto que se trata da execução de um software. Como exemplo, um mesmo dispositivo de proteção pode executar tarefas como medição, monitoramento, controle, localização de faltas, entre outras.

Outro benefício a ser destacado consiste na possibilidade de implementação de técnicas inteligentes [9]. Os relés digitais são passíveis de implementação de sistemas de proteção que empregam ferramentas como as redes neurais artificiais, a lógica Fuzzy, Algoritmos Genéticos, entre outras.

\subsubsection{Classificação de Relés}

Independentemente da tecnologia de fabricação - eletromecânica, estática ou digital - pode-se classificar a maioria dos relés de proteção de SEPs como a seguir [7]:

- Relés de Magnitude: estes relés respondem à magnitude dos sinais de entrada. Um exemplo simples e típico é o relé de sobrecorrente o qual responde às mudanças na magnitude do sinal de corrente que lhe é fornecido como entrada.

- Relés Direcionais: tais relés respondem ao ângulo de fase entre dois sinais de entrada em CA (Corrente Alternada). Desta forma, eles são capazes de identificar a direção do fluxo de corrente, ou seja, em posição anterior ou posterior à sua localização física. Normalmente, o sinal de referência para medição do ângulo é um sinal de tensão.

- Relés de Distância: são dispositivos que respondem à impedância observada entre a localização do relé e a localização da falta. A impedância é calculada 
através da razão entre dois sinais de entrada (tensão e corrente), expressos em forma fasorial. Devido ao fato da impedância de uma linha de transmissão, por quilômetro, ser "favoravelmente" constante, os relés de distância respondem então à distância da falta ocorrida na linha. Daí vem a denominação de relés de distância.

- Relés Diferenciais: são relés que operam quando o vetor da diferença entre duas ou mais grandezas elétricas semelhantes excede uma quantidade prédeterminada ou limiar (threshold). Na sua forma mais comum, estes relés respondem à soma algébrica de sinais de corrente incidentes em uma zona de proteção. Caso não haja uma falha interna, esta soma algébrica deve ser próxima de zero.

- Relés com Canal piloto: consistem em uma adaptação do princípio dos relés diferenciais para a proteção de seções de linhas de transmissão. Estes relés utilizam informação de locais remotos como sinal de entrada. Este tipo de proteção geralmente comunica a decisão feita por um relé local de um dos quatro tipos descritos anteriormente para relés em terminais remotos de uma LT. Essa comunicação é viabilizada por meio de fio piloto, onda portadora, microondas, etc.

\subsubsection{Características Funcionais dos Relés}

Conforme destaca Caminha [8], sensibilidade, seletividade, velocidade de atuação e confiabilidade são termos comumente usados para descrever as características funcionais de um relé de proteção. De fato, estas são características funcionais 
desejáveis de um relé, qualquer que seja sua classificação. A seguir são descritas com mais pormenores cada uma dessas características.

- Sensibilidade: um relé deve ser suficientemente sensível de forma a operar adequadamente quando requerido, mesmo que as condições de operação do SEP sejam desfavoráveis, ou seja, produzindo uma mínima tendência para a atuação da proteção.

- Seletividade: um relé deve reconhecer adequadamente o tipo de defeito e qual a parte do sistema de potência está em condição faltosa, isolando unicamente esta do restante. O relé deve selecionar adequadamente qual o tipo de operação a ser executada, seja ela imediata, temporizada ou até mesmo não executar nada.

- Velocidade de atuação: característica imprescindível para se remover o quanto antes uma situação de falta. Um relé deve operar com a velocidade requerida para a correta proteção de um componente. A relação entre o tempo de resposta do relé e o grau de certeza da sua decisão é uma função inversa do tempo e deve ser considerada no projeto de um relé. A velocidade de atuação visa a diminuir a extensão de possíveis danos ocorridos, auxiliar a manutenção de estabilidade de máquinas operando em paralelo, entre outros aspectos.

- Confiabilidade: é definida a confiabilidade como a probabilidade de um componente, um equipamento ou um sistema satisfazer a função prevista para ele, sob dadas circunstâncias. Um relé é confiável e seguro se operar somente nas condições para os quais foi projetado, ou seja, não operando para qualquer 
outra condição que, por ventura, venha a ocorrer sobre o sistema. Considerando que os relés ficam inoperantes durante a maior parte do tempo em um SEP, um programa de manutenção adequado desempenha um papel vital para a confiabilidade de um relé.

\subsection{Fundamentos da Proteção de Distância}

Para a proteção digital de linhas de transmissão, apesar da possibilidade do emprego de relés de sobrecorrente e de relés direcionais, os relés de distância são largamente utilizados [9]. O princípio de proteção diferencial, apesar de seus aspectos positivos e confiáveis, é frequentemente antieconômico para LTs devido às enormes distâncias envolvidas, às tensões ou arranjos de condutores [8].

Conforme colocado anteriormente, os relés de distância operam segundo a impedância observada entre a localização do relé e a localização da falta, denominada impedância aparente. O princípio desta técnica pode ser compreendido com a análise do circuito monofásico da Figura 3, onde é suposta uma falta a uma distância $d$ do relé. Considerado um curto-circuito franco, ou seja, com a resistência nula $(R=0 \Omega)$, é fácil perceber que a impedância vista pelo relé corresponde à impedância do caminho pqrs simbolizado na figura. A comparação desta impedância aparente com a impedância total da linha, que é uma função do comprimento da mesma, define a atuação do relé de distância.

Em uma análise mais realística, considerando um sistema trifásico com uma LT de comprimento $L$, pode-se escrever a impedância vista pelo relé como [10],

$$
\dot{Z}=m \dot{Z}_{1}+\Delta \dot{Z}
$$

Em (1.1), $m=d / L$, representa a distância $d$ da falta com relação ao comprimento total da linha, e $\dot{Z}_{1}$ é a impedância de sequência positiva da linha. A parcela $\Delta \dot{Z}$ consiste em um 
erro (incerteza) associado ao cálculo da impedância vista pelo relé e contribui para degradar, possivelmente, o desempenho da proteção. Este erro é função da resistência de falta, dentre outros parâmetros. A impedância de (1.1) deve ser calculada de acordo com o tipo de falta ocorrido, conforme apresentado no capítulo a seguir.

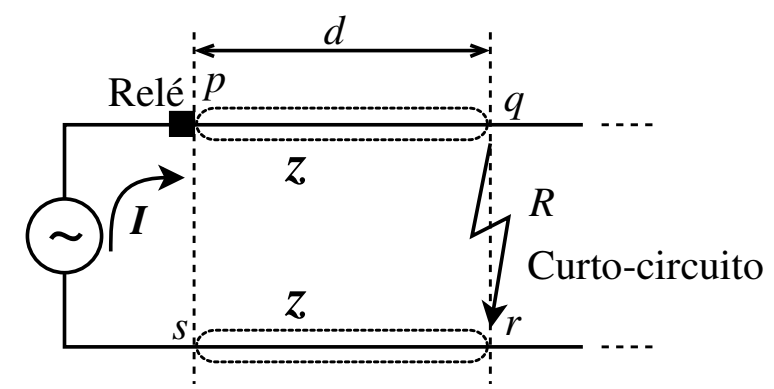

Figura 3. Princípio de medição dos relés de distância.

\subsection{Justificativa e contribuições da pesquisa}

Apesar das características positivas e benefícios do emprego de relés digitais, temse reportado na literatura uma série de limitações dos algoritmos que podem ser empregados nestes dispositivos, para a proteção de linhas de transmissão. Além da incerteza observada em (1.1), os algoritmos de proteção realizam, normalmente, um processo de filtragem, necessário para a estimação fasorial. Portanto, o desempenho da proteção é dependente da "qualidade" das repostas transitória e estacionária desses filtros, dentre outros aspectos, tal como tratado no Capítulo 2 desta tese.

Em oposição, a pesquisa descrita neste trabalho, consiste na aplicação de um grupo de estatísticas de ordem superior, também conhecidas como cumulantes, em conjunto com as redes neurais artificiais para proteção de linhas de transmissão. Visando lidar com os aspectos que afetam negativamente o desempenho de técnicas de proteção tidas como tradicionais, o presente trabalho alia duas ferramentas que já se mostraram eficazes em problemas de detecção e classificação em outras áreas do 
conhecimento, conforme será exposto ao longo do texto. Esta é a motivação principal deste trabalho.

Apesar da posterior abordagem sobre aplicações das estatísticas, a título de ilustração e curiosidade, é apresentada na Figura 4 uma aplicação de detecção de distúrbios relacionados à Qualidade da Energia Elétrica (QEE). Este gráfico é um resultado de Marques [11] e indica claramente que um sinal elétrico com distúrbio pode ser diferenciado de um sinal elétrico sem distúrbio com o uso das estatísticas de ordem superior (variáveis $C_{2}$ e $C_{4}$ ). De fato, a localização geométrica dos padrões no espaço é particular de cada condição.

Dada a importância do SEP e as limitações de métodos tradicionais de proteção frente a vários aspectos de ordem prática, a presente pesquisa se justifica no sentido de que tais estatísticas são imunes a ruídos gaussianos e, além disso, fornecem um grande conjunto de informações para serem tratados, de forma a resolver o problema em questão.

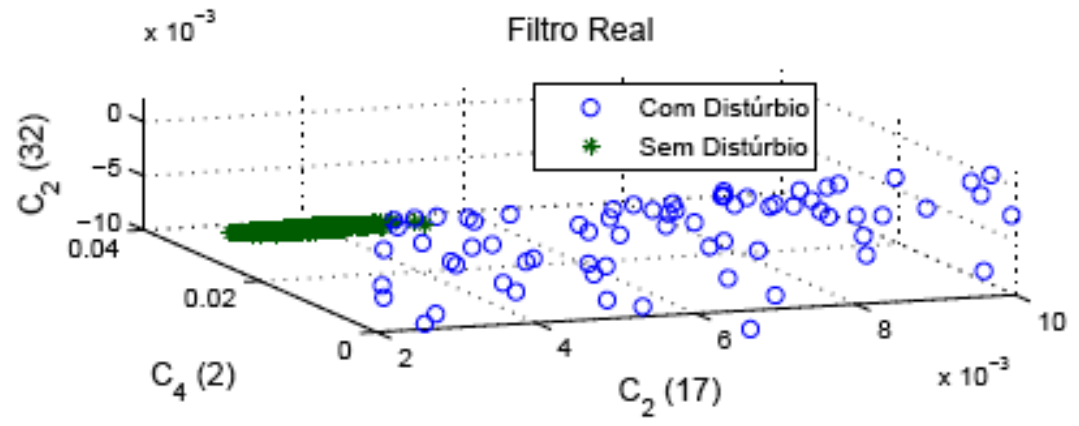

Figura 4. Detecção de distúrbios de QEE com a utilização de cumulantes ${ }^{1}$.

As redes neurais, ferramentas que têm demonstrado aplicabilidade em proteção de sistemas elétricos e nas mais diversas áreas do conhecimento, vêm trazer ao método proposto vantagens como tratamento de sistemas de alto grau de não linearidade,

\footnotetext{
${ }^{1}$ Figura reproduzida com autorização de Marques [11].
} 
adaptação por experiência, capacidade de reconhecer padrões e mapear funções complexas, etc. Ademais, a utilização das redes neurais artificiais diminui o número de ajustes que um engenheiro deve fazer para configuração do sistema de proteção. Como a rede "aprende" através de exemplos, a mesma incorpora as características de operação do sistema a ser protegido, ajustando-se automaticamente.

A aplicação dos cumulantes visa aliar velocidade de operação com imunidade a ruídos presentes em sinais elétricos. Por fim, cabe ressaltar que a alta frequência de amostragem permite o uso de janelas de dados com um vasto número de amostras, mas que corresponde a um intervalo de tempo fracionário em relação ao período fundamental.

Em linhas gerais, podem ser enumeradas as seguintes importantes contribuições desta pesquisa para o ramo da proteção digital, dentre outras:

- Aplicação de uma poderosa ferramenta de análise de sinais, promissora no campo da proteção, para emprego em novos algoritmos de relés digitais;

- Emprego de sinais de corrente apenas na proteção de LTs, não sendo necessários, portanto, o uso de TPs para esta aplicação proposta;

- Elevado índice de acerto do protótipo de relé (modelo computacional) proposto na tese, considerando todos os tipos de falta;

\subsection{Organização geral da tese}

A presente tese está organizada com exposto a seguir. O Capítulo 2 apresenta um levantamento bibliográfico das publicações na área de proteção de LTs. Este levantamento é delineado em duas frentes principais. A primeira consiste na apresentação dos aprimoramentos relativos às metodologias de proteção baseadas em impedância aparente e a segunda consiste na apresentação dos trabalhos que fazem uso 
de redes neurais na proteção de LTs. Os fundamentos de estatísticas de ordem superior e redes neurais artificiais são apresentados no Capítulo 3. No Capítulo 4, são apresentados e descritos o sistema de proteção proposto e o sistema elétrico considerado para estudo. No Capítulo 5, são apresentados os resultados de treinamento e validação dos sistemas de detecção, classificação e localização. Neste capítulo, esses módulos da proteção são tratados de forma individualizada, com enfoque na escolha das estatísticas escolhidas para cada módulo e no aprendizado das redes neurais. O Capítulo 6 apresenta os resultados da operação do protótipo (modelo computacional) de relé de distância desenvolvido. Os resultados são comparados com a metodologia tradicional de proteção, apresentada no Capítulo 2, com uma discussão minuciosa acerca dos mesmos. Finalmente, no Capítulo 7, são estabelecidos os comentários conclusivos e são enumeradas algumas sugestões para trabalhos futuros no tema. 


\section{LEVANTAMENTO BIBLIOGRÁFICO}

Neste capitulo, é realizado um estudo pormenorizado da proteção de linhas de transmissão. Apresenta-se, inicialmente, um sistema completo de proteção digital de distância, baseado em técnicas amplamente reportadas na literatura. Desta forma, para todos os efeitos, define-se o sistema descrito no início deste capítulo como metodologia tradicional de proteção de distância, ou até mesmo, relé tradicional, o qual será adotado para a comparação de resultados realizada no Capítulo 6. Por fim, é realizado levantamento bibliográfico de relevantes trabalhos científicos publicados em periódicos especializados, tratando o tema da proteção de LTs e propondo técnicas que proporcionam melhorias na proteção destes componentes dos SEPs.

\subsection{Um Sistema Tradicional Completo para Proteção Digital de Distância}

Um modelo de proteção de distância completo contra faltas nas LTs é constituído pelas seguintes etapas [9]:

- Detecção: determina a ocorrência da falta. Assim que a mesma é detectada, o sistema de proteção entra em operação.

- Classificação: após a falta ser detectada, ela é classificada, ou seja, são indicadas quais as fases envolvidas e também é verificada a participação da terra.

- Localização: este módulo determina o local de ocorrência da falta, ou seja, a distância da falta em relação ao local de instalação do relé. Normalmente, este procedimento é realizado através do cálculo da impedância aparente. 
No que se segue, são apresentados os fundamentos de técnicas tradicionais empregadas para a execução das etapas mencionadas. Estes algoritmos de proteção de distância, mais especificamente a etapa de classificação e a de localização, fazem uso dos fasores da componente fundamental dos sinais elétricos. Desta forma, inicia-se esta seção com a apresentação de uma ferramenta específica para este fim, amplamente utilizada no processamento de sinais de SEPs: A Transformada Discreta de Fourier.

\subsubsection{Extração de fasores com a Transformada Discreta de Fourier}

Os métodos disponíveis para extração da componente fundamental de um sinal elétrico constituem um extenso conjunto e, dentre os mais comuns, destaca-se a Transformada Discreta de Fourier (DFT - Discrete Fourier Transform) e suas versões modificadas. O resultado da aplicação desta técnica é, de fato, a série de Fourier para um sinal discreto. Apesar do fato de haver dependência do resultado da DFT com a frequência do SEP, será assumida nas simulações do SEP a frequência nominal constante $f_{0}=60 \mathrm{~Hz}$, o que permite o emprego direto desta ferramenta, sem prejuízos no que concerne ao desempenho.

Seja, portanto, $\{x[n]\}$ uma sequência discreta de tamanho N. A Transformada Discreta de Fourier desta sequência é definida como [12],

$$
X_{k}=\sum_{m=0}^{N-1} x[m] e^{-j 2 \pi k m / N} ; k=0,1, \ldots, N
$$

onde $X_{k}$ consiste em um número complexo que possui a informação do $k$-ésimo harmônico que compõe o sinal discreto $\{x[n]\}$. Considerando o tamanho da sequência $N$ igual ao número de amostras por ciclo fundamental, então $X_{1}$ fornece a informação da componente fundamental do sinal analisado. Desde que a DFT retorna resultados complexos para sequências reais como um sinal elétrico, as amplitudes e fases de cada 
componente podem ser calculadas utilizando os operadores "Re" (parte real) e "Im" (parte imaginária). Para o cálculo do módulo ou da amplitude da componente, é necessária ainda a utilização de um fator de correção igual a 2/N [13], para recuperação da sua amplitude correta. Matematicamente, tem-se:

$$
\begin{aligned}
& \left|X_{1}\right|=\frac{2}{N} \sqrt{\operatorname{Re}\left(X_{1}\right)^{2}+\operatorname{Im}\left(X_{1}\right)^{2}} \\
& \angle X_{1}=\tan ^{-1}\left(\frac{\operatorname{Im}\left(X_{1}\right)}{\operatorname{Re}\left(X_{1}\right)}\right)
\end{aligned}
$$

\subsubsection{Detecção de faltas pelo método de comparação de amostras}

Existem várias técnicas tradicionais para realizar a detecção de faltas em SEPs. Entre elas, pode-se destacar [9]: (i) método de comparação amostra-a-amostra; (ii) método de comparação ciclo-a-ciclo; (iii) o método estimativo e; (iv) método de retificação de ondas. Sinais de tensão ou corrente podem ser utilizados nestes processos de detecção de faltas. Neste trabalho, dar-se-á ênfase à técnica de comparação ciclo-aciclo, eleita para compor a etapa de detecção do algoritmo tradicional.

De acordo com Mohanty, Pradhan e Routray [14], o método de comparação cicloa-ciclo é baseado na diferença do valor da amostra atual com a amostra equivalente do ciclo anterior. Ainda de acordo com esta referência, este é um dos principais métodos aplicados para detecção de faltas. Este fato, aliado à simplicidade de implementação, guiaram a escolha da técnica para aplicação neste trabalho. Em uma condição normal de operação, o valor esperado para o índice de comparação ciclo-a-ciclo é zero e, para uma condição faltosa, é diferente de zero. Matematicamente tem-se:

$$
s_{c}[n]=|s[n]-s[n-N+1]|
$$

onde $N$ é o número de amostras por ciclo. A falta é detectada quando o índice $s_{c}[n]>h$, com $h$ sendo um limiar a ser estabelecido para a correta detecção. Na Figura 5 tem-se um exemplo de utilização deste índice para detecção de faltas. A diferença de amostras 
em ciclos consecutivos é nula em situação de pré-falta e aumenta quando da ocorrência da falta, ultrapassando o limiar.

O grande desafio desta metodologia consiste em estabelecer valores adequados para o limiar. De fato, a simples variação da frequência do SEP na sua operação diária, torna não nulo o índice $s_{c}$ em situações de regime de operação normal. A presença de ruído também tende a influenciar negativamente o desempenho deste método de detecção de faltas. Nestes casos, não pode haver uma indicação equivocada de falta e a correta escolha do limiar é de fundamental importância. Um valor comumente utilizado para $h$, de acordo com Coury, Oleskovicz e Giovanini [9], é 0,06 pu (por unidade). Finalmente, se ocorrer essa diferença em um determinado número de amostras consecutivas, a falta é detectada.

(a)

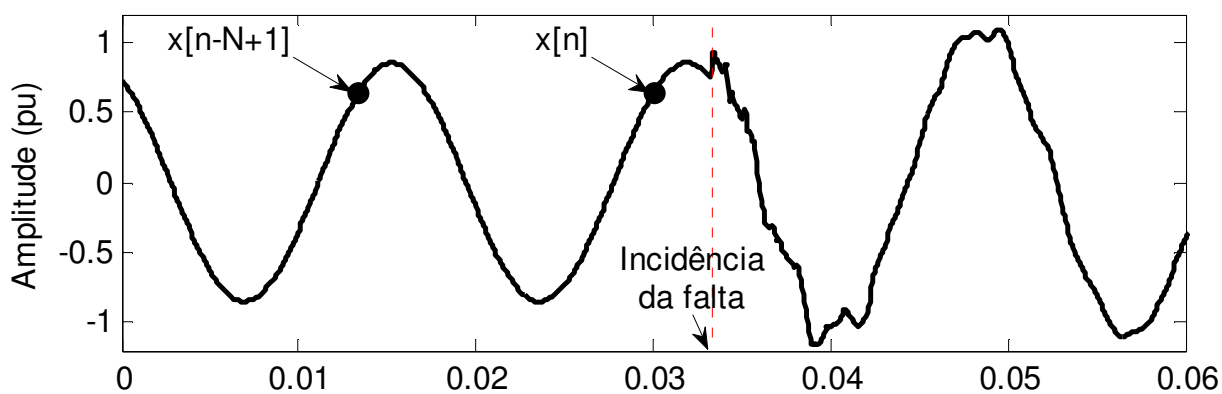

(b)

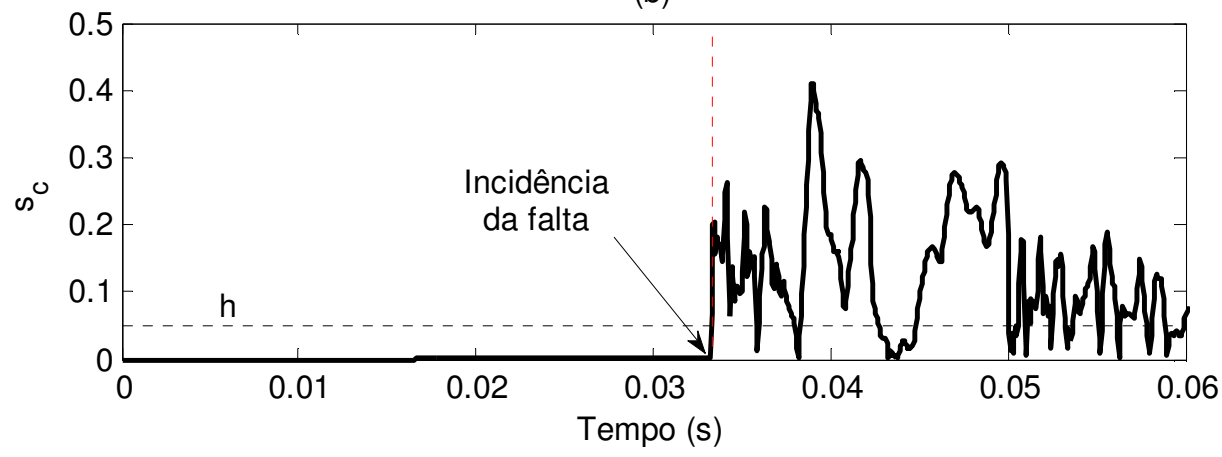

Figura 5. Detecção de faltas pela comparação ciclo-a-ciclo: (a) sinal elétrico e; (b) índice $s_{c}$. 


\subsubsection{Classificação de faltas pelo método das correntes superpostas}

O método de classificação de faltas tradicional, adotado para efeitos de comparações nesta pesquisa, é embasado na análise de fasores de corrente. As correntes de regime pós-falta podem apresentar transitórios eletromagnéticos, com presença de componente CC, além de componentes de alta frequência. Desta forma, a metodologia em questão deve ser capaz de extrair os fasores relativos à frequência fundamental de 60 $\mathrm{Hz}$ com eficiência. A técnica utiliza componentes superpostas de correntes, ao invés de valores totais [15]. A utilização de componentes superpostas proporciona uma precisão adicional na classificação da falta, a partir do momento que elimina possíveis erros devidos ao estado de carga do sistema em regime de pré-falta.

Matematicamente, têm-se os fasores de correntes superpostos definidos como,

$$
\begin{aligned}
& \dot{I}_{A}^{\text {sup }}=\dot{I}_{A}^{p o ́ s}-\dot{I}_{A}^{p r e ́} \\
& \dot{I}_{B}^{\text {sup }}=\dot{I}_{B}^{\text {pós }}-\dot{I}_{B}^{p r e ́} \\
& \dot{I}_{C}^{\text {sup }}=\dot{I}_{C}^{p o ́ s}-\dot{I}_{C}^{p r e ́}
\end{aligned}
$$

Os valores de correntes da equação anterior devem ser normalizados, considerando a divisão pelo maior deles. Adicionalmente, o fasor de sequência zero também deve ser analisado de modo a permitir a identificação da participação da terra na falta. Utilizando-se a comparação descrita em [9], tem-se a análise especificada nas equaçãos (2.5) para a correta identificação do tipo de falta ocorrido.

Uma série de estudos realizados por Souza [16] determina que um valor apropriado para a razão entre correntes, fator $k$ nas equações (2.5), é 0,52. Desta forma, as comparações nestas equações podem ser simplificadas, de forma que: $(i)$ se a corrente superposta da fase é maior que 0,6 , então esta fase se encontra em regime de falta e; (ii) se a corrente superposta da fase for menor que 0,3 , então esta fase não está envolvida na falta. Finalmente, ainda de acordo com [16], o limiar $I_{\text {mín }}$ para identificação da participação da terra na falta ocorrida pode ser utilizado como sendo 0,007 . 


$\begin{array}{lll}\text { TIPO DE FALTA } & \Rightarrow & \text { CONDIÇÕES } \\ \text { Falta A-T } & \Rightarrow & \left|\dot{I}_{B}^{\text {sup }}\right|<k\left|\dot{I}_{A}^{\text {sup }}\right| \mathbf{e}\left|\dot{I}_{C}^{\text {sup }}\right|<k\left|\dot{I}_{A}^{\text {sup }}\right| \\ \text { Falta B-T } & \Rightarrow & \left|\dot{I}_{A}^{\text {sup }}\right|<k\left|\dot{I}_{B}^{\text {sup }}\right| \mathbf{e}\left|\dot{I}_{C}^{\text {sup }}\right|<k\left|\dot{I}_{B}^{\text {sup }}\right| \\ \text { Falta C-T } & \Rightarrow & \left|\dot{I}_{A}^{\text {sup }}\right|<k\left|\dot{I}_{C}^{\text {sup }}\right| \mathbf{e}\left|\dot{I}_{B}^{\text {sup }}\right|<k\left|\dot{I}_{C}^{\text {sup }}\right| \\ \text { Falta A-B-T } & \Rightarrow & \left|\dot{I}_{C}^{\text {sup }}\right|<k\left|\dot{I}_{A}^{\text {sup }}\right| \mathbf{e}\left|\dot{I}_{A}^{\text {sup }}\right| \cong\left|\dot{I}_{B}^{\text {sup }}\right| \mathbf{e}\left|\dot{I}_{0}\right|>I_{\text {min }} \\ \text { Falta B-C-T } & \Rightarrow & \left|\dot{I}_{A}^{\text {sup }}\right|<k\left|\dot{I}_{B}^{\text {sup }}\right| \mathbf{e}\left|\dot{I}_{B}^{\text {sup }}\right| \cong\left|\dot{I}_{C}^{\text {sup }}\right| \mathbf{e}\left|\dot{I}_{0}\right|>I_{\text {min }} \\ \text { Falta C-A-T } & \Rightarrow & \left|\dot{I}_{B}^{\text {sup }}\right|<k\left|\dot{I}_{C}^{\text {sup }}\right| \mathbf{e}\left|\dot{I}_{A}^{\text {sup }}\right| \cong\left|\dot{I}_{C}^{\text {sup }}\right| \mathbf{e}\left|\dot{I}_{0}\right|>I_{\text {min }} \\ \text { Falta A-B } & \Rightarrow & \left|\dot{I}_{C}^{\text {sup }}\right|<k\left|\dot{I}_{A}^{\text {sup }}\right| \mathbf{e}\left|\dot{I}_{A}^{\text {sup }}\right| \cong\left|\dot{I}_{B}^{\text {sup }}\right| \mathbf{e}\left|\dot{I}_{0}\right|<I_{\text {min }} \\ \text { Falta B-C } & \Rightarrow & \left|\dot{I}_{A}^{\text {sup }}\right|<k\left|\dot{I}_{B}^{\text {sup }}\right| \mathbf{e}\left|\dot{I}_{B}^{\text {sup }}\right| \cong\left|\dot{I}_{C}^{\text {sup }}\right| \mathbf{e}\left|\dot{I}_{0}\right|<I_{\text {min }} \\ \text { Falta C-A } & \Rightarrow & \left|\dot{I}_{B}^{\text {sup }}\right|<k\left|\dot{I}_{C}^{\text {sup }}\right| \mathbf{e}\left|\dot{I}_{A}^{\text {sup }}\right| \cong\left|\dot{I}_{C}^{\text {sup }}\right| \mathbf{e}\left|\dot{I}_{0}\right|<I_{\text {min }} \\ \text { Falta A-B-C } & \Rightarrow & \left|\dot{I}_{A}^{\text {sup }}\right| \cong\left|\dot{I}_{B}^{\text {sup }}\right| \cong\left|\dot{I}_{C}^{\text {sup }}\right|\end{array}$

Os critérios de classificação de faltas que acabam de ser mencionados são exemplificados nos gráficos da Figura 6, que mostram as correntes superpostas normalizadas, representadas em gráficos de barras, para quatro situações distintas. Temse, nesta figura, em (a), (b), (c) e (d), respectivamente, situações equivalentes às faltas A-T, A-B, A-B-T e A-B-C.
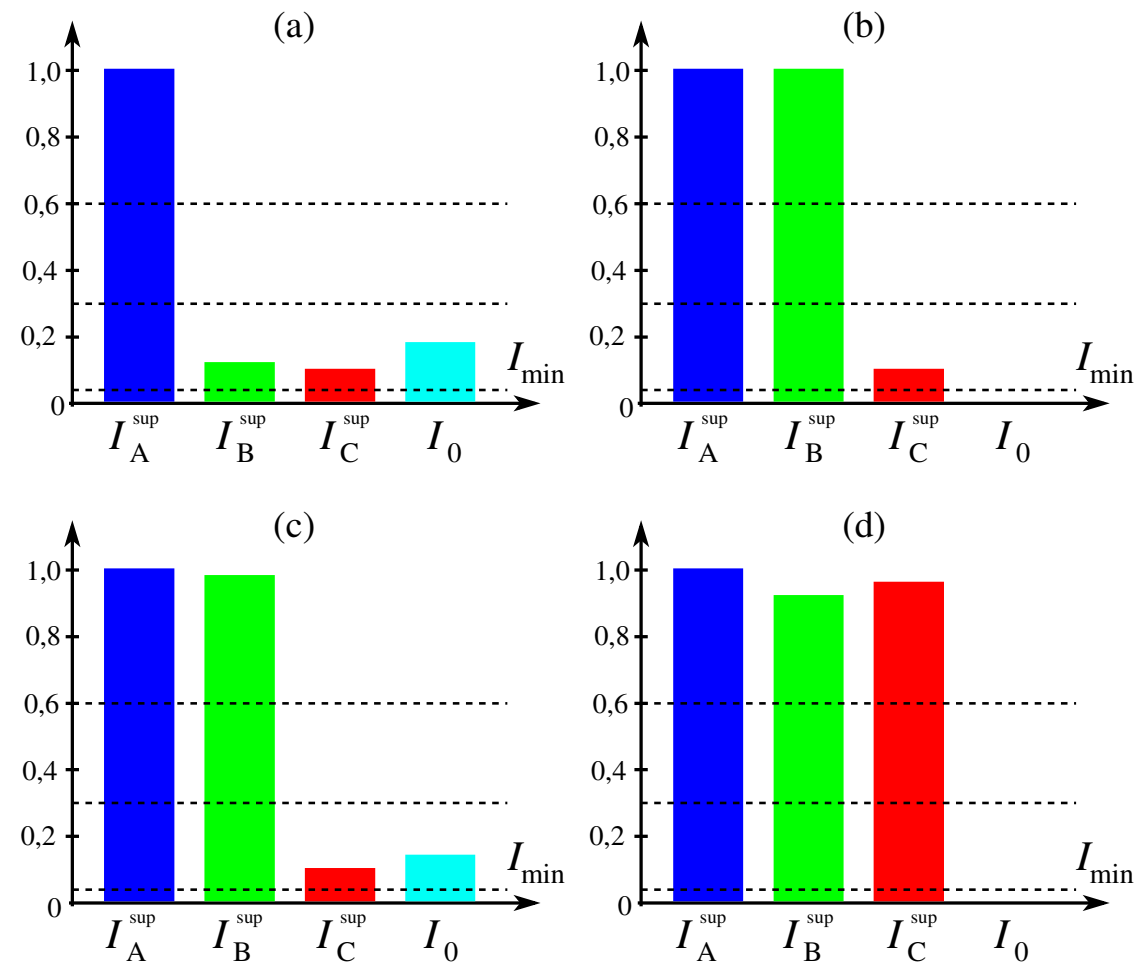

Figura 6. Exemplo de classificação de faltas pelo método das correntes superpostas: (a) falta A-T; (b) falta A-B; (c) falta A-B-T e (d) falta A-B-C. 


\subsubsection{Localização de faltas pelo método da Impedância Aparente}

Dando prosseguimento à análise da falta ocorrida no sistema, após a detecção e a classificação da mesma deve ser realizada a etapa de localização. Um método amplamente difundido consiste no cálculo da impedância da linha, desde o ponto de alocação do relé até o ponto de ocorrência do curto, como relatado anteriormente. Este parâmetro é denominado impedância aparente e a estratégia da proteção consiste em comparar o valor obtido com a impedância de sequência positiva da LT.

Utilizando os fasores de tensão e corrente, a impedância aparente é calculada conforme equacionamento abaixo, para cada tipo de falta [16]:

- Falta monofásica: considerando a fase faltosa a fase $x$ tem-se,

$$
\dot{Z}_{a p}=\frac{\dot{V}_{x}}{\left(\dot{I}_{x}+3 k_{0} \dot{I}_{0}\right)}
$$

- Falta bifásica, com terra e sem terra: considerando as fases faltosas sendo as fases $x$ e $y$ tem-se,

$$
\dot{Z}_{a p}=\frac{\dot{V}_{x}-\dot{V}_{y}}{\dot{I}_{x}-\dot{I}_{y}}
$$

- Falta trifásica: qualquer par de fases pode ser escolhido e aplica-se a equação anterior.

Para faltas monofásicas, tem-se o fator de compensação relativo à corrente de sequência zero $\left(\dot{I}_{0}\right)$ no denominador de (2.6), sendo que a constante $k_{0}$ é determinada em função das impedâncias de sequência zero $\left(\dot{Z}_{0}\right)$ e positiva $\left(\dot{Z}_{1}\right)$ da LT em questão,

$$
k_{0}=\frac{\dot{Z}_{0}-\dot{Z}_{1}}{\dot{Z}_{1}}
$$

Analisando (2.6) e (2.7) é fácil perceber que o resultado é um número complexo o ponto em $Z$ é utilizado para indicar este fato, não significando que a impedância se 
trata de um fasor. Com efeito, o resultado das operações é obtido por divisões de fasores. Desta forma, a comparação da impedância aparente com a impedância que representa o trecho da linha protegido normalmente é feita através da utilização do plano complexo R-X (Resistência-Reatância). Neste plano são definidas regiões de falta, no entorno da impedância da LT, as quais levam em consideração a resistência da falta e várias fontes de imprecisão no processo de estimação fasorial. A maior parte das regiões de atuação de relés de distância tem formato circular, devido a características inerentes aos relés eletromecânicos utilizados para a proteção de distância [9]. Os relés digitais permitem o uso de regiões mais complexas e diferentes como é o caso de uma região quadrilateral. Na Figura 7 são apresentadas duas regiões distintas. Em (a) tem-se uma das regiões circulares comuns (relé de admitância ou mho) e, em (b), tem-se um relé com área de atuação quadrilateral. Se a impedância calculada estiver contida na região sombreada, o relé entra em operação.

Finalmente, a distância do ponto de ocorrência da falta até o relé de proteção, com referência à distância total da linha protegida, pode ser estimada como:

$$
d(\%)=\frac{\operatorname{Im}\left(\dot{Z}_{a p}\right)}{\operatorname{Im}\left(\dot{Z}_{1}\right)} \times 100 \%
$$

(a)

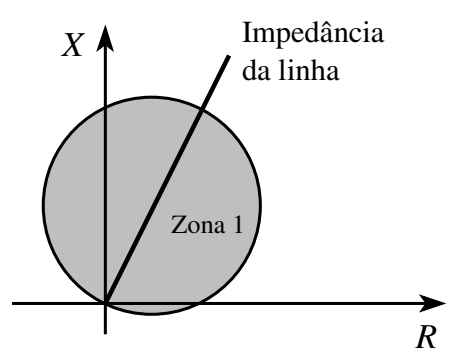

(b)

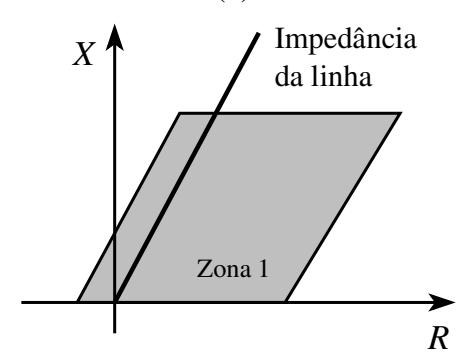

Figura 7. Tipos de características funcionais de relés de distância: (a) região de proteção circular e (b) região de proteção quadrilateral. 


\subsubsection{Aspectos negativos para o desempenho do relé tradicional}

Da exposição anterior, resta claro que os fasores relativos à componente fundamental nos sinais de tensão e corrente são obtidos através dos sinais continuamente amostrados pelo sistema de proteção. Neste cenário, fica evidente a dependência de desempenho dos algoritmos de proteção com a exatidão e precisão da estimação fasorial, tal como adiantado na Seção 1.4. Entre os principais fatores que influenciam os métodos de estimação fasorial em sistemas de potência estão, entre outros:

- Amostragem assíncrona;

- Presença de Ruído aditivo;

- Presença de componente CC de decaimento exponencial:

- Tamanho de janela de dados analisada;

- Saturação de TCs;

- Resposta transitória de filtros digitais.

Nas próximas seções, são apresentadas técnicas publicadas na literatura especializada, cujo foco é a proteção de linhas de transmissão. Entre uma série de aspectos, pode-se afirmar que os pesquisadores envolvidos neste tema trabalham no desenvolvimento de algoritmos de proteção que visam tratar ao menos um dos aspectos prejudiciais à proteção de distância, como os citados anteriormente. 


\subsection{Avanços na proteção de distância: técnicas baseadas na impedância aparente}

\subsubsection{Ajuste de Mínimos Quadrados}

A técnica de mínimos quadrados pode ser utilizada para estimação fasorial. O método consiste na minimização de uma função custo tal como,

$$
E=\int_{0}^{T}\left\{x(t)-\left[K_{0} e^{-t / \tau}-\sum_{n=1}^{H}\left(K_{2 n} \operatorname{sen} n \omega t+K_{2 n+1} \cos n \omega t\right)\right]\right\}^{2} d t
$$

onde $x(t)$ é o sinal analisado e $K_{1}, K_{2}, K_{3}, \ldots, K_{2 H+1}$ são as incógnitas do problema representando o modelo do sinal elétrico. Tratando-se de sistemas de tempo discreto, a integral de (2.10) é aproximada por um somatório. Baseado no princípio de ajuste por mínimos quadrados, inicialmente destaca-se o trabalho de Munday, Luckett e Murray [17] com a minimização da expressão (2.10).

Brooks Jr. [18] aproxima o sinal elétrico em situação de falta como sendo uma constante acrescida da componente de frequência fundamental, simplificando (2.10). Entretanto, há de se salientar que tal procedimento é impreciso tendo em vista as componentes de mais alta frequência normalmente presentes em sinais elétricos quando da ocorrência de faltas.

No trabalho de Sachdev e Beribeau [19] foi apresentado um método mais robusto que o anterior para utilização em relés de distância. Os autores consideraram a componente CC de decaimento exponencial e o terceiro harmônico. Para simplificar o modelo, os termos senoidais da expressão foram expandidos em série de Taylor e o problema final consiste na resolução de um sistema linear.

Um melhoramento na técnica de mínimos quadrados foi atingido com a proposta de Alfuhaid e El-Sayed [20], onde se utiliza uma versão recursiva para a minimização da função custo. Esta abordagem reduz significativamente o esforço computacional do relé, sendo possível estimar a distância e também a resistência de falta. 
Uma desvantagem dos trabalhos mencionados baseados no ajuste de mínimos quadrados consiste na consideração de frequência fixa para o sistema elétrico. Essa consideração é um fator que degrada o desempenho das técnicas mencionadas devido ao contínuo balanço de potência dos SEPs que resulta em pequenas variações da frequência de operação.

\subsubsection{Transformada Discreta de Fourier}

Outra forma de medição fasorial consiste no uso da Transformada discreta de Fourier, conforme colocado por Phadke e Thorp [7]. Essa ferramenta, introduzida na Seção 2.1.1, assume que o tamanho da janela de dados utilizada para análise contenha múltiplos inteiros de um ciclo completo para todas as componentes de frequência presentes no sinal.

Utilizando a DFT pode-se destacar inicialmente o trabalho de Phadke, Hlibka e Ibrahim [21]. Os autores propuseram o algoritmo da DFT de meio ciclo, objetivando a melhoria do tempo de resposta. Em contrapartida, erros de estimativas de fasores são introduzidos utilizando esta abordagem devido à presença de componentes CC e componentes de alta frequência.

Procurando lidar com os erros devido à amostragem assíncrona, Phadke, Thorp e Adamiak [22] propuseram um método de correção para o resultado da DFT. O método é baseado em uma das duas parcelas do erro de fase resultante do desvio de frequência fundamental. O algoritmo proposto não incorpora harmônicos no modelo do sinal elétrico em análise, fator que limita sua aplicação e, para pequenos desvios de frequência, produz resultados satisfatórios.

Em termos de esforço computacional, a DFT recursiva [23] e a Transformada Rápida de Fourier [24], amplamente conhecida como FFT (Fast Fourier Transform), 
representaram avanços nas técnicas de proteção de distância para implementação prática de relés.

O comportamento transitório na estimação fasorial foi tratado e melhorado no trabalho de Eichhorn, Ladniak e Lobos [25]. Os autores sugeriram um método baseado em uma dupla filtragem utilizando a DFT (ou, possivelmente, os filtros de Kalman) e também utilizando uma janela de tamanho variável.

Yu e Gu [26] apresentam um algoritmo o qual combina os estágios de filtragem analógica, através de um filtro passa-baixas, e de filtragem digital, com o uso da DFT de um ou meio ciclo. O principal objetivo desta metodologia é a remoção da componente $\mathrm{CC}$ dos sinais analisados. $\mathrm{O}$ algoritmo proposto elimina efetivamente a componente de decaimento exponencial provendo uma rápida extração das componentes fundamentais dos sinais de tensão e corrente para estimação da impedância aparente.

Um grande avanço na estimação fasorial usando a técnica de Fourier foi dada com a publicação do trabalho de Wang e Sun [27]. Os autores propuseram um método de correção do resultado da DFT que considera o erro total do ângulo de fase, decorrente da amostragem assíncrona. $\mathrm{O}$ algoritmo para correção é recursivo e faz adaptação do tamanho de janela utilizada para suprimir efeito de leakage ocasionado por componentes harmônicas. O método tem o desempenho prejudicado com presença de componente de decaimento CC.

Finalmente, merece destaque o trabalho de Chen, Liu e Jiang [28] o qual utiliza uma filtragem adaptativa através da DFT. Em suma, após a detecção da falta, uma janela de tamanho fracionário, em relação ao ciclo fundamental, é utilizada para estimação dos fasores. Esta janela só possui amostras pós-falta e, com o decorrer do tempo, o tamanho da janela é incrementado até compor um ciclo completo. Adicionalmente, a componente CC é eliminada do sinal analisado. Este método 
permitiu melhorar o tempo de resposta para estimativa da impedância aparente, assim como a exatidão da mesma em regime permanente, implicando em um sistema de proteção de distância rápido e confiável.

\subsubsection{Filtros de Kalman}

O Filtro de Kalman trata-se de um estimador ótimo recursivo. Esta teoria de filtragem é bem conhecida em controle e engenharia de comunicação e pode também ser utilizado na estimação de fasores em sinais elétricos que apresentam conteúdo ruidoso. Uma das desvantagens da metodologia consiste no fato de ser necessário o conhecimento preciso da natureza do ruído.

A primeira publicação a ser ressaltada com este tema é a de Girgis e Brown [29]. Os autores definem como ruído as componentes transitórias de frequência nãofundamental que surgem nos sinais de tensão e corrente logo após a incidência de faltas. Apesar de diversos fatores exercerem influência sobre tais componentes, tais como o carregamento da linha, a sua estrutura e a ausência de transposição, os autores contornam a dificuldade na caracterização do ruído realizando uma série de simulações para os mais diversos tipos de faltas e, portanto, levantando experimentalmente os dados almejados. Os resultados demonstraram rapidez de convergência das estimativas e imunidade à taxa amostral. Além disso, a técnica alia baixo esforço computacional.

Girgis [30] apresenta, em seguida, um estudo mais específico do filtro de Kalman aplicado à proteção de distância. Neste trabalho, o autor avalia a sensibilidade do algoritmo de filtragem para variações da inicialização da variância do ruído da corrente, variações da matriz de covariância inicial, entre outros aspectos. A técnica de filtragem se mostrou robusta.

Um método probabilístico é proposto por Girgis e Brown [31] para classificação de faltas em LTs. Segundo os autores, a técnica é plausível, considerada os aspectos 
aleatórios relativos aos tipos de falta e suas localizações. A técnica é baseada na análise de sinais de tensão através de um modelo melhorado para o Filtro de Kalman. Os resultados demonstraram uma extrema rapidez na classificação de faltas, com tempo médio observado de $1 \mathrm{~ms}$. Entretanto, foi destacado também o aumento do esforço computacional requerido pela nova técnica.

Em adição, considerando um modelo linear para o filtro de Kalman complexo, Pradhan, Routray e Sethi [32] implementaram um método sem problemas de estabilidade, como nos filtros não lineares. O uso do filtro complexo carrega vantagens como fácil modelagem e menos operações a serem efetuadas. Os resultados de estimativas com o uso de sinais com desvio de frequência e ruído aditivo se mostraram com características de rápida convergência e baixo erro de regime permanente.

\subsection{Avanços na proteção de distância: técnicas baseadas em Redes Neurais Artificiais}

Alternativamente às técnicas tradicionais, surgem as Redes Neurais Artificiais (RNAs) como ferramentas para a proteção de distância. As pesquisas nestas aplicações remontam ao início da década de 1990, pouco tempo após a retomada definitiva das pesquisas envolvendo RNAs - ocasionada especialmente com o advento do algoritmo Backpropagation de treinamento de redes com várias camadas.

Um dos trabalhos pioneiros a ser destacado é o de Khaparde, Kale e Agarwal [33]. De fato, neste trabalho, os autores afirmam enfaticamente: “Aqui nós encaramos o relé como um dispositivo classificador de padrões. Isto abre uma nova dimensão na filosofia de relés, a qual necessita uma ampla investigação." (tradução nossa). Apesar de esta não ser uma abordagem nova - a abordagem de relés como classificadores de padrões é creditada a Sakaguchi [34] - os autores dão um impulso às pesquisas de proteção de SEPs com a utilização das RNAs. Neste trabalho, empregam-se umas das redes mais 
básicas, o ADALINE, que possui como entrada amostras de tensão e corrente. Apesar da metodologia simples, que se restringe à discriminação de classes linearmente separáveis, fica demonstrada a adequabilidade das RNAs para propósitos de proteção de LTs.

Chakravarthy, Nayar, e Achuthan [35], apesar de não aplicarem especificamente as redes neurais, realizam um estudo detalhado do problema de proteção de distância modelado como um problema de reconhecimento de padrões. Os autores demonstram com precisão que este princípio pode resultar em um sistema de proteção "natural", ou seja, que incorpora todos os possíveis fatores que prejudicam as técnicas baseadas em impedância aparente.

O problema de classificação de faltas é abordado por Dalstein e Kuliche [36]. A metodologia faz uso de uma arquitetura neural de múltiplas camadas (Perceptron Multicamadas - PMC) cujas entradas são cinco amostras consecutivas de tensões e correntes das três fases. Os resultados alcançados indicam uma rápida (5 a $7 \mathrm{~ms}$ ) e confiável classificação das faltas ocorridas. Adicionalmente, os autores trataram as faltas com arco de forma a promover estratégias de religamento bem sucedidas. Os resultados são encorajadores, indicando que o sistema pode de fato substituir um sistema tradicional de proteção de linhas.

Jongepier e Van der Sluis [37] trabalham com o conceito de proteção adaptativa utilizando redes neurais. O principal objetivo é tratar o erro de estimação de distância de faltas em linhas paralelas decorrente do acoplamento mútuo. Os autores propõem então um método que emprega um relé tradicional, mas que tem os seus ajustes definidos por uma RNA, neste caso, um PMC. A rede desempenha basicamente o papel de estimador do estado de operação do sistema, de forma a adaptar a região de operação do sistema de proteção no plano R-X. Desta forma, conseguiu-se manter praticamente constante a 
porção da linha protegida, facilitando a coordenação e a seletividade dos sistemas de proteção.

O uso de um PMC funcionando como relé de distância toma lugar com o trabalho de Coury e Jorge [38]. Os autores utilizam a DFT para extração dos fasores fundamentais das tensões e correntes das três fases do sistema. Esses parâmetros são as entradas do PMC utilizado e treinado para responder à distância da linha que é protegida. Os resultados alcançados demonstraram que o método é robusto, respondendo bem às mudanças nas condições de falta e às condições de operação do SEP simulado.

A proteção de distância com o uso de redes neurais foi também alvo do trabalho de Oleskovicz, Coury e Aggarwal [39]. Mais especificamente, os autores tratam a etapa de classificação de faltas para integrar um esquema completo de proteção de distância. Quatro amostras consecutivas das tensões e correntes nas três fases compõem as entradas da rede, sendo utilizado um PMC de três camadas neste trabalho. Os resultados demonstraram uma classificação rápida e eficiente. De fato, depois de decorridos apenas 9 ms da ocorrência da falta, 99,16 \% dos casos testados foram classificados corretamente.

A estimação da distância da falta em relação ao relé de distância foi abordada no trabalho de Osman, Abdelazim e Malik [40], também usando RNAs. Foi demonstrado, através de simulações, que o método respondeu bem às variações dos parâmetros da falta, assim como às condições de carga do sistema simulado. As estimativas de distância de falta ocorreram com menos de um ciclo fundamental. Mais importante, deve ser ressaltada a implementação prática do método em plataformas DSP (Digital Signal Processor), assim como sua aplicação a um sistema de transmissão real, com desempenho similar ao obtido nas simulações computacionais. 
Zhang e Kezunovic [41] propõem a combinação de Transformada Wavelet (TW) com redes neurais para propósitos de proteção de distância. As RNAs utilizadas são do tipo ART (Adaptive Ressonance Theory), de aprendizado competitivo. Em suma, após o pré-processamento dos sinais elétricos de tensão e corrente, ocorre a decomposição dos mesmos através da TW. Os níveis de detalhes da TW, os quais possuem as componentes de alta frequência, são utilizados para treino de uma rede cuja tarefa é identificar a zona de ocorrência da falta. Já os níveis de aproximação, os quais possuem as componentes de baixa frequência, são utilizados para treino de uma nova rede cuja tarefa é identificar o tipo de falta. Os resultados demonstraram que a metodologia é apropriada ao propósito de proteção de distância.

A proteção de distância com as RNAs também foi recentemente tratada por Dutta e Kadu [42]. Os autores empregaram um PMC para o propósito, cujas entradas são amostras consecutivas do sinal de corrente do SEP simulado. Com os resultados, podese afirmar que a metodologia provê uma operação rápida e precisa.

\subsection{Outras técnicas avançadas de proteção de distância}

Outras técnicas aplicadas à proteção de distância têm sido abordadas na literatura. Nesta seção, serão apresentadas e comentadas algumas destas técnicas que merecem destaque.

A discussão se inicia com a abordagem de proteção baseado no Cálculo de Parâmetros pelo modelo $R-L$. Diferentemente das metodologias baseadas em impedância aparente, onde o foco está na modelagem dos sinais de tensão e corrente, o método em questão se propõe a modelar a dinâmica de uma LT sob falta através da sua representação em equações diferenciais. Um dos trabalhos a ser destacado, nesta linha, é o de Ranjbar e Cory [43] que remonta a meados da década de 1970. O método proposto 
por estes autores faz uma filtragem de harmônicos de baixa frequência que melhora o desempenho nas estimativas dos parâmetros $\mathrm{R}$ e $\mathrm{L}$ da linha. A técnica necessita, entretanto, de um desenvolvimento extra para aplicação em sistemas com linhas paralelas com forte acoplamento, por exemplo.

Duas décadas mais tarde Akke e Thorp [44] propõem melhorias no método baseado no modelo R-L de uma LT. A técnica combina um classificador booleano de faltas com o estimador de distância. Desta forma, foi possível incorporar todas as equações para os diferentes tipos de faltas em um único estimador, com um novo algoritmo de filtragem que melhora as estimativas dos parâmetros. Os resultados demonstraram melhorias de velocidade de atuação do sistema de proteção para as faltas trifásicas.

Outra abordagem importante para proteção de LTs é baseada no Fenômeno de Ondas Viajantes. Trata-se de um tópico bastante estudado por permitir uma extinção extremamente rápida da falta. Em oposição aos métodos baseados na impedância aparente, que utilizam apenas a componente fundamental, este método requer o uso de componentes de alta frequência. Na década de 1970, os métodos baseados neste princípio encontraram grande limitação de ordem prática, especialmente devido à tecnologia de conversores A/D.

Os algoritmos mais utilizados baseados em ondas viajantes realiza a estimação da distância de falta através da medição do intervalo de tempo entre a chegada de uma onda incidente e a correspondente onda refletida pela falta [9], como na proposta de Crossley e Maclaren [45]. Os autores utilizam função de correlação cruzada entre os sinais mencionados para medição do intervalo de tempo. Conforme ressaltado, os resultados demonstraram a exatidão na localização de faltas próximas aos limites das 
zonas de proteção. Desta forma, o método deve prover uma zona de proteção primária que incorpora uma grande porção da linha protegida.

O trabalho de Dutta e Gupta [46] apresenta três abordagens diferentes para medição da distância da falta através de ondas viajantes. Um dos métodos, baseados em análise espectral, obtém ótimos resultados com elevada resistência de falta. Mais importante, os autores apresentam resultados com as três abordagens programadas em plataforma microprocessada ( $\mu \mathrm{P} 8085)$.

Merecem destaque os métodos de proteção de distância que empregam a Transformada Wavelet (TW). Esta ferramenta possui a capacidade de decompor o sinal em diferentes bandas de frequência usando o que se denomina de análise multiresolução. Um dos trabalhos com essa abordagem é o de Zhang e Kezunovic [41], que emprega também as RNAs e que foi citado anteriormente.

Osman e Malik [47] aplicam a TW na detecção de faltas e estimação fasorial dos sinais de tensão e corrente. Os testes realizados, os quais incluem faltas sólidas e faltas fase-fase, faltas com alta impedância e diferentes condições de carregamento, mostraram que o sistema de proteção proposto operou corretamente, classificando as faltas com menos de um ciclo fundamental após a incidência das mesmas. Deve-se citar também a implementação prática da metodologia em plataforma DSP (Digital Sinal Processor).

Ainda em se tratando de transformada Wavelet, Liang e Jeyasurya [48] aplicam a MODWT (Maximal Overlap Discrete Wavelet Transform) para diminuir as distorções no nível de aproximação e permitir uma estimação fasorial mais fidedigna. Tal estimação é feita de forma recursiva, com o uso das amostras de tensão e corrente no passo atual e no passo anterior. Os resultados, comparados com a DFT de um ciclo completo, demonstraram rapidez de convergência do algoritmo e precisão na estimativa. 
O conceito de fasores dinâmicos é introduzido no trabalho de Grcar et. al. [49]. Os autores propõem quatro metodologias para aplicação em proteção de distância, que levam em conta a natureza variante dos parâmetros de sinais elétricos. Os resultados apresentados, comparados com a tradicional DFT, demonstraram maior rapidez e precisão dos métodos propostos, especialmente se são consideradas distorções severas nos sinais analisados.

No trabalho de $\mathrm{Yu}$ [50], é proposto um estimador fasorial adaptativo baseado na DFT e em filtro mímico. O foco deste trabalho está na remoção das componentes CC de decaimento exponencial dos sinais de corrente, que podem ocasionar problemas severos na proteção, especialmente de sobrealcance do relé. Diferentemente dos filtros mímicos tradicionais, a constante de tempo de decaimento é constantemente atualizada com base nos sinais de tensão e corrente. O método proposto se mostrou efetivo na remoção da componente CC, melhorando o desempenho da proteção de distância.

Cho et. al. [51] propõem equações para estimação da componente $\mathrm{CC}$ de decaimento exponencial, através da integração dos sinais de corrente. A metodologia proposta está apta a cancelar o efeito desta componente na estimativa fasorial com um ciclo fundamental.

O emprego de Algoritmos Genéticos (AGs) na proteção de distância é reportado em Coury, Oleskovicz e Souza [52]. Os autores formulam o problema de estimação fasorial como um problema de otimização que é solucionado com o emprego de um AG específico. Os resultados demonstraram que a metodologia proposta teve desempenho superior à tradicional implementação da DFT especialmente quando utilizada janela de dados de tamanho fracionário em relação ao ciclo fundamental.

Finalmente, a utilização de Estatísticas de Ordem Superior (EOS) em classificação de faltas é abordada superficialmente em Pradhan, Routray e Biswal [53]. 
Neste trabalho, é apresentada a vantagem do uso destas estatísticas para sinais que apresentam componente de ruído aditivo com distribuição Gaussiana. Os autores propõem a combinação das EOS com sistemas Fuzzy para o propósito de classificação de faltas em uma LT com compensação série. Os resultados apresentados demonstram a correta operação da metodologia proposta, com a identificação das fases em situação de falta.

\subsection{Considerações finais do capítulo}

Neste capítulo, apresentou-se os fundamentos de um sistema tradicional de proteção digital de distância para linhas de transmissão, o qual será utilizado no Capítulo 6 para efeitos de comparação de resultados. Após a apresentação de aspectos que prejudicam o desempenho deste sistema, foi realizado um levantamento bibliográfico de trabalhos divulgados na literatura que visam lidar com estes aspectos e, consequentemente, minimizar os seus efeitos. Este levantamento bibliográfico foi iniciado com a abordagem de técnicas baseadas na impedância aparente. Os métodos que empregam redes neurais foram tratados logo depois. Finalmente, foram descritas outras metodologias importantes, também empregadas na proteção das linhas de transmissão. 


\section{FERRAMENTAS UTILIZADAS}

Este capítulo apresentará uma sucinta, mas também completa e objetiva introdução às ferramentas utilizadas no sistema de proteção de distância desenvolvido nesta pesquisa de doutorado.

\subsection{Estatísticas de Ordem superior (EOS)}

\subsubsection{Introdução}

O uso de Estatísticas de Ordem Superior (EOS) em problemas de detecção tem sido reportado na literatura, como nos trabalhos de Giannakis e Tsatsanis [54] e de Colonnese e Scaranos [55]. No primeiro, os autores utilizam os cumulantes em processos de detecção e também de classificação automática de sinais. Já no segundo, os autores utilizam momentos de alta ordem na detecção de sinais de transitórios. Na pesquisa desta tese, empregam-se os cumulantes.

De fato, uma das áreas onde os cumulantes encontraram aplicações é em processos de detecção, conforme ressaltado por Boashash [56]. A motivação por detrás da utilização destas estatísticas em processamento de sinais está atrelada a técnicas de supressão de ruído colorido gaussiano, identificação de sistemas de fase não-mínima, identificação de sistemas não lineares, entre outras [57].

No início da década de 1990, especialmente, foi notado um grande aumento no interesse nas EOS e suas aplicações. Conforme destaca Mendel [58], foi verificada a aplicação dos cumulantes em diversos campos do conhecimento, como em sonares e radares, biomedicina, processamento de dados sísmicos, reconstrução de imagens, estimação de harmônicos, entre outras. Estas estatísticas fornecem mais informações do que as disponíveis simplesmente provindas da média e da variância de um processo 
[11]. Desta forma, pode-se afirmar que elas permitem uma melhor forma de discriminação de padrões em algumas aplicações.

Os cumulantes, em conjunto com as transformadas de Fourier associadas conhecidas como poliespectro - revelam não unicamente a informação de amplitude de componentes de um processo. Outrossim, revelam informação de fase. Este é um aspecto importante em algumas aplicações destas estatísticas haja vista que o espectro de potências, por exemplo, não possui tal informação.

As EOS são aplicáveis, especialmente em processos não Gaussianos, os quais ocorrem frequentemente na prática. No passado, com a falta de ferramentas analíticas apropriadas, os pesquisadores foram forçados a tratar tais processos como se fossem Gaussianos.

No que concerne aos sistemas elétricos, além da aplicação de cumulantes na proteção de distância [53], citada e comentada no capítulo anterior, destacam-se as aplicações na área de Qualidade de Energia Elétrica (QEE) [59]-[61]. Ribeiro et. al. [59] atacam especificamente o problema de detecção de distúrbios de QEE de forma a obter um sistema automático de monitoramento que possa armazenar janelas de dados quando da ocorrência das anomalias, tais como: spikes, notches, harmônicos, entre outros. Já Gerek e Ece [60] e Ferreira et. al. [61] tratam o problema da classificação dos distúrbios visando à obtenção de um sistema automático que possa identificar o tipo de anomalia ocorrida no sistema elétrico.

Nesta seção, são apresentadas definições relativas aos cumulantes, com base na teoria apresentada por Mendel [58] e, também, fazendo uso das considerações de Marques [11]. 


\subsubsection{Fundamentos matemáticos}

Seja $X$, portanto, um processo aleatório constituído pelo conjunto de variáveis aleatórias $\left(x_{1}, x_{2}, \ldots, x_{n}\right)$. Para variáveis aleatórias reais com média zero, os cumulantes de $2^{\mathrm{a}}, 3^{\mathrm{a}}$ e $4^{\mathrm{a}}$ ordens são dados por,

$$
\begin{aligned}
\operatorname{cum}\left(x_{1}, x_{2}\right) & =E\left(x_{1} x_{2}\right) \\
\operatorname{cum}\left(x_{1}, x_{2}, x_{3}\right) & =E\left(x_{1} x_{2} x_{3}\right) \\
\operatorname{cum}\left(x_{1}, x_{2}, x_{3}, x_{4}\right) & =E\left(x_{1} x_{2} x_{3} x_{4}\right)-E\left(x_{1} x_{2}\right) E\left(x_{3} x_{4}\right) \\
& -E\left(x_{1} x_{3}\right) E\left(x_{2} x_{4}\right)-E\left(x_{1} x_{4}\right) E\left(x_{2} x_{3}\right)
\end{aligned}
$$

Em (3.1) o operador $E(\cdot)$ representa o operador expectância ou valor médio. Supondo $x(t)$ um sinal aleatório estacionário de média zero, o cumulante de ordem $k$ desta variável é definido em termos dos sinais $x(t), x\left(t+\tau_{1}\right), \ldots, x\left(t+\tau_{k}\right)$, onde $\tau_{1, \ldots,} \tau_{k}$ são deslocamentos no tempo - também chamados lags. Assim, de (3.1), os cumulantes de $2^{\mathrm{a}}, 3^{\mathrm{a}}$ e $4^{\mathrm{a}}$ ordens podem ser reescritos como,

$$
\begin{aligned}
C_{2, x}\left(\tau_{1}\right) & =E\left\{x(t) x\left(t+\tau_{1}\right)\right\} \\
C_{3, x}\left(\tau_{1}, \tau_{2}\right) & =E\left\{x(t) x\left(t+\tau_{1}\right) x\left(t+\tau_{2}\right)\right\} \\
C_{4, x}\left(\tau_{1}, \tau_{2}, \tau_{3}\right) & =E\left\{x(t) x\left(t+\tau_{1}\right) x\left(t+\tau_{2}\right) x\left(t+\tau_{3}\right)\right\} \\
& -C_{2, x}\left(\tau_{1}\right) C_{2, x}\left(\tau_{2}-\tau_{3}\right) \\
& -C_{2, x}\left(\tau_{2}\right) C_{2, x}\left(\tau_{3}-\tau_{1}\right) \\
& -C_{2, x}\left(\tau_{3}\right) C_{2, x}\left(\tau_{1}-\tau_{2}\right)
\end{aligned}
$$

Fazendo $\tau_{1}=\tau_{2}=\tau_{3}=\tau[11]$, pode-se reescrever (3.2),

$$
\begin{aligned}
& C_{2, x}(\tau)=E\{x(t) x(t+\tau)\} \\
& C_{3, x}(\tau)=E\left\{x(t) x^{2}(t+\tau)\right\} \\
& C_{4, x}(\tau)=E\left\{x(t) x^{3}(t+\tau)\right\}-3 C_{2, x}(\tau) C_{2, x}(0)
\end{aligned}
$$

Ora, tratando-se da análise de um sinal de tempo discreto, $x[n]$, não se pode utilizar (3.3) diretamente. Pode-se, no entanto, utilizar aproximações, 


$$
\begin{aligned}
C_{2, x}(\tau) & =\frac{1}{N / 2} \sum_{n=0}^{N / 2-1} x[n] x[n+\tau] \\
C_{3, x}(\tau) & =\frac{1}{N / 2} \sum_{n=0}^{N / 2-1} x[n] x^{2}[n+\tau] \\
C_{4, x}(\tau) & =\frac{1}{N / 2} \sum_{n=0}^{N / 2-1} x[n] x^{3}[n+\tau] \\
& -\frac{3}{(N / 2)^{2}} \sum_{n=0}^{N / 2-1} x[n] x[n+\tau] \cdot \sum_{n=0}^{N / 2-1} x^{2}[n]
\end{aligned}
$$

As aproximações realizadas para a obtenção de (3.4) dizem respeito à substituição das integrais utilizadas no cálculo da expectância pelos somatórios destas equações. Conforme enfatizado por Marques [11], utilizando (3.4) perde-se informação no cálculo dos cumulantes, já que não são utilizadas todas as amostras para o cálculo. Isto por que, se $n$ exceder $N / 2-1, n+\tau$ excede o tamanho total do sinal $x[n]$ disponível. A estratégia adotada para contornar essa situação consiste em considerar a continuação da última amostra para a primeira, ou seja, um deslocamento circular. Matematicamente, a substituição de $n+\tau$ quando $n+\tau N-1$, pode ser dada por,

$$
\bmod (n+\tau, N)=(n+\tau)-b N
$$

onde $b$ é o número inteiro obtido quando se desconsidera as casas decimais da divisão de $\mathrm{n}+\tau$ por $N$, o que na verdade resulta no resto da divisão de $\mathrm{n}+\tau$ por $N$. Assim,

$$
\begin{aligned}
C_{2, x}(\tau) & =\frac{1}{N} \sum_{n=0}^{N-1} x[n] x[\bmod (n+\tau, N)] \\
C_{3, x}(\tau) & =\frac{1}{N} \sum_{n=0}^{N-1} x[n] x^{2}[\bmod (n+\tau, N)] \\
C_{4, x}(\tau) & =\frac{1}{N} \sum_{n=0}^{N-1} x[n] x^{3}[\bmod (n+\tau, N)] \\
& -\frac{1}{N^{2}} \sum_{n=0}^{N-1} x[n] x[\bmod (n+\tau, N)] \cdot \sum_{n=0}^{N-1} x^{2}[n]
\end{aligned}
$$

A grande vantagem na utilização de (3.6) para o cálculo dos cumulantes reside no fato da possibilidade de utilizar as $N$ amostras da janela considerada do sinal no cálculo dos cumulantes. Neste conjunto de equações, os valores assumidos pelo lag são 
$\tau=0,1, \ldots, N-1$. Essas equações, aliadas às RNAs, são a base para a metodologia de proteção de distância em LTs apresentada. Finalizando, é importante comentar que os cumulantes fornecem não só correlações de alta ordem de um processo, mas também uma medida do desvio do mesmo em relação a um processo gaussiano com mesma média e variância [58]. Com efeito, os cumulantes com ordem superior a dois são todos nulos para processos gaussianos, o que coloca este tipo de processo como referência em análises com EOS.

\subsubsection{Processo de cálculo de cumulantes}

Os cumulantes apresentados em (3.6) são para sinais de tamanho finito, conforme colocado. Desta forma, para aplicação em sinais elétricos, considera-se uma janela deslizante de dados de tamanho $N$. Este processo é exemplificado na Figura 8 para um sinal $x[n]$ qualquer. Tem-se, nessa figura, a representação do cálculo de cumulante de $2^{\mathrm{a}}$ ordem para o instante de tempo $n_{0}$. O conjunto de amostras $\left\{x\left[n_{0}-N+1\right], x\left[n_{0}-N+2\right], \ldots\right.$, $\left.x\left[n_{0}-2\right], x\left[n_{0}-1\right], x\left[n_{0}\right]\right\}$ será utilizado, portanto, para aplicação das expressões em (3.6). Esta janela de dados é reproduzida na figura, onde também é representada a janela deslocada utilizando o valor do lag $\tau$ escolhido. O cálculo do cumulante consiste basicamente na multiplicação ponto-a-ponto das janelas, denominadas original e com deslocamento, para aplicação do somatório nos resultados destas multiplicações. Analisando (3.6), é fácil perceber que o processo é simples também para os demais cumulantes. Para os de $3^{\text {a }}$ ordem, basta elevar as amostras ao quadrado antes de efetuar as multiplicações. 


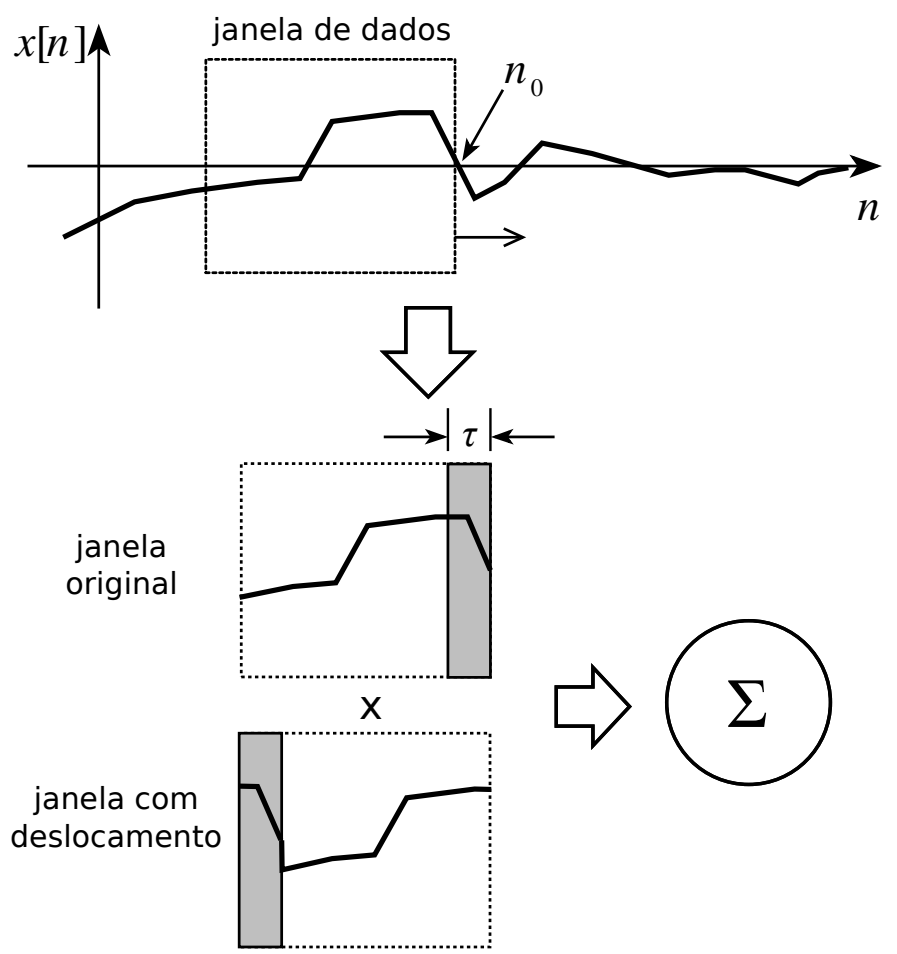

Figura 8. Cálculo de cumulantes para janelas deslizantes de sinais elétricos.

\subsection{Redes Neurais Artificiais (RNA)}

\subsubsection{Introdução}

As RNAs podem ser definidas como um conjunto de unidades de processamento (neurônios) que são interligadas por um grande número de interconexões (sinapses artificiais), as quais são responsáveis pelo armazenamento da informação, ou seja, pelo aprendizado da rede. Elas consistem basicamente em modelos computacionais que são inspirados no sistema nervoso dos seres vivos [62].

Os primeiros trabalhos sobre RNAs publicados datam de meados do século 20 . Considerando o histórico delineado por Haykin [63], é possível enumerar os seguintes relevantes trabalhos, em ordem cronológica:

- 1943 - McCulloch e Pitts publicam o primeiro trabalho relacionado à neurocomputação [64], no qual foi desenvolvido o primeiro modelo matemático inspirado em um neurônio biológico; 
- 1949 - Surge o primeiro método de treinamento de redes neurais artificiais, proposto por Hebb [65], e então denominado regra de aprendizado de Hebb;

- 1958 - Frank Rosenblatt idealizou o primeiro modelo do Perceptron [66], o qual tinha capacidade de reconhecimento de padrões simples;

- 1960 - Motivados pelo desenvolvimento do Perceptron, os pesquisadores Widrow e Hoff desenvolveram uma rede denominada Adaline [67] (ADAptive LINear Element), a qual possuía uma regra de aprendizagem denominada regra Delta, baseada no ajuste dos mínimos quadrados;

- 1969 - Em um período de muito interesse em RNAs, Minsky e Papert [68] demostraram as sérias limitações das redes até então desenvolvidas (Perceptron, Adaline, etc.) para solução de problemas tão simples como o do operador OUExclusivo (XOR);

- 1980 - Após a publicação do trabalho anterior, entre as poucas pesquisas desenvolvidas destaca-se o trabalho de Grossberg [69] no desenvolvimento da rede ART (Adaptive Ressonance Theory);

- 1982 - Ainda em um período de estagnação das pesquisas com redes neurais, ocorre a formulação dos mapas auto-organizáveis por Kohonen [70] e o desenvolvimento de redes recorrentes baseadas em funções de energia, por Hopfield [71]. 
- 1986 - Neste ano, o trabalho de Rumelhart, Hinton e Williams [72] permitiu finalmente o ajuste de pesos de redes neurais com mais de uma camada (algoritmo backpropagation), onde foi solucionado o antigo problema do operador OU-Exclusivo.

Como destacado por Silva, Spatti e Flauzino [62], a proposição do algoritmo backpropagation, juntamente com os trabalhos de Grossberg, Kohonen e Hopfield, do início da década de 1980, reascendeu e motivou definitivamente as pesquisas em redes neurais artificiais. Estas foram impulsionadas também pelo desenvolvimento de computadores com grande capacidade de processamento e melhoria da eficiência de métodos de otimização para treinamento, além de novas descobertas acerca do sistema nervoso humano. Desde então, além de muitas aplicações nos mais diversos ramos de conhecimento, novos trabalhos têm sido publicados de forma a incrementar a teoria de redes neurais.

Com a retomada das pesquisas teóricas em RNAs, avançou paralelamente o interesse na aplicação desta ferramenta em sistemas de tempo real. De fato, pesquisando o banco de dados do Instituto de Engenheiros Eletrônicos e Eletricistas (IEEE - Institute of Electrical and Electronic Engineers), observa-se uma forte frente de trabalho para a implementação das redes em hardware a partir de 1988. Como colocado por Graf e Jackel [73], neste mesmo ano: "Várias maneiras de se construir estes circuitos amplamente conectados estão sendo exploradas." (tradução nossa). Observa-se na literatura, desde então, o emprego de hardware de uso geral, semidedicado e dedicado para implementação de RNAs, estes últimos com técnicas analógicas, digitais ou híbridas (combinação de analógica e digital). 
Algumas das características mais relevantes das RNAs são [62]:

- Aprendizado através de exemplos: Os parâmetros da rede (pesos) são ajustados com base na apresentação sucessiva de exemplos (padrões, amostras, etc.);

- Capacidade de se adaptar: Através de certo treinamento, a RNA consegue "extrair" a relação entre as diversas variáveis de um dado problema;

- Habilidade de generalizar: Ocorrido o treinamento, a rede é capaz de generalizar, ou seja, estimar uma solução para uma entrada desconhecida;

- Tolerância a falhas: Dado o grande número de interconexões, a tolerância a falhas é elevada se somente uma pequena parcela da RNA é corrompida;

- Capacidade de agrupamento/organização de dados: Capacidade de agrupamento de dados que apresentem características/particularidades comuns.

Dentre o total de aplicações das redes neurais, aproximadamente $90 \%$ destas são representadas por reconhecimento de padrões e por aproximações de funções. No primeiro tipo de aplicações, a rede deve atribuir o padrão que lhe foi apresentado a uma das classes pré-definidas. Já no segundo tipo, ela deve encontrar uma estimativa da saída em função, somente, das suas entradas.

\subsubsection{Fundamentos matemáticos}

O modelo da unidade básica de processamento de uma RNA, o neurônio, é apresentado na Figura 9. As entradas $x_{1}, . ., x_{N}$ são multiplicadas pelos pesos sinápticos $w_{1}, . . w_{N}$ e somadas, incluindo o termo $\theta$, o limiar de ativação neural. A saída do 
combinador linear, $u$, passa pela função de ativação $g($.$) , resultando na saída do$ neurônio, $y$. Matematicamente [63],

$$
\left\{\begin{array}{l}
u=\sum_{i=1}^{N} w_{i} x_{i}-\theta \\
y=g(u)
\end{array}\right.
$$

Se for considerada uma entrada $x_{0}=-1$, o limiar de ativação $\theta$ pode ser representado por um peso $w_{0}$, ou seja,

$$
\left\{\begin{array}{l}
u=\sum_{i=0}^{N} w_{i} x_{i} \\
y=g(u)
\end{array}\right.
$$

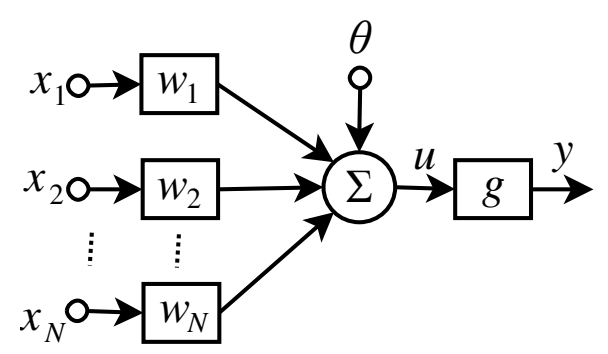

Figura 9. Modelo de um neurônio artificial.

Na engenharia, grande parte das aplicações de RNAs é realizada com a aplicação das redes Perceptron Multicamadas (PMCs). Tratam-se de redes do tipo Feedforward (fluxo único de informação) constituídas por uma camada de entrada de informações $\left(x_{1}, . ., x_{N}\right)$, pelo menos uma camada neural intermediária e uma camada neural de saída. Na Figura 10, essas terminologias são indicadas para um PMC de duas camadas neurais. A camada neural intermediária é a primeira camada neural e é também denominada camada escondida. Cada círculo representa um neurônio básico da Figura 9, onde o limiar e a função de ativação estão implícitos. Para este caso, a camada de entrada possui $N$ componentes, a primeira camada neural e a camada neural de saída possuem $N_{1}$ e $N_{2}$ neurônios, respectivamente. 


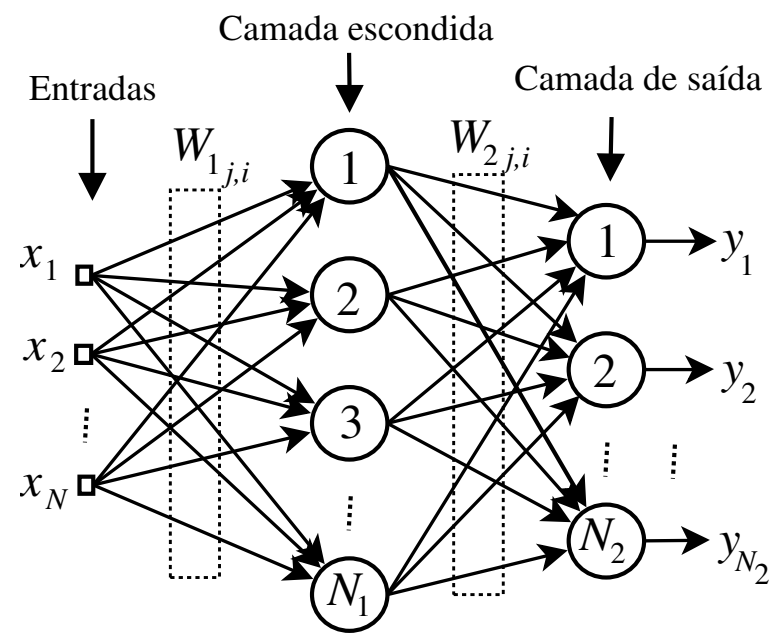

Figura 10. Perceptron Multicamadas (2 camadas neurais).

As conexões entre as camadas da rede são realizadas pelas matrizes de pesos sinápticos $W_{1}$ e $W_{2}$, com ordens $N_{1} \times(N+1)$ e $N_{2} \times\left(N_{1}+1\right)$, respectivamente. O PMC pertence à classe de RNAs que possuem treinamento supervisionado. Isto significa que ele é aplicado em problemas que dispõem de um conjunto de entradas $x_{1}(k), . ., x_{N}(k)$ com um conjunto de saídas $d_{1}(k), . ., d_{N 2}(k)$ associado. A rede aprende, ou seja, é treinada, ajustando suas matrizes de pesos, de forma que, se apresentado um padrão $k$ na entrada da rede, $y_{j}(k)$ seja "igual" a $d_{j}(k)\left(j=1, . ., N_{2}\right)$. O processo de treinamento destas redes é realizado aplicando o algoritmo Backpropagation [63], método também conhecido como "Regra Delta Generalizada". O procedimento consiste de dois passos: (a) Foreward: o padrão é aplicado nas entradas da rede e é propagado para a saída, através da interação com os pesos sinápticos; e (b) Backward: A partir das saídas, calcula-se o erro que é retropropagado objetivando o ajuste das matrizes de pesos. O processo de ajuste de pesos é realizado através do Gradiente do erro quadrático apresentado pela rede, em relação aos pesos sinápticos,

$$
\in(k)=\frac{1}{2} \sum_{j=1}^{N_{2}}\left[d_{j}(k)-y_{j}(k)\right]^{2}
$$


Dada a utilização do Gradiente, as funções de ativação devem ser diferenciáveis. Dentre as funções utilizadas, destacamos a função logística, dada por:

$$
g(u)=\frac{1}{1+e^{-\beta_{R N A} u}}
$$

onde o fator $\beta_{\text {RNA }}$ descreve a faixa de transição da função. Se $u$ tende a $-\infty, \mathrm{g}(u)$ tende a zero e, se $u$ tende a $+\infty, \mathrm{g}(u)$ tende a um. Quanto maior $\beta_{\mathrm{RNA}}$, mais abrupta a transição de zero para um, localizada em $u=0$.

Tratando-se do processo de ajuste de pesos, uma equação geral para o peso que realiza a ligação do neurônio $j$ da camada corrente à sua entrada $i$ pode ser escrita como,

$$
w_{j i}(t+1)=w_{j i}(t)+\eta \delta_{j} y_{i}
$$

onde $\eta$ é a taxa de aprendizagem, $\delta_{j}$ é o gradiente local do erro para o neurônio $j$, $w_{j i}(t+1)$ é o peso ajustado e $w_{j i}(t)$ o peso no passo anterior. A velocidade de convergência dos ajustes pode ser aumentada, (sem perigo de instabilidade) com a inserção do termo denominado momentum $\left(\alpha_{\mathrm{RNA}}\right)$,

$$
w_{j i}(t+1)=w_{j i}(t)+\alpha_{R N A}\left(w_{j i}(t)-w_{j i}(t-1)\right)+\eta \delta_{j} y_{i}
$$

Os detalhes de implementação do algoritmo Backpropagation podem ser encontrados em [62] e [63].

\subsection{Considerações Finais do Capítulo}

Este capítulo realizou uma abordagem sucinta e objetiva das ferramentas empregadas no método de proteção proposto nesta tese. Os cumulantes foram tratados inicialmente, com a apresentação da fundamentação teórica e de trabalhos que empregam estatísticas de ordem superior em processos de detecção. Em seguida, foram tratadas as redes neurais artificiais, com a apresentação de um breve histórico deste tema, acompanhado das principais características e fundamentos. 


\section{NOVO MÉTODO DE PROTEÇÃO COM EOS E RNA}

Este capítulo apresenta a metodologia proposta para proteção de linhas de transmissão, a qual emprega as estatísticas de ordem superior e as redes neurais artificiais. As EOS são utilizadas como ferramenta de extração de características, para as etapas de detecção, classificação e localização de faltas. As redes neurais artificiais possuem como entradas os cumulantes e serão responsáveis pela lógica do relé desenvolvido. Por fim, cabe salientar que, no universo de estudo desta tese, é considerada a hipótese de que ocorreu uma falta no SEP em análise. Desta forma, à metodologia proposta cabe executar os processos de detecção, classificação e localização desta falta.

\subsection{Sistema de proteção proposto}

\subsubsection{Descrição dos componentes do sistema}

O princípio adotado neste trabalho é o que se tem de habitual em proteção digital de LTs. Isto é, os processos de detecção, classificação e localização são realizados de forma consecutiva e ordenados. Este princípio é representado na Figura 11. Nesta figura, pode-se verificar que as amostras dos sinais elétricos são particionadas em três agrupamentos ordenados.

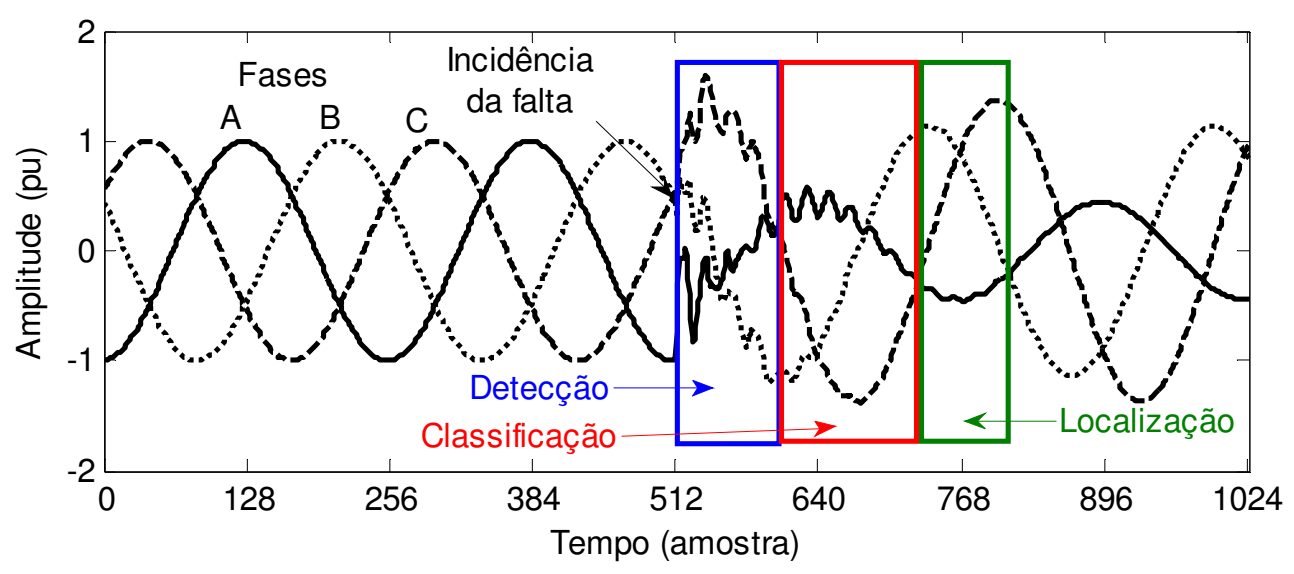

Figura 11. O princípio de operação adotado para o sistema proposto: três sistemas distintos responsáveis pelas operações de detecção, classificação e localização de faltas em LTs. 
A primeira partição apresentada na Figura 11 consiste das amostras exatamente após a ocorrência da falta no sistema. Este conjunto de amostras é utilizado para a implementação do módulo de detecção, visando rapidez e confiabilidade deste processo. A segunda partição de dados consiste nas amostras empregadas no desenvolvimento do módulo de classificação. Finalmente, a terceira partição consiste das amostras empregadas no sistema de localização. Realizada a classificação, pode-se ter um sistema de localização especializado para o tratamento de cada tipo de falta passível de ocorrência. Esta estratégia de particionamento visa à simplificação das etapas de proteção, sem prejuízo ao desempenho das mesmas.

A determinação do tamanho das partições apresentadas na Figura 11 não possui regra específica. Entretanto, de forma a satisfazer os requisitos de tempo da proteção, os conjuntos de dados podem ser escolhidos em partições cujo tamanho é fracionário, comparado com o tamanho do período fundamental. O módulo de detecção utiliza, ainda, um conjunto de dados anteriores à ocorrência do curto, para diferenciação das situações de pré- e pós-falta.

Uma representação generalizada da estrutura proposta a ser utilizada nas etapas de proteção de distância pelo método proposto é mostrada na Figura 12. Esta representação é dita generalizada haja vista que cada etapa possui uma configuração particular no que diz respeito às estatísticas empregadas e à topologia da rede neural utilizada.

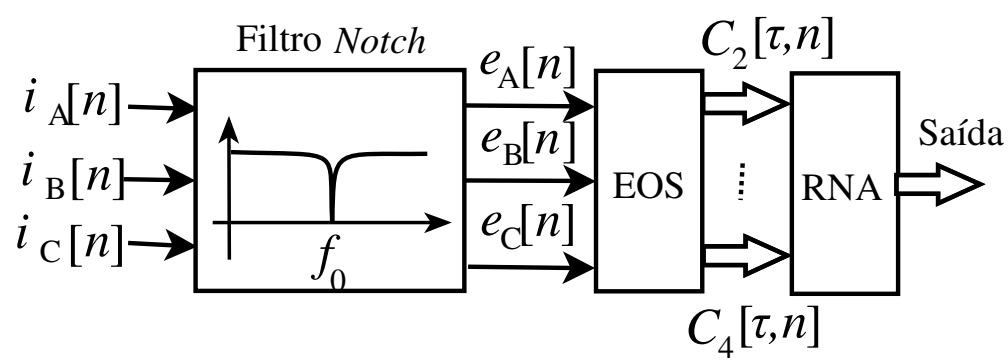

Figura 12. Diagrama funcional generalizado para as etapas de detecção, classificação e localização de faltas do sistema de proteção proposto. 
Inicia-se a descrição da estrutura apresentada anteriormente na Figura 12 enfatizando-se a busca por uma solução que utiliza apenas sinais de corrente como entrada. Com efeito, isto pode ser visualizado nesta mesma figura, com os sinais de corrente constituindo a única entrada da estrutura. Esta abordagem representa uma inovação frente à proteção de distância tradicional que faz uso de sinais de tensão e corrente obrigatoriamente. O primeiro estágio é composto por um processo de filtragem, realizado com o emprego de filtros notch. Este estágio é comum às três etapas do sistema de proteção. O filtro notch utilizado é do tipo IIR (Infinite Impulse Response) parametrizado cuja função de transferência é dada por [12],

$$
H(z)=\frac{1+\alpha}{2} \frac{1-2 \beta z^{-1}+z^{-2}}{1-\beta(1+\alpha) z^{-1}+\alpha z^{-2}}
$$

onde $\alpha$ e $\beta$ controlam, respectivamente, a largura da faixa de rejeição e a freqüência de notch.

O filtro notch remove completamente a componente de frequência fundamental $\left(f_{0}\right)$ dos sinais de corrente. $\mathrm{O}$ emprego desse filtro diz respeito ao fato de várias técnicas de detecção utilizarem sinais de erro. Desta forma, a seguinte formulação para o problema em particular em questão pode ser introduzida. Esta formulação é composta de duas hipóteses,

$$
\begin{array}{ll}
H_{0}: & e_{x}[n]=r_{x}[n] \\
H_{1}: & e_{x}[n]=r_{x}[n]+t_{x}[n]
\end{array}
$$

onde $x$ representa as fases do SEP, ou seja, $x=\{A, B, C\}$. O sinal de ruído $r_{x}[n]$, é uma componente de fundo gaussiana e o sinal $t_{x}[n]$ é uma componente de transitórios. A hipótese $H_{0}$ é a hipótese nula do problema e é associada à condição de operação normal da LT. A hipótese alternativa $H_{1}$ está associada à condição de falta. Essa formulação é plausível, considerando os baixos níveis harmônicos na transmissão, e foi adotada previamente por Gerek e Ece [60]. 
Seguindo o estágio de filtragem, o bloco EOS é utilizado para calcular os cumulantes dos sinais de erro. Os cumulantes são calculados através de janelas móveis no tempo, de tamanho $N$, para os sinais $e_{A}, e_{B}$ e $e_{C}$. A utilização de janelas com tamanho fracionário, com referência ao período fundamental, é um dos atrativos do trabalho.

Apesar das considerações de Mendel [58] sobre os cumulantes de $3^{\mathrm{a}}$ ordem - para algumas distribuições amostrais são nulos ou muito próximos de zero - além da não utilização dos mesmos por Marques [11], neste trabalho, decidiu-se investigar a sua aplicabilidade ao problema em questão. Assim, no instante $n$ as saídas do segundo estágio serão compostas pelos sinais,

$$
\left[\begin{array}{c}
C_{2, i}(0, n) \\
C_{2, i}(1, n) \\
\vdots \\
C_{2, i}(N-1, n)
\end{array}\right] \quad\left[\begin{array}{c}
C_{3, i}(0, n) \\
C_{3, i}(1, n) \\
\vdots \\
C_{3, i}(N-1, n)
\end{array}\right] \quad\left[\begin{array}{c}
C_{4, i}(0, n) \\
C_{4, i}(1, n) \\
\vdots \\
C_{4, i}(N-1, n)
\end{array}\right]
$$

De (4.3), pode-se perceber que um total de $N$ cumulantes de segunda, terceira e quarta ordens estão disponíveis, por fase, para os processos de detecção, classificação e localização. Deve-se destacar esse grande número de parâmetros disponíveis para implementação da lógica de operação do relé.

Uma combinação de cumulantes para as fases $A, B$ e $C$ constitui a entrada do terceiro e último estágio. Este estágio é composto por redes neurais artificiais, cada uma específica para a sua função. A arquitetura de rede utilizada no trabalho é o Perceptron Multicamadas, introduzido no capítulo anterior.

\subsubsection{Diagrama funcional de operação}

A Figura 13 apresenta um diagrama funcional do sistema de proteção proposto. Neste esquema, é apresentada a lógica para obtenção da proteção de linhas de transmissão, através da interconexão dos subsistemas de detecção, classificação e localização. 


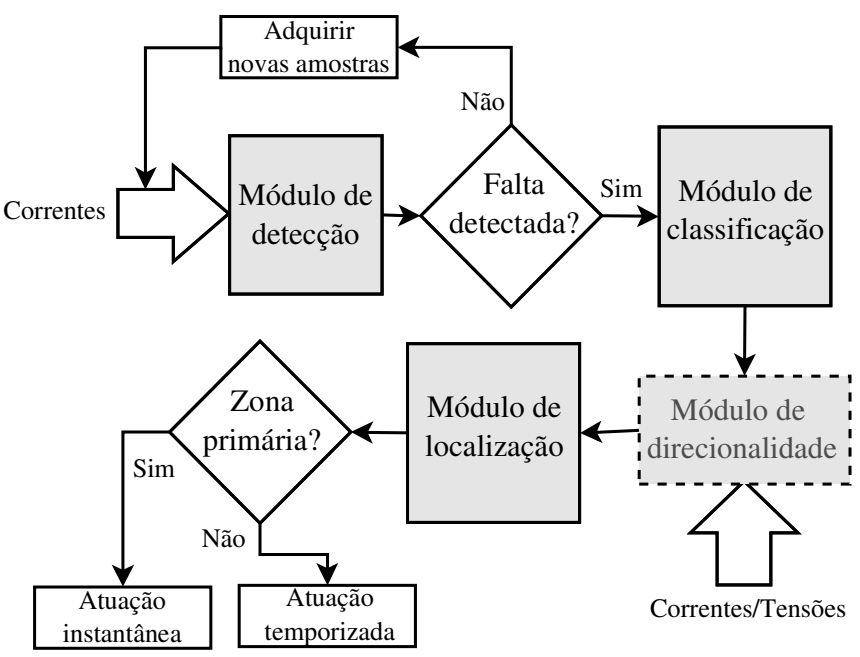

Figura 13. Diagrama funcional do sistema de proteção proposto.

Inicialmente, destaca-se a operação única do módulo de detecção, que recebe como entrada os sinais de corrente elétrica do barramento onde está alojado o relé. Quando da operação normal do sistema elétrico, ou seja, sem a ocorrência de falta, este é o único módulo em funcionamento. Ele provê o monitoramento da situação do SEP e deve indicar prontamente uma situação de falta quando de sua ocorrência. Deve-se destacar novamente a utilização única de sinais de corrente neste processo. Uma rede neural artificial dedicada é utilizada, nesta etapa, para diferenciação de situações de préfalta e pós-falta. Na incidência de uma falta sustentada, o módulo de detecção dispara um contador que é utilizado para confirmar, ou validar, a situação de falta no SEP.

Confirmada a situação de falta, depois de transcorrido o tempo equivalente ao tamanho da janela utilizada para projeto do sistema de detecção (vide Figura 11), o mesmo é desabilitado e é habilitado então do módulo de classificação. Tal módulo possui um total de quatro saídas para a identificação da participação das fases A, B e C e da terra na falta. A classificação da falta é realizada também utilizando processo de contagem, para confirmação de resultado. 
Por fim, é acionado o módulo de localização, sendo desabilitado o módulo de classificação. O último módulo é subdividido em quatro submódulos, sendo cada um responsável pela localização da falta de acordo com o tipo da mesma (F-T, F-F, F-F-T ou F-F-F), previamente classificada. A saída deste módulo consiste na indicação da zona de falta para atuação do relé junto ao sistema elétrico. Cabe frisar que, normalmente, a localização consiste em uma indicação da distância da falta em relação ao relé. Nestes termos, apesar de no método proposto ser dada a zona de ocorrência da falta - e não a distância - utilizar-se-á o termo localização para designar esta etapa.

O módulo de localização deverá ser precedido, dependendo da configuração do sistema elétrico de potência, por um módulo de direcionalidade, tal como apresentado na Figura 13. Neste trabalho, optou-se por adotar um algoritmo tradicional e simples para determinação da direção da falta, baseado na análise dos ângulos de fase dos sinais elétricos das fases faltosas [7].

\subsection{Seleção de parâmetros de Estatísticas de Ordem Superior}

Como relatado na Seção anterior, um grande número de cumulantes está disponível para aplicação na proteção do sistema elétrico. A pergunta que surge decorrente desta ampla gama de dados é simples e pertinente: quais as estatísticas - qual ordem e qual lag - que devem ser escolhidas de forma a detectar, classificar e localizar uma falta? Neste cenário, um método de seleção mostra-se altamente relevante.

São reportados na literatura inúmeros métodos, lineares ou não lineares, para seleção de parâmetros. A técnica adotada consiste na determinação de um índice que fornece uma medida do grau de separação de duas classes. O índice escolhido é o Discriminante Linear de Fisher (FDR-Fisher Discriminant Ratio), por sua simplicidade 
e facilidade de implementação. No que se segue, são apresentados os fundamentos desta ferramenta.

Sejam definidas, inicialmente, duas classes distintas $C_{1}$ e $C_{2}$ que representam um determinado problema de classificação de padrões. As amostras, ou padrões, pertencentes a cada uma dessas classes possuem, associadas a elas, quantidades relativas a três variáveis quaisquer, denominadas $x, y$ e $z$. Na Figura 14, são apresentadas algumas das possibilidades para a distribuição destas amostras ao longo dos eixos das variáveis deste problema. Percebe-se claramente que em (a) e (b) ocorre interseção entre os dois conjuntos. Entretanto, essas duas configurações são distintas em sua essência, como será colocado a seguir. Já em (c) não há sobreposição dos padrões de classes diferentes.

O fundamento do método do FDR para seleção de parâmetros pode ser facilmente compreendido com base na Figura 14. Observe que a melhor separação ocorre na variável $z$, em (c). Nesta variável, os dois conjuntos possuem médias distantes entre si e variâncias reduzidas. Em (a) tem-se conjuntos com variâncias reduzidas também. No entanto, as médias são próximas entre si. Já em (b), os conjuntos exibem na variável y valores médios com uma considerável distância. Por sua vez, as variâncias associadas aos conjuntos são elevadas e proporcionam a sobreposição das classes.

Diante do exposto, sejam consideradas duas classes, $C_{1}$ e $C_{2}$. Considerando uma variável qualquer associada aos padrões destas classes, são definidos os valores médios, $\mu_{1}$ e $\mu_{2}$, e as variâncias, $\sigma_{1}^{2}$ e $\sigma_{2}^{2}$, associadas às classes $C_{1}$ e $C_{2}$, respectivamente. $\mathrm{O}$ índice FDR é então definido como [74],

$$
F D R=\frac{\left(\mu_{1}-\mu_{2}\right)^{2}}{\sigma_{1}^{2}+\sigma_{2}^{2}}
$$

De (4.4) pode-se perceber que o FDR é um índice que permite quantificar o grau de separabilidade entre duas classes, para uma determinada variável associada aos 
padrões destas classes. O índice calculado em (4.4) é analisado para cada variável associada aos padrões das classes $C_{1}$ e $C_{2}$. Como colocam Candan e Sapino [75], a variável que resulta em um valor elevado para o FDR possui grande chance de prover uma melhor separação entre as duas classes.

Apesar de o discriminante estar fortemente relacionado à estrutura dos dados do problema [76], é importante frisar duas das características elementares deste índice. Primeiramente, os valores elevados do FDR para um dado problema não permite concluir, obrigatoriamente, que as classes são totalmente separáveis. Em segundo lugar, baixos valores para o discriminante não significam que as classes não são separáveis. Podem significar, no entanto, que a fronteira (reta) de separação não é perpendicular à direção do eixo de nenhuma das variáveis associadas ao padrão.

Finalmente, conforme enfatizado por Mira e Álvarez [76], o esforço computacional do método é bastante baixo, característica importante especialmente quando se trata de um elevado número de variáveis associadas ao problema em que está sendo aplicado.

(a)

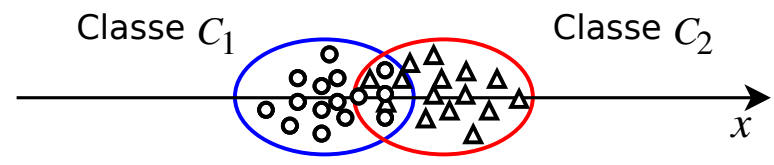

(b)

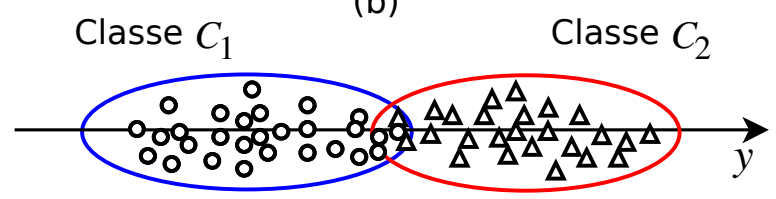

(c)

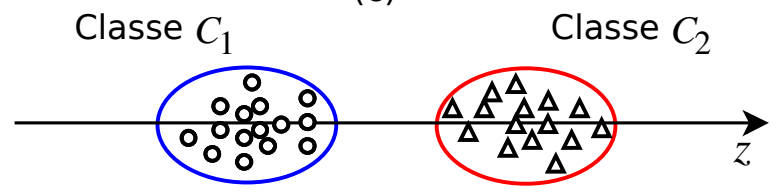

Figura 14. Representação do problema de separação de classes: (a) médias próximas com baixa variância; (b) médias afastadas com variância elevada e; (c) médias afastadas e baixa variância. 


\subsection{Condicionamento dos sinais elétricos}

Pode-se sintetizar o processo de medição de sinais elétricos de uma linha de transmissão, por parte de um relé, tal como apresentado na Figura 15. Nesta figura, temse representada uma LT com o relé alocado junto ao barramento da unidade de geração $G_{1}$.

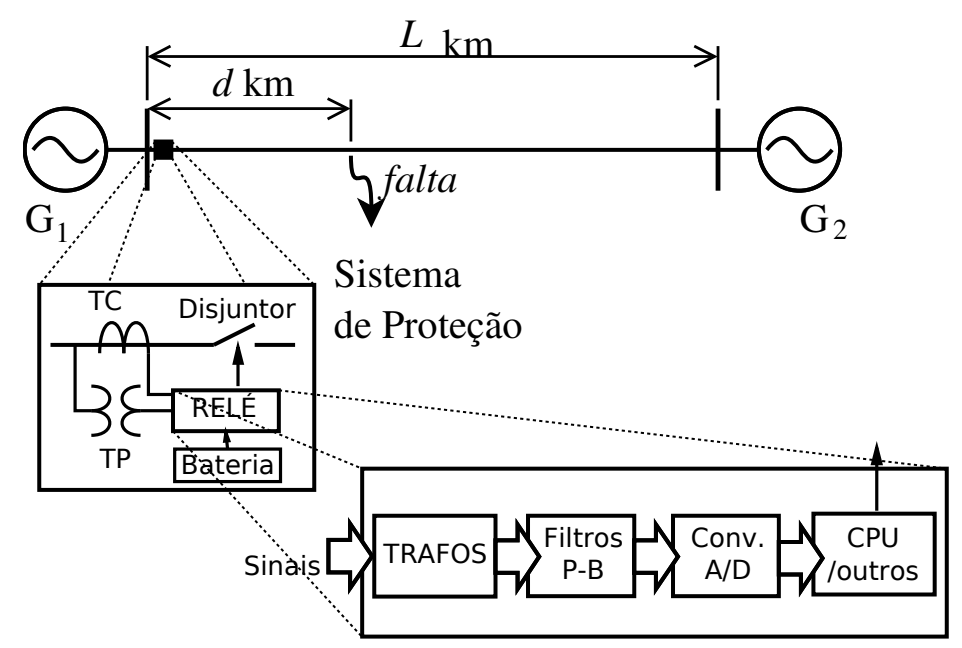

Figura 15. Representação do processo de medição de sinais elétricos nos relés digitais.

Verifica-se na Figura 15, no primeiro nível de detalhamento, a existência dos transformadores de potencial e transformadores de corrente. Como colocado no Capítulo 1, estes componentes são responsáveis pela transformação dos elevados níveis de tensão e corrente do sistema de transmissão em valores suficientemente reduzidos, de forma que essas variáveis sejam utilizadas por sistemas de medição, controle e proteção. Há de se destacar que também promovem o isolamento em relação ao circuito de potência. Os sinais de tensão e corrente, coletados pelos TPs e TCs são fornecidos à entrada de um relé digital. A arquitetura apresentada na Figura 15 é um modelo simplificado da arquitetura de um relé digital, discutida em [9]. Inicialmente, faz-se uso de transformadores para redução dos níveis de tensão a valores adequados para tratamento destes sinais pelo sistema digital embutido no relé. Os filtros que se seguem consistem em filtros analógicos do tipo passa-baixas (P-B) e têm como objetivo limitar 
a faixa de frequência dos sinais do SEP, atenuando componentes de alta frequência. Este é um pré-requisito essencial de forma que seja evitado o fenômeno de sobreposição de espectros, denominado aliasing, quando do processo de discretização dos sinais analógicos. Esses filtros são denominados filtros anti-aliasing. Em conjunto com dispositivos Sample-and-Hold $(\mathrm{S} / \mathrm{H})$, não representados na figura, os conversores A/D promovem a transformação periódica dos sinais analógicos em suas entradas para representações binárias (digitais) equivalentes. Por fim, essa informação digital é processada em unidades de processamento (CPUs) que dispõem de uma série de outros componentes funcionando em conjunto, tal como memórias, dispositivos de entrada/saída, etc. A CPU tem como função implementar a lógica do relé digital.

Diante do exposto anteriormente, pode-se perceber que as simulações computacionais devem considerar, portanto, uma série de componentes. Neste trabalho, considerar-se-á, para todos os efeitos, o emprego de TPs e TCs ideais. Estes componentes são modelados basicamente por um ganho, constante, que é responsável pela atenuação dos sinais de tensão e corrente de entrada. Desta forma, com o uso destes modelos simplificados não se terá a avaliação da metodologia frente a efeitos indesejados que ocorrem da aplicação prática destes componentes, como a saturação dos transformadores de correntes. A seguir, apresenta-se uma abordagem sucinta e objetiva de filtros anti-aliasing e conversores A/D, componentes empregados nas simulações deste trabalho.

\subsubsection{Filtro anti-aliasing}

Os filtros anti-aliasing são dispositivos básicos que visam à preparação de um sinal analógico, de tempo contínuo, para a sua transformação em um sinal discreto. Desta forma, pode-se trabalhar ou processar informações deste sinal discreto através de técnicas de Processamento Digital de Sinais (PDS ou DSP-Digital Signal Processing). 
Em suma, o processo de discretização de um sinal analógico resulta em um sinal discreto cuja representação no domínio da frequência é composta de réplicas da resposta em frequência do sinal original. Estas réplicas aparecem centradas nas frequências $k \times f_{S}$, com $k \in \mathbb{Z}$, onde $f_{S}$ é a frequência de amostragem. Esta operação de discretização está simbolizada na Figura 16 para um sinal qualquer $x(t)$, considerando dois casos distintos de amostragem. Nesta figura, o eixo de frequências está representado com frequências angulares. Pode-se observar em (a) que o sinal original possui banda de frequências limitada. De fato, não existem componentes com frequência superior a $\omega_{M}$. Em (b) é apresentado o espectro de um sinal amostrado com uma taxa amostral $\omega_{S 1}$. Pode-se perceber que o valor escolhido para este parâmetro foi responsável pela criação de réplicas do espectro original que se encontram consideravelmente espaçadas entre si. Este não é o caso da representação da Figura 16(c) onde a frequência de amostragem $\omega_{\$ 2}$ foi escolhida de forma inadequada e resultada na sobreposição de componentes de frequência. A sobreposição observada nesta figura consiste no fenômeno denominado de aliasing [77].

O teorema da amostragem estabelece os critérios para a correta amostragem de um sinal contínuo. Ele é enunciado aqui, com uma adaptação do enunciado por Diniz, Silva e Netto [77]:

\footnotetext{
"Se um sinal $x(t)$ no tempo contínuo tem largura de faixa limitada, isto é, sua transformada de Fourier é nula para $f>f_{M}$, então $x(t)$ pode ser completamente recuperado a partir de um sinal discreto $x[n]=x\left(n T_{S}\right)$ se, e somente se, a frequência de amostragem $f_{S}$ satisfaz a relação $f_{S}>2 f_{M}$."
}

No enunciado, $f_{M}$ é a componente de frequência máxima do sinal $x(t)$ e $T_{S}$ é o período de amostragem $\left(=1 / f_{S}\right)$. Com base no teorema da amostragem, se um sistema 
digital possui uma frequência de amostragem de trabalho fixa é fundamental que o sinal analógico a ser processado seja de banda limitada. Este objetivo pode ser alcançado com o uso de filtros passa-baixas que garantirão a anulação de componentes com frequências superiores a $f_{S} / 2$.

(a)
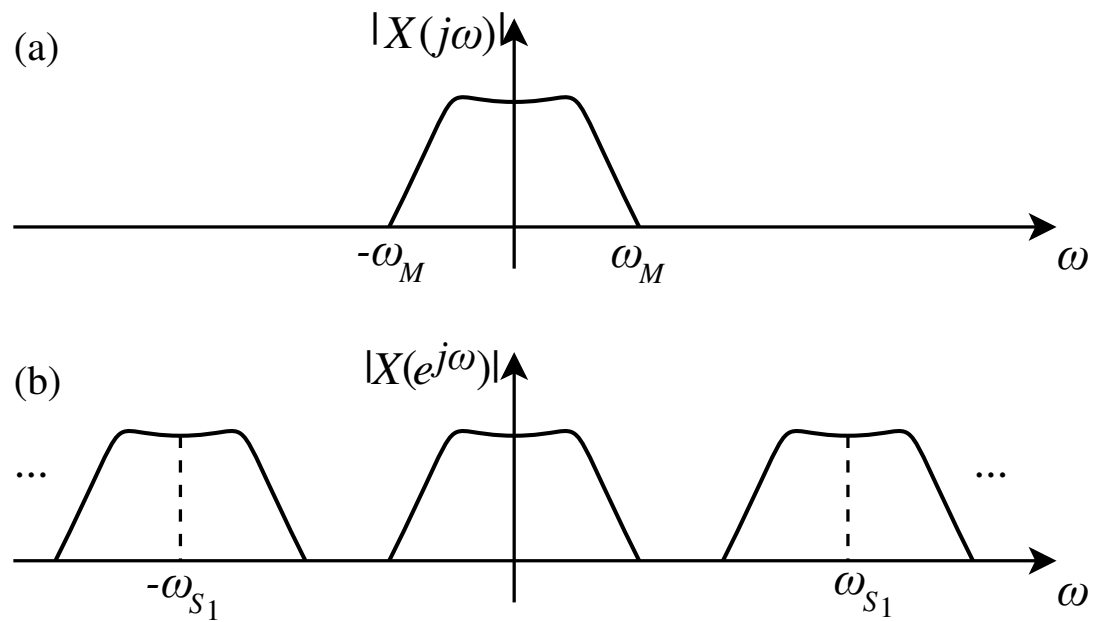

(c)

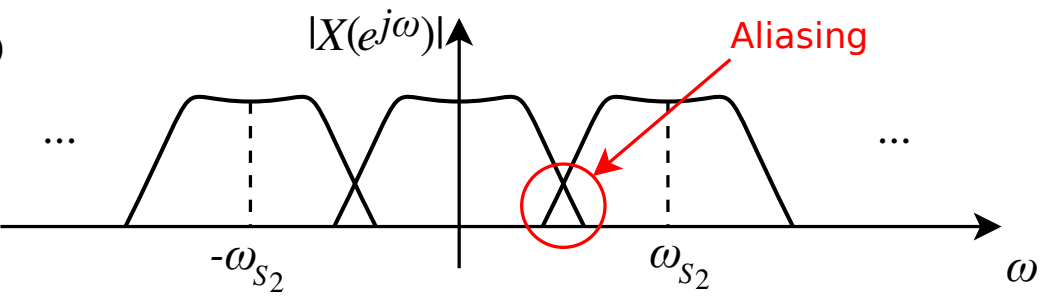

Figura 16. Representação dos espectros dos sinais: (a) analógico; (b) discreto com frequência de amostragem adequada e; (c) discreto com frequência de amostragem inadequada.

Os filtros passa-baixas do tipo Butterworth e Chebyshev satisfazem aos requisitos dos relés digitais, conforme reportado em [9]. Neste trabalho, optou-se pela utilização do do filtro Butterworth. Este filtro possui uma diminuição monotônica no seu ganho com todos os zeros da sua função de transferência em $\omega=\infty$. Trata-se, portanto, de um filtro somente de polos. O módulo da resposta do filtro Butterworth de $N$-ésima ordem é dado por [78], 


$$
\left|H_{B}(j \omega)\right|=\frac{1}{\sqrt{1+\left(\frac{\omega}{\omega_{c}}\right)^{2 N}}}
$$

onde $\omega_{C}$ é a frequência de corte do filtro e a atenuação nesta frequência é de $3 \mathrm{~dB}$ para esta equação.

Na Figura 17, têm-se representadas curvas de respostas do filtro Butterworth considerando várias ordens, além da resposta desejada de um filtro ideal. Observa-se que, para baixas frequências, a resposta é muito próxima da unidade, além de significativamente plana. Esta característica dá origem ao nome de resposta maximamente plana para a resposta deste tipo de filtro. Observa-se também que, com o aumento da ordem do filtro, a resposta se aproxima à de um filtro ideal, com transferência unitária na faixa de passagem e atenuação completa na faixa de rejeição. No entanto, o incremento da ordem do filtro leva ao aumento da defasagem da resposta, não representada nesta figura.

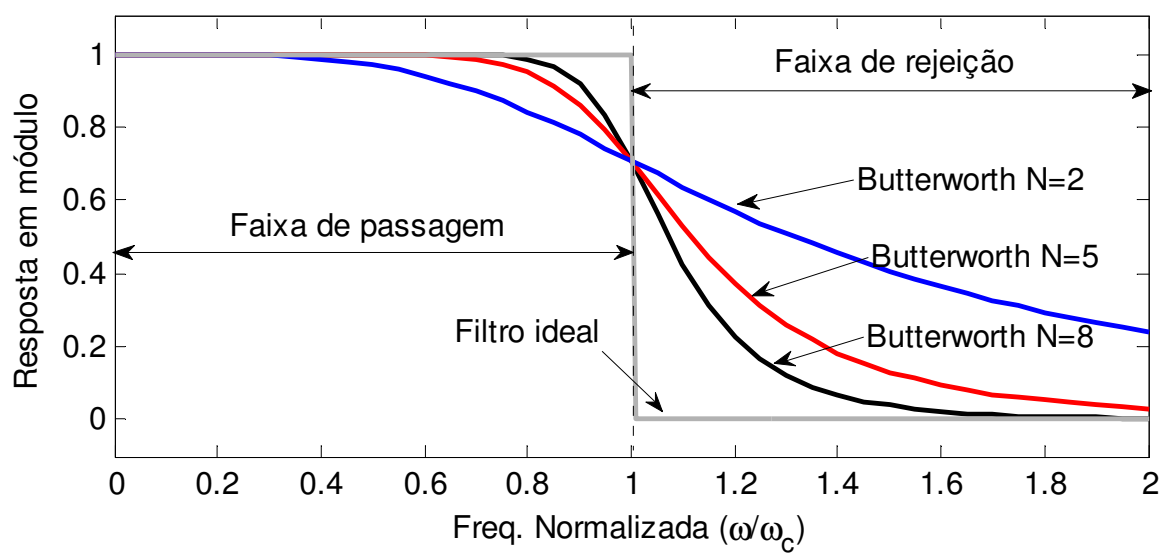

Figura 17. Resposta em módulo de um filtro ideal e do filtro Butterworth de várias ordens.

Conforme reportado por Coury, Oleskovicz e Giovanini [9], filtros de $2^{\mathrm{a}}$ ordem satisfazem aos requisitos dos relés digitais e, consequentemente, serão os filtros utilizados neste trabalho. A frequência de corte deve ser escolhida de forma que a atenuação seja significativa a partir de $f_{S} / 2$ - da ordem de $40 \mathrm{~dB}$, por exemplo. 
Por fim, os filtros anti-aliasing serão responsáveis pela atenuação de componentes de alta frequência que são produzidas nos sinais de tensão e corrente do SEP quando da ocorrência de curtos-circuitos, como exemplificado na Figura 18. A falta simulada na amostra 512 implicou na geração de oscilações no sinal original. Um filtro Butterworth de $2^{\mathrm{a}}$ ordem, com frequência de corte de $300 \mathrm{~Hz}$ foi responsável por atenuar essas oscilações. Observa-se também nesta figura a defasagem imposta pelo filtro.

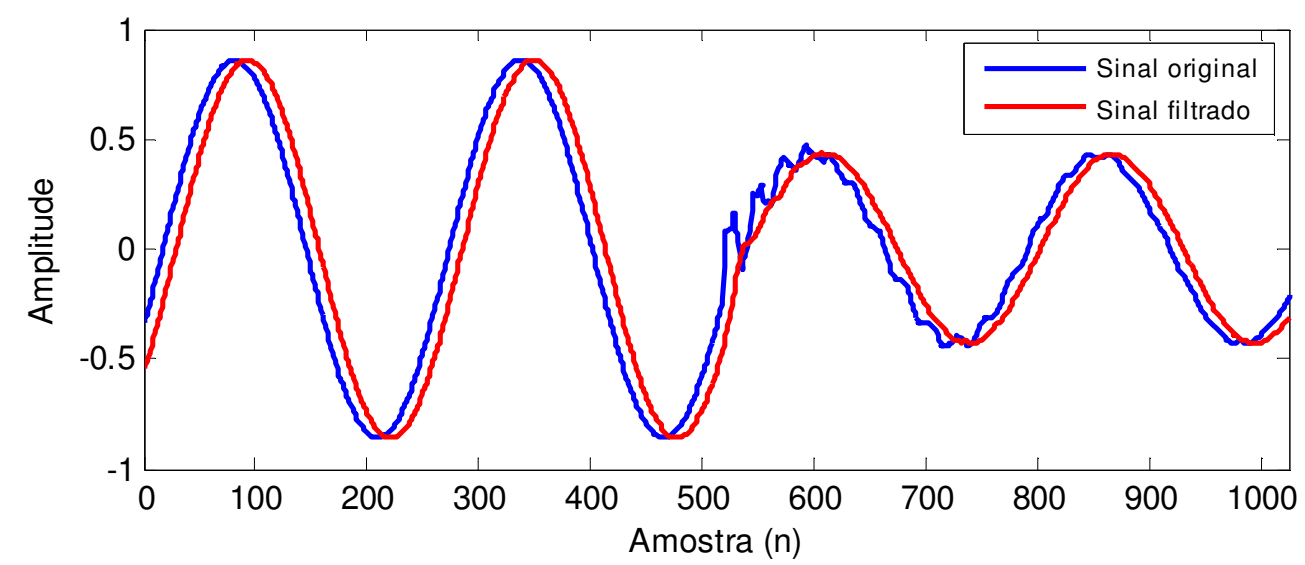

Figura 18. Exemplo de filtragem de um sinal elétrico por um filtro anti-aliasing.

\subsubsection{Conversão Analógica-Digital}

Os avanços de tecnologia digital têm permitido o emprego de técnicas avançadas para resolução de problemas nas mais diversas áreas do conhecimento. Em se tratando da área de proteção de sistemas elétricos, o cenário não é diferente, como relatado anteriormente neste trabalho. Os relés digitais impõe uma série de benefícios para a proteção de equipamentos elétricos, como relatado nas Seções 1.2.1 e 1.2.2.

O tratamento de sinais por relés digitais requer, entretanto, que as informações destes sinais estejam representadas em um formato adequado. Este consiste no formato binário. Os processadores digitais manipulam bits, os quais podem assumir apenas dois valores distintos: 0 ou 1. O termo bit advém, inclusive, de binary digit. Uma sequência destes bits forma uma palavra binária ou um número no formato binário. 
Um Conversor Analógico-Digital (CAD) é um dispositivo que recebe uma tensão analógica de entrada e, após certo tempo, produz um código digital de saída (palavra binária) que representa esta entrada analógica [79]. Uma representação simplificada de um CAD é mostrada na Figura 19. Para uma entrada analógica $x$ qualquer, tem-se a palavra binária de $N$ bits resultante da conversão A/D dada por $B_{N-1} B_{N-2 \ldots} B_{2} B_{1} B_{0}$.

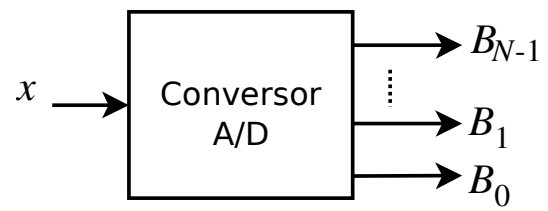

Figura 19. Modelo simplificado de um conversor A/D.

Os sinais analógicos normalmente se desenvolvem em uma faixa limitada de valores. Assim, adotando-se um valor $x_{\min }$ e um valor $x_{m a ́ x}$ como limites para variação destes sinais, o processo de conversão é realizado considerando esta faixa. Assumindose um número $N$ de bits para a palavra digital, tem-se um total de $2^{N}$ valores discretos para representação do intervalo de variação $\left[x_{\text {minn }}, x_{\text {máx }}\right]$. Resta claro, portanto, que o processo de conversão A/D resulta em uma aproximação do sinal analógico, dada em saltos, tal como representado na Figura 20. Este salto é a denominado resolução do CAD, representada pela letra grega $\delta$,

$$
\delta=\frac{x_{\max }-x_{\min }}{2^{N}-1}
$$

A curva de relação entre entrada/saída representada na Figura 20 é uma curva típica para estes dispositivos e foi obtida fazendo $x_{\text {min }}=0$. Pode-se observar que a conversão A/D realizada com base nessa curva provê valores nulos na representação digital para qualquer valor negativo na entrada. É fácil perceber que, todos os valores de entrada entre 0 e $\delta$ são identificados como 0 pelo CAD. Por outro lado, se o valor de entrada estiver contido no intervalo delimitado por $\delta$ e $2 \delta$, o dispositivo interpreta essa 
informação como possuindo o valor $\delta$, e assim sucessivamente. Por fim, observa-se uma saturação no processo de conversão para valores superiores a $x_{\text {máx }}$ na entrada do componente.

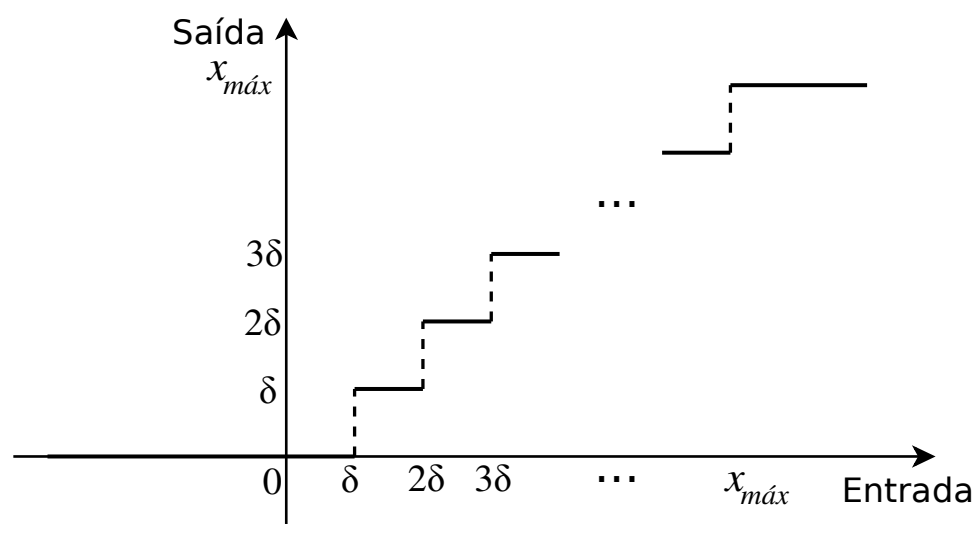

Figura 20. Relação entrada/saída típica de um CAD.

A aplicação de um conversor A/D na leitura de sinais elétricos é exemplificada na Figura 21. Nesta figura, além do sinal original do SEP e do sinal filtrado, tem-se o sinal de saída do conversor. $\mathrm{Na}$ janela de detalhes, percebe-se facilmente o efeito do processo, com o sinal de saída representando uma aproximação da entrada. O erro observado, proveniente do processo de conversão A/D, é denominado erro de quantização. Conforme ressalta Tocci e Widmer [79], esse erro é normalmente especificado como sendo o erro relativo ao bit menos significativo da representação, ou seja, com valor da resolução $\delta$. Da análise de (4.6), pode-se perceber que o aumento o número de bits pode reduzir o erro do processo de conversão A/D para valores apropriados à aplicação em que é empregado. É importante ressaltar que, usualmente, os relés de proteção utilizam CADs com $N=12$ bits ou mais [80]. 


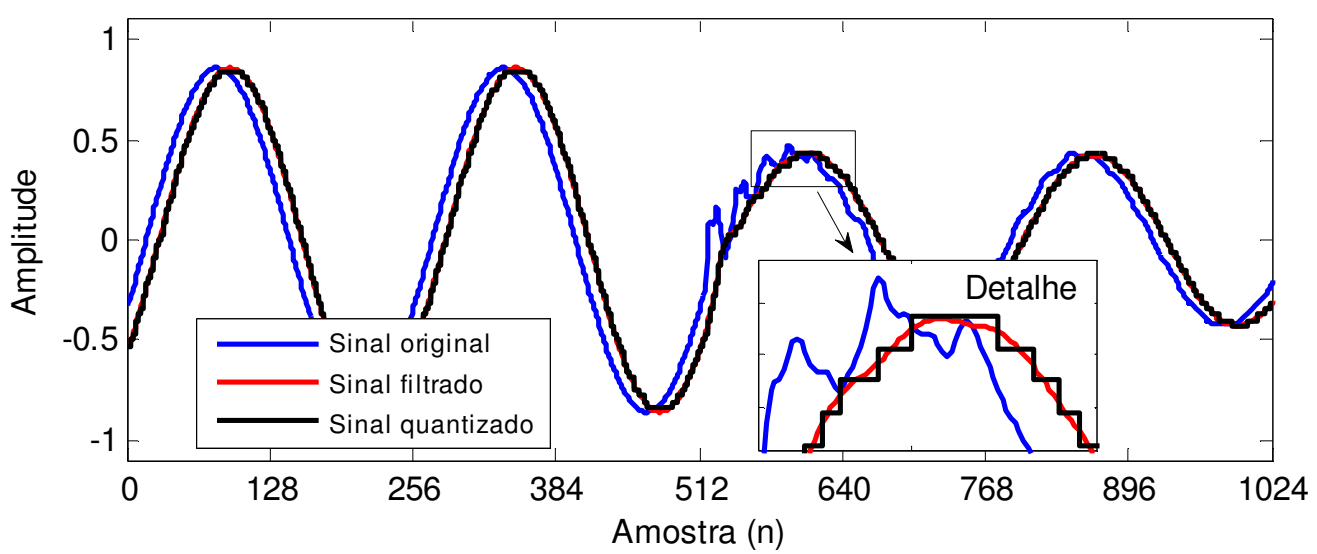

Figura 21. Exemplo do processo de conversão A/D de um sinal elétrico.

\subsection{O Sistema Elétrico de Potência Simulado}

O sistema elétrico simulado é apresentado na Figura 22. Optou-se por trabalhar com esse sistema pela disponibilidade de dados e, principalmente, pelo fato do mesmo ter sido alvo de vários outros estudos realizados no Laboratório de Sistemas de Energia Elétrica (LSEE) da Escola de Engenharia de São Carlos ([16], [81]-[82]).

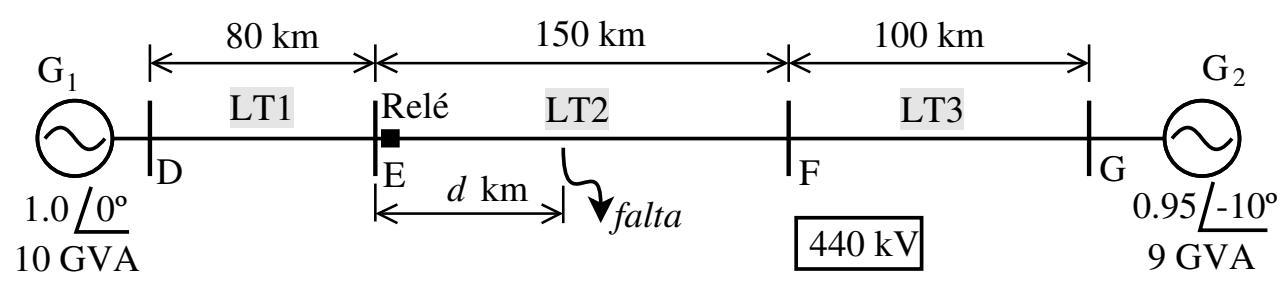

Figura 22. Sistema elétrico simulado.

O relé é alocado no barramento E para proteção da linha intermediária de $150 \mathrm{~km}$. As faltas foram implementadas com as resistências entre fases $\left(R_{f}\right)$ e entre fase e terra $\left(R_{t}\right)$, conforme especificado na Figura 23. 
(a)

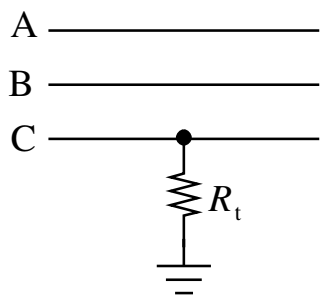

(c)

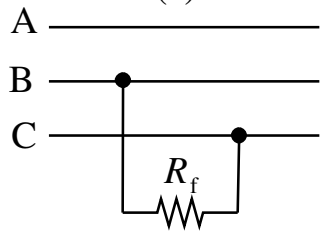

(b)

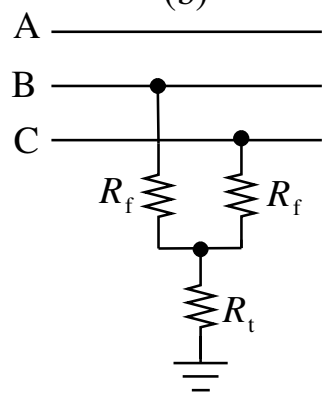

(d)

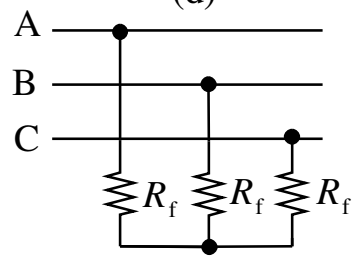

Figura 23. Arranjo das resistências para simulações das faltas: (a) fase-terra; (b) fase-fase-terra; (c) fase-fase e; (d) trifásica.

\subsubsection{Especificação de torres e cabos}

A estrutura da linha de transmissão de $440 \mathrm{kV}$ da Figura 22 corresponde a uma linha típica da CESP (Companhia Energética de São Paulo) [9]. Os condutores são especificados conforme dados da Tabela 4-1. Outros dados, como a resistividade do solo e as flechas de meio vão, são apresentados na Tabela 4-2.

Finalmente, a representação das torres de transmissão com as respectivas disposições geométricas entre os condutores está disposta na Figura 24.

Tabela 4-1. Especificação dos condutores do sistema elétrico simulado

\begin{tabular}{l|c|l}
\hline \hline \multirow{2}{*}{ CONDUTOR } & TIPO & \multicolumn{1}{c}{ ESPECIFICAÇÕES } \\
\hline \hline \multirow{2}{*}{ Condutor de fase } & Cabo Grosbeak & $\begin{array}{l}\text { - Raio externo do condutor: } 12,57 \mathrm{~mm} \\
\text { - Raio interno do condutor: } 4,635 \mathrm{~mm} \\
\text { - Resistência em corrente contínua: } 0,08998 \Omega / \mathrm{km}\end{array}$ \\
\hline \multirow{2}{*}{ Cabo pára-raios } & EHS 3/8” & $\begin{array}{l}\text { - Raio externo do condutor: } 4,572 \mathrm{~mm} \\
\text { - Resistência em corrente contínua: } 4,188 \Omega / \mathrm{km}\end{array}$ \\
\hline \hline
\end{tabular}


Tabela 4-2. Demais parâmetros da LT

\begin{tabular}{c|l}
\hline \hline PARÂMETRO & ESPECIFICAÇÕES \\
\hline \hline Resistividade do solo & $-\rho_{\text {solo }}=1000 \Omega \cdot \mathrm{km}$ \\
\hline Flecha a meio vão & $\begin{array}{l}\text { - Para fase: } 13,43 \mathrm{~m} \\
\text { - Para pára-raios: } 6,4 \mathrm{~m}\end{array}$ \\
\hline \hline
\end{tabular}

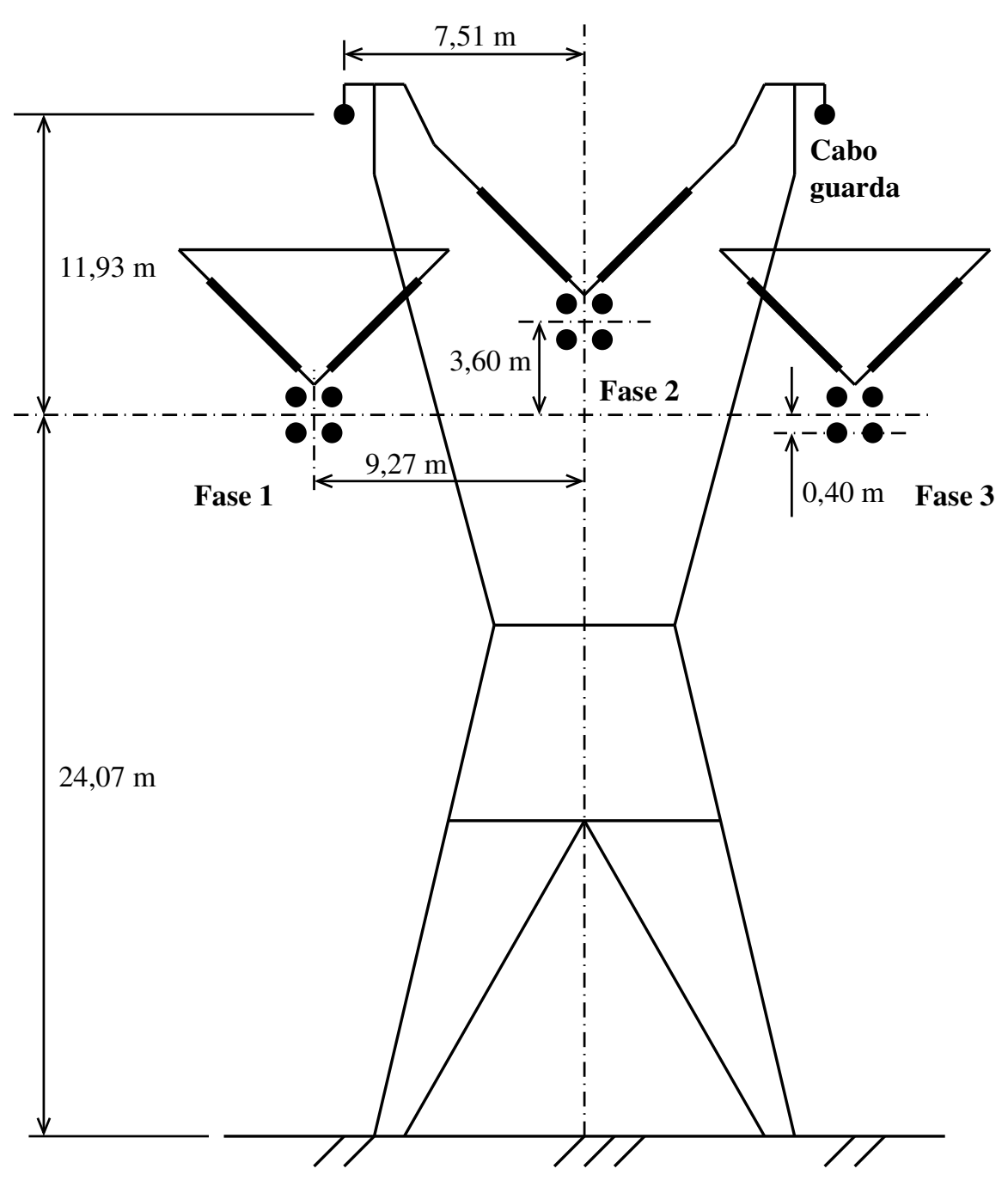

Figura 24. Estrutura da torre de transmissão com as disposições geométrica dos condutores.

\subsubsection{Parâmetros elétricos do sistema}

Tendo em vista os valores apresentados na Tabela 4-1 e na Tabela 4-2, além da disposição geométrica de condutores representada na Figura 24, a rotina LINE CONSTANTS, incorporada ao software ATP (Alternative Transient Program) [83], foi 
utilizada para determinação dos parâmetros elétricos da linha de transmissão - foi considerado o caso de linhas transpostas. Estes parâmetros estão dispostos na Tabela 4-3. E, por fim, para efeitos de clareza, os dados das barras de geração, já apresentadas na Figura 22, são sumarizados na Tabela 4-4.

Tabela 4-3. Parâmetros elétricos da LT simulada

\begin{tabular}{c|c|c|c}
\hline \hline \multirow{2}{*}{ PARÂMETRO } & SEQUÊNCIA & SÍMBOLO & VALOR \\
\hline \hline \multirow{2}{*}{ Resistência } & Positiva & $R^{+}$ & $3,853 \times 10^{-2} \Omega / \mathrm{km}$ \\
& Zero & $R^{0}$ & $1,861 \Omega / \mathrm{km}$ \\
\hline \multirow{2}{*}{ Indutância } & Positiva & $L^{+}$ & $7,410 \times 10^{-1} \mathrm{mH} / \mathrm{km}$ \\
& Zero & $L^{0}$ & $2,230 \mathrm{mH} / \mathrm{km}$ \\
\hline \multirow{2}{*}{ Capacitância } & Positiva & $C^{+}$ & $1,570 \times 10^{-2} \mu \mathrm{F} / \mathrm{km}$ \\
& Zero & $C^{0}$ & $9,034 \times 10^{-3} \mu \mathrm{F} / \mathrm{km}$ \\
\hline \hline
\end{tabular}

Tabela 4-4. Parâmetros elétricos da geração nas barras D e G

\begin{tabular}{c|c|c}
\hline \hline PARÂMETRO & $\begin{array}{c}\text { GERADOR 1 } \\
\text { BARRA D }\end{array}$ & $\begin{array}{c}\text { GERADOR 2 } \\
\text { BARRA G }\end{array}$ \\
\hline \hline Potência (GVA) & 10 & 9 \\
\hline Tensão (pu) & 1,05 & 0,95 \\
\hline Ângulo de fase (Graus) & 0 & -10 \\
\hline \hline
\end{tabular}

\subsubsection{Condições de faltas simuladas}

O ambiente de simulação escolhido para a execução das situações de falta no SEP estudado foi o Simulink ${ }^{\circledR}$ do software MATLAB®, através do uso do Toolbox SimPowerSystems ${ }^{\mathrm{TM}}$. As situações de faltas testadas foram obtidas através das variações dos seguintes parâmetros: 


\section{Linha de transmissão 1 (LT1):}

- Distância $d$ da falta, em km, com referência ao barramento D;

- Resistências de falta $R_{t}$ e $R_{f}$, mostradas na Figura 23;

- Tipo de falta: A-T, B-T, C-T, A-B, B-C, C-A, A-B-T, B-C-T, C-A-T,A-B-C;

- Ângulo de incidência da falta, sempre com referência à primeira fase.

\section{Linha de transmissão 2 (LT2):}

- Distância $d$ da falta, em km, com referência ao barramento E;

- Resistências de falta $R_{t}$ e $R_{f}$, mostradas na Figura 23;

- Tipo de falta: A-T, B-T, C-T, A-B, B-C, C-A, A-B-T, B-C-T, C-A-T, A-B-C;

- Ângulo de incidência da falta, sempre com referência à primeira fase.

\section{Linha de transmissão 3 (LT3):}

- Distância $d$ da falta, em km, com referência ao barramento F;

- Resistências de falta $R_{t}$ e $R_{f}$, mostradas na Figura 23;

- Tipo de falta: A-T, B-T, C-T, A-B, B-C, C-A, A-B-T, B-C-T, C-A-T, A-B-C;

- Ângulo de incidência da falta, sempre com referência à primeira fase.

Os valores utilizados para as condições de faltas, utilizadas nas simulações, estão dispostos na Tabela 4-5, na Tabela 4-6 e na Tabela 4-7, respectivamente, para as linhas LT1, LT2 e LT3. Conforme pode ser verificado, o incremento de distância escolhido foi pequeno, de forma a gerar um extenso banco de dados para o desenvolvimento da metodologia. Apesar de não serem utilizados todos os casos de faltas para treinamentos e testes de redes neurais, conforme pode ser verificado adiante, no Capítulo 5, optou-se por gerar um extenso banco de dados. 
Tabela 4-5. Conjunto de parâmetros de condições de faltas simuladas para LT1

\begin{tabular}{|c|c|c|c|}
\hline TIPO DE FALTA & DISTÂNCIA $d(\mathbf{k m})$ & INCIDÊNCIA $\left({ }^{\circ}\right)$ & RESISTÊNCIAS $(\Omega)$ \\
\hline $\mathrm{F}-\mathrm{T}$ & $\begin{array}{c}1,5,10,15,20,25,30,35,40 \\
45,50,55,60,65,70,75,79\end{array}$ & $0,30,60, \ldots, 180$ & $\begin{array}{c}R_{t}=0 ; 1 ; 10 ; 25 \\
50 ; 75 ; 100\end{array}$ \\
\hline F-F-T & $\begin{array}{c}1,5,10,15,20,25,30,35,40 \\
45,50,55,60,65,70,75,79\end{array}$ & $0,30,60, \ldots, 180$ & $\begin{array}{c}R_{t}=0 ; 1 ; 10 ; 25 \\
50 ; 75 ; 100 \\
R_{f}=0\end{array}$ \\
\hline F-F & $\begin{array}{c}1,5,10,15,20,25,30,35,40 \\
45,50,55,60,65,70,75,79\end{array}$ & $0,30,60, \ldots, 180$ & $R_{f}=0 ; 0,5 ; 2 ; 5 ; 10$ \\
\hline F-F-F & $\begin{array}{c}1,5,10,15,20,25,30,35,40 \\
45,50,55,60,65,70,75,79\end{array}$ & $0,30,60, \ldots, 180$ & $R_{f}=0 ; 0,5 ; 2 ; 5 ; 10$ \\
\hline
\end{tabular}

Tabela 4-6. Conjunto de parâmetros de condições de faltas simuladas para LT2

\begin{tabular}{|c|c|c|c|}
\hline TIPO DE FALTA & DISTÂNCIA $\boldsymbol{d}(\mathbf{k m})$ & INCIDÊNCIA $\left(^{\circ}\right)$ & RESISTÊNCIAS $(\Omega)$ \\
\hline F-T & $\begin{array}{c}1,5,10,15,20,25,30,35,40,45,50 \\
55,60,65,70,75,80,85,90,95,100 \\
105,110,115,120,125,130,135,140 \\
145,149\end{array}$ & $0,30,60, \ldots, 180$ & $\begin{array}{l}R_{t}=0 ; 1 ; 10 ; 25 \\
\quad 50 ; 75 ; 100\end{array}$ \\
\hline F-F-T & $\begin{array}{c}1,5,10,15,20,25,30,35,40,45,50 \\
55,60,65,70,75,80,85,90,95,100 \\
105,110,115,120,125,130,135,140 \\
145,149\end{array}$ & $0,30,60, \ldots, 180$ & $\begin{array}{c}R_{t}=0 ; 1 ; 10 ; 25 ; \\
50 ; 75 ; 100 \\
R_{f}=0\end{array}$ \\
\hline F-F & $\begin{array}{c}1,5,10,15,20,25,30,35,40,45,50 \\
55,60,65,70,75,80,85,90,95,100 \\
105,110,115,120,125,130,135,140 \\
145,149\end{array}$ & $0,30,60, \ldots, 180$ & $R_{f}=0 ; 0,5 ; 2 ; 5 ; 10$ \\
\hline F-F-F & $\begin{array}{c}1,5,10,15,20,25,30,35,40,45,50 \\
55,60,65,70,75,80,85,90,95,100 \\
105,110,115,120,125,130,135,140 \\
145,149\end{array}$ & $0,30,60, \ldots, 180$ & $R_{f}=0 ; 0,5 ; 2 ; 5 ; 10$ \\
\hline
\end{tabular}

Tabela 4-7. Conjunto de parâmetros de condições de faltas simuladas para LT3

\begin{tabular}{|c|c|c|c|}
\hline TIPO DE FALTA & DISTÂNCIA $\boldsymbol{d}(\mathrm{km})$ & INCIDÊNCIA $\left(^{\circ}\right)$ & RESISTÊNCIAS $(\Omega)$ \\
\hline $\mathrm{F}-\mathrm{T}$ & $\begin{array}{c}1,5,10,15,20,25,30,35,40,45 \\
50,55,60,65,70,75,80,85,90,95 \\
99\end{array}$ & $0,30,60, \ldots, 180$ & $\begin{array}{c}R_{t}=0 ; 1 ; 10 ; 25 ; \\
50 ; 75 ; 100\end{array}$ \\
\hline F-F-T & $\begin{array}{c}1,5,10,15,20,25,30,35,40,45 \\
50,55,60,65,70,75,80,85,90,95 \\
99\end{array}$ & $0,30,60, \ldots, 180$ & $\begin{array}{c}R_{t}=0 ; 1 ; 10 ; 25 \\
50 ; 75 ; 100 \\
R_{f}=0\end{array}$ \\
\hline F-F & $\begin{array}{c}1,5,10,15,20,25,30,35,40,45 \\
50,55,60,65,70,75,80,85,90,95 \\
99\end{array}$ & $0,30,60, \ldots, 180$ & $R_{f}=0 ; 0,5 ; 2 ; 5 ; 10$ \\
\hline F-F-F & $\begin{array}{c}1,5,10,15,20,25,30,35,40,45 \\
50,55,60,65,70,75,80,85,90,95 \\
99\end{array}$ & $0,30,60, \ldots, 180$ & $R_{f}=0 ; 0,5 ; 2 ; 5 ; 10$ \\
\hline
\end{tabular}




\subsubsection{Modelagem do sistema no Simulink®}

O sistema elétrico foi modelado no Simulink, conforme mostrado na Figura 25. Conforme pode ser verificado, foi utilizado modelo de parâmetros distribuídos para representação dos trechos de linhas. Apenas em distâncias próximas aos barramentos, quando há a necessidade de diminuição do período de amostragem para simulação com modelo de parâmetros distribuídos, tal trecho entre a falta e o barramento foi substituído pelo modelo pi. As faltas são simuladas automaticamente através da variação das condições das mesmas por meios de arquivos script que executam o modelo no Simulink.

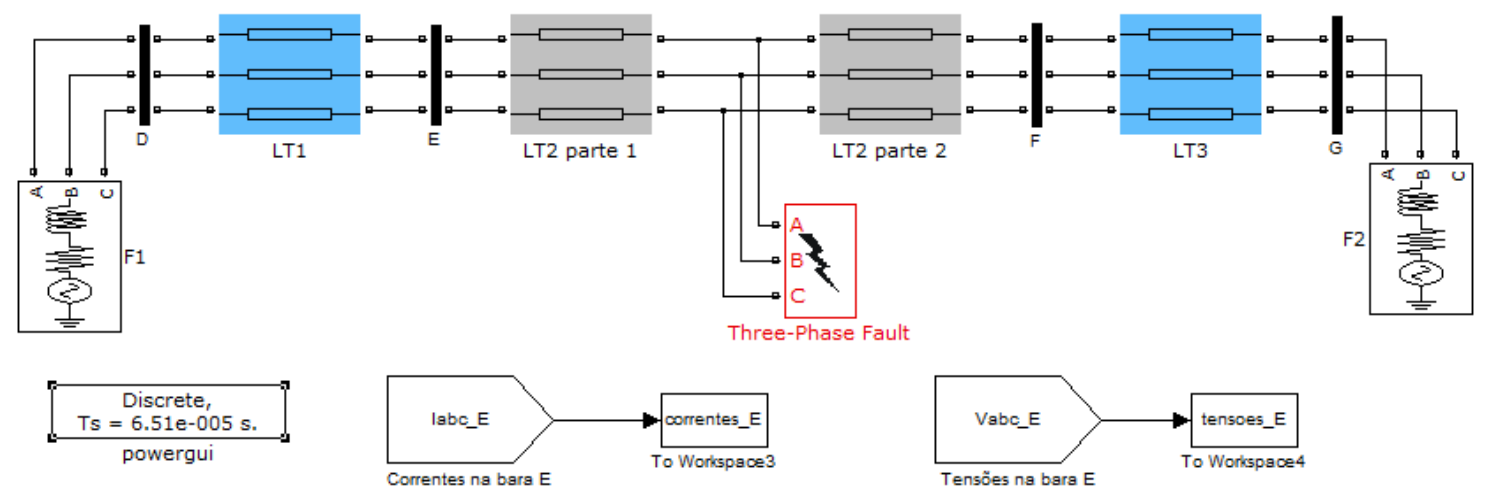

Figura 25. Modelagem do SEP estudado no Simulink @.

Um exemplo de simulação do modelo da Figura 25 é apresentado na Figura 26. Nesta simulação, considerou-se uma falta do tipo A-T com distância de $65 \mathrm{~km}$ em relação ao relé. Ademais, a incidência se deu em $90^{\circ}$ e a resistência de falta considerada foi de $25 \Omega$. Na Figura 26(a) são visualizados os sinais de tensão nas três fases e em (b) são visualizados os sinais de corrente. Observa-se, claramente, uma queda de tensão da fase A, acompanhada do respectivo aumento da corrente desta mesma fase. 
(a)

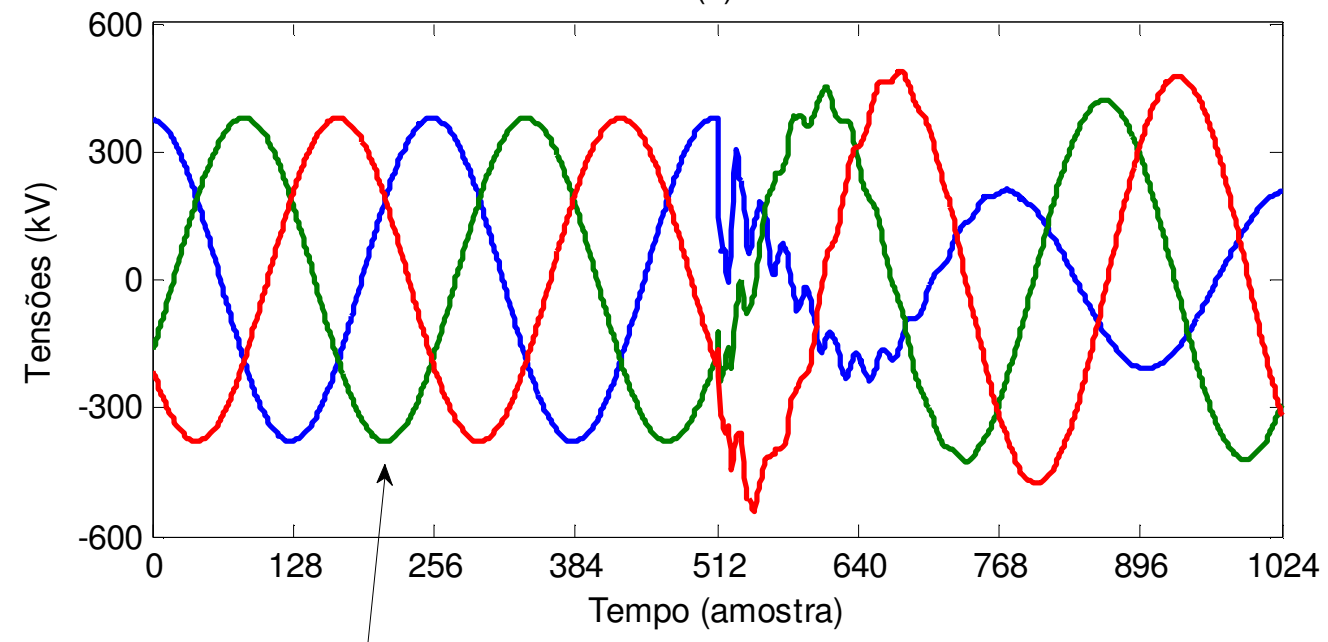

(b)

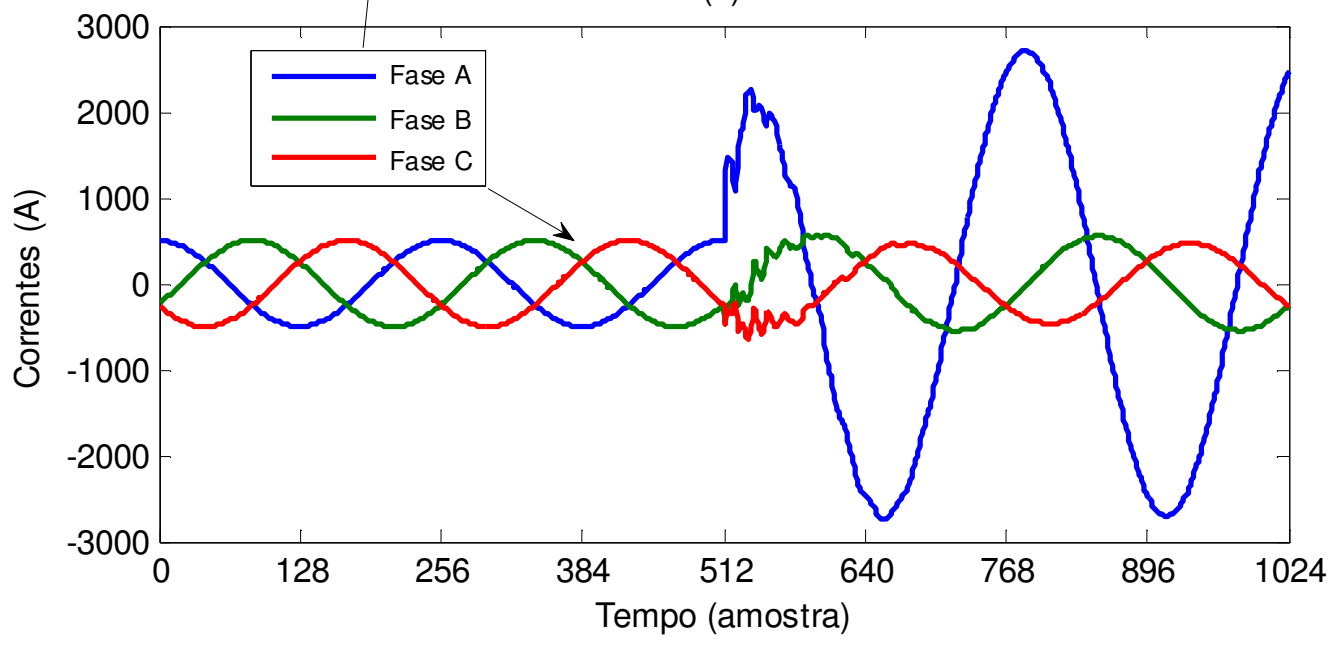

Figura 26. Exemplo de simulação do modelo: em (a) sinais de tensão e em (b) sinais de corrente para uma falta A-T a $65 \mathrm{~km}$ do relé, com incidência de $90^{\circ}$ e resistência de falta $R_{t}=25 \Omega$.

\subsection{Considerações finais do capítulo}

Este capítulo apresentou uma descrição do sistema de proteção proposto neste trabalho, o qual emprega os cumulantes em conjunto com redes PMC. Foi descrita a estrutura proposta de proteção e a forma de obtenção de dados para o projeto da mesma. Em seguida, apresentou-se uma ferramenta para seleção de parâmetros a serem utilizados nas etapas de proteção. Esta consiste no Discriminante linear de Fisher. A etapa de condicionamento de sinais elétricos foi também abordada, sendo descritos os 
filtros anti-aliasing e os conversores $\mathrm{A} / \mathrm{D}$, componentes típicos utilizados na aquisição de sinais em SEPs. Por fim, foi apresentado o sistema elétrico de potência simulado nesta pesquisa, com seus parâmetros elétricos, e a sua modelagem no ambiente de simulação Simulink. 


\section{RESULTADOS OBTIDOS PARA OS MÓDULOS DE DETECÇÃO, CLASSIFICAÇÃO E LOCALIZAÇÃO.}

A apresentação dos resultados alcançados nesta pesquisa é iniciada neste capítulo.

A frequência de amostragem utilizada em todas as simulações, realizadas no software MATLAB, é dada por $f_{S}=N \times f_{0}$, com $N=256$. Sendo a frequência fundamental $f_{0}=60 \mathrm{~Hz}$, são utilizados, portanto, $N=256$ pontos por ciclo de $60 \mathrm{~Hz}$. Os tamanhos de janelas utilizados nos cálculos dos cumulantes são especificados no que se segue, para cada submódulo do sistema de proteção.

Cabe enfatizar que as etapas de detecção, classificação e localização são tratadas, inicialmente, de forma separada. Mais importante, nas referidas etapas não é feito uso do sistema de pré-processamento (condicionamento) dos sinais elétricos com filtro antialiasing e conversor $\mathrm{A} / \mathrm{D}$, tal como abordado no capítulo anterior. O objetivo deste procedimento é possibilitar um controle maior de temporização, com respeito ao instante de ocorrência da falta, para a mais adequada distinção possível entre dados de regime pré- e pós-falta. O único processamento utilizado nestas seções é a redução dos níveis dos sinais de corrente considerando uma relação de transformação de 500:1.

Os submódulos de detecção, classificação e localização são então combinados, no Capítulo 6, para formar um protótipo de relé baseado em EOSs e RNAs. É realizada, portanto, uma extensa bateria de testes para verificação do seu desempenho. Nesta etapa seguinte, são realizados testes com o sistema de pré-processamento e condicionamento dos sinais incluso no modelo de simulação, como indicado.

Cabe salientar, por fim, que os testes realizados dão enfoque total nas faltas ocorridas nas linhas LT2 e LT3. Esta estratégia se deve ao fato de a tarefa de determinação de direção da falta estar atribuída a outro componente do sistema de proteção, abordado oportunamente na Seção 6.3. 


\subsection{Detecção da Falta}

A etapa de detecção utiliza uma janela de dados de $1 / 4$ do período fundamental, ou seja, N/4, para o cálculo dos cumulantes. Esta escolha se deve, principalmente, ao fato de que, pelo menos intuitivamente, poucas amostras de regime pós-falta serem mais significativas no cálculo de cumulantes em uma janela de tamanho reduzido. Adicionalmente, há de se destacar que o uso de uma janela de tamanho reduzido pode permitir uma distinção segura do regime pós-falta, com a análise de um conjunto de dados completo deste regime depois de transcorrido apenas 1/4 de ciclo, neste caso.

Para seleção dos cumulantes empregados na etapa de detecção, foi realizado levantamento do FDR, considerando os cumulantes de $2^{\mathrm{a}}, 3^{\mathrm{a}}$ e $4^{\mathrm{a}}$ ordens. Os parâmetros utilizados para geração deste índice são os especificados na Tabela 4-6. Por fim, os dados das classes pré-falta e pós-falta são gerados conforme os intervalos de tempo especificados na Figura 27. Conforme pode ser constatado nesta figura, são considerados intervalos de tamanho igual a meio ciclo para geração das classes. A janela móvel de 1/4 de ciclo é utilizada para cálculo dos cumulantes. Foi considerado um intervalo de tempo no qual os dados são descartados e que corresponde ao início da transição da classe pré-falta para a classe pós-falta. O objetivo deste descarte é o provimento de uma melhor separação de padrões.

Diante do exposto, pode-se resumir o procedimento como a geração das duas classes características: a classe $C_{1}$ - "Pré-falta" - relativa ao conjunto de dados quando da operação normal do SEP e a classe $C_{2}$ - "Pós-falta" - relativa ao conjunto de dados quando da operação em condição de falta do SEP. Equivalentemente,

- Classe $\boldsymbol{C}_{\mathbf{1}}$ : valor associado "0" (Dados coletados em regime pré-falta)

- Classe $\boldsymbol{C}_{2}$ : valor associado “1” (Dados coletados em regime pós-falta) 


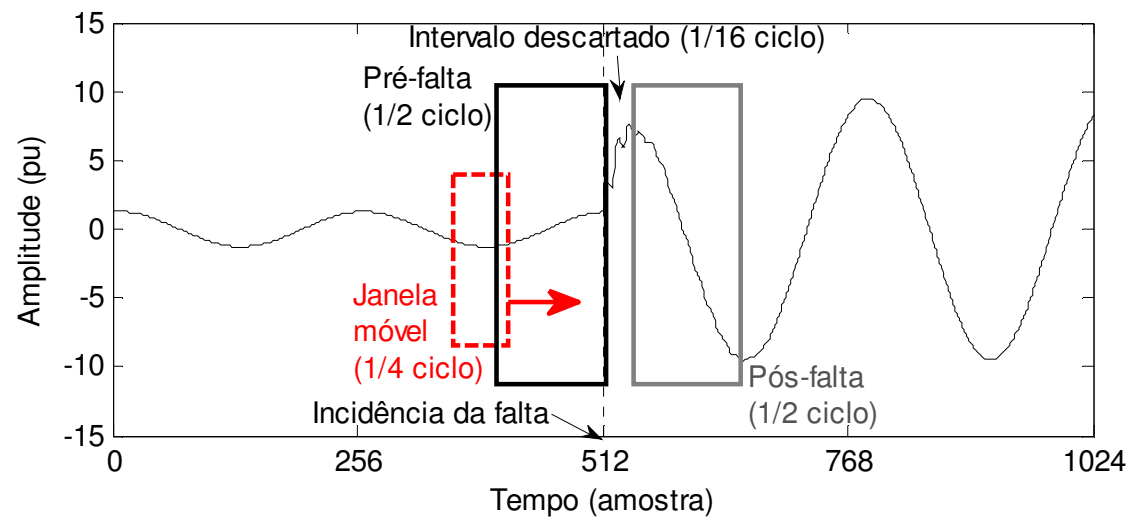

Figura 27. Intervalos de tempo utilizados para geração dos padrões do problema de detecção.

Na Figura 28, são apresentados os índices FDR obtidos dos sinais de corrente da fase A. Considerando a simetria dos sinais para o sistema elétrico em estudo, a análise da fase A é suficiente para análise e escolha dos cumulantes. Observa-se que as estatísticas de $2^{\mathrm{a}}$ e $4^{\mathrm{a}}$ ordem apresentam maior FDR. Destacam-se, especialmente, os cumulantes com lags $\tau=29$ e $\tau=7$, respectivamente, para estatísticas de $2^{\mathrm{a}}$ e $4^{\mathrm{a}}$ ordem.

(a)
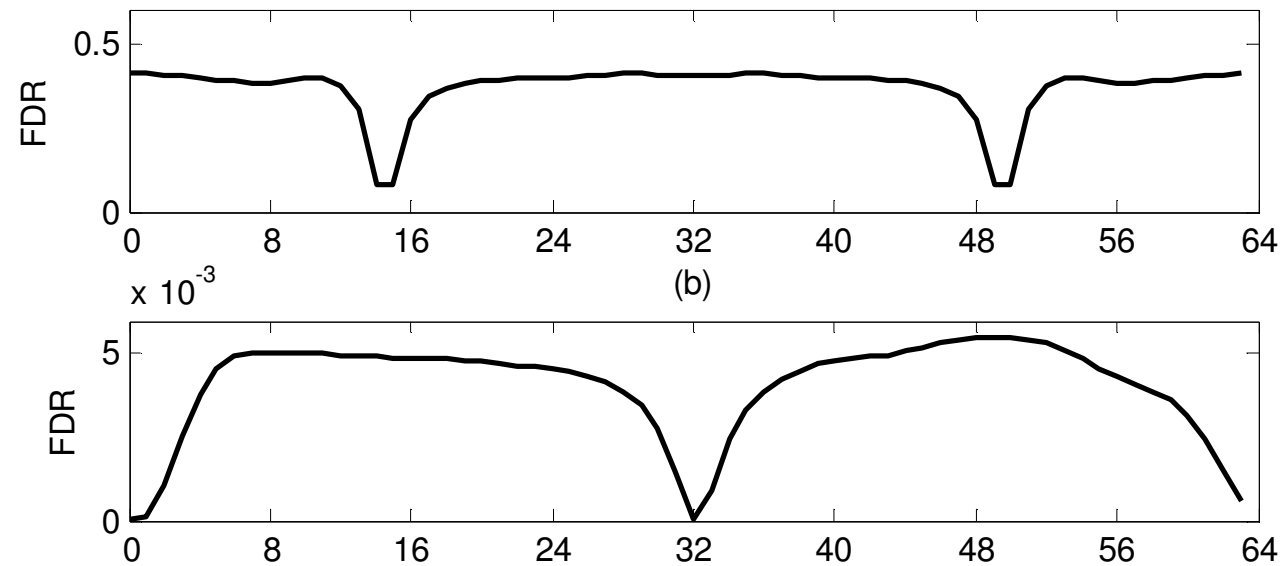

(c)

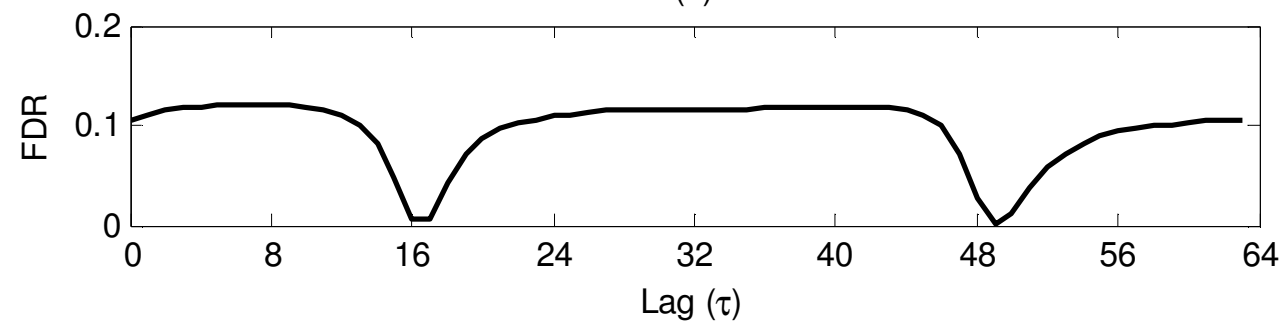

Figura 28. Fisher Discriminant Ratio para o problema de detecção: (a) cumulantes de $2^{\mathrm{a}}$ ordem; (b) cumulantes de $3^{\text {a }}$ ordem e; (c) cumulantes de $4^{\text {a }}$ ordem. 
Visando um sistema mais simples para a detecção foram então considerados os cumulantes de $2^{\mathrm{a}}$ ordem, com lag $\tau=29$. Os parâmetros utilizados para a geração de padrões e, posteriormente, para o treinamento da rede de detecção são apresentados na Tabela 5-1. Na Figura 29, tem-se a visualização de padrões em uma escala adequada para identificação dos mesmos, equivalentes ao estado pré-falta (padrões pretos) e ao estado pós-falta (padrões cinza). Dos padrões disponíveis, foi realizado o particionamento para obtenção dos conjuntos de treinamento $(70 \%)$ e de validação $(30 \%)$.

Utilizando uma RNA de duas camadas, representada na Figura 30, onde se verificam a primeira camada com $N_{1}=6$ neurônios e a segunda e última camada com $N_{2}=1$ neurônio, foi realizado treinamento para separação das classes envolvidas neste processo. Cabe salientar que foi utilizada redução da taxa de amostragem dos sinais de cumulantes, com o fator de downsample $M=16$. Esta estratégia tem como objetivo otimizar a utilização de recursos de processamento e memória para o treinamento da rede neural. Por fim, é imprescindível comentar a utilização de ruído branco gaussiano adicionado aos sinais de corrente, com relação sinal ruído (SNR - Signal-to-noise Ratio) de $30 \mathrm{~dB}$.

Tabela 5-1. Conjunto de parâmetros de falta utilizados para geração de padrões de treinamento e validação da rede neural de detecção

\begin{tabular}{c|c|c|c}
\hline \hline TIPO DE FALTA & DISTÂNCIA $\boldsymbol{d}(\mathbf{k m})$ & INCIDÊNCIA $\left.\mathbf{(}^{\mathbf{o}}\right)$ & RESISTÊNCIAS $(\boldsymbol{\Omega})$ \\
\hline \hline & Linha 2 (referência: barra E): & & \\
F-T, F-F-T, & $1,5,25,45,65,85$, & & $R_{t}=0 ; 25 ; 50 ; 75 ; 100$ \\
F-F e F-F-F & $105,125,145,149$ & $0,30,60, \ldots, 180$ & \\
& Linha 3 (referência: barra F): & & $R_{f}=0 ; 5 ; 10$. \\
& $5,25,45,65,85$ & & \\
\hline \hline
\end{tabular}




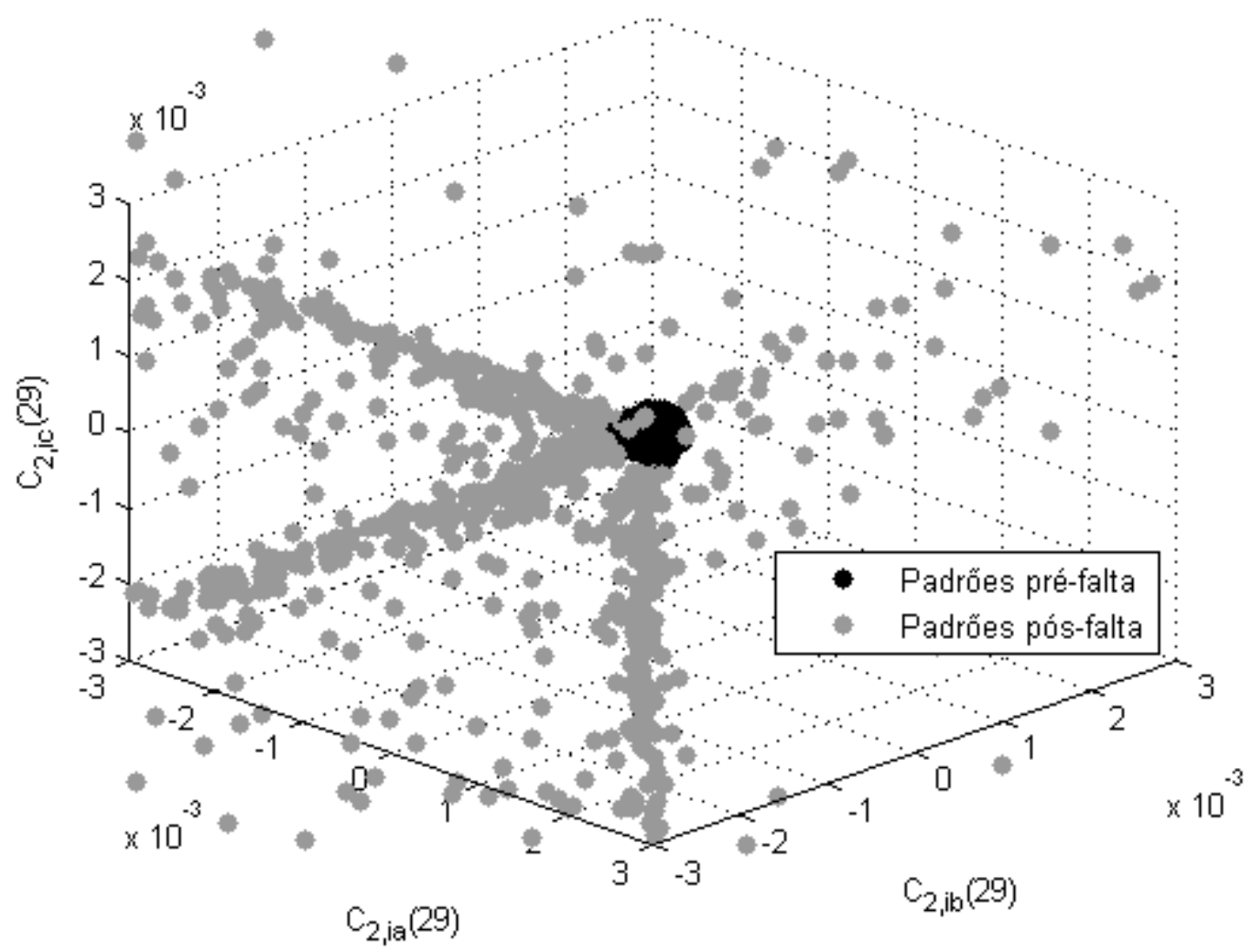

Figura 29. Padrões de regime pré- e pós-falta gerados para o problema de detecção.

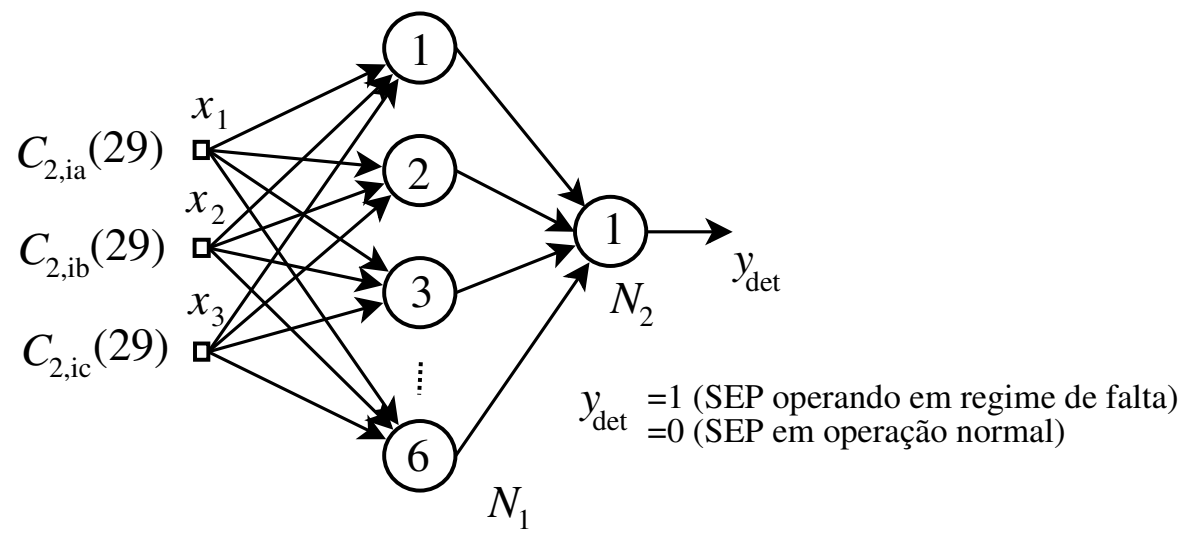

Figura 30. Representação da rede neural utilizada para detecção de falta.

$\mathrm{O}$ treinamento da rede foi executado admitindo-se um valor limite de 5000 épocas e visando um Erro Quadrático Médio (EQM) mínimo de $1,0 \times 10^{-6}$, estipulado para convergência. O valor atingido para este parâmetro foi de $3,9021 \times 10^{-4}$, na $816^{\mathrm{a}}$ época, quando o algoritmo convergiu com o treinamento exibindo um valor de gradiente do erro igual a $9,5331 \times 10^{-11}$, o qual é inferior ao valor padrão mínimo de $1,0 \times 10^{-10}$. Na 
Figura 31(a), é exibida a evolução do EQM em função da época do treinamento. O resultado de validação da rede é apresentado na Figura 31(b), onde são apresentadas as curvas do valor desejado e da saída da rede. Conforme observado, foi alcançada uma taxa de acerto de 99,96\%, para um total de 16800 padrões disponíveis para este processo de validação.

(a)

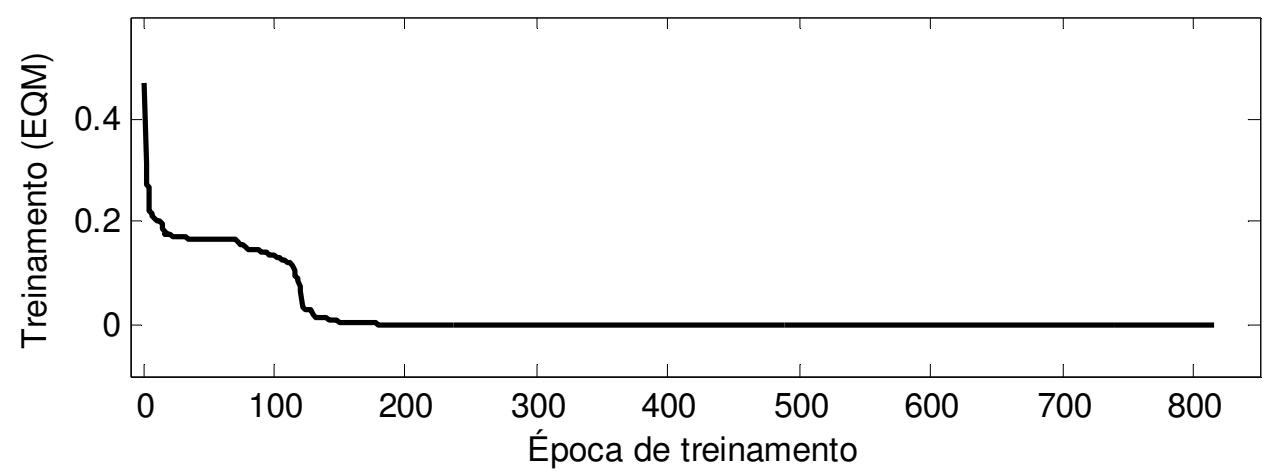

(b)

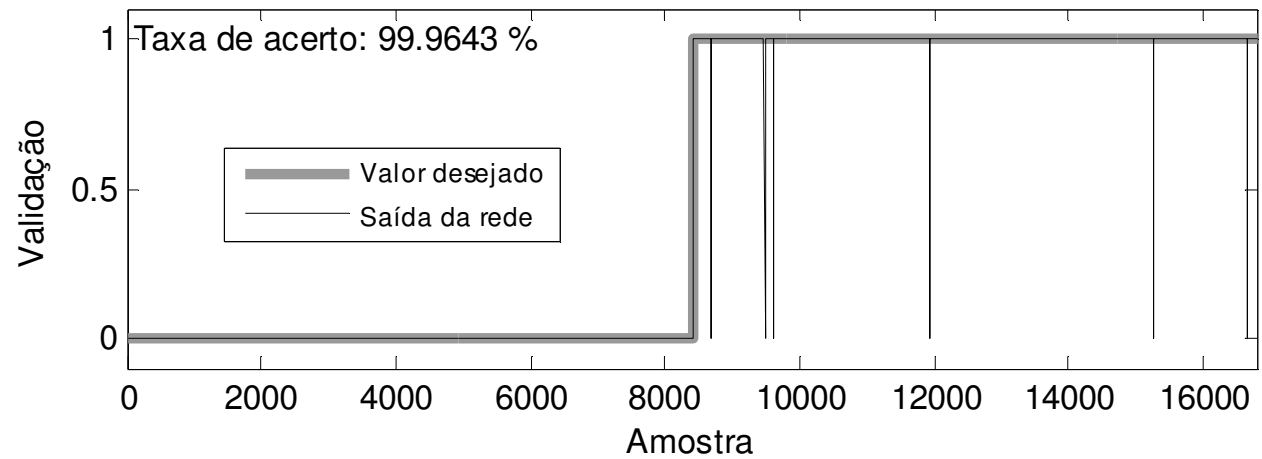

Figura 31. Resultados obtidos para a RNA de detecção: (a) evolução do EQM no treinamento e; (b) validação.

Na Figura 32, é apresentado um resultado particular do sistema de detecção simulando a operação desta etapa no monitoramento do SEP. Neste caso, simulou-se uma falta do tipo A-T na linha LT2, a $85 \mathrm{~km}$ do barramento E, com resistência de falta $R_{t}=100 \Omega$ e ângulo de incidência de falta $\phi=90^{\circ}$. A incidência da falta é imposta na amostra 256. Os sinais de corrente são contaminados com ruído branco Gaussiano, de forma que a relação sinal-ruído seja $S N R=35 \mathrm{~dB}$. Nesta figura, em (a) são apresentados os sinais de corrente seguidos, em (b), pelas respectivas saídas do filtro notch, ou seja, 
os sinais de erro. Utilizando os sinais de erro, são calculados os cumulantes, $C_{2}(29)$, mostrados em (c). Finalmente, tendo como entrada os padrões formados pelos cumulantes das fases $\mathrm{A}, \mathrm{B}$ e $\mathrm{C}$ no instante de tempo $n$, a saída da rede de detecção é apresentada em (d). Observa-se que o módulo responde prontamente à situação da falta.

(a)

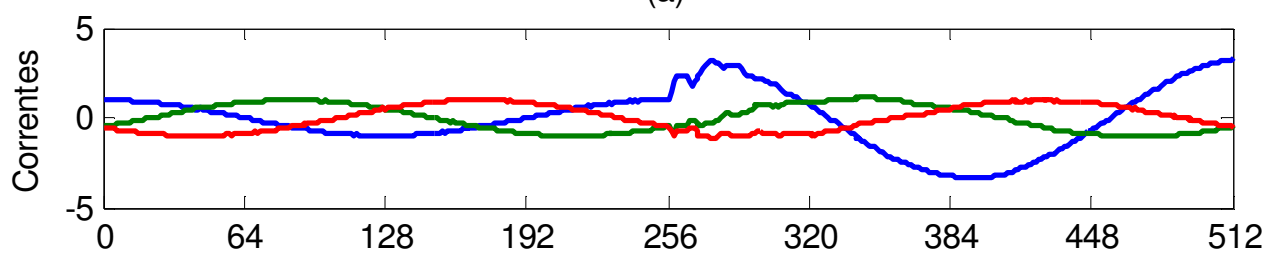

(b)

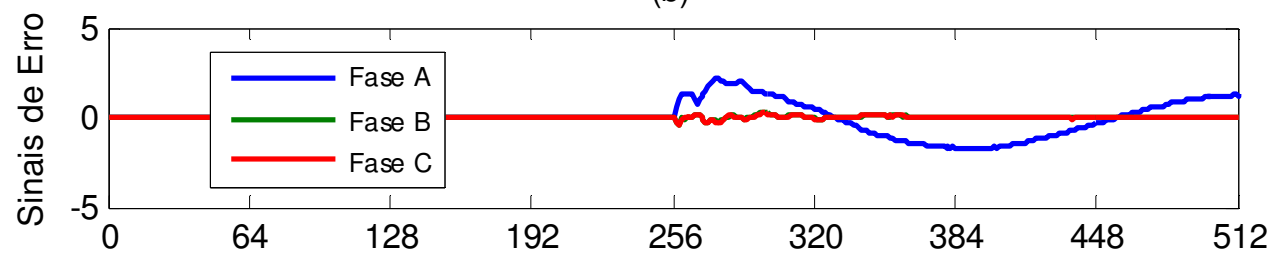

(c)

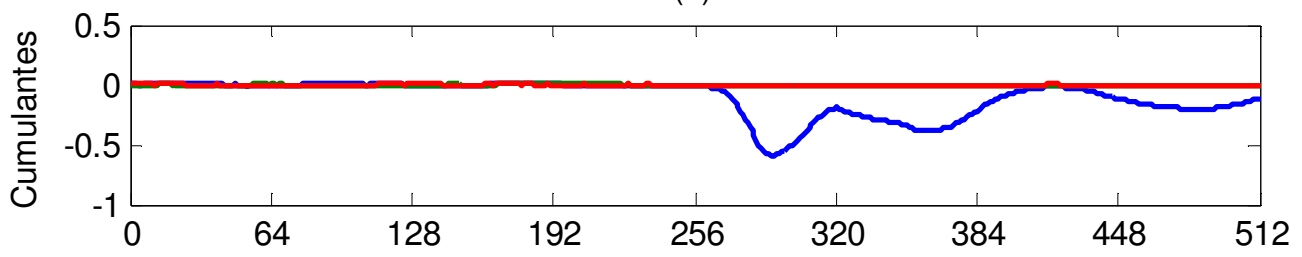

(d)

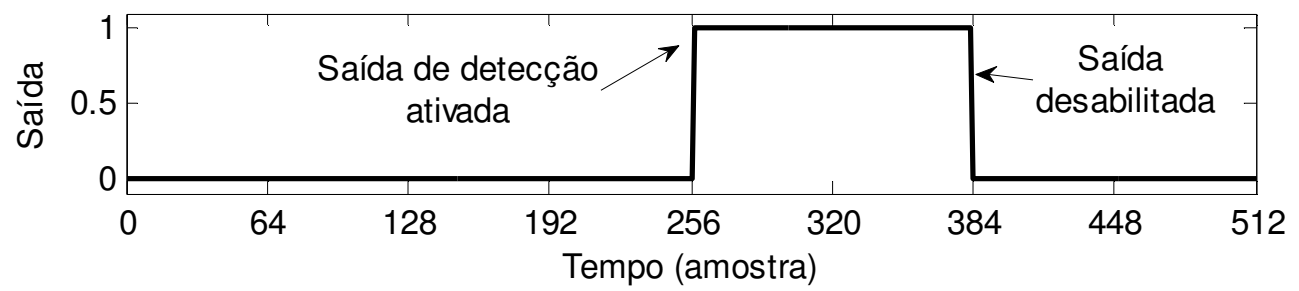

Figura 32. Simulação de falta A-T na linha LT2 a $85 \mathrm{~km}$ do barramento E, com $R_{t}=100 \Omega$ e $\phi=90^{\circ}$.

Sinais: (a) correntes; (b) saídas do filtro notch; (c) cumulantes e; (d) saída da rede de detecção.

Visando uma investigação preliminar de desempenho de detecção foram consideradas simulações nas linhas LT2 e LT3 em três casos distintos. Uma bateria completa de testes levantará o desempenho geral dos módulos do sistema de proteção proposto, no Capítulo 6. Os testes apresentados aqui visam, apenas, uma investigação prévia do comportamento do sistema de detecção, frente a situações diversas de faltas, 
especialmente em relação à localização da falta no SEP e ao tipo das mesmas. Para tanto, foram considerados os seguintes parâmetros para configuração do curto, sendo executados todos os dez tipos de falta ${ }^{2}$ :

- Caso 1: $\quad$ Linha LT2 $\operatorname{com} d=10 \mathrm{~km}, R_{t}=10 \Omega, R_{f}=2 \Omega$ e $\phi=0^{\circ}$

- Caso 2: $\quad$ Linha LT2 $\operatorname{com} d=130 \mathrm{~km}, R_{t}=1 \Omega, R_{f}=1 \Omega$ e $\phi=90^{\circ}$

- Caso 3: $\quad$ Linha LT3 $\operatorname{com} d=200 \mathrm{~km}, R_{t}=10 \Omega, R_{f}=4 \Omega$ e $\phi=150^{\circ}$

Confrontando os parâmetros dos casos testados com os dados de treinamento e validação do sistema de detecção, apresentados na Tabela 5-1, pode-se perceber que os resultados destes testes também fornecerão uma prévia da capacidade de generalização da rede neural.

As saídas do módulo de detecção para os Casos 1, 2 e 3 são apresentadas, respectivamente, na Figura 33, na Figura 34 e na Figura 35. Nestas figuras, as respostas temporais do módulo de detecção são exibidas de forma emparelhada, para cada tipo de falta simulada. A incidência das faltas ocorre na amostra 256 e pode-se observar que, para todos os casos, o módulo de detecção acusou a ocorrência das faltas prontamente. Em algumas situações, pode-se verificar um pequeno, mas desprezível atraso, na ativação da saída de detecção.

\footnotetext{
${ }^{2}$ As distâncias possuem como referência o barramento E, tanto para as faltas na linha LT2 quanto na linha LT3.
} 


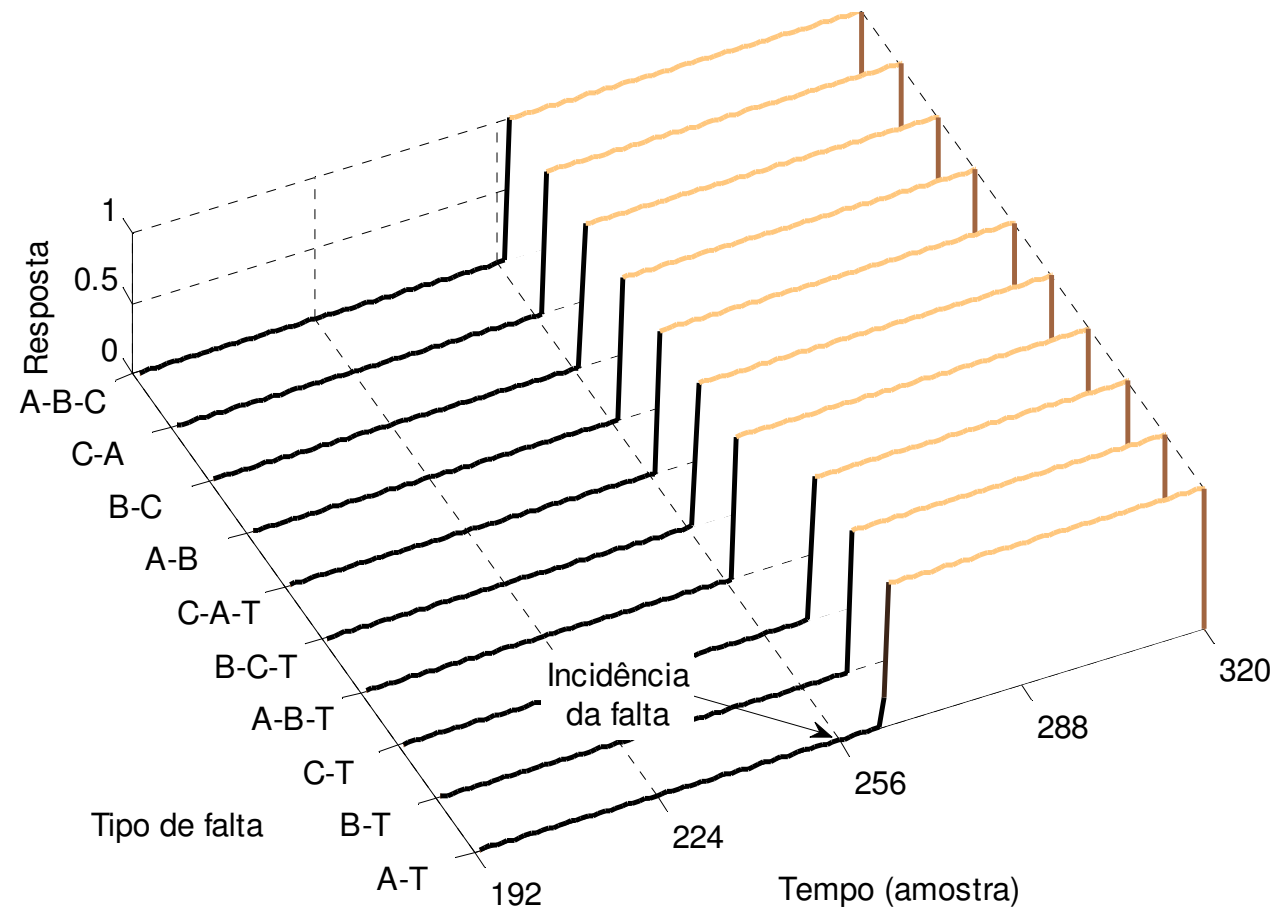

Figura 33. Resultados de detecção para simulações de faltas na linha LT2 $\operatorname{com} d=10 \mathrm{~km}, R_{t}=10 \Omega$,

$$
R_{f}=2 \Omega \text { е } \phi=0^{\circ}
$$

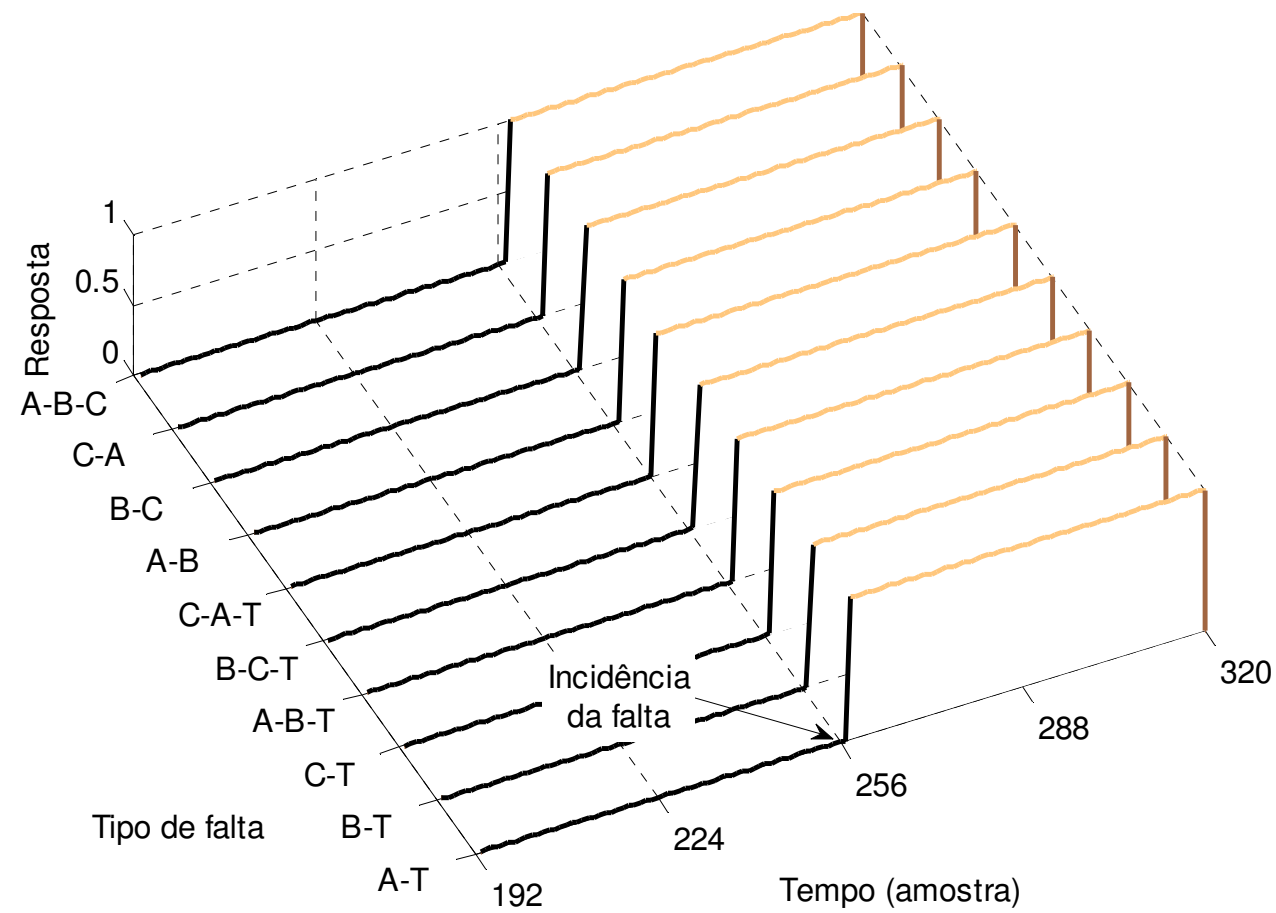

Figura 34. Resultados de detecção para simulações de faltas na linha LT2 $\operatorname{com} d=130 \mathrm{~km}, R_{t}=1 \Omega$,

$$
R_{f}=1 \Omega \text { e } \phi=90^{\circ}
$$




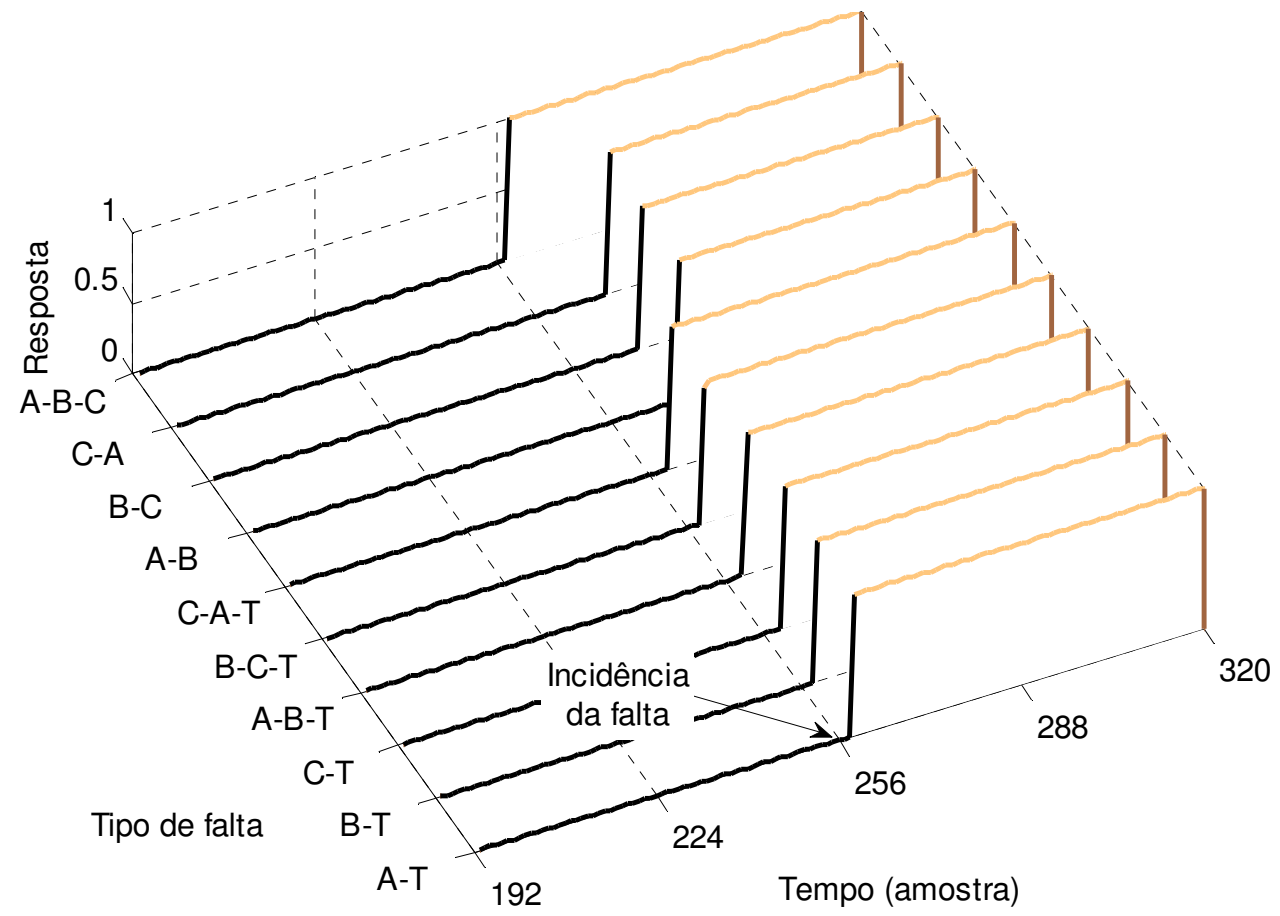

Figura 35. Resultados de detecção para simulações de faltas na linha LT3 com $d=200 \mathrm{~km}, R_{t}=10 \Omega$, $R_{f}=4 \Omega$ e $\phi=150^{\circ}$

\subsection{Classificação da Falta}

A etapa de classificação utiliza no cálculo dos cumulantes uma janela móvel de dados de um período fundamental completo, ou seja, $N$ amostras de corrente para cada fase. O principal motivo do aumento desta janela é aumentar o número de estatísticas disponíveis para solucionar o problema em questão. O módulo de classificação de faltas é dividido em duas funções. Desta forma, pode-se colocar que o mesmo se compõe de dois submódulos, executados de forma paralela. O primeiro realiza o monitoramento de cada fase individualmente e identifica a participação daquela fase na falta ocorrida. Essa função de monitoramento é executada por um único sistema funcional, replicado um total de três vezes, um para cada fase. Já o segundo e último submódulo identifica a participação da terra na falta ocorrida. Estes dois componentes são tratados a seguir, separadamente. 


\subsubsection{Identificação do envolvimento da fase monitorada na falta}

A seleção de cumulantes para serem empregados na etapa de classificação também é realizada através da análise do FDR. O levantamento deste índice levou em conta o conjunto total de simulações, cujos parâmetros estão especificados na Tabela 4-6. Seguindo o princípio adotado para o desenvolvimento do método proposto (Figura 11), o intervalo de tempo considerado para a coleta de amostras a serem utilizadas para classificação da falta está especificado na Figura 36. Conforme apresentado, o intervalo considerado se inicia depois de transcorrido tempo equivalente a $1 / 4$ de ciclo, contado a partir do instante de incidência da falta. Pode-se verificar também a utilização de um intervalo para coleta de amostras de tamanho correspondente a $1 / 2$ ciclo fundamental. Verifica-se também uma sobreposição entre os conjuntos de dados utilizados na detecção e na classificação de faltas.

Dado o objetivo deste procedimento, o qual consiste na identificação de participação da fase monitorada no curto-circuito, adotou-se arbitrariamente a fase A como fase analisada. Assim, para os conjuntos de padrões analisados foram associados os seguintes valores, para a geração das duas classes pertinentes ao problema: a classe $C_{1}$ - "Fase faltosa" - que corresponde às faltas que envolvem a fase $\mathrm{A}$ e a classe $C_{2}-$ "Fase não faltosa" - que corresponde às faltas que não envolvem a fase A. Equivalentemente,

- Classe $C_{1}$ : valor associado "1" (Faltas: A-T, A-B-T, C-A-T, A-B, C-A, A-B-C)

- Classe $\boldsymbol{C}_{2}$ : valor associado “0” (Faltas: B-T, C-T, B-C-T, B-C)

Na Figura 37, são apresentados os índices FDR obtidos. Observa-se nesta figura que as estatísticas de $2^{\mathrm{a}}$ e $4^{\mathrm{a}}$ ordem continuam a apresentar maior FDR. Os destaques 
vão para os cumulantes de $2^{\mathrm{a}}$ ordem com lags $\tau=\{68,69,70\}$ e os cumulantes de $4^{\mathrm{a}}$ ordem com lags $\tau=\{29,30,31\}$.

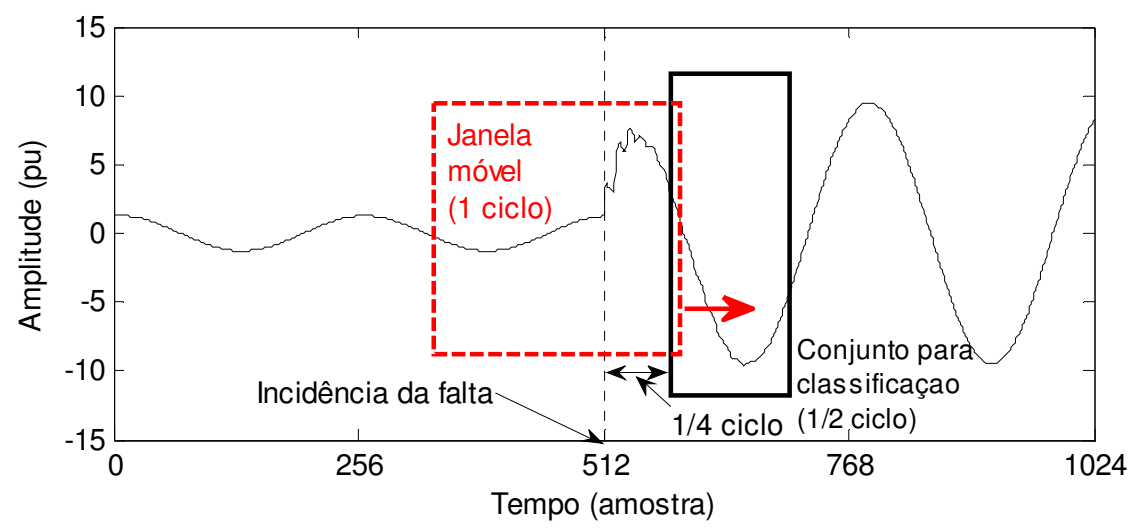

Figura 36. Intervalo de tempo utilizado para geração dos padrões do problema de classificação.

(a)

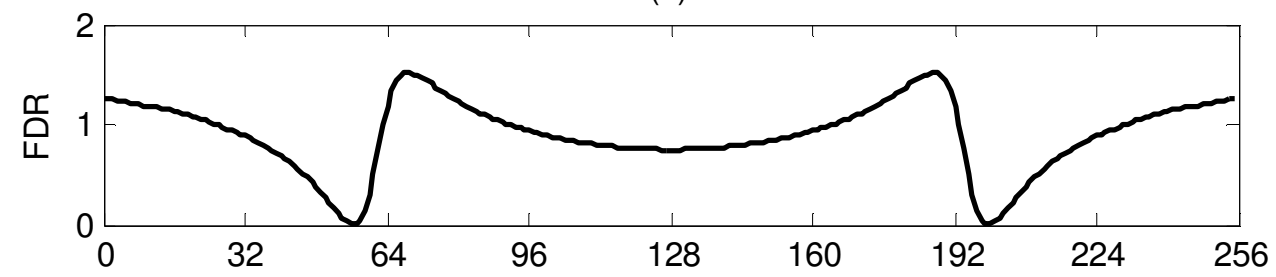

(b)

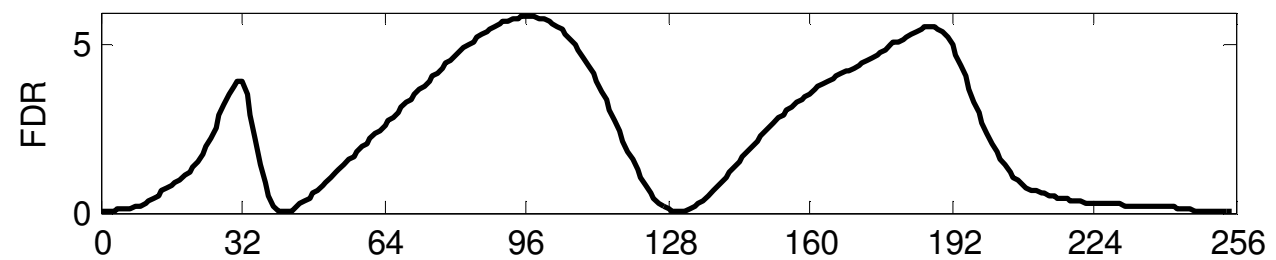

(c)

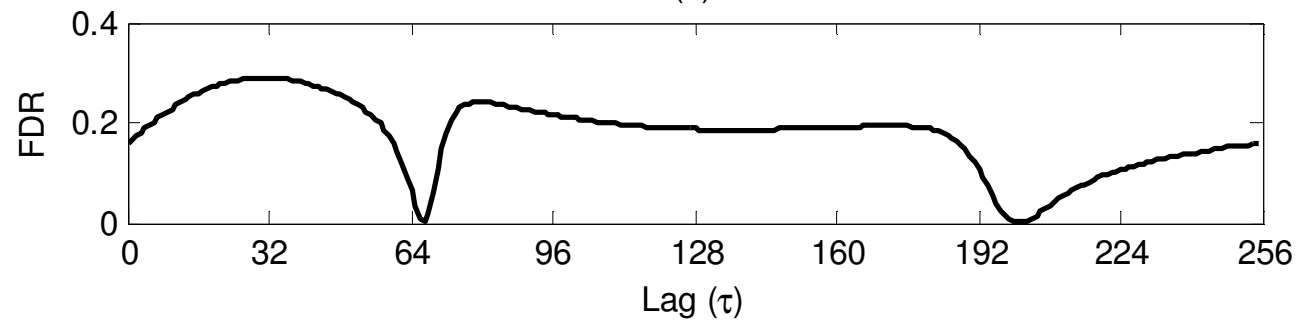

Figura 37. Fisher Discriminant Ratio para o problema de classificação (a) cumulantes de $2^{\mathrm{a}}$ ordem; (b) cumulantes de $3^{\text {a }}$ ordem e; (c) cumulantes de $4^{\text {a }}$ ordem.

Considerando o resultado apresentado na Figura 37, foi escolhida uma combinação de cumulantes que corresponde aos máximos valores de FDR observados, para ordens 2 e 4 . Assim, tem-se respectivamente para as fases A, B e C os cumulantes 
$C_{2}(69), C_{4}(31)$ e $C_{4}(31)$. Os parâmetros utilizados para a geração de padrões e para o posterior treinamento da rede de classificação são especificados na Tabela 5-2. O resultado da geração de padrões pode ser verificado na Figura 38. Nesta figura, os padrões pretos são relativos às faltas que não contam com a participação da fase A e os padrões cinza indicam a participação da fase A no defeito.

Tabela 5-2. Conjunto de parâmetros de falta utilizados para geração de padrões de treinamento e validação da rede neural de classificação

\begin{tabular}{c|c|c|c}
\hline \hline TIPO DE FALTA & DISTÂNCIA $\boldsymbol{d}(\mathbf{k m})$ & INCIDÊNCIA $\left(^{\mathbf{0}}\right)$ & RESISTENCIAS $(\boldsymbol{\Omega})$ \\
\hline \hline & $\begin{array}{c}\text { Linha } 2 \text { (referência: barra E): } \\
1,5,20,35,50,65,80,95, \\
\text { F-T, F-F-T, }\end{array}$ & & \\
F-F e F-F-F & $\begin{array}{l}110,125,140 \\
\end{array}$ & $\begin{array}{c}\text { Linha 3 (referência: barra F): } \\
5,20,35,50,65,80,95\end{array}$ & 150,$180 ; 50 ; 100$ \\
& & & $R_{f}=0 ; 10$ \\
\hline \hline
\end{tabular}

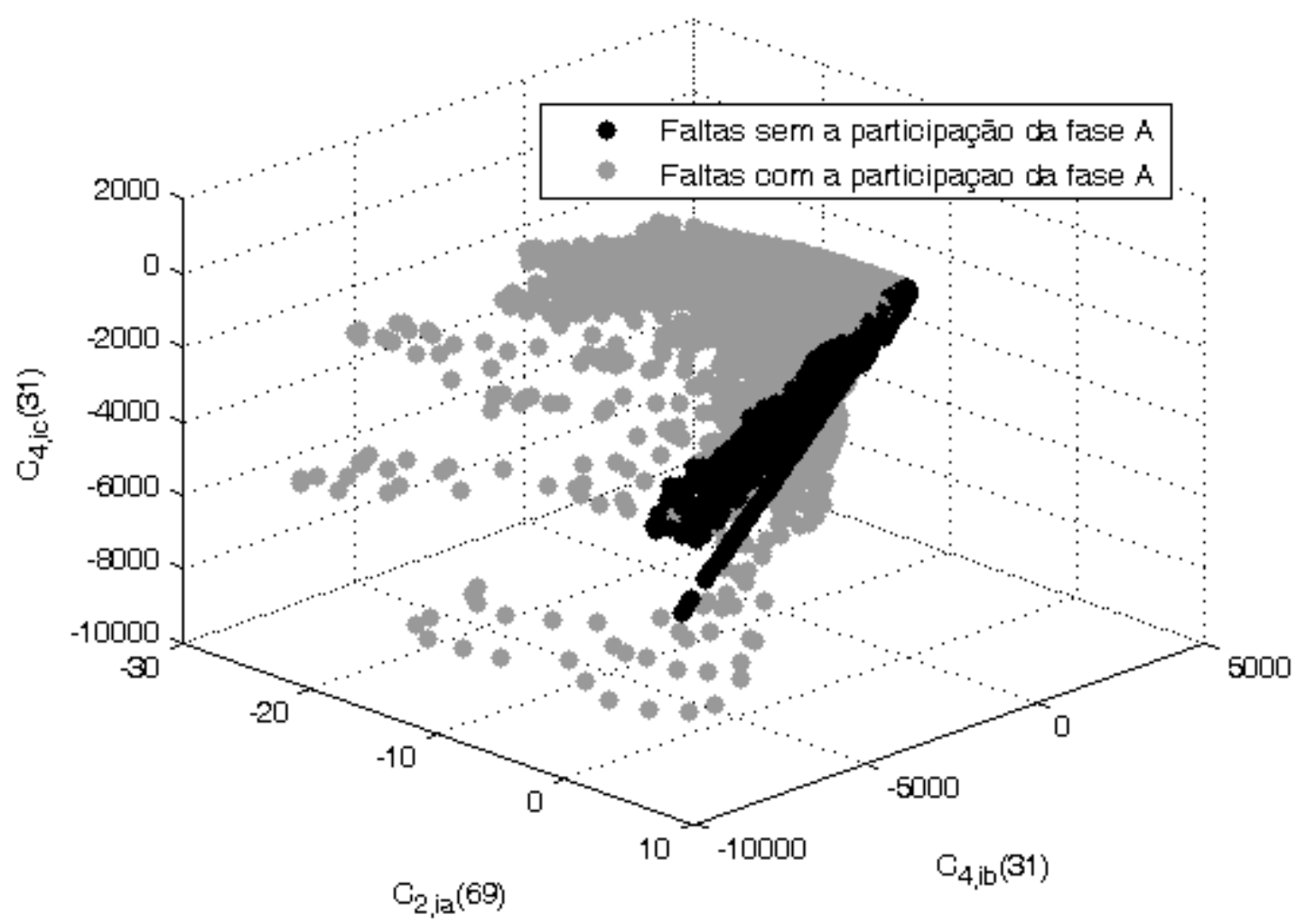

Figura 38. Padrões gerados para o problema de classificação quanto ao envolvimento da fase monitorada na falta ocorrida: caso do monitoramento da fase $\mathrm{A}$. 
Utilizando uma RNA de duas camadas, tal como mostrado na Figura 39, com $N_{1}=6$ neurônios na primeira camada e $N_{2}=1$ neurônio na última camada, foi realizado treinamento para separação das classes envolvidas neste processo. Neste caso, também foi realizada redução da taxa de amostragem com fator $M=8$ e utilizou-se contaminação dos sinais de corrente por ruído branco gaussiano com $\mathrm{SNR}=30 \mathrm{~dB}$.

O treinamento da rede foi executado com $70 \%$ dos padrões disponíveis e admitindo-se um valor limite de 5000 épocas e visando um EQM mínimo de $1,0 \times 10^{-6}$. O algoritmo foi executado pelas 5000 épocas sem convergência pelo critério do EQM ou do gradiente. O erro quadrático médio final obtido foi $5,642 \times 10^{-3}$. A evolução deste parâmetro em função do número de épocas é apresentado na Figura 40(a). Também nesta figura, em (b), é exibido o resultado de validação da rede, com a comparação das curvas de valores desejados e de saída da rede. A taxa de acerto obtida foi de 99,504\%, sendo avaliados 6048 padrões neste processo de validação.

No que tange à operação, um resultado em particular é apresentado na Figura 41. Neste caso, simulou-se uma falta do tipo A-T a $50 \mathrm{~km}$ do barramento E com resistência de falta $R_{t}=100 \Omega$ e ângulo de incidência de falta $\phi=150^{\circ}$. A incidência da falta é imposta na amostra 256. Os sinais de corrente são contaminados com ruído branco Gaussiano, de forma que a relação sinal-ruído seja $S N R=35$ dB. Nesta figura, em (a) são apresentados os sinais de corrente seguidos, em (b), pelos sinais de erro provenientes das saídas do filtro notch. Utilizando estes sinais, são calculados os cumulantes, $C_{2}(29)$ para a fase $\mathrm{A}$ e $C_{4}(31)$ para as fases $\mathrm{B}$ e $\mathrm{C}$, mostrados em (c). Finalmente, tendo como entrada os padrões formados pelos cumulantes das fases A, B e C no instante de tempo $n$, a saída da rede de classificação é apresentada em (d). Observa-se que é identificada a participação da fase A na falta simulada (falta A-T), após decorrido intervalo de tempo de $1 / 4$ de ciclo a partir do instante de incidência do defeito. 


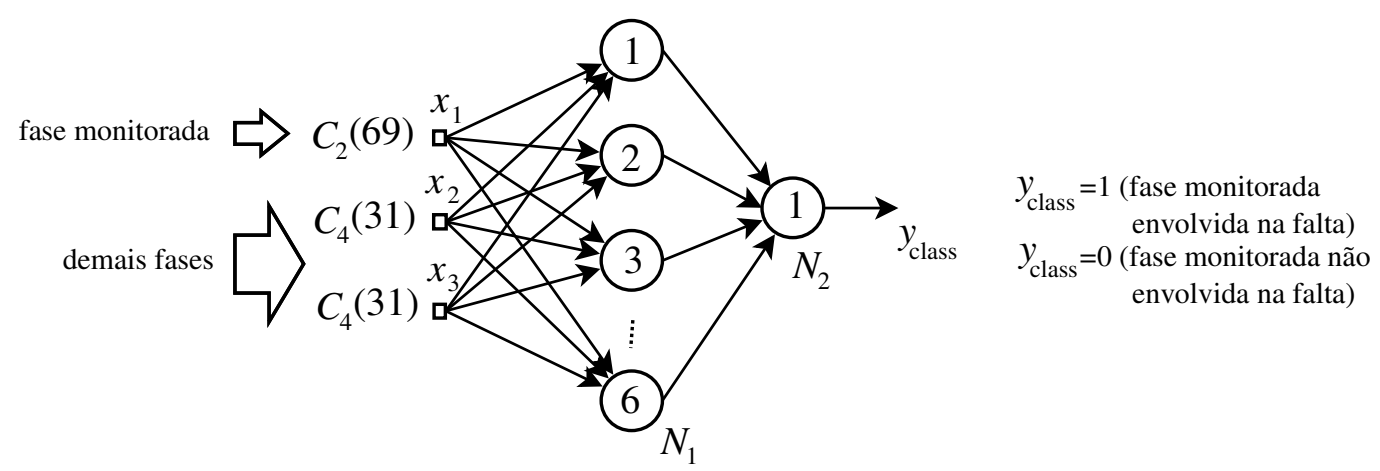

Figura 39. Representação da rede neural utilizada para classificação de falta.

(a)

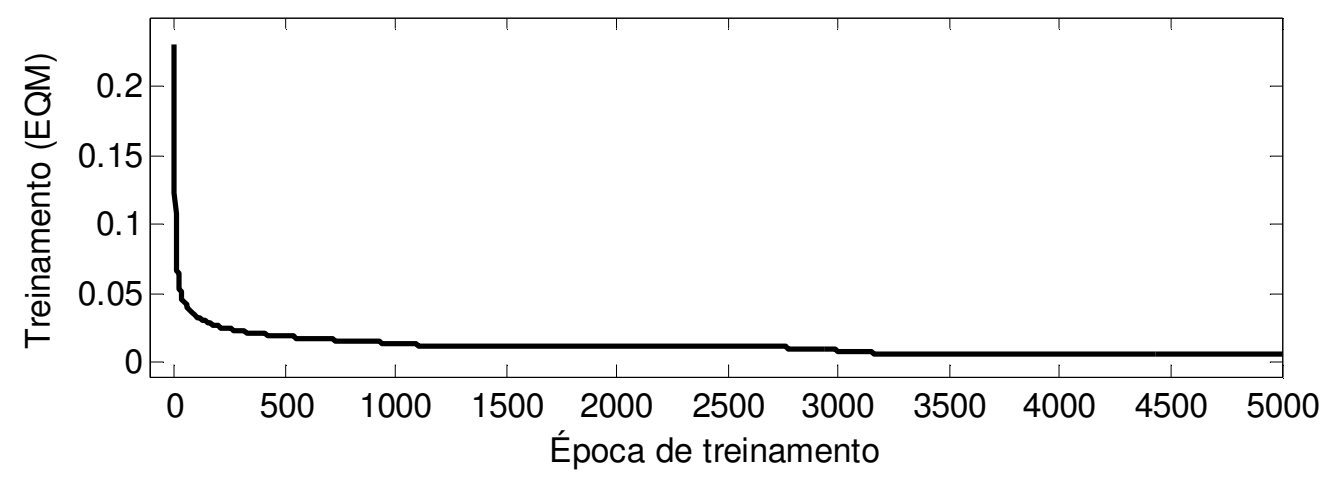

(b)

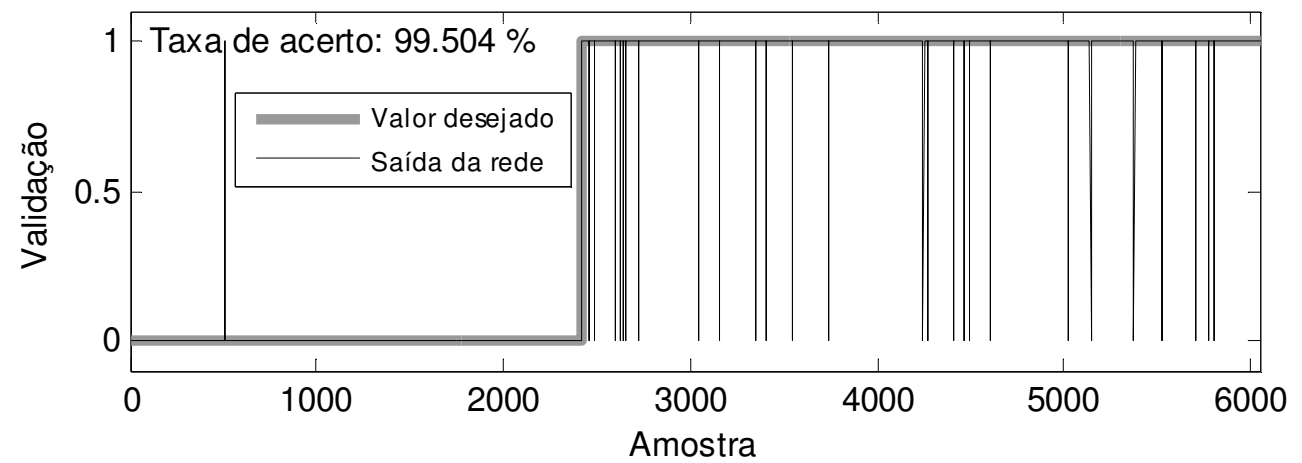

Figura 40. Resultados obtidos para a RNA de classificação: (a) evolução do EQM no treinamento e; (b) validação.

Adicionalmente, um segundo resultado de operação é apresentado na Figura 42. Neste caso, simulou-se uma falta do tipo C-T. A configuração desta é idêntica à da falta A-T simulada anteriormente, com distância de $50 \mathrm{~km}$ a partir do barramento E, resistência de falta $R_{t}=100 \Omega$ e ângulo de incidência de falta $\phi=150^{\circ}$. A incidência da falta é imposta novamente na amostra 256. Considera-se, também, a contaminação dos sinais de corrente por ruído branco gaussiano com $\mathrm{SNR}=35$ dB. Na Figura 42, são 
apresentados os sinais de corrente, em (a), e os sinais de erro, em (b). Os cumulantes são apresentados em (c). Por fim, considerando como entrada do módulo de classificação os cumulantes desta figura, em (d) é apresentada a saída da rede. Observa-se que este módulo de classificação, responsável pelo monitoramento da fase A, mantém sua saída inativa, indicando a não participação desta fase no defeito ocorrido, Este é, de fato, o resultado esperado, já que se trata de uma falta envolvendo a fase $\mathrm{C}$ e a terra.

(a)

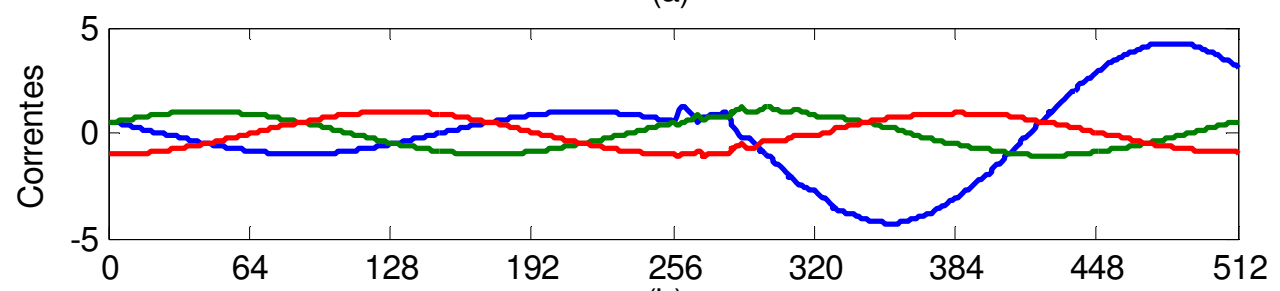

(b)

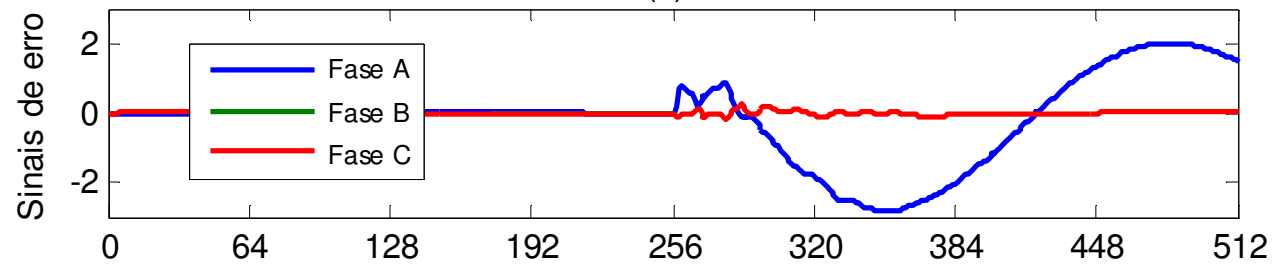

(c)

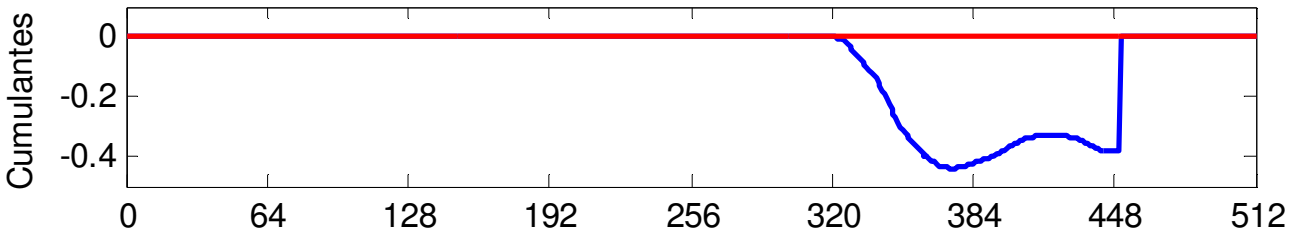

(d)

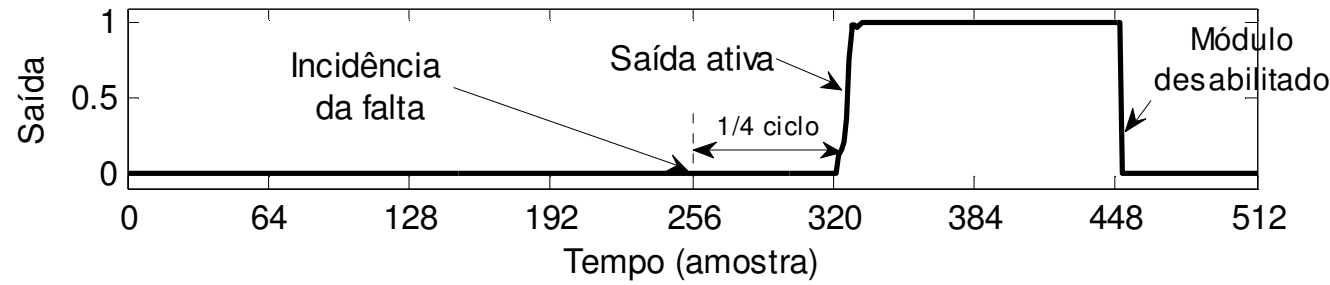

Figura 41. Simulação de falta A-T a $50 \mathrm{~km}$ do relé, com $R_{t}=100 \Omega$ e $\phi=150^{\circ}$. Sinais: (a) correntes; (b) saídas do filtro notch; (c) cumulantes e; (d) saída da rede de classificação correspondente à Fase A. 
(a)
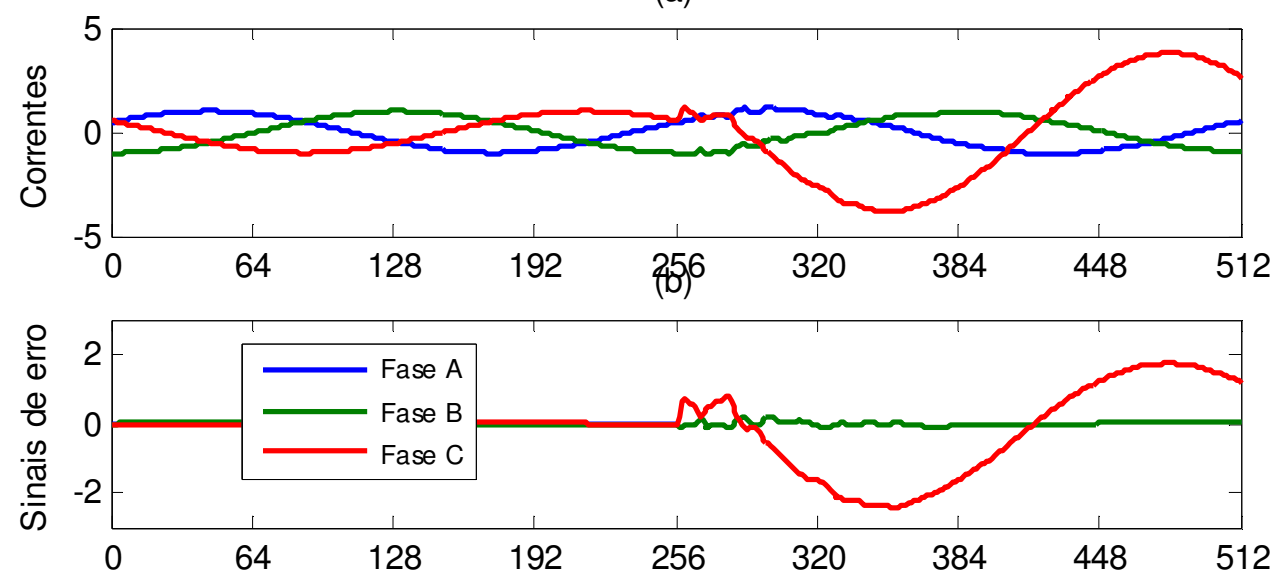

(c)

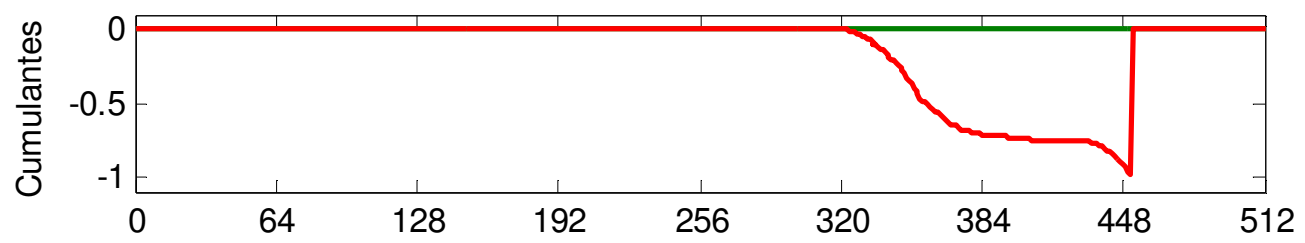

(d)

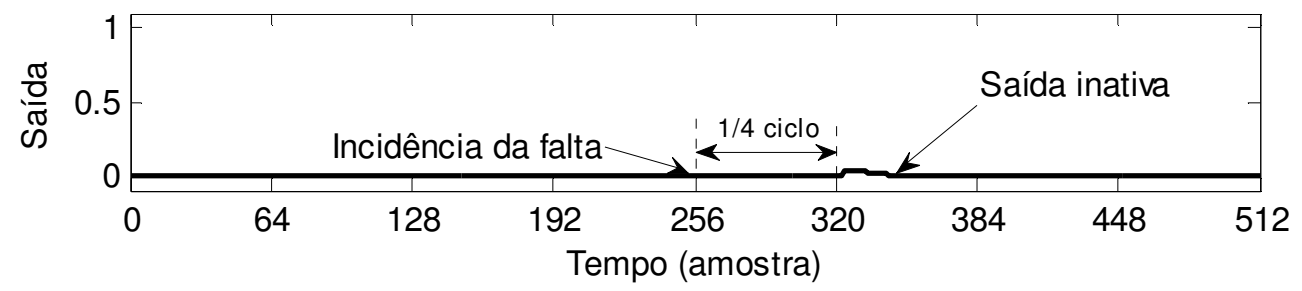

Figura 42. Simulação de falta C-T a $50 \mathrm{~km}$ do relé, $\operatorname{com} R_{t}=100 \Omega$ e $\phi=150^{\circ}$. Sinais: (a) correntes; (b) saídas do filtro notch; (c) cumulantes e; (d) saída da rede de classificação correspondente à Fase A.

Testes adicionais visando uma investigação preliminar da classificação de faltas são executados na próxima seção para três casos distintos de falta, sendo cada um em uma das três zonas de proteção.

\subsubsection{Identificação do envolvimento da terra na falta}

A etapa de classificação de falta, além da indicação de participação de determinada fase na falta, requer também a indicação da terra ou não na falta em questão. Nesta tarefa, optou-se por um procedimento inicial mais simples do que o abordado na Seção anterior. A justificativa desta modificação adotada se deve à relativa facilidade de identificação da participação da terra nas faltas pelo método tradicional 
baseado nos fasores de correntes, abordado na Seção 2.1.3. Foi reportado nesta seção que um limiar $I_{m i n}$ de valor 0,007 é suficiente para detectar a participação da terra na falta, sendo avaliado o módulo do fasor de corrente de sequência zero. No entanto, deve-se procurar por um procedimento que elimine operações matemáticas com números complexos, tal como ocorrido na DFT.

Diante do exposto, a primeira tentativa de identificação de terra na falta utilizando EOS foi realizada empregando a estatística mais simples, ou seja, de $2^{\mathrm{a}}$ ordem com lag $\tau=0$, no sinal de corrente de sequência zero. Utilizando os dados da Tabela 4-6, foi realizado o levantamento desta estatística para cada falta, associando os cumulantes a duas classes, de acordo com o tipo da falta. A janela de dados para o cálculo dos cumulantes possui tamanho de 1 período fundamental. A classe $C_{1}$ engloba as faltas com a participação da terra, ao passo que a classe $C_{2}$ engloba as faltas sem a participação da terra. Equivalentemente tem-se:

- Classe $\boldsymbol{C}_{1}$ : valor associado "1" (Faltas: A-T, B-T, C-T, A-B-T, C-A-T, B-C-T)

- Classe $\boldsymbol{C}_{2}$ : valor associado “0” (Faltas: A-B, B-C, C-A, A-B-C)

As distribuições amostrais das estatísticas associadas às classes $C_{1}$ e $C_{2}$ são apresentadas na Figura 43. Conforme pode ser observado, as distribuições ocupam intervalos bem distintos entre si. Com efeito, nenhuma amostra pertencente à classe das faltas que envolvem a terra apresentou cumulante inferior a 0,01082. Por outro lado, na classe associada às faltas que não envolvem a participação da terra, nenhum cumulante calculado foi superior a $8,8513 \times 10^{-5}$. Desta forma, tem-se disponível um intervalo relativamente grande para se estabelecer um limiar adequado à correta distinção entre as classes envolvidas neste problema. Neste trabalho, adotou-se a constante 0,001 para este 
limiar. Assim, pode-se resumir a operação de identificar a participação da terra na falta, no instante de tempo $n$, como,

$$
\begin{aligned}
& C_{2, i_{0}}(0)>0,001 \Rightarrow y_{T}=1 ; \quad \text { (Falta com Terra) } \\
& C_{2, i_{0}}(0) \leq 0,001 \Rightarrow y_{T}=0 ; \quad \text { (Falta sem Terra) }
\end{aligned}
$$

(a)

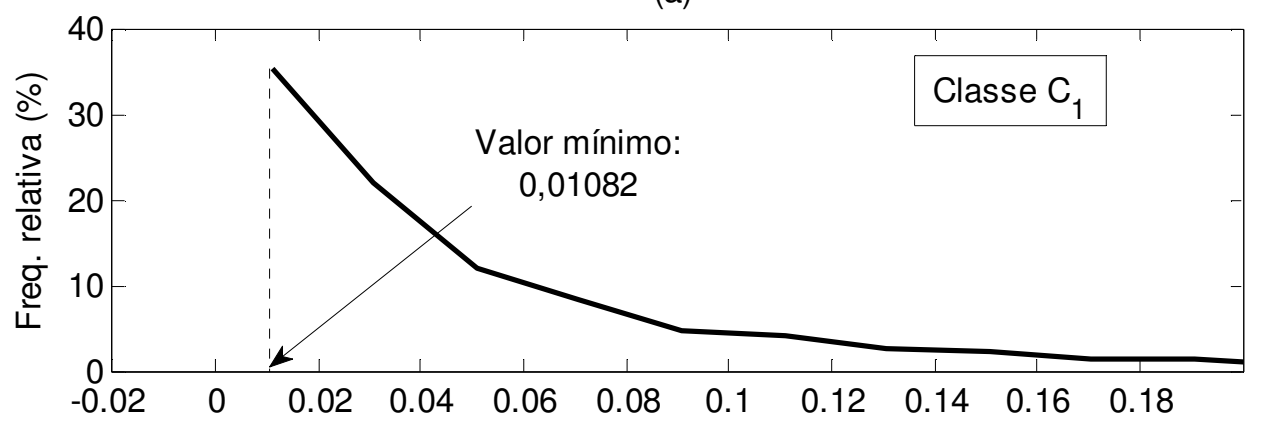

(b)

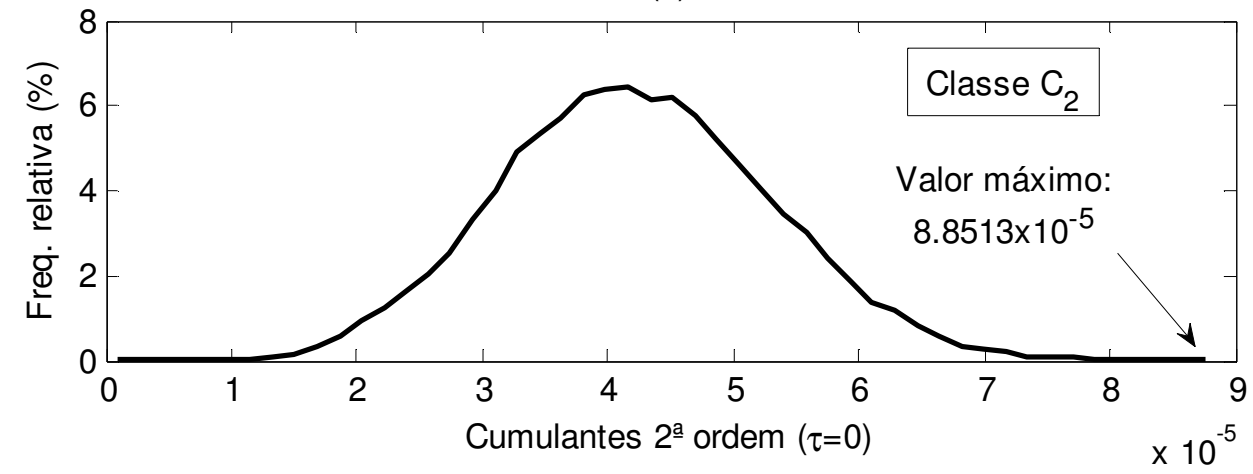

Figura 43. Distribuição amostral do cumulante de $2^{\mathrm{a}}$ ordem com lag $\tau=0$, para as classes $C_{1}$ e $C_{2}$, associadas ao problema de identificação da terra na falta.

Um exemplo de operação de classificação de participação da terra na falta é apresentado na Figura 44. As condições de simulação deste caso são idênticas à da Seção anterior (Figura 41), quando do teste de identificação da participação da fase A na falta. Na Figura 44, em (a) são apresentados os sinais de corrente e, em seguida, em (b), é apresentada a corrente de sequência zero. Utilizando este sinal, o cumulante de $2^{\mathrm{a}}$ ordem $C_{2}(0)$ é calculado e mostrado em (c). Finalmente, executando a comparação de (5.1), é determinada a saída de classificação de terra na falta, exibida em (d). Observa-se 
que é identificada a participação da terra na falta simulada (falta A-T), depois de decorrido intervalo de tempo de $1 / 4$ de ciclo a partir do instante de incidência do defeito.

(a)

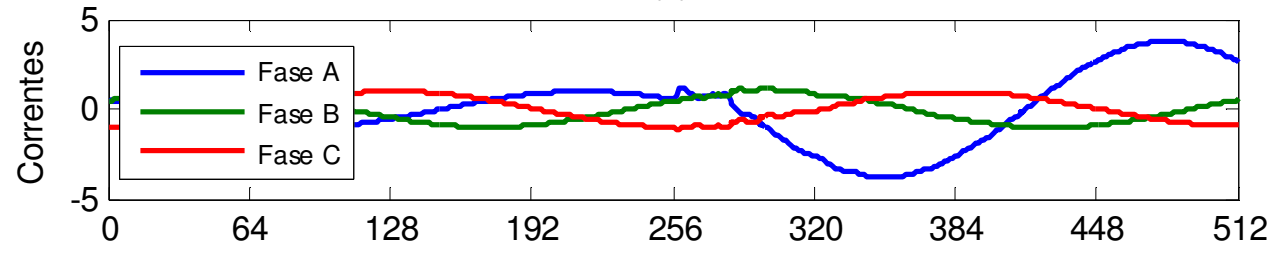

(b)

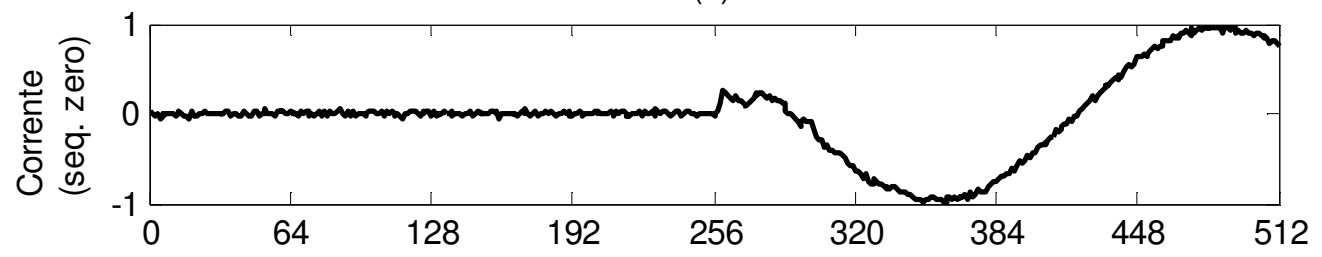

(c)

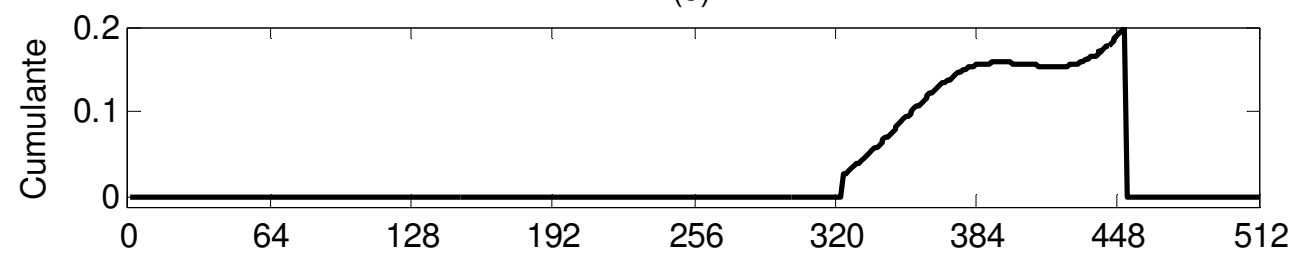

(d)

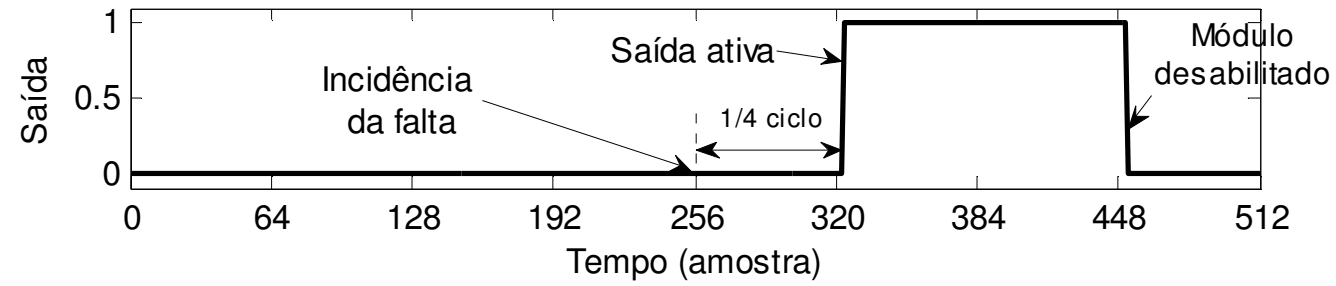

Figura 44. Simulação de falta A-T a $50 \mathrm{~km}$ do relé, $\operatorname{com} R_{t}=100 \Omega$ e $\phi=150^{\circ}$. Sinais: (a) correntes; (b) corrente de sequência zero; (c) cumulante e; (d) saída de classificação de terra.

Por fim, objetivando novamente uma investigação preliminar do desempenho do sistema de classificação, assim como no caso da detecção, foram consideradas faltas nas linhas LT2 e na linha LT3 em três casos distintos. Os testes consistem no monitoramento de todas as fases e também da terra, simulando a operação desta etapa da proteção. Foram considerados os seguintes parâmetros de falta ${ }^{3}$ :

\footnotetext{
${ }^{3}$ As distâncias possuem como referência o barramento E, tanto para as faltas na linha LT2 quanto na linha LT3.
} 
- Caso 1: $\quad$ Linha LT2 $\operatorname{com} d=10 \mathrm{~km}, R_{t}=0 \Omega, R_{f}=10 \Omega$ e $\phi=60^{\circ}$

- Caso 2: $\quad$ Linha LT2 $\operatorname{com} d=115 \mathrm{~km}, R_{t}=75 \Omega, R_{f}=1 \Omega$ e $\phi=0^{\circ}$

- Caso 3: $\quad$ Linha LT3 $\operatorname{com} d=220 \mathrm{~km}, R_{t}=25 \Omega, R_{f}=4 \Omega$ e $\phi=90^{\circ}$

Comparando os parâmetros dos casos testados com os dados de treinamento e validação do sistema de classificação, apresentados na Tabela 5-2, pode-se perceber que, também nesta análise, os resultados destes testes fornecerão, igualmente, um entendimento prévio sobre a capacidade de generalização da rede neural.

As saídas do módulo de classificação para os Casos 1, 2 e 3 são apresentadas, respectivamente, na Figura 45, na Figura 46 e na Figura 47. Nestas figuras, em (a), (b), (c) e (d) têm-se, respectivamente, as respostas de monitoramento das fases A, B, C e da terra. Novamente, as respostas temporais são exibidas de forma emparelhada, para cada tipo de falta simulada. A incidência das faltas é simulada sempre na amostra 256. Podese observar que, em todos os casos, o módulo de classificação responsável pelo monitoramento da fase $\mathrm{A}$ indicou a participação da mesma na falta, para todos os defeitos que envolvem esta fase (Figura 45(a), Figura 46(a) e Figura 47(a)). Esta indicação ocorre depois de transcorrido um intervalo mínimo de um quarto de ciclo contado do instante da incidência da falta, período no qual o módulo de detecção encontra-se ativo. Analisando as saídas de monitoramento das fases B e C e da terra, observa-se comportamento similar ao da fase A, podendo-se afirmar, portanto, que a classificação das faltas foi realizada com total sucesso.

Analisando mais detalhadamente a Figura 47, podem ser observar leves estados de ativação dos módulos de classificação em casos onde os mesmo não deveriam ocorrer. De fato, basta observar que o módulo de monitoramento da Fase C não provê resposta igualmente nula para as faltas A-T e B-T, entre as amostras 320 e 448. Entretanto, há de 
se salientar que o comportamento observado não tende a promover respostas errôneas de classificação. Os valores de saídas das redes neurais são na sua maioria próximos de zero e, como colocado no próximo capítulo, uma etapa de pós-processamento é utilizada para diferenciar uma saída efetivamente ativa de uma saída inativa.
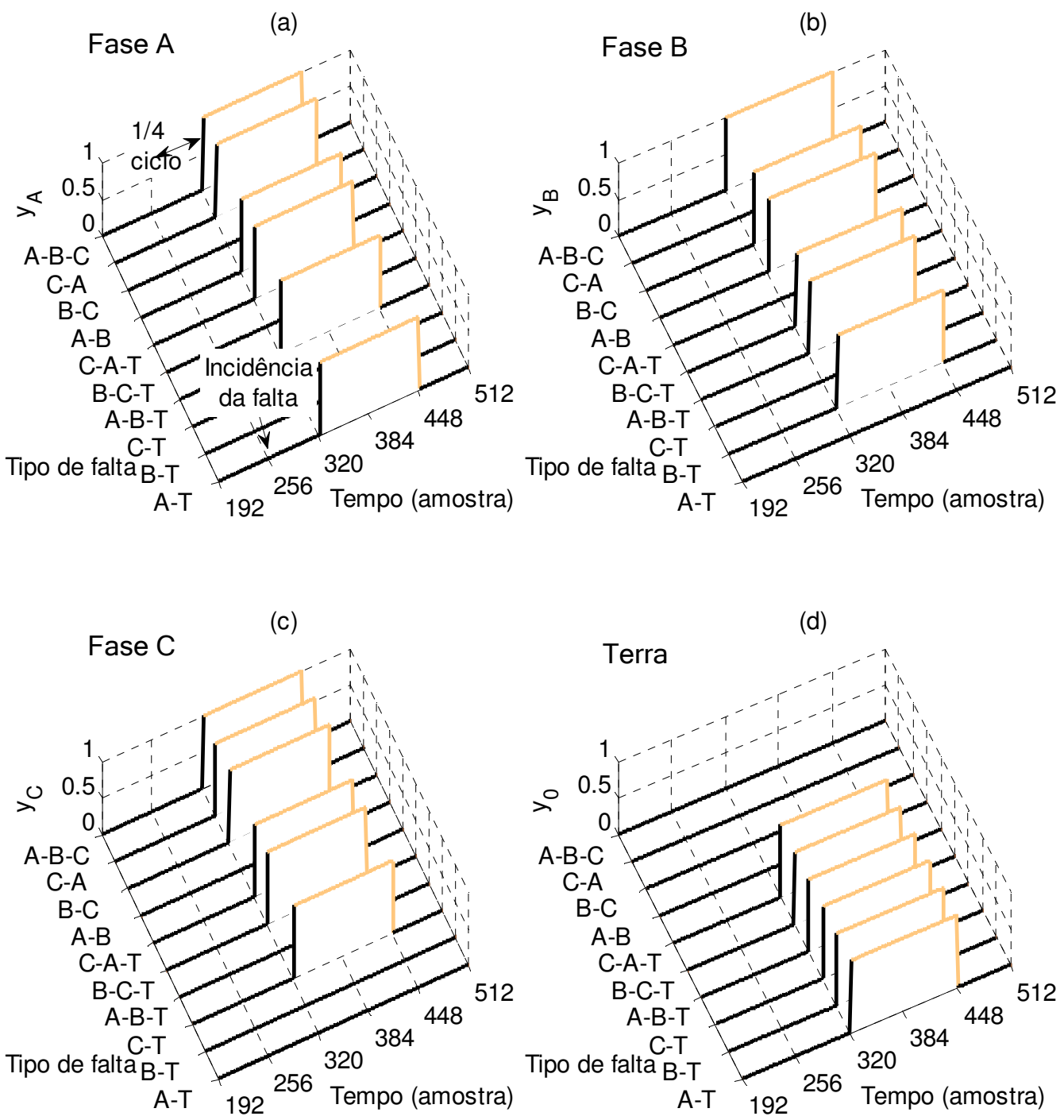

Figura 45. Resultados de classificação para simulações de faltas na linha $\operatorname{LT} 2 \operatorname{com} d=10 \mathrm{~km}, R_{t}=0 \Omega$, $R_{f}=10 \Omega$ e $\phi=60^{\circ}$. Saídas do módulo de classificação: (a) fase A; (b) fase B; (c) fase C; e (d) terra. 
(a)

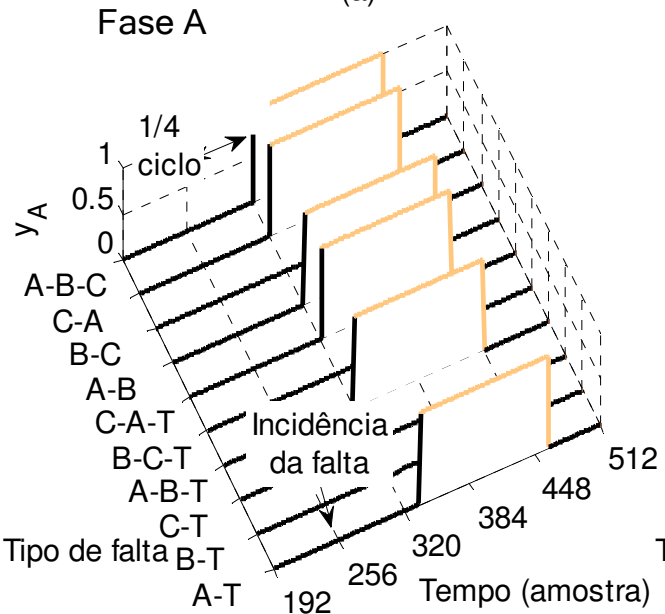

A-T 192

(c)

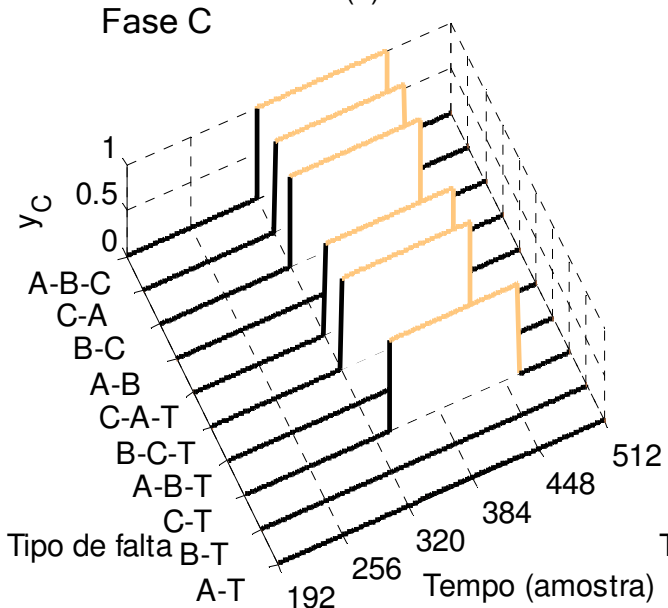

(b)

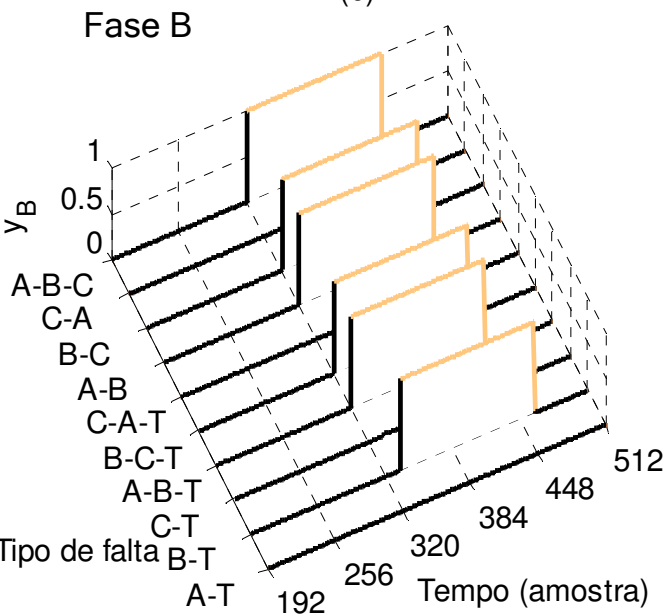

(d)

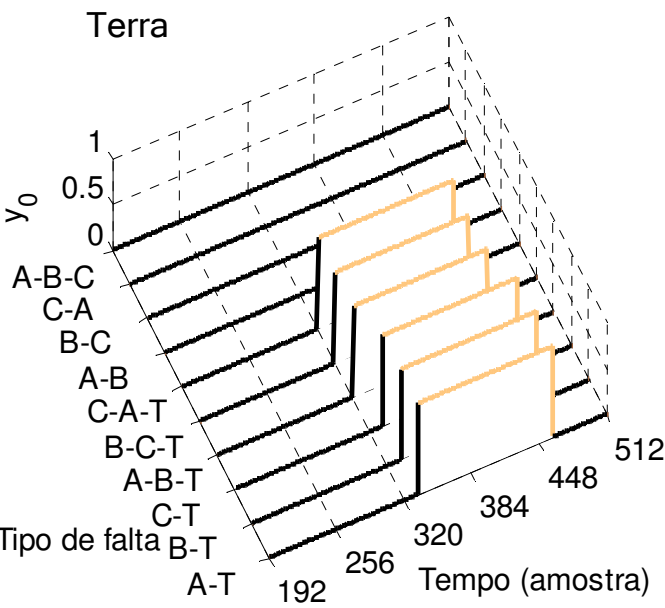

Figura 46. Resultados de classificação para simulações de faltas na linha LT2 com $d=115 \mathrm{~km}, R_{t}=75$ $\Omega, R_{f}=1 \Omega$ e $\phi=0^{\circ}$. Saídas do módulo de classificação: (a) fase A; (b) fase B; (c) fase C; e (d) terra. 
(a)

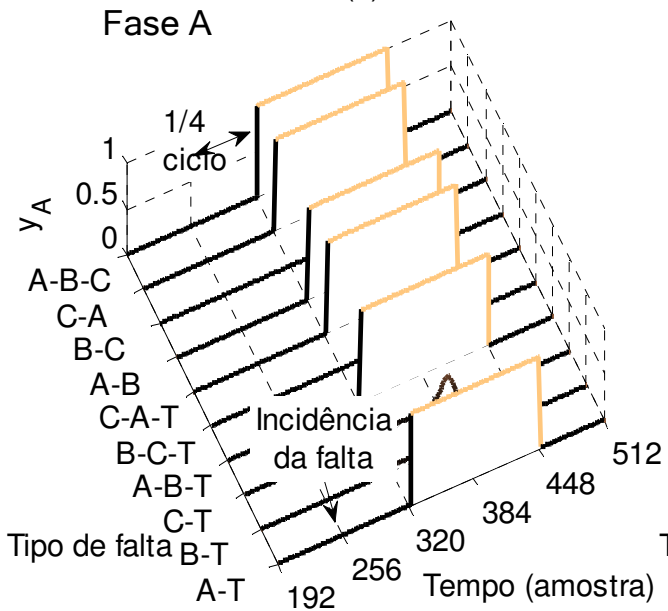

(c)

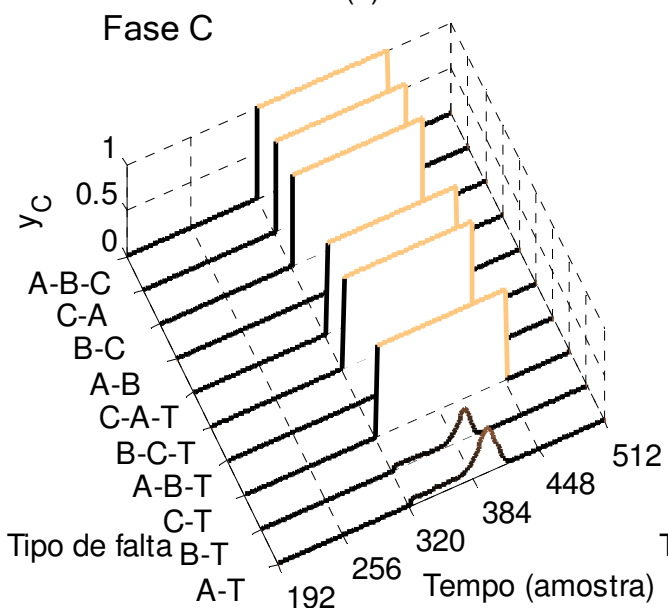

(b)

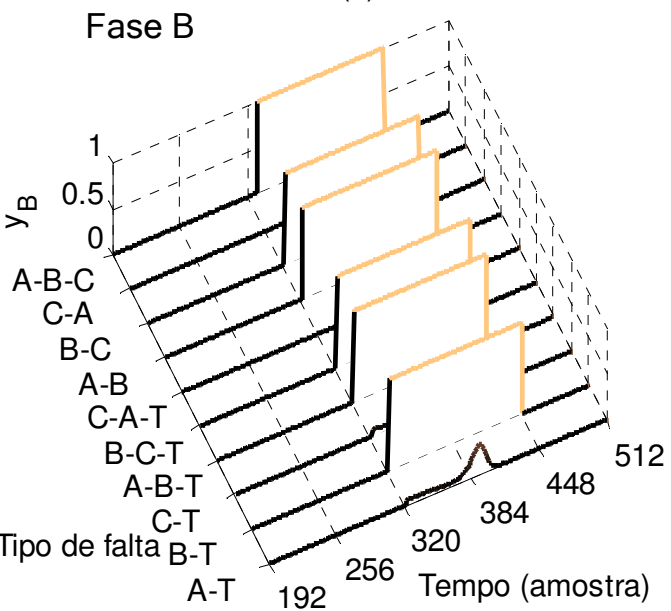

(d)

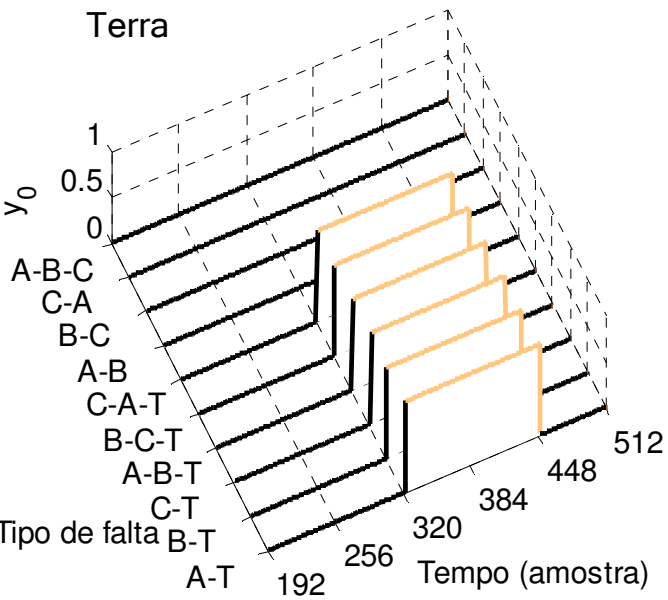

Figura 47. Resultados de classificação para simulações de faltas na linha LT3 $\operatorname{com} d=220 \mathrm{~km}, R_{t}=25$ $\Omega, R_{f}=4 \Omega$ e $\phi=90^{\circ}$. Saídas do módulo de classificação: (a) fase A; (b) fase $B$; (c) fase $C$; e (d) terra.

\subsection{Localização da Falta}

A etapa de localização da falta segue a etapa de classificação no processo de proteção digital de LTs. O objetivo desta etapa é identificar a zona de ocorrência da falta, sem a determinação da distância da mesma. No entanto, para todos os efeitos, refere-se à mesma como localização. Neste trabalho, o módulo de localização é constituído de quatro submódulos, a saber. O primeiro deles é responsável por 
identificar a zona de ocorrência para faltas envolvendo uma única fase e a terra, ou seja, para as faltas do tipo A-T, B-T e C-T. O segundo submódulo é empregado no caso de faltas envolvendo duas fases e a terra, ou seja, as faltas A-B-T, B-C-T e C-A-T. O terceiro módulo processa faltas bifásicas sem a terra, ou seja, as faltas A-B, B-C e C-A. Por fim, o quarto submódulo identifica a zona onde ocorreu o defeito considerando a falta trifásica considerada neste trabalho, isto é, a falta do tipo A-B-C. A possibilidade de utilização de um único sistema para processamento de faltas do mesmo tipo simplifica o método de proteção, sendo necessário somente uma etapa prévia de chaveamento das entradas para o correto funcionamento.

O algoritmo de localização é executado, para todos os tipos de falta, com o emprego de uma janela de dados deslizante de tamanho de um período fundamental no cálculo de cumulantes. Esta janela é representada na Figura 48. Nesta figura, é também identificada a janela utilizada para compor o conjunto de dados analisados para o processo de localização. Conforme pode ser verificado, o conjunto corresponde a uma janela de tamanho de $1 / 4$ do período fundamental, coletada exatamente no fim do primeiro ciclo de regime de pós-falta. Desta forma, tem-se o sistema de proteção proposto o qual deve ser executado inteiramente em um intervalo de $16,67 \mathrm{~ms}$, que se inicia quando da incidência da falta. Cabe comentar que, neste caso, não foi considerada sobreposições das janelas de dados de classificação e localização.

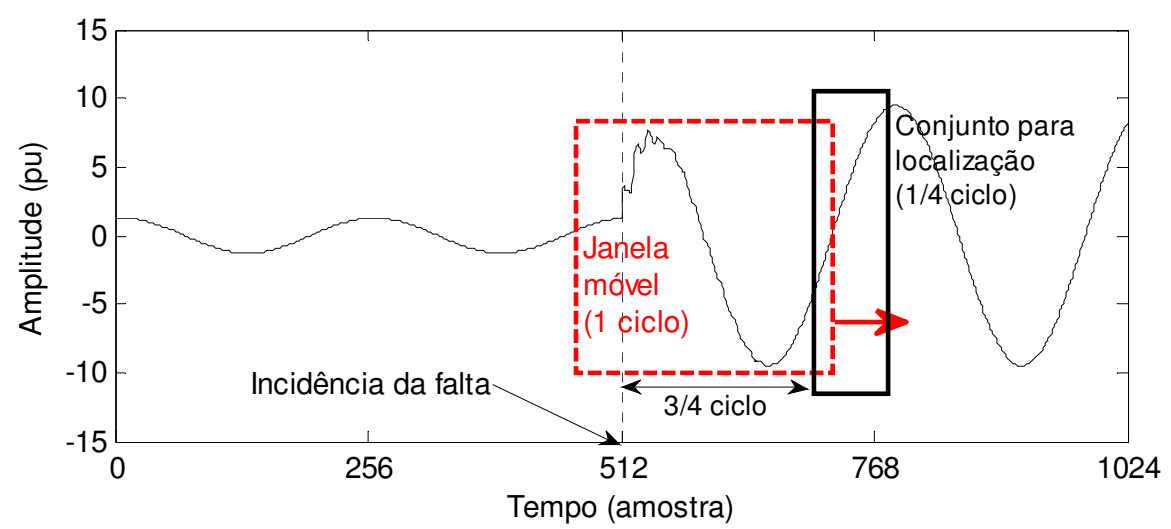

Figura 48. Intervalo de tempo utilizado para geração dos padrões do problema de localização. 
Três zonas de proteção foram definidas no problema de localização, tal como apresentado na Figura 49. A zona 1 corresponde à zona primária de atuação do relé em questão e possui comprimento equivalente a $80 \%$ do comprimento da linha de transmissão LT2. A zona 2 corresponde à zona secundária e abrange o comprimento da linha 1 acrescido de $20 \%$ do comprimento da linha de transmissão LT3. A Zona 3 completa a extensão total das linhas LT2 e LT3. Desta forma, para os conjuntos de padrões analisados foram associados os seguintes valores, para a geração de três classes associadas a este problema: a classe $C_{1}$ - "Zona 1" - que corresponde às faltas ocorridas a uma distância de 0 a $120 \mathrm{~km}$ em relação ao relé, a classe $C_{2}$ - "Zona 2" - que corresponde às faltas ocorridas a distâncias de 120 a $170 \mathrm{~km}$ do relé e a classe $C_{3}$ “Zona 3" - que corresponde às faltas ocorridas com distâncias superiores a 170 km a partir do relé. Equivalentemente, considerando três saídas para este problema particular, tem-se:

- Classe $\boldsymbol{C}_{\mathbf{1}}$ : valores associados $\left[\begin{array}{lll}1 & 0 & 0\end{array}\right]$ (Condição: $\left.0<d \leq 120\right)$

- Classe $\boldsymbol{C}_{2}$ : valores associados [0 10 0] (Condição: $\left.120<d \leq 170\right)$

- Classe $\boldsymbol{C}_{3}$ : valores associados [0 001 (Condição: $\left.170<\mathrm{d} \leq 250\right)$

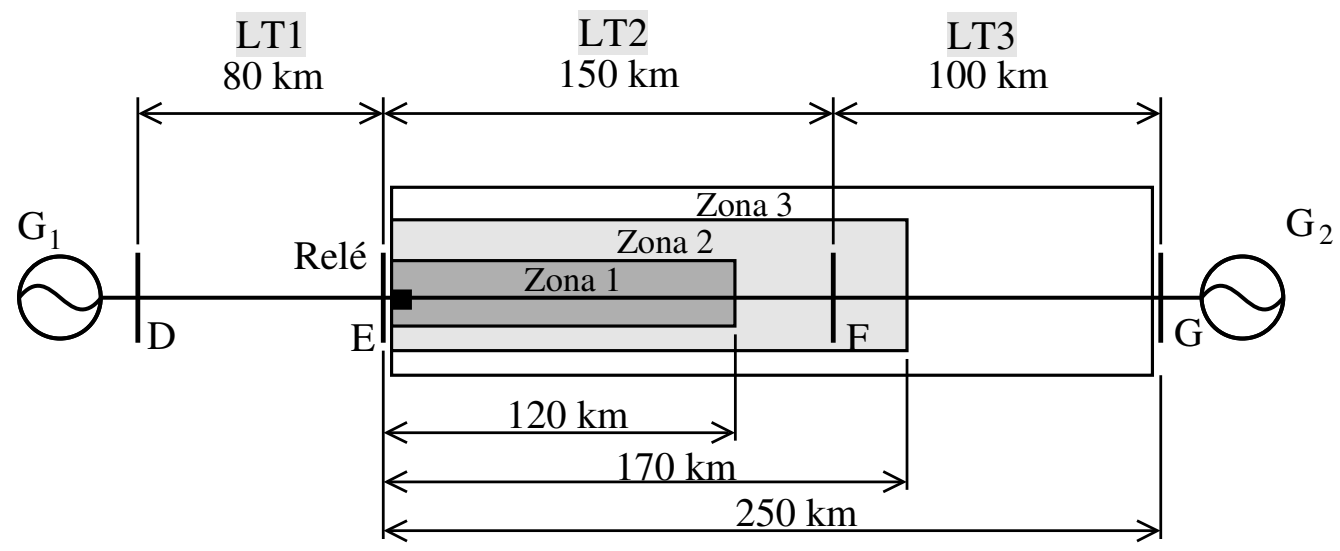

Figura 49. Definição das zonas de proteção para o SEP simulado. 
Por fim, no que se segue são apresentados os resultados de localização de forma separada, para cada tipo de falta, iniciando com as faltas do tipo fase-terra.

\subsubsection{Faltas envolvendo uma fase e a terra (F-T)}

A análise de faltas envolvendo uma única fase e a terra inicia-se com o levantamento do Discriminante de Fisher. Para tal fim, visando simplicidade e rapidez na análise, foram consideradas apenas as classes do problema de localização relativas às zonas de proteção primária e secundária. Isto é, o FDR mede, portanto, o grau de separabilidade dos padrões relativos às faltas na zona 1 e na zona 2 . $\mathrm{O}$ objetivo desta simplificação consiste em continuar aplicando a formulação do Discriminante de Fisher apresentada anteriormente, evitando a aplicação de uma técnica mais elaborada de seleção de parâmetros em problemas multiclasses. Posteriormente, na geração de padrões, deve ser verificada a habilidade de se prover separação dos dados relativos à Zona 3. Elegendo as faltas do tipo A-T para o estudo em questão, os índices FDR foram obtidos considerando a fase faltosa - a fase $\mathrm{A}$ - e uma das fases não faltosas - neste caso, escolhida arbitrariamente como sendo a fase B.

Na Figura 50 e na Figura 51, são apresentados os índices obtidos, respectivamente, para a fase faltosa e para a fase não-faltosa. No primeiro caso, observa-se que o FDR possui valores mais expressivos para os cumulantes de $2^{\mathrm{a}}$ e $4^{\mathrm{a}}$ ordens. Tem-se como destaque o valor de lag $\tau=67$ para as estatísticas de $2^{\text {a }}$ ordem e os valores de lag $\tau=\{9,81\}$ para as estatísticas de $4^{\mathrm{a}}$ ordem. Procedendo com a análise da fase não-faltosa, na Figura 51, percebe-se que os índices FDR mais expressivos ocorrem para os cumulantes de $2^{\mathrm{a}}$ e $3^{\mathrm{a}}$ ordem. Em especial, destaca-se o cumulante de $2^{\mathrm{a}}$ ordem com lag 57 e os cumulantes de $3^{\mathrm{a}}$ ordem com lags $\tau=\{10,67\}$.

Considerando os dados de faltas especificados na Tabela 5-3, os padrões gerados para o problema de localização de faltas do tipo F-T são apresentados na Figura 52. 
Como pode ser verificado nesta figura, utilizou-se para a fase A o cumulantes $C_{4}(0)$ e para as fases B e C utilizou-se, respectivamente, os cumulantes $C_{2}(128)$ e $C_{2}(0)$. Combinações referentes aos valores de pico dos gráficos da Figura 50 e da Figura 51 não se apresentaram de maneira otimizada para a solução do problema, quando comparadas com a combinação ora apresentada. Com efeito, como colocado anteriormente, os valores máximos de FDR não representam, obrigatoriamente, a melhor solução para o problema. Os padrões apresentados na Figura 52 são representativos das três classes do problema de localização - Zona 1, Zona 2 e Zona 3 e, como pode ser verificado, há de fato a possibilidade da separação dos padrões apresentados.

(a)

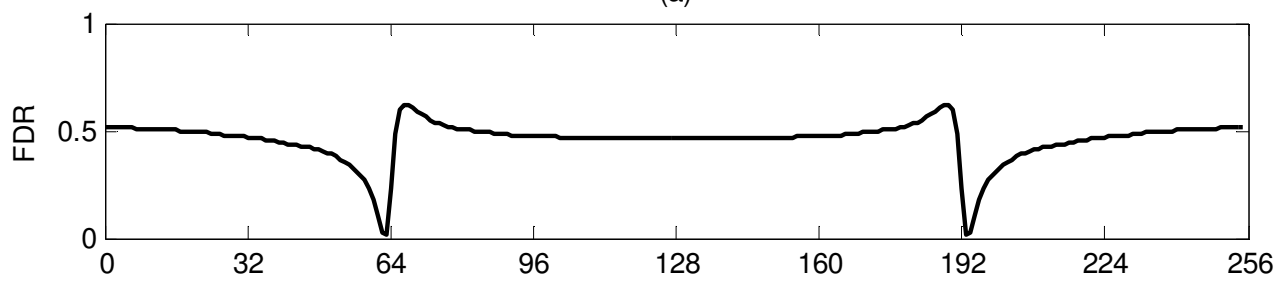

(b)

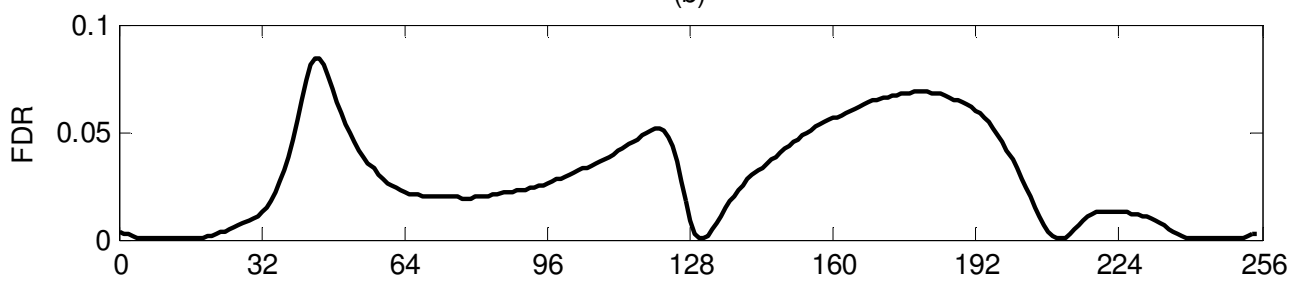

(c)

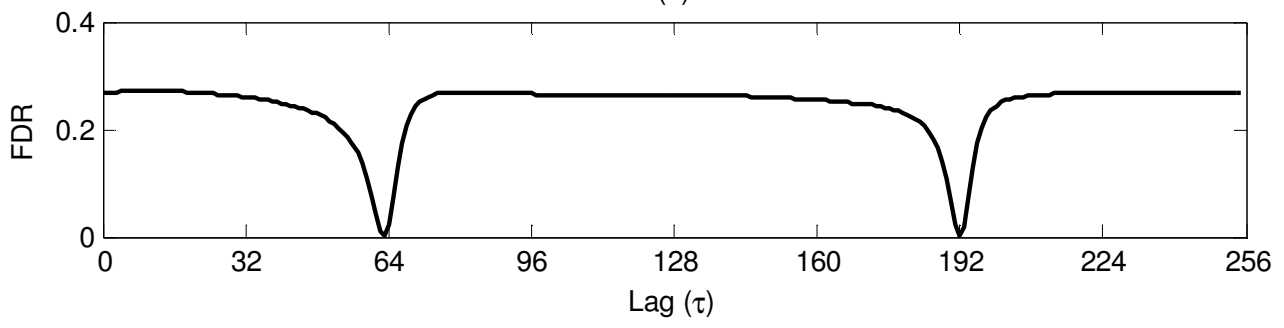

Figura 50. Fisher Discriminant Ratio para o problema de localização de faltas F-T (fase em falta):

(a) cumulantes de $2^{\mathrm{a}}$ ordem; (b) cumulantes de $3^{\mathrm{a}}$ ordem e; (c) cumulantes de $4^{\mathrm{a}}$ ordem. 
(a)

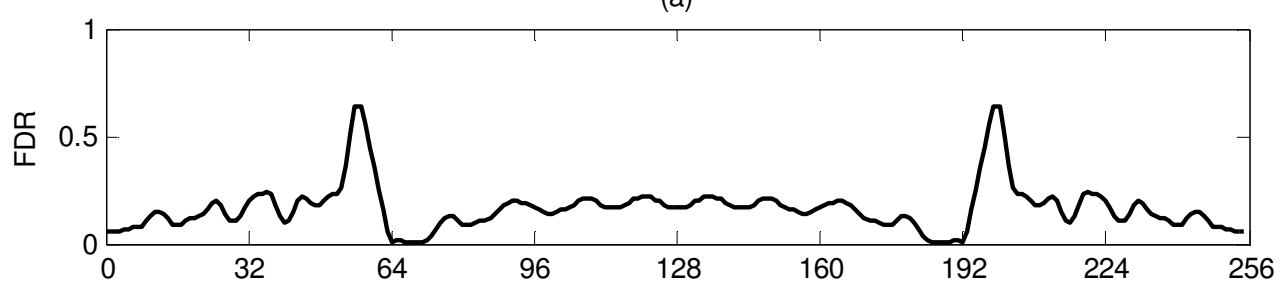

(b)

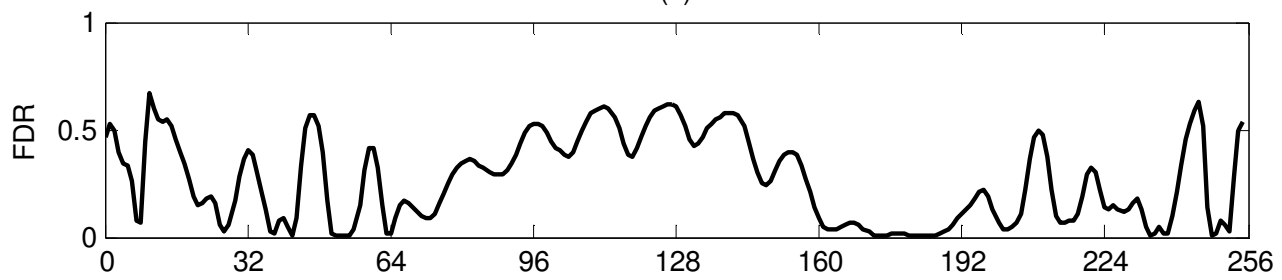

(c)

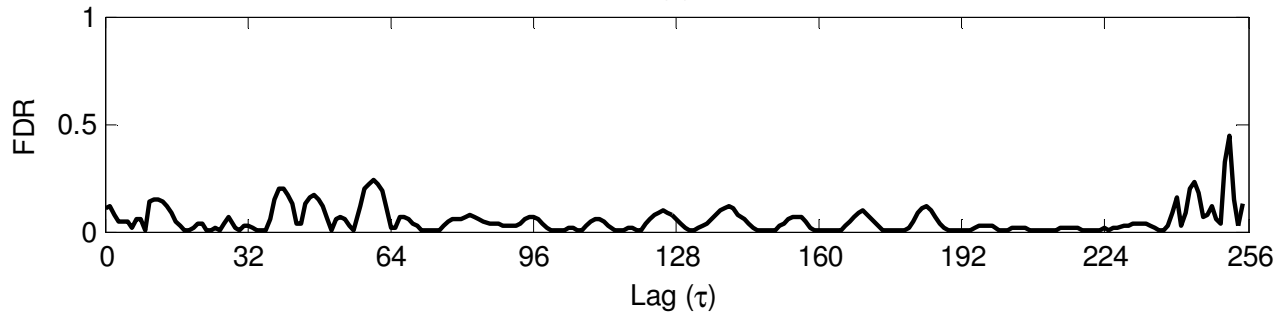

Figura 51. Fisher Discriminant Ratio para o problema de localização de faltas F-T (fase não faltosa): (a) cumulantes de $2^{\mathrm{a}}$ ordem; (b) cumulantes de $3^{\mathrm{a}}$ ordem e; (c) cumulantes de $4^{\mathrm{a}}$ ordem.

Tabela 5-3. Conjunto de parâmetros de falta utilizados para geração de padrões de treinamento e validação das redes neurais de localização.

\begin{tabular}{c|c|c|c}
\hline \hline TIPO DE FALTA & DISTÂNCIA $\boldsymbol{d}(\mathbf{k m})$ & INCIDÊNCIA $\left(^{{ }^{\circ}}\right)$ & RESISTÊNCIAS $(\boldsymbol{\Omega})$ \\
\hline \hline & Linha 2 (referência: barra E): & & \\
& $1,5,10,20,30,45,65,70,90,105$, & & $R_{t}=0 ; 25 ; 50$ \\
F-T, F-F-T, & $110,115,120,125,130,135,145$ & $0,30,60,90,120$, & $R_{t}=0 ; 4 ; 10$ \\
F-F, F-F-F & Linha 3 (referência: barra F): & 150,180 & \\
& $10,15,40,45,60,70,80,95$ & & \\
& & & \\
& & & \\
\hline \hline
\end{tabular}




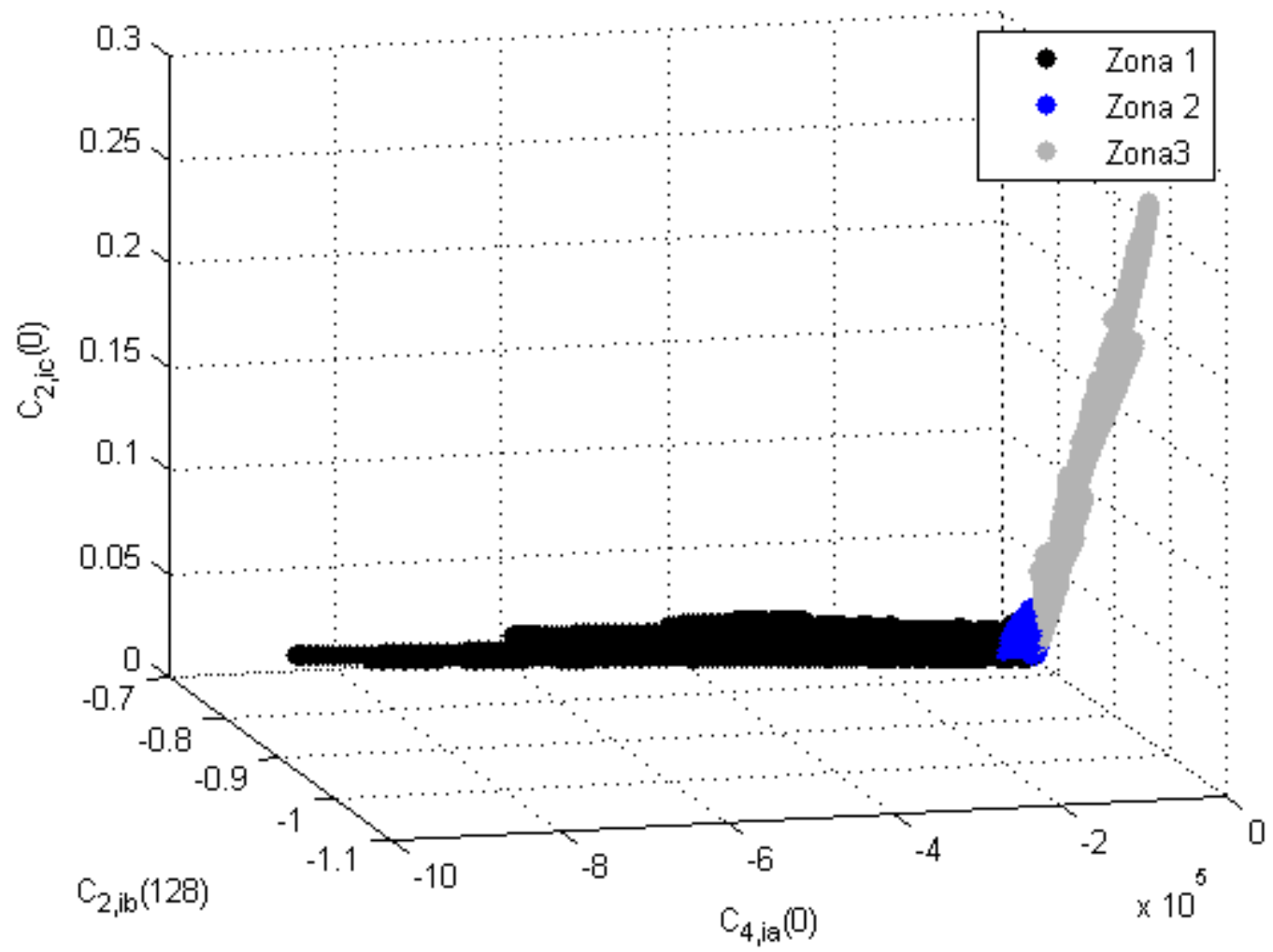

Figura 52. Padrões gerados para o problema de localização de faltas do tipo fase-terra.

Uma rede neural de duas camadas, representada na Figura 53, com $N_{1}=40$ neurônios na camada escondida e $N_{2}=3$ neurônios na camada de saída, foi utilizada para a separação das classes apresentadas na Figura 52. Foi considerada a presença de ruído aditivo gaussiano para geração dos padrões, com $\mathrm{SNR}=40 \mathrm{~dB}$, e também uma redução na taxa de amostragem para redução do esforço computacional no treinamento da rede. Este foi executado admitindo-se um valor limite de 5000 épocas e visando um EQM mínimo de $1,0 \times 10^{-6}$. O algoritmo foi executado durante as 5000 épocas, sem que fosse constatada convergência, seja pelo critério do EQM ou do gradiente. O erro quadrático médio final obtido foi $1,0407 \times 10^{-3}$ e sua evolução em função da época de treinamento pode ser visualizada na Figura 54(a). Também nesta figura, em (b), (c) e (d) são exibidas as saídas $y_{1}, y_{2}$ e $y_{3}$, respectivamente, para o processo de validação da rede, 
com a comparação das respostas da rede com as curvas de valores desejados. A taxa de acerto obtida foi de 99,97 \%, sendo avaliados 3494 padrões neste processo de validação.

Um resultado particular de simulação de falta e identificação da zona de proteção é apresentado na Figura 55. Trata-se de uma falta do tipo A-T na zona primária de proteção, com distância de $110 \mathrm{~km}$ do barramento E, resistência de falta $R_{t}=10 \Omega$ e ângulo de incidência de falta $\phi=30^{\circ}$. A incidência é imposta na amostra 256 . Os sinais de corrente são contaminados com ruído branco Gaussiano, com SNR=40 dB. Nesta figura, estes sinais de corrente são apresentados em (a) e são seguidos pelos sinais de erro provenientes do filtro notch, em (b). Os cumulantes calculados $-C_{4}(0)$ para a fase $\mathrm{A}, C_{2}(128)$ para a fase $\mathrm{B}$ e $C_{2}(0)$ para a fase $\mathrm{C}$ - são mostrados em (c). Por fim, em (d) são apresentadas as saídas da rede de localização. Como pode ser verificado, a saída $y_{1}$, indicando ocorrência de falta na Zona 1, é ativada após transcorrido tempo equivalente a 3/4 do período fundamental, período no qual estão sendo executadas as etapas de detecção e classificação, nesta ordem.

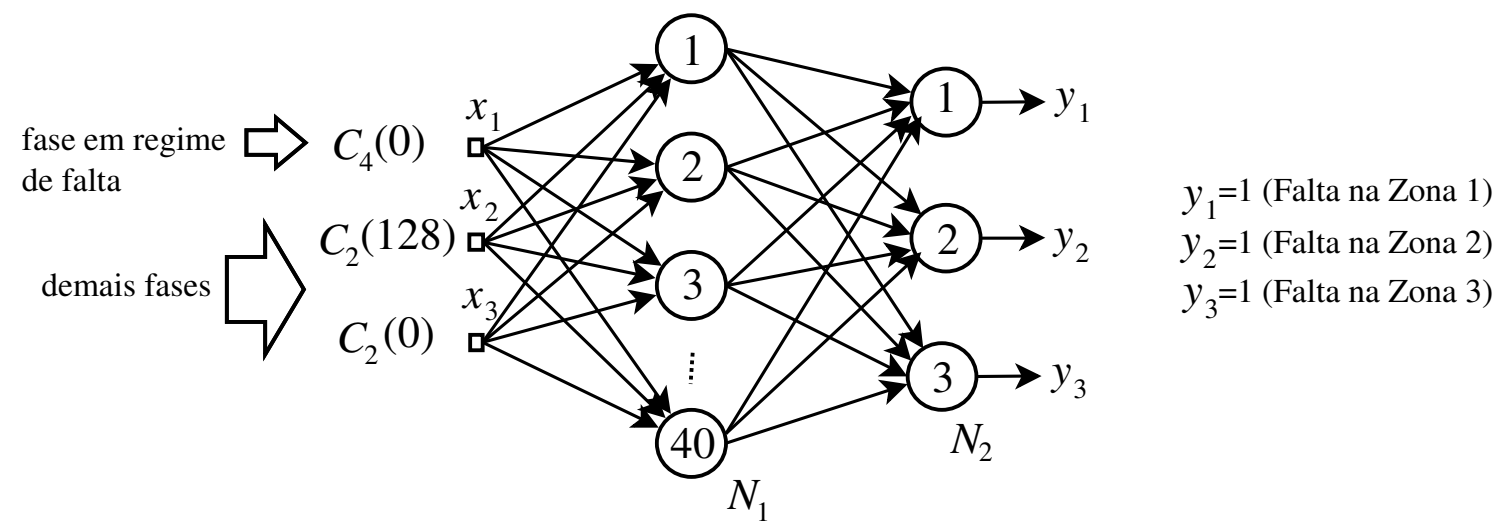

Figura 53. Representação da rede neural utilizada no problema de localização de faltas F-T. 


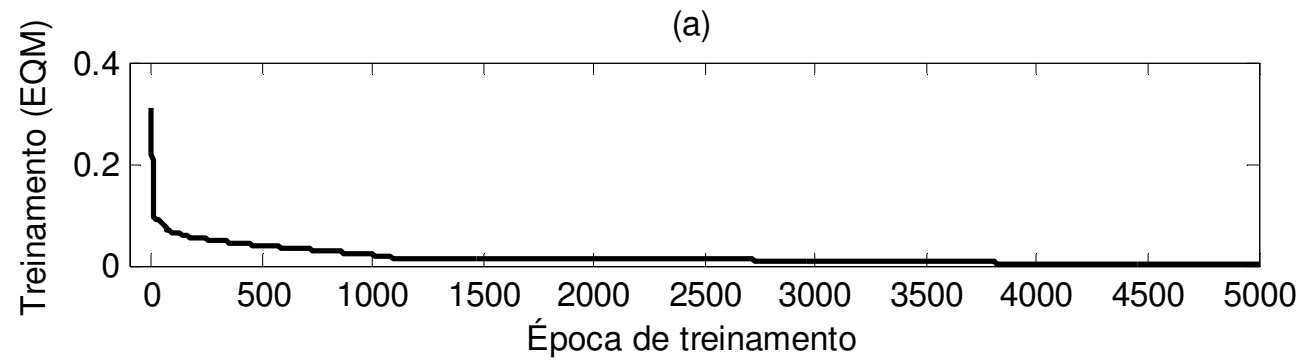

(b)

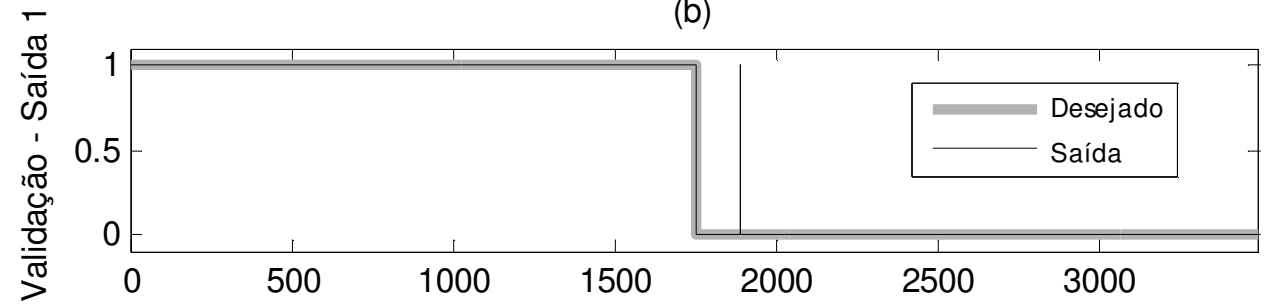

(c)

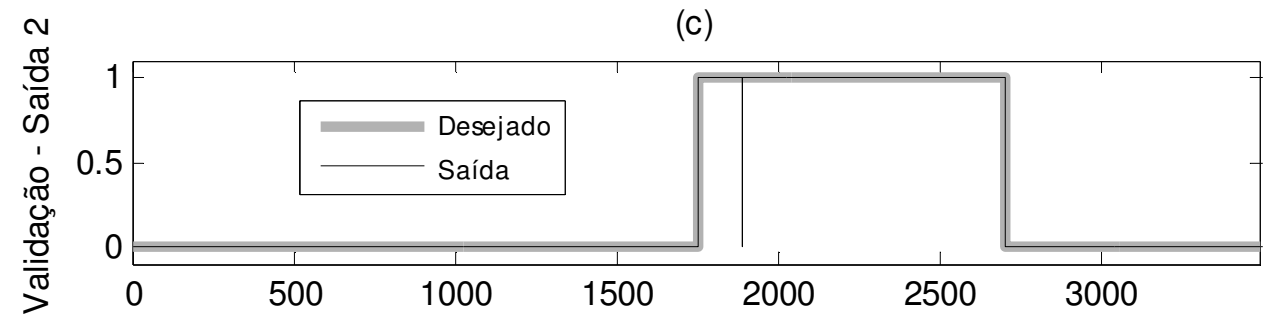

(d)

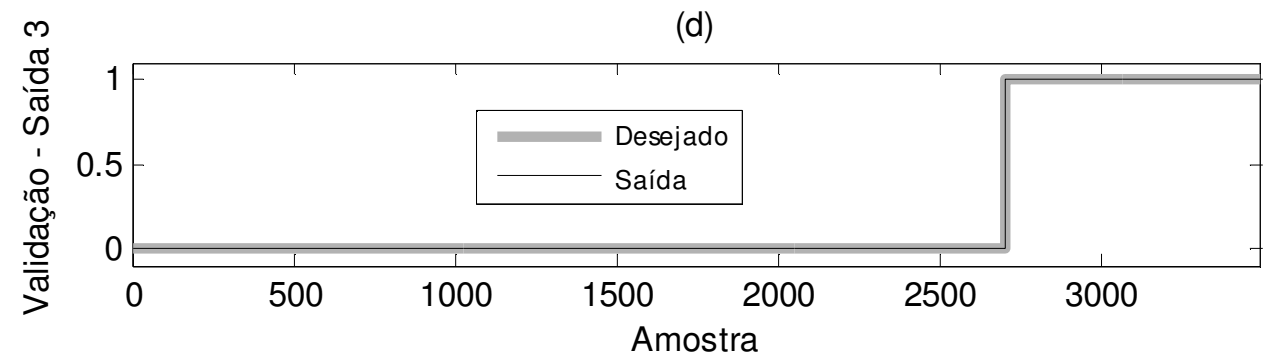

Figura 54. Resultados obtidos para a RNA de localização (faltas do tipo F-T): (a) evolução do EQM no treinamento e; validação da rede: (b) saída $y_{1 ;}$ (c) saída $y_{2 ;}$ e (d) saída $y_{3}$. 
(a)

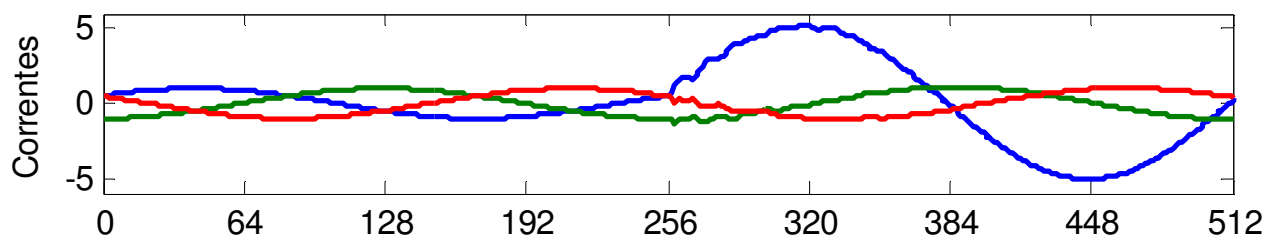

(b)

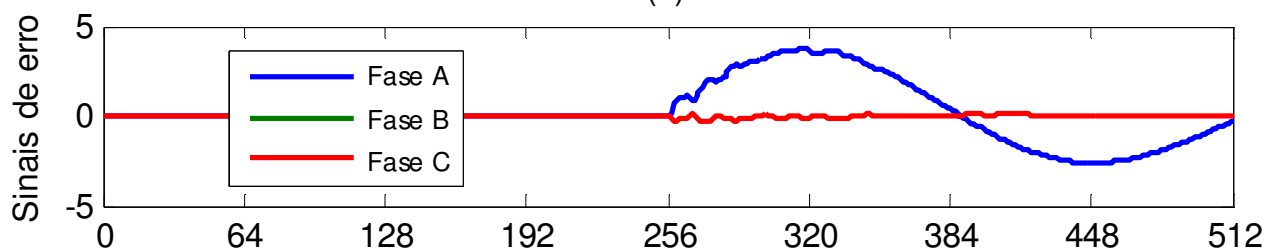

(c)

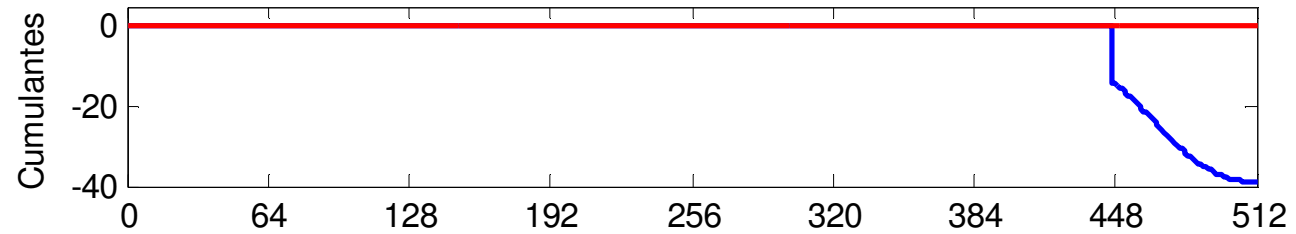

(d)

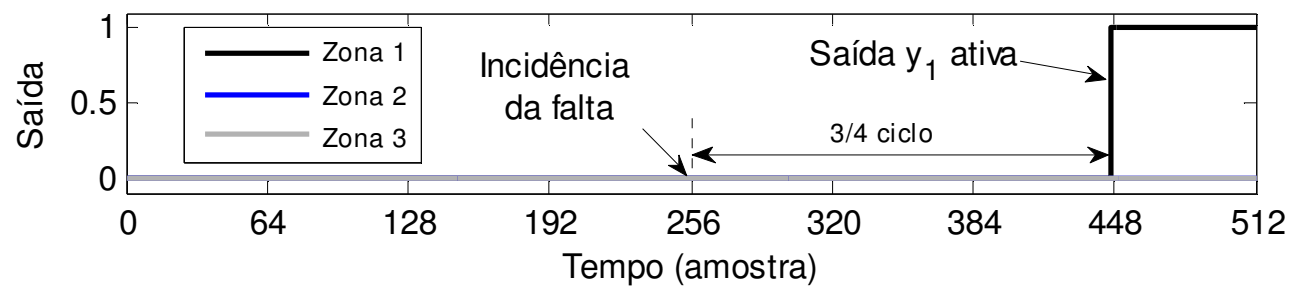

Figura 55. Simulação de falta A-T a $110 \mathrm{~km}$ do relé, $\operatorname{com} R_{t}=10 \Omega$ e $\phi=30^{\circ}$. Sinais: (a) correntes; (b) saídas do filtro notch; (c) cumulantes e; (d) saídas da rede de localização para faltas F-T.

Como anteriormente, na análise de resultados das etapas detecção e classificação, foram consideradas faltas nas linhas LT2 e LT3 com configurações distintas daquelas utilizadas na etapa de treinamento e validação das redes. Os três casos distintos para uma avaliação mais ampla da etapa de localização possuem os seguintes parâmetros ${ }^{4}$ :

- Caso 1: $\quad$ Linha LT2 com $d=25 \mathrm{~km}, R_{t}=75 \Omega$ e $\phi=30^{\circ}$

- Caso 2: $\quad$ Linha LT2 $\operatorname{com} d=140 \mathrm{~km}, R_{t}=1 \Omega$ e $\phi=90^{\circ}$

- Caso 3: $\quad$ Linha LT3 com $d=200 \mathrm{~km}, R_{t}=10 \Omega$ e $\phi=120^{\circ}$

\footnotetext{
${ }^{4}$ As distâncias possuem como referência o barramento E, tanto para as faltas na linha LT2 quanto na linha LT3.
} 
Em se tratando da análise de faltas do tipo fase-terra, são consideradas as faltas AT, B-T e C-T. Um único módulo de localização é utilizado para qualquer uma das faltas, sendo realizado apenas o adequado chaveamento nas entradas do mesmo. Os resultados dos casos de teste 1, 2 e 3 são apresentados, respectivamente, na Figura 56, na Figura 57 e na Figura 58. Novamente, verifica-se a exibição das respostas temporais de forma emparelhada, com o curto ocorrendo na amostra 256. Observa-se na Figura 56 que, para os tipos de falta testados, a saída $y_{1}$ é ativada indicando a incidência da falta na zona primária, como esperado. Para os casos 2 e 3, tem-se também a correta indicação da zona de ocorrência do defeito, com a ativação das saídas $y_{2}$ e $y_{3}$ do módulo de localização, respectivamente. Nestas três figuras, pode-se observar que a ativação das saídas do módulo de localização ocorre depois de transcorrido intervalo de tempo equivalente a $3 / 4$ do ciclo fundamental, período no qual estão sendo executadas as etapas de detecção e localização.

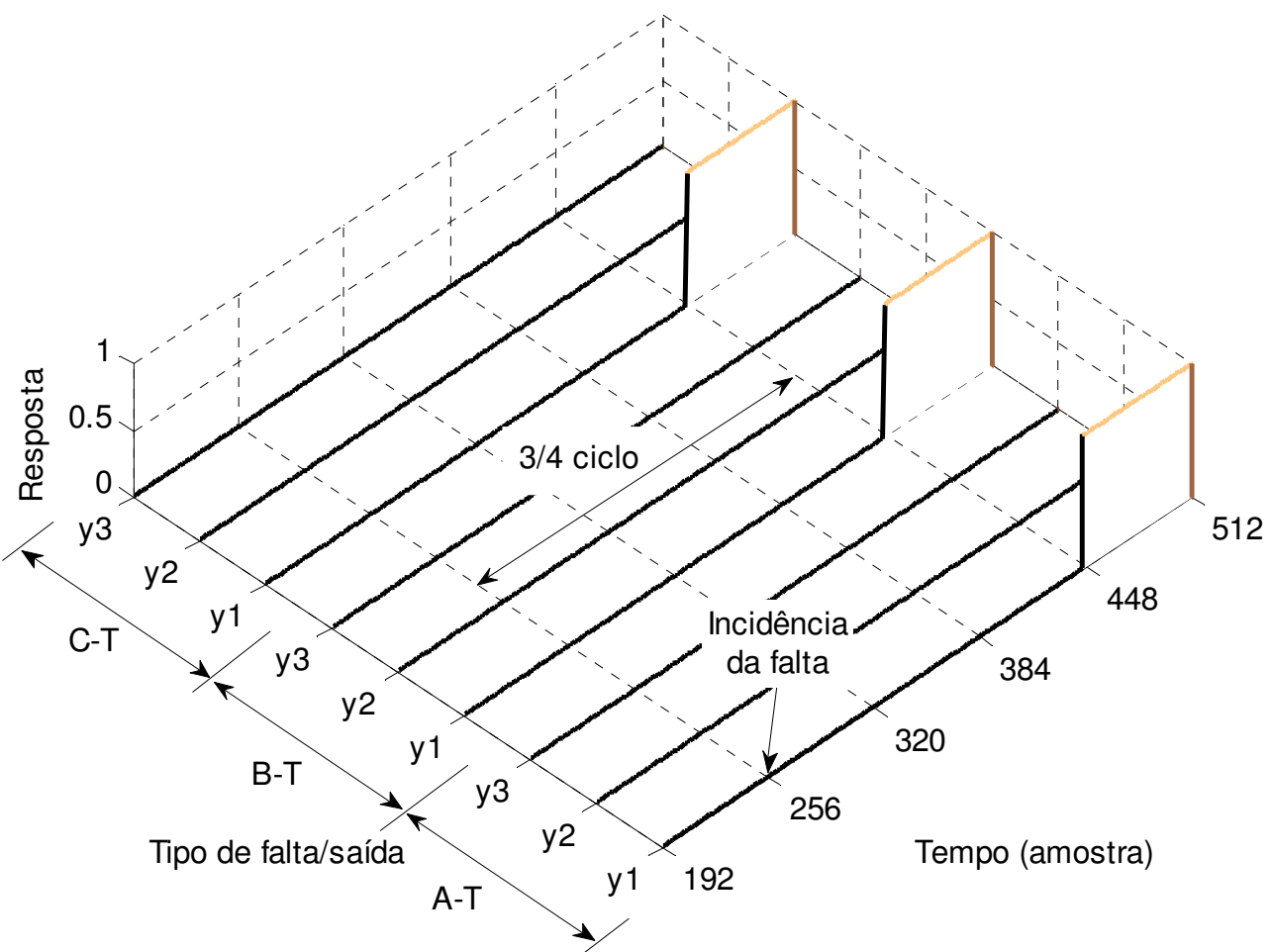

Figura 56. Resultados de localização para simulações de faltas fase-terra na linha LT2 $\operatorname{com} d=25$ $\mathrm{km}, R_{t}=75 \Omega$ e $\phi=30^{\circ}$ 


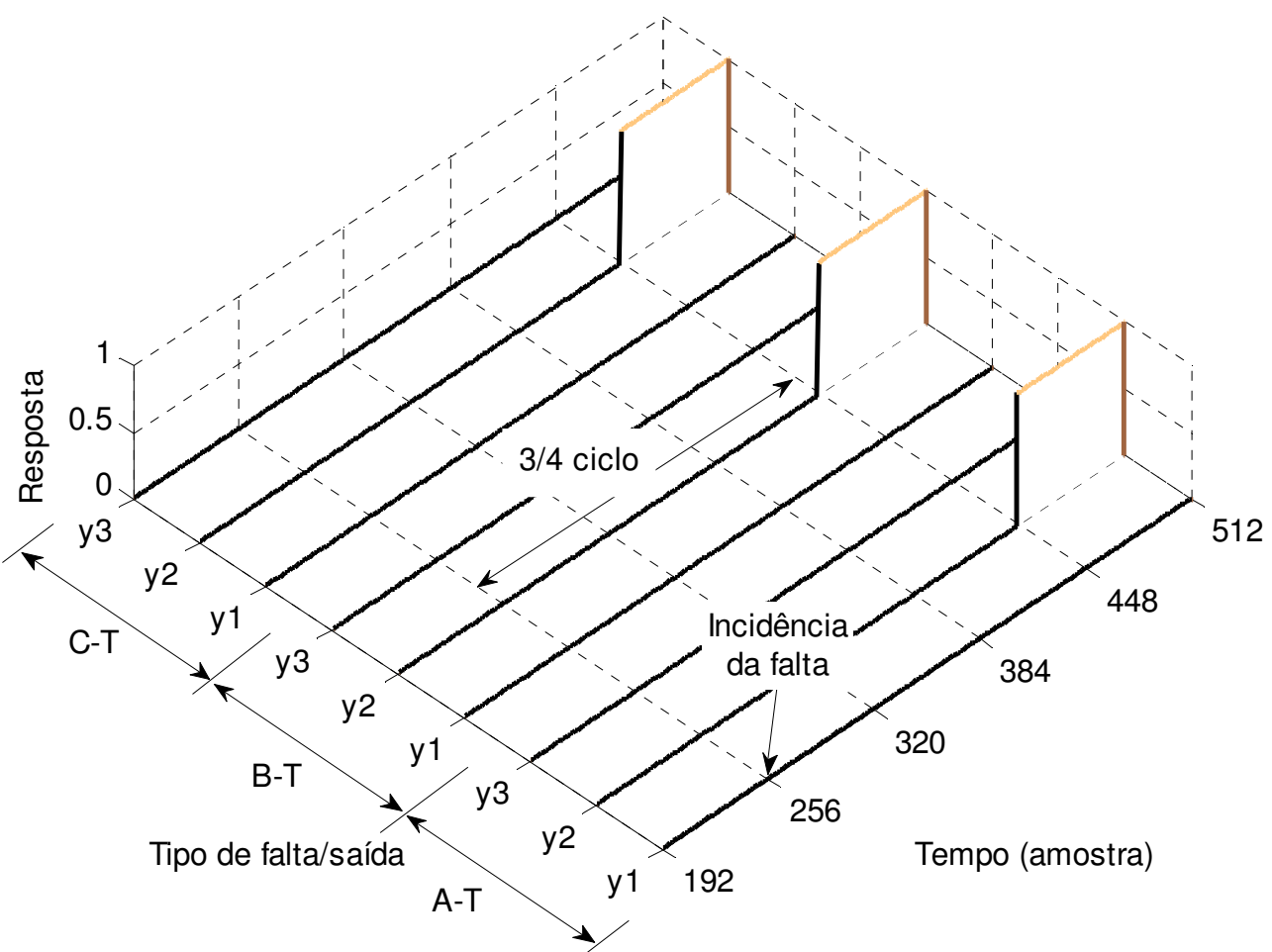

Figura 57. Resultados de localização para simulações de faltas fase-terra na linha LT2 $\operatorname{com} d=140$ $\mathrm{km}, R_{t}=1 \Omega$ e $\phi=90^{\circ}$

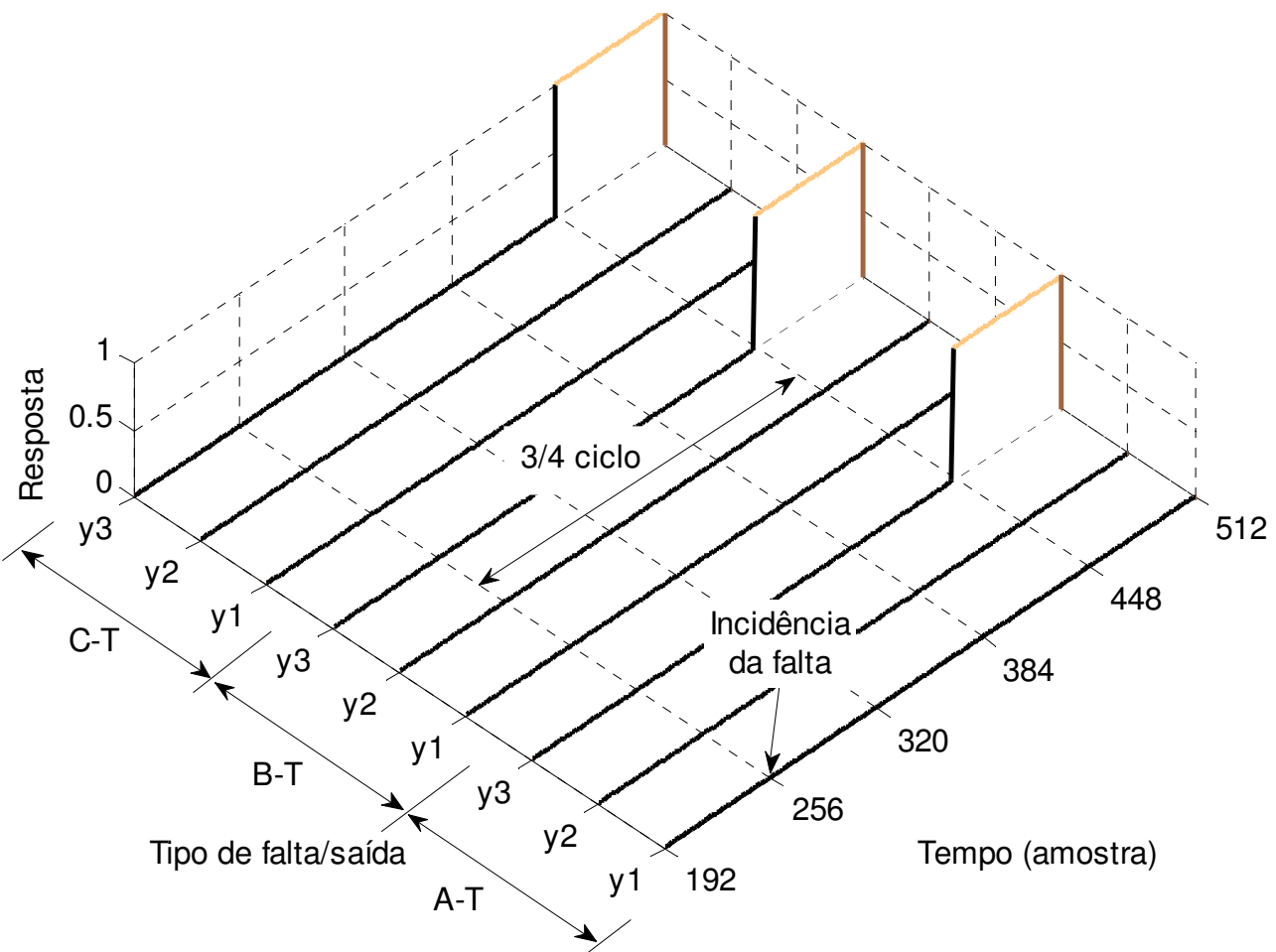

Figura 58. Resultados de localização para simulações de faltas fase-terra na linha LT3 com $d=200$ $\mathrm{km}, R_{t}=10 \Omega$ e $\phi=120^{\circ}$ 


\subsubsection{Faltas envolvendo duas fases e a terra (F-F-T)}

Com procedimento idêntico ao do descrito na Seção 5.3.1, é realizado levantamento do Discriminante de Fisher para faltas do tipo F-F-T. As faltas envolvendo as fases A e B e a terra foram consideradas para os estudos desta seção. Desta forma, os índices FDR foram obtidos considerando uma das fases faltosas - neste caso, escolhida arbitrariamente como sendo fase A - e a fase não faltosa - fase C.

Os índices FDR são apresentados na Figura 59 e na Figura 60, respectivamente, para a fase faltosa e para a fase não-faltosa. Para o primeiro caso, observa-se na Figura 59 que estes índices possuem valores mais expressivos para os cumulantes de $2^{\mathrm{a}}$ e $4^{\mathrm{a}}$ ordens. Podem ser destacadas as estatísticas de $2^{\mathrm{a}}$ ordem com lag $\tau=\{21,67\}$ e as estatísticas de $4^{\mathrm{a}}$ ordem com lag $\tau=\{14,86\}$. Continuando a análise, agora com respeito à fase não faltosa, percebe-se índices FDR expressivos para cumulantes de $2^{\mathrm{a}}, 3^{\mathrm{a}}$ e $4^{\mathrm{a}}$ ordens. Em especial, destacam-se o cumulante de $2^{\mathrm{a}}$ ordem com lag $\tau=54$, o cumulante de $3^{\mathrm{a}}$ ordem com lag $\tau=34$ e o cumulante de $4^{\mathrm{a}}$ ordem com lag $\tau=186$.

Considerando os dados de faltas especificados anteriormente na Tabela 5-3, são gerados padrões para solução do problema de localização de faltas do tipo F-F-T. Inicialmente, considerou-se um cumulante por fase, estratégia esta que não resultou em uma solução viável para a correta distinção das zonas de faltas. Desta forma, acompanhando intuitivamente o resultado obtido para faltas monofásicas, optou-se por considerar apenas uma das fases em situação de falta. Neste caso, foi considerado o sinal de corrente da fase A e descartado o sinal de corrente da fase B. A fase C foi considerada, portanto, para o cálculo de duas estatísticas. O resultado da geração de padrões encontra-se na Figura 61. Foi considerada presença de ruído aditivo gaussiano para geração dos padrões, com $\mathrm{SNR}=40 \mathrm{~dB}$, e também a diminuição da taxa de amostragem para redução do esforço computacional no processo de treinamento. 
(a)

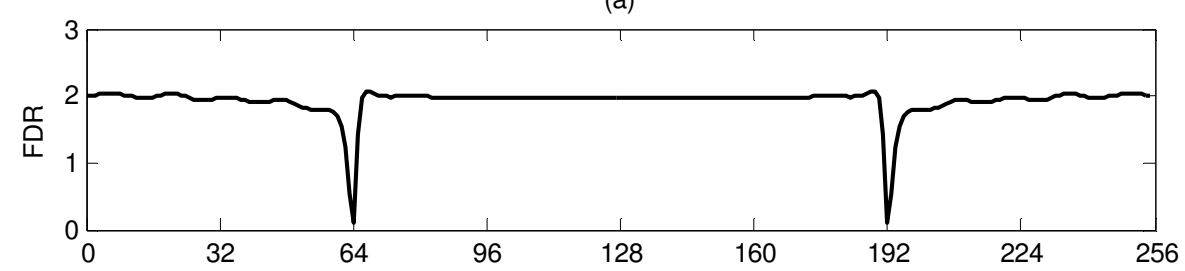

(b)

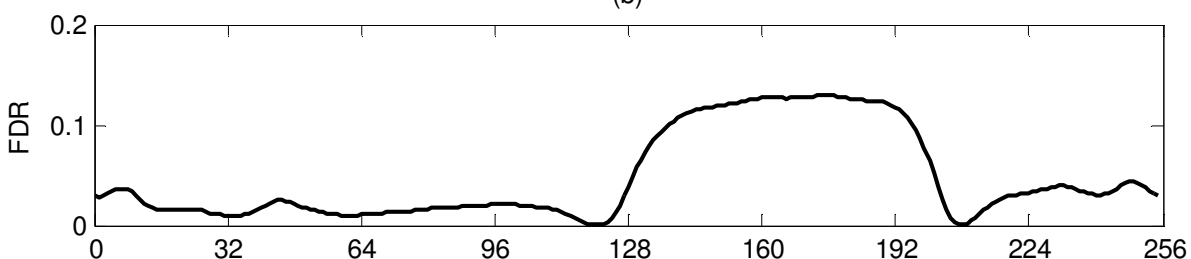

(c)

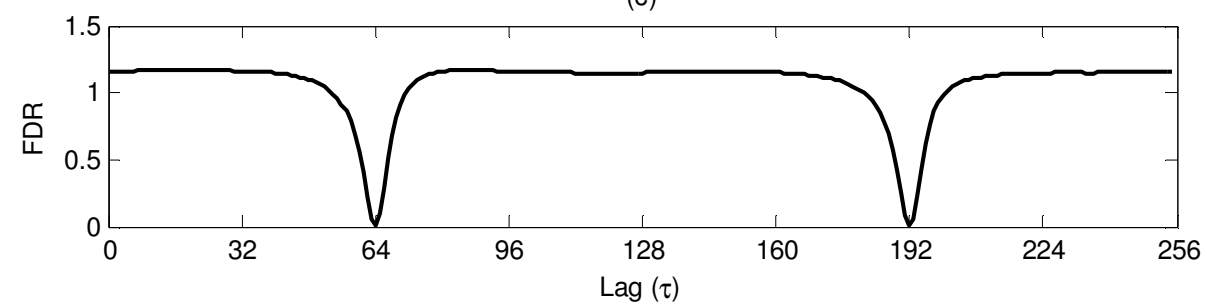

Figura 59. Fisher Discriminant Ratio para o problema de localização de faltas F-F-T (fase em falta):

(a) cumulantes de $2^{\mathrm{a}}$ ordem; (b) cumulantes de $3^{\mathrm{a}}$ ordem e; (c) cumulantes de $4^{\mathrm{a}}$ ordem.

(a)

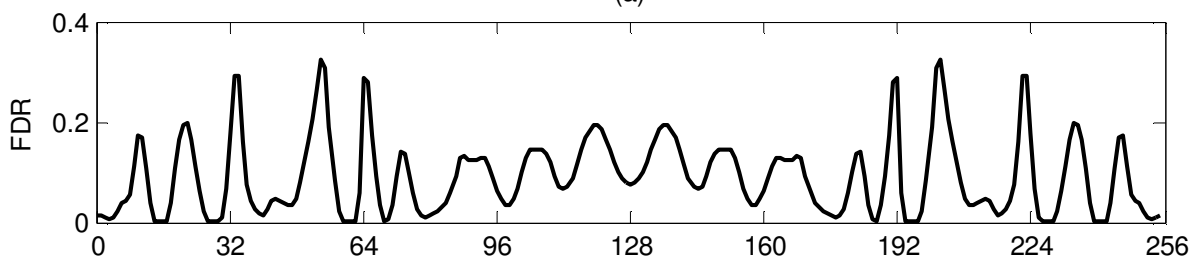

(b)

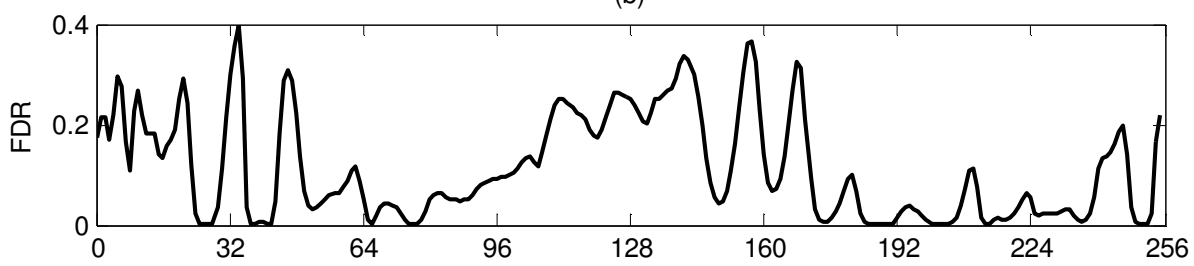

(c)

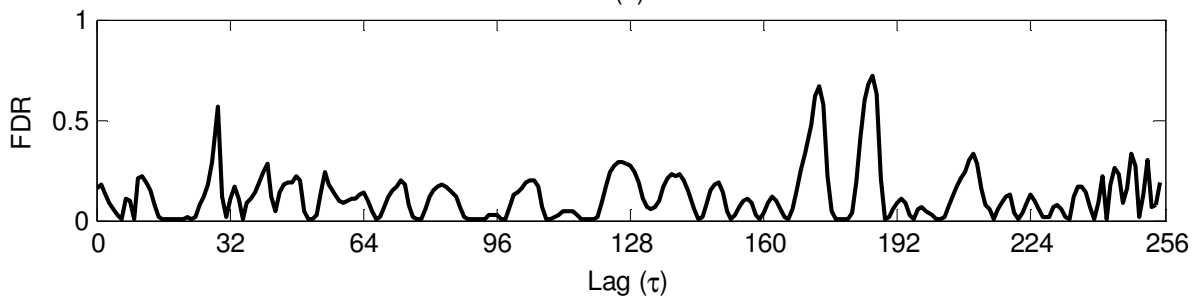

Figura 60. Fisher Discriminant Ratio para o problema de localização de faltas F-F-T (fase não faltosa): (a) cumulantes de $2^{\mathrm{a}}$ ordem; (b) cumulantes de $3^{\mathrm{a}}$ ordem e; (c) cumulantes de $4^{\mathrm{a}}$ ordem. 


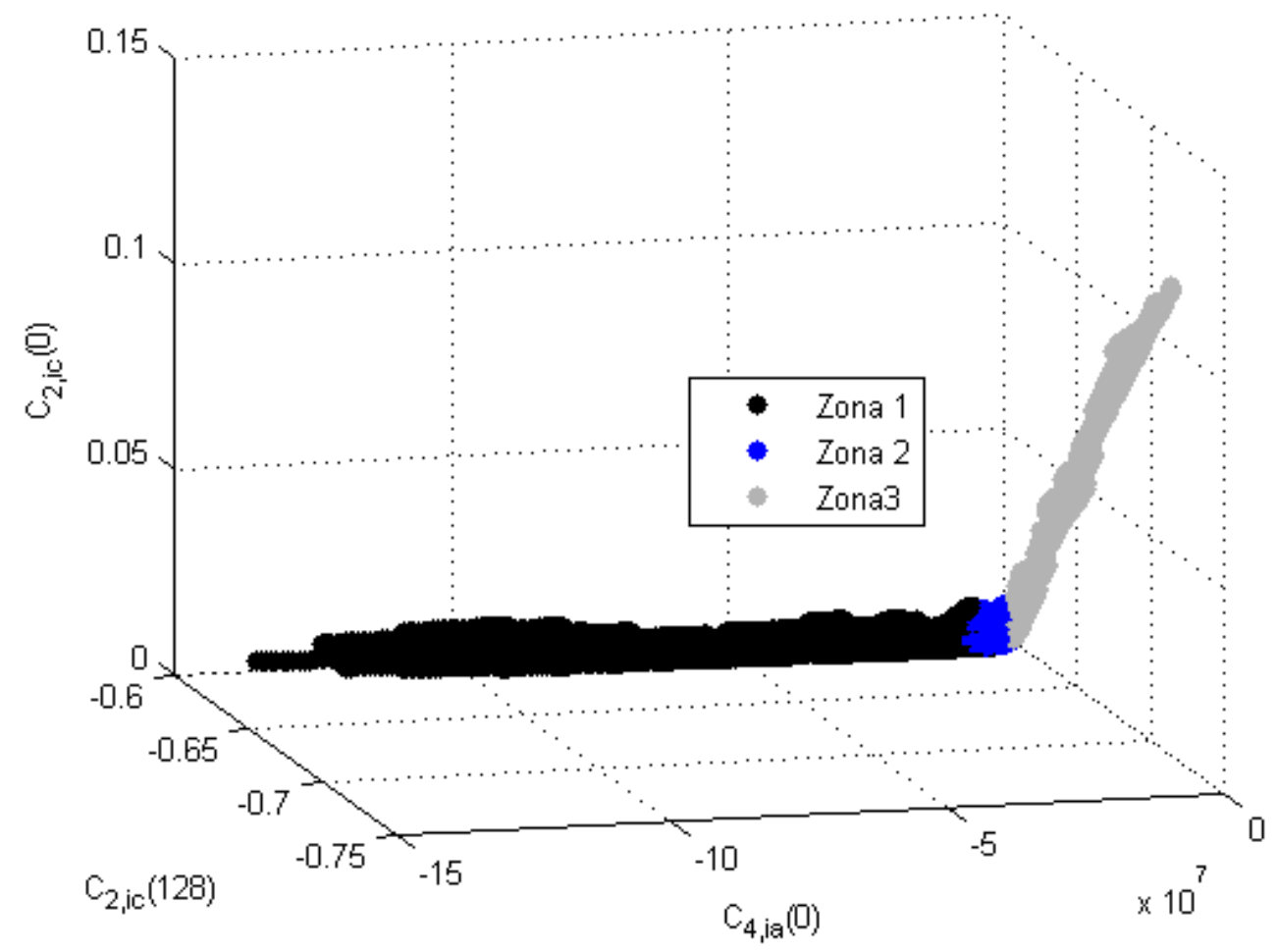

Figura 61. Padrões gerados para solução do problema de localização de faltas do tipo fase-faseterra.

Percebe-se na Figura 61 que, para a fase, A tem-se determinado o cumulante $C_{4}(0)$ e para a fase $C$ têm-se os cumulantes $C_{2}(128)$ e $C_{2}(0)$. Apesar de não corresponderem aos valores máximos dos índices FDR, os cumulantes utilizados forneceram uma combinação interessante no sentido de se distinguir entre as três classes representativas do problema: Zona 1, Zona 2 e Zona 3.

Uma rede neural de duas camadas, com $N_{1}=40$ neurônios na camada escondida e $N_{2}=3$ neurônios na camada de saída, tal como a utilizada no caso de faltas do tipo F-T (Figura 53), foi utilizada para a separação das classes apresentadas na Figura 61. O treinamento desta RNA foi executado admitindo-se o máximo de 5000 épocas e visando um EQM mínimo de $1,0 \times 10^{-6}$, como nos casos anteriores. O algoritmo de treinamento foi executado pelas 5000 épocas sem que fosse verificada a convergência pelo critério do EQM e pelo critério do gradiente. A evolução do EQM durante o treinamento pode 
ser visualizado na Figura 62(a). O valor final obtido para este parâmetro foi $5,5793 \times 10^{-3}$. O resultado de validação da rede também é exibido na Figura 62, com as saídas $y_{1}, y_{2}$ e $y_{3}$, apresentadas em (b), (c) e (d), respectivamente. A taxa de acerto da etapa de validação foi de $98,74 \%$, com um total de 3494 padrões disponíveis neste processo.

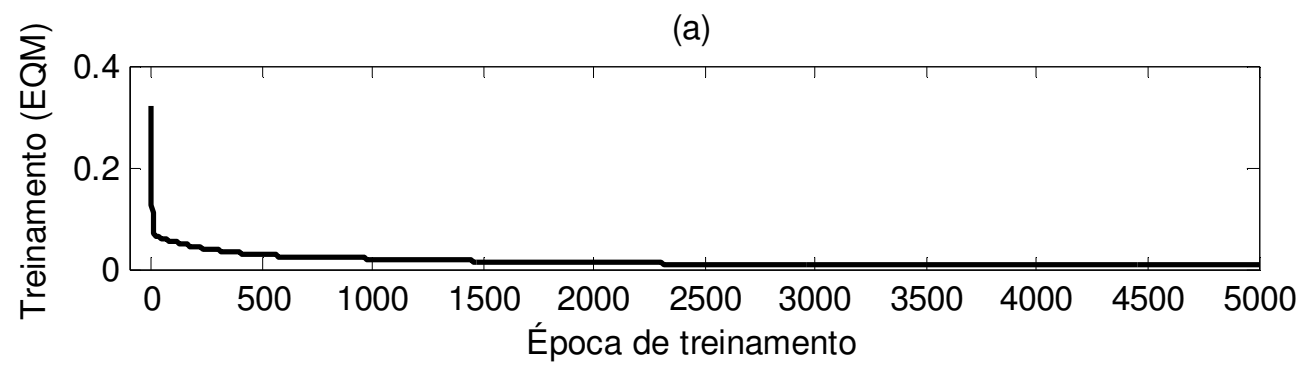

(b)

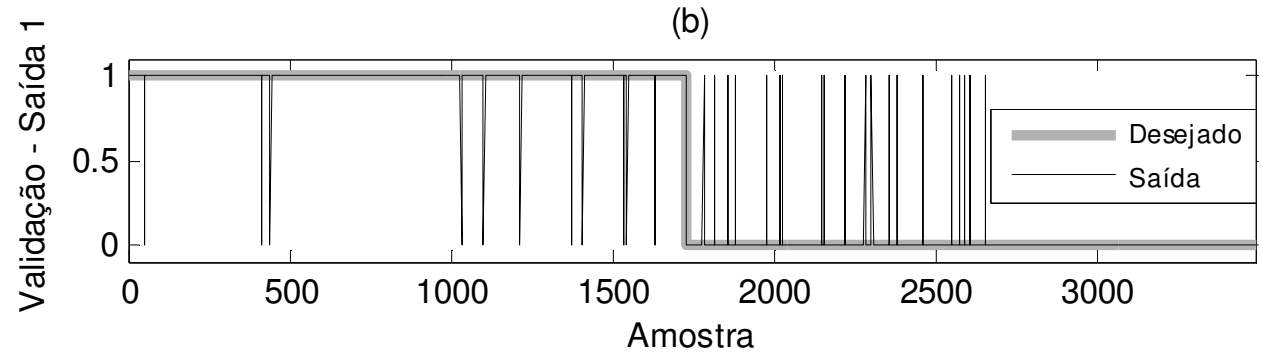

(c)

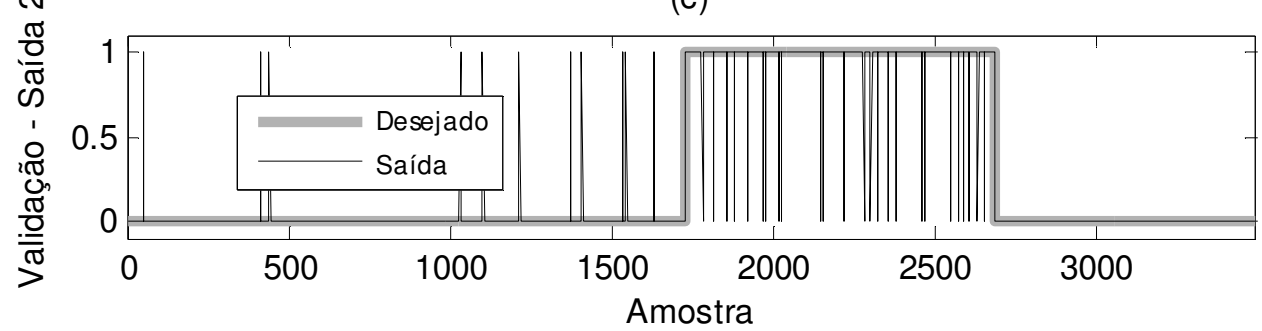

(d)

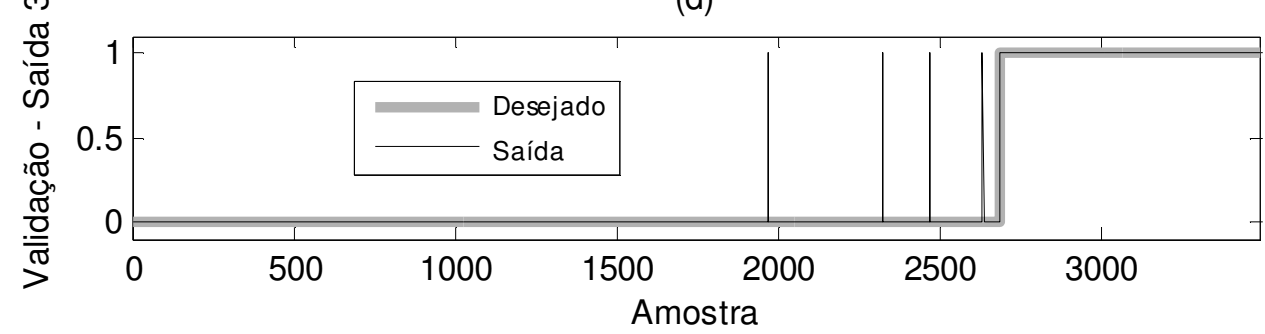

Figura 62. Resultados obtidos para a RNA de localização (faltas do tipo F-F-T): (a) evolução do EQM no treinamento e; validação da rede: (b) saída $y_{1 ;}$ (c) saída $y_{2 ;}$ e (d) saída $y_{3}$. 
Considerando a operação do sistema para este tipo de falta, um resultado particular é apresentado na Figura 63, para uma falta A-B-T. Os parâmetros da falta são distância de 140 km em relação ao barramento E, que corresponde a uma falta na Zona 2 , resistência de falta $R_{t}=10 \Omega$ e ângulo de incidência de falta $\phi=90^{\circ}$. Considera-se contaminação dos sinais de corrente por ruído branco Gaussiano com $\mathrm{SNR}=40 \mathrm{~dB}$. Na Figura 63(a), são apresentados os sinais de corrente, onde é possível observar a incidência da falta sendo imposta na amostra 256. Os sinais de saída do filtro notch são apresentados em (b). Em seguida, em (c), são apresentados os cumulantes $-C_{4}(0)$ para a fase A, $C_{2}(128)$ e $C_{2}(0)$ para a fase C. Finalmente, a saída do identificador de zona de proteção é mostrada em (d). Como pode ser observado, a saída $y_{2}$, indicando ocorrência de falta na Zona 2, é ativada após transcorrido intervalo de tempo equivalente a 3/4 do ciclo fundamental

Os últimos resultados apresentados nesta Seção também visam fornecer uma avaliação mais ampla do método proposto para faltas envolvendo duas fases e a terra. Como anteriormente, serão consideradas faltas nas linhas LT2 e na LT3 com configurações distintas daquelas utilizadas na etapa de treinamento e validação das redes. Os três casos distintos possuem os seguintes parâmetros ${ }^{5}$ :

- Caso 1: $\quad$ Linha LT2 $\operatorname{com} d=15 \mathrm{~km}, R_{t}=100 \Omega$ e $\phi=90^{\circ}$

- Caso 2: $\quad$ Linha LT2 $\operatorname{com} d=130 \mathrm{~km}, R_{t}=10 \Omega$ e $\phi=150^{\circ}$

- Caso 3: $\quad$ Linha LT3 $\operatorname{com} d=215 \mathrm{~km}, R_{t}=1 \Omega$ e $\phi=0^{\circ}$

Nesta análise de faltas do tipo fase-fase-terra, são consideradas as faltas A-B-T, B-C-T e C-A-T. O mesmo módulo de localização é utilizado para qualquer uma das

\footnotetext{
${ }^{5}$ As distâncias possuem como referência o barramento E, tanto para as faltas na linha LT2 quanto na linha LT3.
} 
faltas, sendo realizado apenas o adequado chaveamento nas entradas deste módulo. Os resultados dos casos de teste 1, 2 e 3 são apresentados, respectivamente, na Figura 64, na Figura 65 e na Figura 66. A exibição das respostas temporais de forma emparelhada, com o curto ocorrendo na amostra 256, permite a avaliação das três saídas do módulo de detecção. Na Figura 64, pode-se observar que a saída $y_{1}$ está ativa, indicando corretamente a incidência da falta na zona primária, independentemente do tipo de falta ocorrido. A etapa de localização é também realizada com sucesso para os casos 2 e 3 , com a ativação das saídas $y_{2}$ e $y_{3}$, respectivamente. No caso 2, especificamente, apesar de uma ativação momentânea da saída $y_{1}$, há de se observar que a saída $y_{2}$ permanece ativa por um intervalo de tempo maior, permitindo a obtenção do resultado correto.

(a)

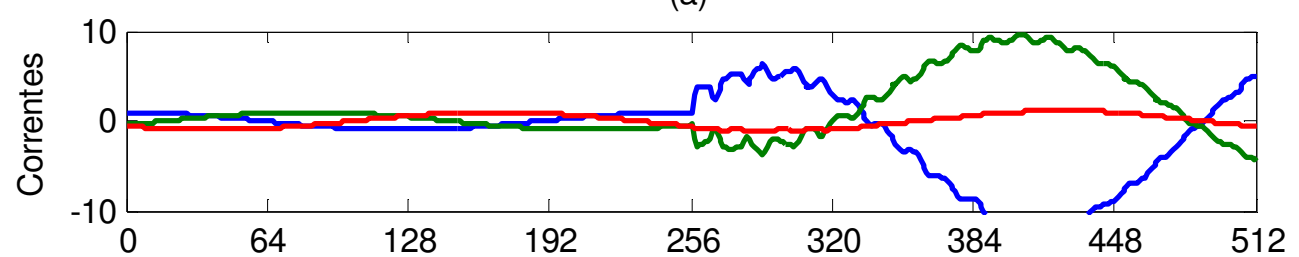

(b)

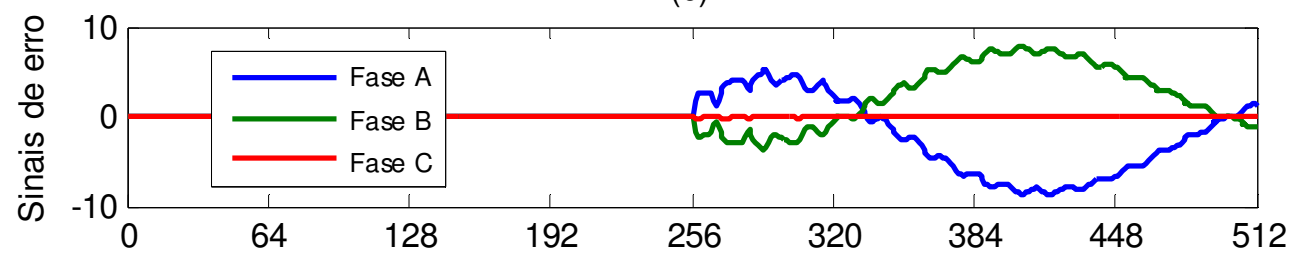

(c)

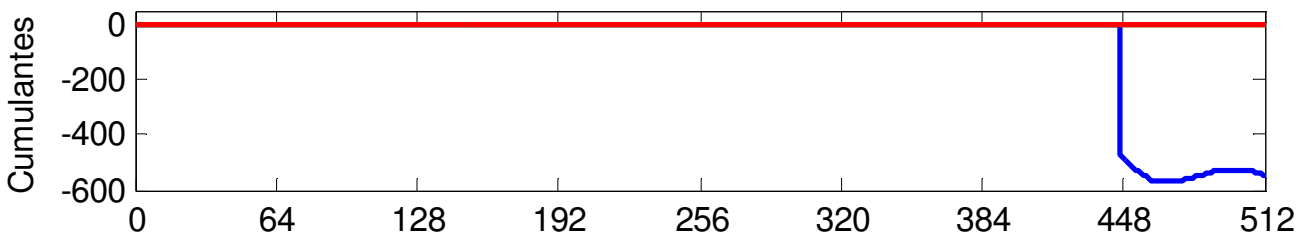

(d)

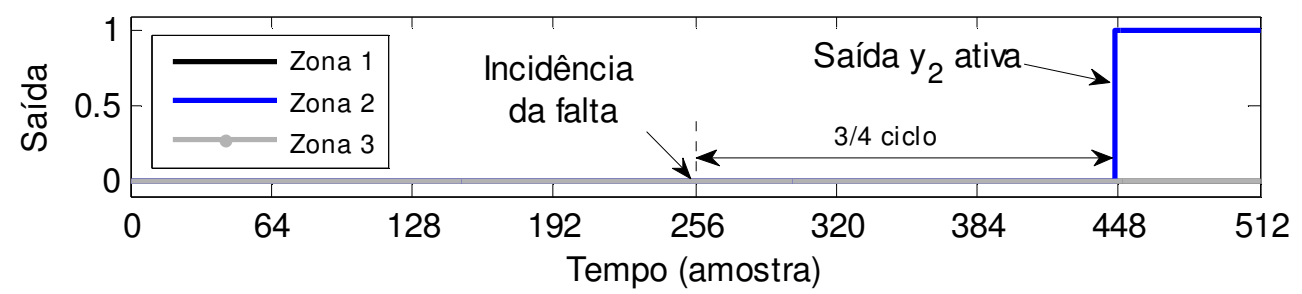

Figura 63. Simulação de falta A-B-T a $140 \mathrm{~km}$ do relé, $\operatorname{com} R_{t}=10 \Omega$ e $\phi=90^{\circ}$. Sinais: (a) correntes; (b) saídas do filtro notch; (c) cumulantes e; (d) saídas da rede de localização para faltas F-F-T. 


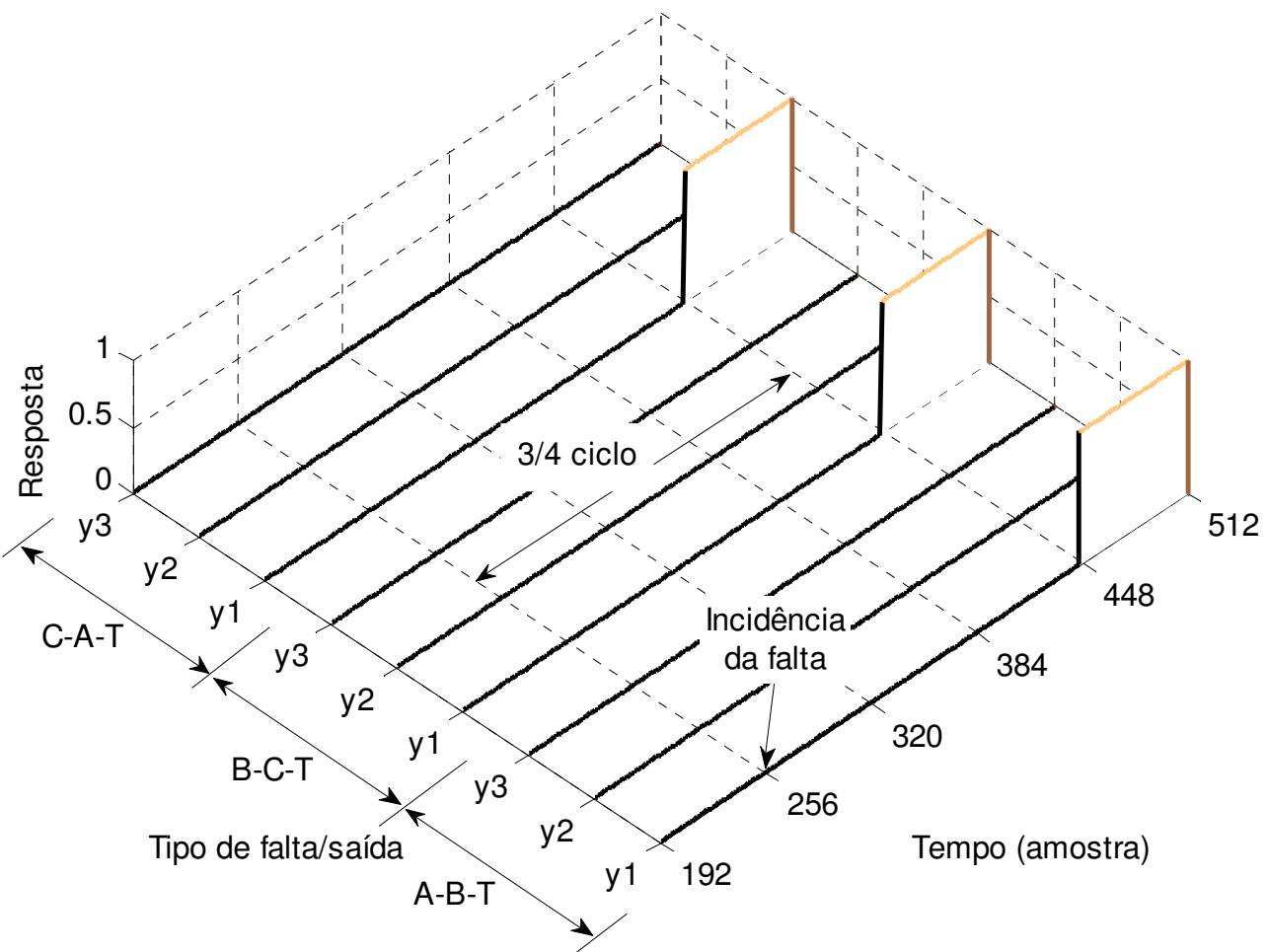

Figura 64. Resultados de localização para simulações de faltas fase-fase-terra na linha LT2 com $d=15 \mathrm{~km}, R_{t}=100 \Omega$ e $\phi=90^{\circ}$

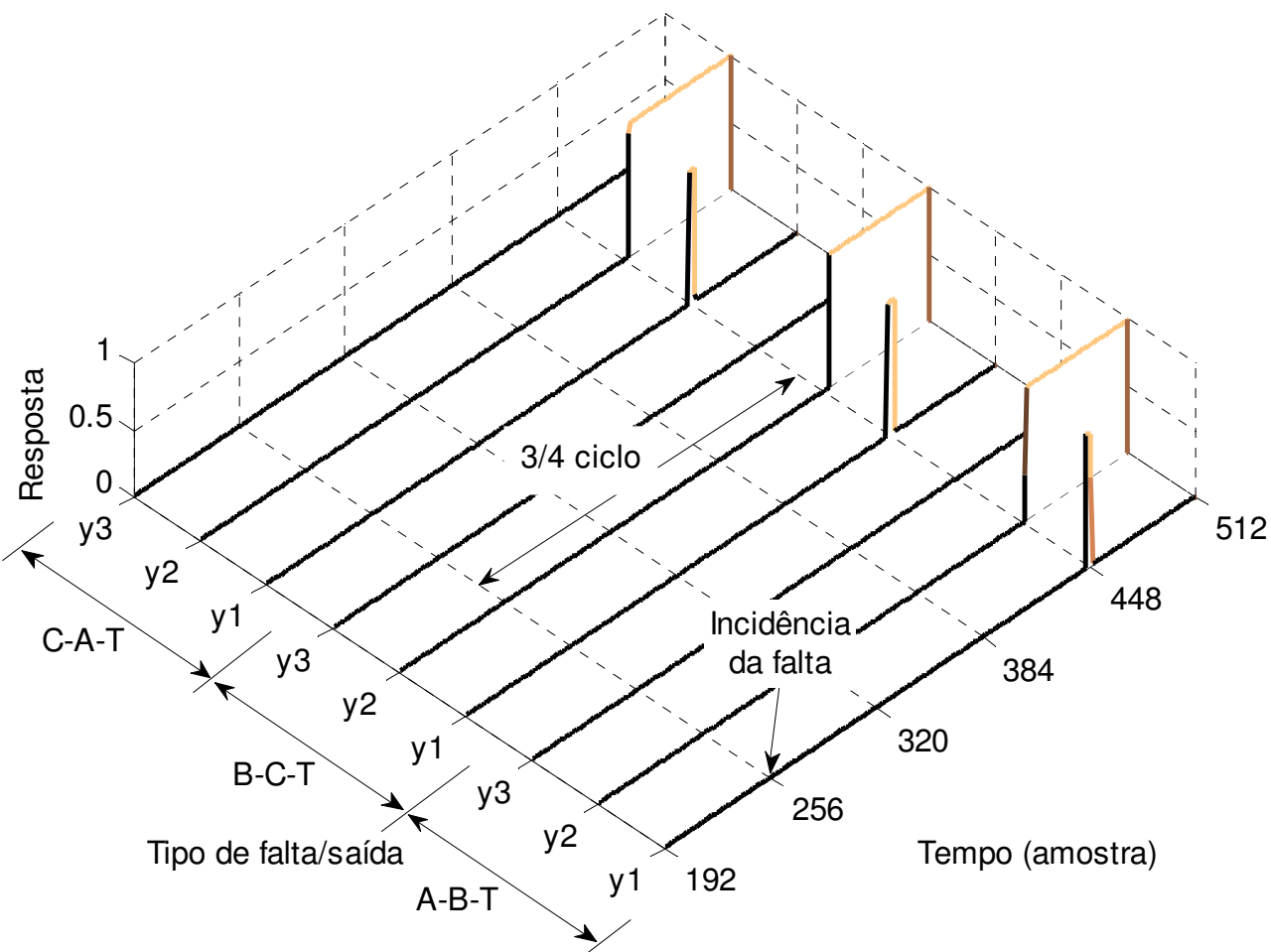

Figura 65. Resultados de localização para simulações de faltas fase-fase-terra na linha LT3 com $d=130 \mathrm{~km}, R_{t}=10 \Omega$ e $\phi=150^{\circ}$ 


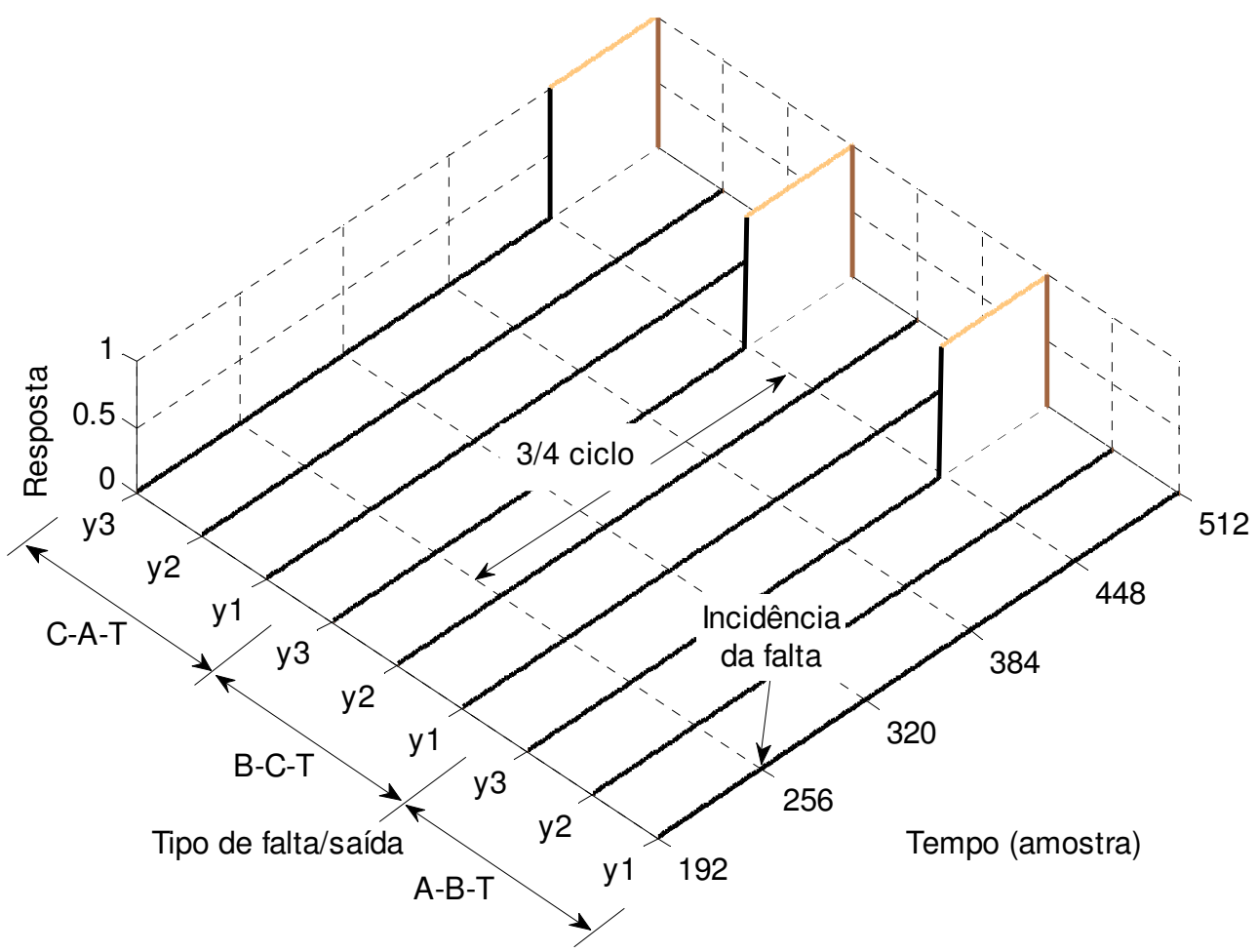

Figura 66. Resultados de localização para simulações de faltas fase-fase-terra na linha LT3 com $d=215 \mathrm{~km}, R_{t}=\mathbf{1} \Omega$ e $\phi=0^{\circ}$

\subsubsection{Faltas envolvendo duas fases (F-F)}

$\mathrm{Na}$ análise de faltas envolvendo duas fases, foi considerada a falta A-B para geração de padrões e treinamento da rede neural. O discriminante de Fisher foi determinado para esse tipo de falta, considerando as análises de uma fase em falta e outra em condição de operação normal. Os resultados encontram-se na Figura 67 e na Figura 68, respectivamente.

Considerando a fase faltosa, observa-se que os cumulantes de $2^{\mathrm{a}}$ ordem apresentam índices mais elevados. Tem-se como destaque os cumulantes de $2^{\mathrm{a}}$ ordem com lag $\tau=\{5,66\}$ e as estatísticas de $4^{\text {a }}$ ordem com lag $\tau=\{21,81\}$. Para a fase não faltosa, observa-se índices baixos para todos os cumulantes. Isto se deve ao fato de o curto influenciar apenas levemente a corrente de falta da fase em condição normal. 
Desta forma, a saída do filtro notch para essa fase possui predominantemente o ruído aditivo utilizado nas simulações. Essa característica é responsável pela não consideração da fase em condição normal de operação no sistema de localização.

(a)

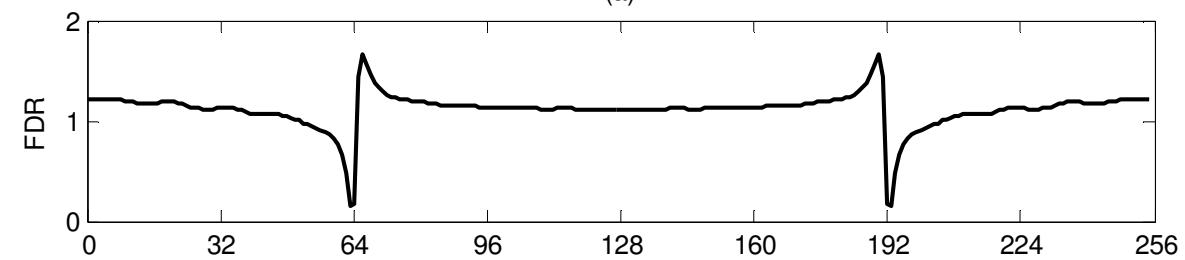

(b)

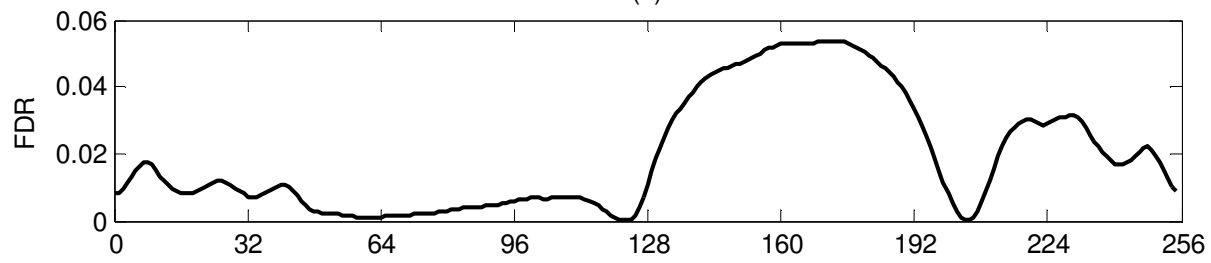

(c)

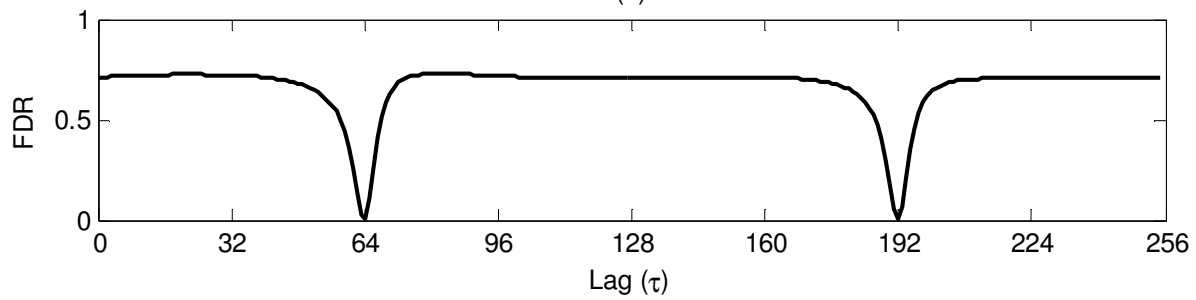

Figura 67. Fisher Discriminant Ratio para o problema de localização de faltas F-F (fase em falta):

(a) cumulantes de $2^{\text {a }}$ ordem; (b) cumulantes de $3^{\text {a }}$ ordem e; (c) cumulantes de $4^{\text {a }}$ ordem.

Os padrões para localização de faltas F-F são gerados considerando os parâmetros da Tabela 5-3 e são apresentados na Figura 69. Pode-se observar que os dados da fase A foram utilizados para o cálculo de dois cumulantes e os da fase B foram utilizados para o cálculo de um cumulante, sendo descartados os dados da fase C. Na geração dos padrões, foi considerada presença de ruído aditivo gaussiano para geração dos padrões, com $\mathrm{SNR}=40 \mathrm{~dB}$, e também a diminuição da taxa de amostragem para redução do esforço computacional no processo de treinamento. 
(a)

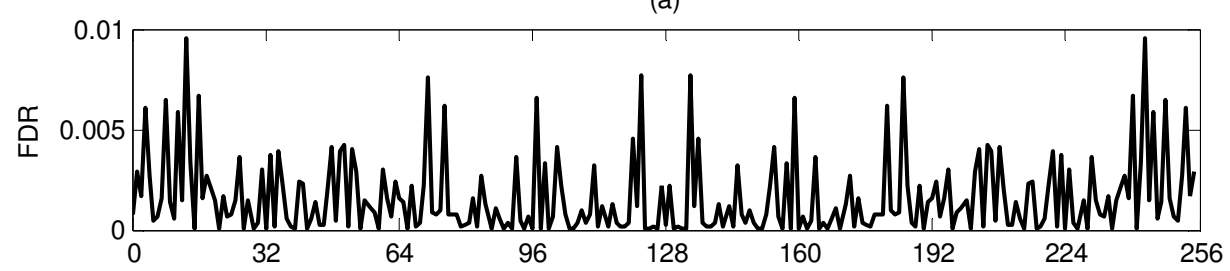

(b)

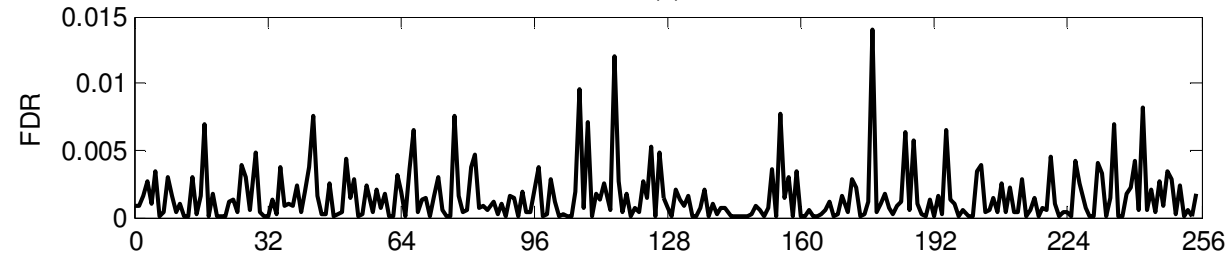

(c)

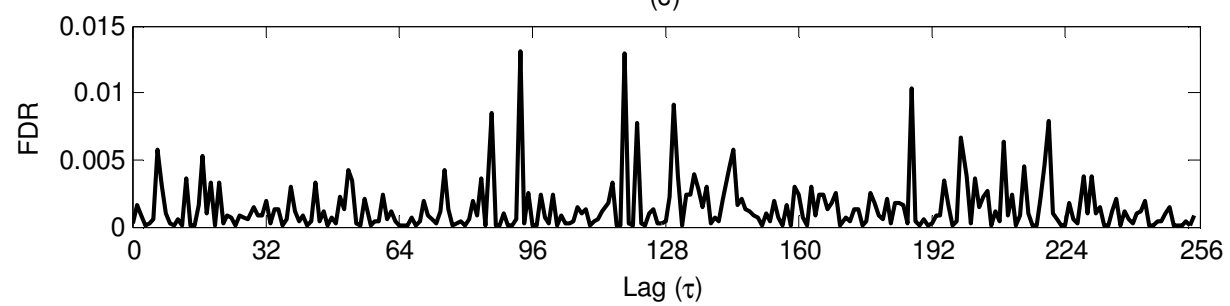

Figura 68. Fisher Discriminant Ratio para o problema de localização de faltas F-F (fase não faltosa):

(a) cumulantes de $2^{\mathrm{a}}$ ordem; (b) cumulantes de $3^{\mathrm{a}}$ ordem e; (c) cumulantes de $4^{\mathrm{a}}$ ordem.

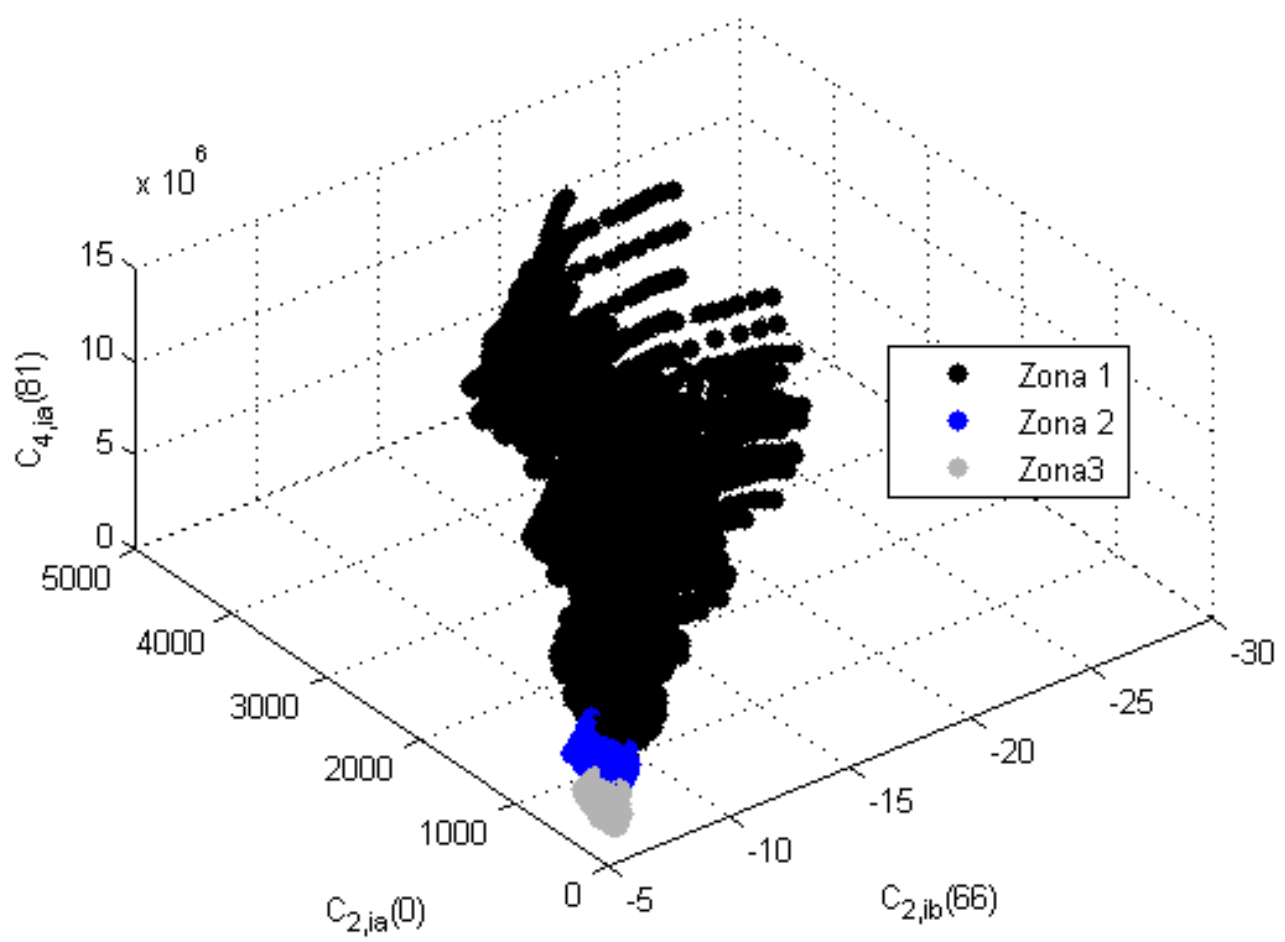

Figura 69. Padrões gerados para solução do problema de localização de faltas do tipo fase-fase. 
Para a separação das classes representadas na Figura 61, foi utilizada uma rede neural de duas camadas, com $N_{1}=40$ neurônios na camada escondida e $N_{2}=3$ neurônios na camada de saída, tal como a da Figura 53. Da mesma forma que nos casos anteriores, foi executado o treinamento desta RNA admitindo-se o máximo de 5000 épocas e visando um EQM mínimo de $1,0 \times 10^{-6}$. O algoritmo de treinamento foi executado por 2218 épocas com a convergência ocorrendo pelo critério do gradiente, parâmetro que atingiu o valor de $6,9321 \times 10^{-11}$. Os resultados do treinamento e da validação da rede estão dispostos na Figura 70. Nesta figura, em (a), tem-se a evolução do EQM durante o treinamento, tendo este parâmetro atingido um valor final de $3,2187 \times 10^{-3}$. As saídas $y_{1}$, $y_{2}$ e $y_{3}$ no processo de validação são apresentadas em (b), (c) e (d), respectivamente, equivalendo a uma taxa de acerto de $99,14 \%$ para um total de 3494 padrões disponíveis neste processo.

Um experimento de operação desta rede na localização é apresentada na Figura 71. Tem-se, neste caso, uma simulação de falta A-B a $85 \mathrm{~km}$ do relé com resistência $R_{f}=5 \Omega$ e ângulo de incidência de $60^{\circ}$. Observa-se, nesta figura, em (a) e (b), os sinais de corrente e os sinais de erro provenientes do filtro notch, respectivamente. Após a incidência e detecção de falta, a partir da amostra 256, são decorridos 3/4 do ciclo fundamental e então o módulo de localização é acionado. Observa-se, portanto, em (c) e (d), respectivamente os cumulantes $-C_{2}(0)$ e $C_{4}(81)$ para a fase $\mathrm{A}$ e $C_{2}(66)$ para a fase $\mathrm{B}$ - e as saídas da rede neural. Apesar de ser observada a ativação das saídas $y_{1}$ e $y_{2}$, a primeira permanece ativa por um período de tempo maior, indicando corretamente a ocorrência da falta na Zona 1.

Três casos de teste distintos são novamente utilizados para testes preliminares do sistema de localização. São consideradas faltas nas linha LT2 e LT3 de forma a verificar as três zonas de proteção. 
Os parâmetros dos testes supracitados são ${ }^{6}$ :

- Caso 1: $\quad$ Linha LT2 $\operatorname{com} d=35 \mathrm{~km}, R_{f}=0 \Omega$ e $\phi=30^{\circ}$

- Caso 2: $\quad$ Linha LT3 com $d=155 \mathrm{~km}, R_{f}=2 \Omega$ e $\phi=90^{\circ}$

- Caso 3: $\quad$ Linha LT3 $\operatorname{com} d=240 \mathrm{~km}, R_{f}=0,5 \Omega$ e $\phi=0^{\circ}$

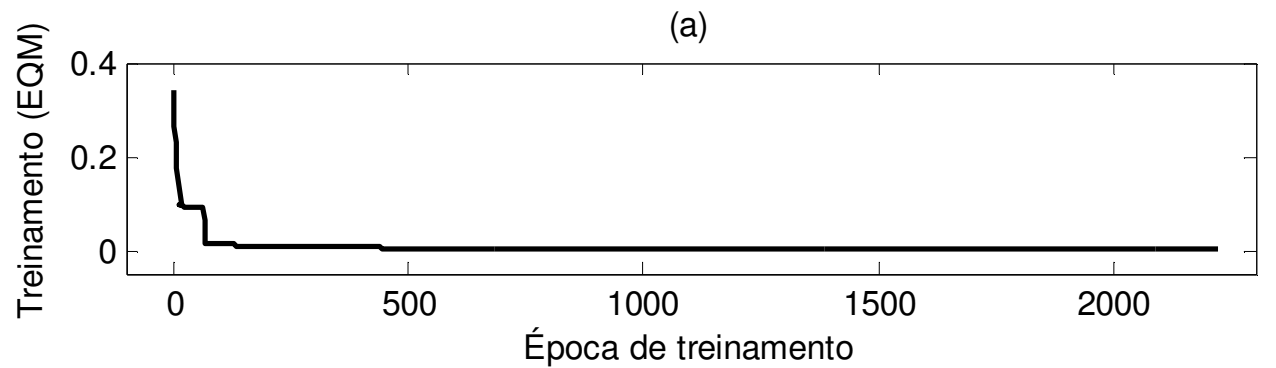

(b)

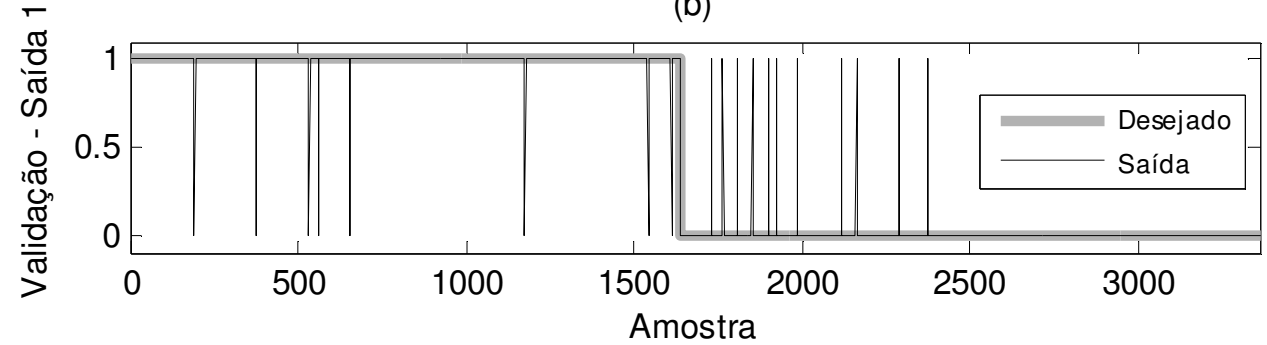

(c)

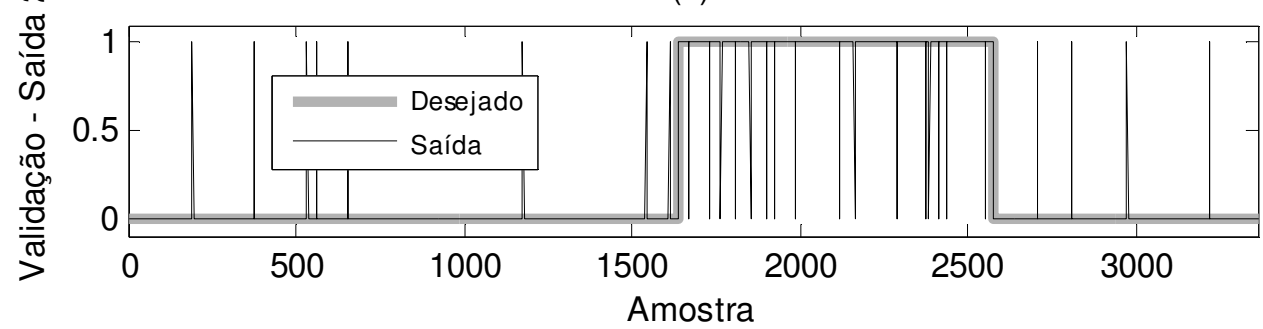

(d)

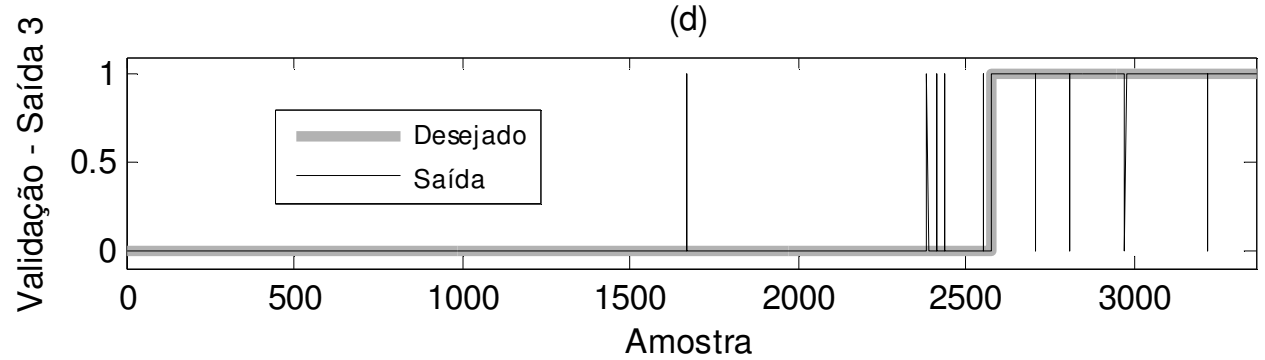

Figura 70. Resultados obtidos para a RNA de localização (faltas do tipo F-F): (a) evolução do EQM no treinamento e; validação da rede: (b) saída $y_{1}$; (c) saída $y_{2}$; (d) saída $y_{3}$.

\footnotetext{
${ }^{6}$ As distâncias possuem como referência o barramento E, tanto para as faltas na linha LT2 quanto na linha LT3.
} 
(a)

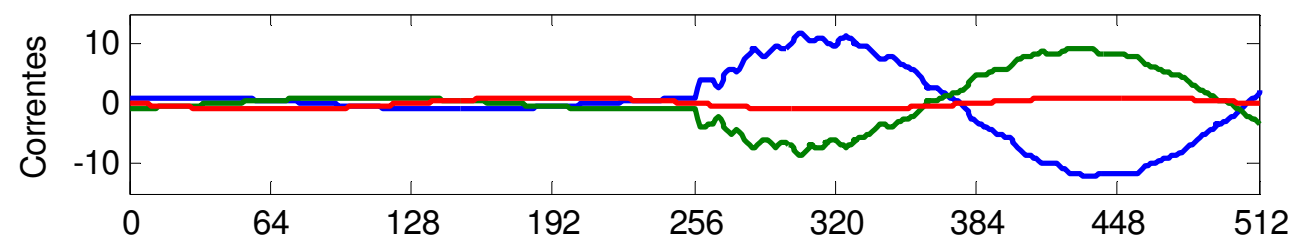

(b)

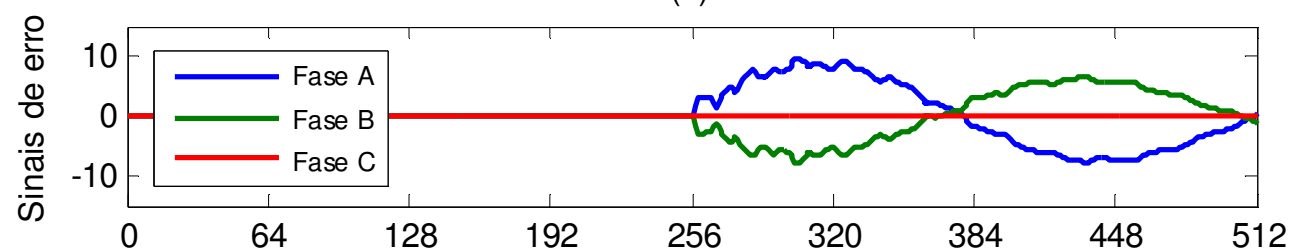

(c)

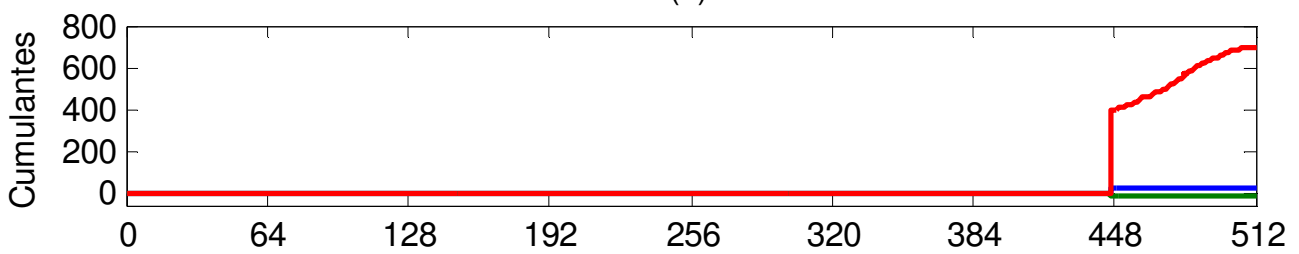

(d)

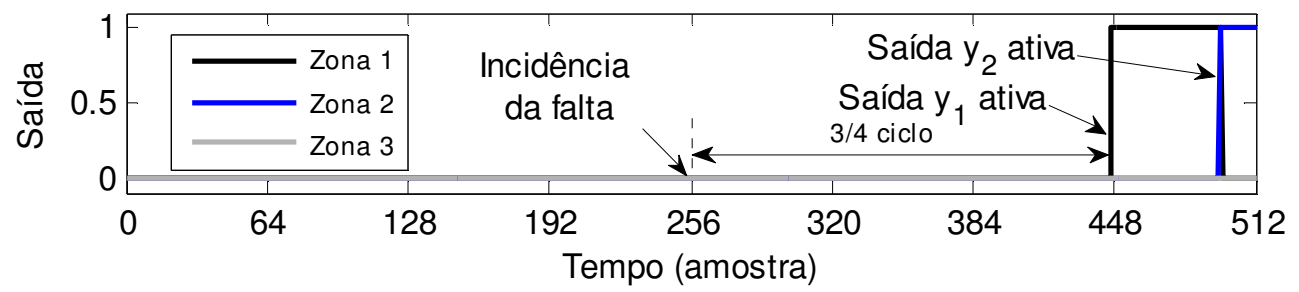

Figura 71. Simulação de falta A-B a $85 \mathrm{~km}$ do relé, $\operatorname{com} \boldsymbol{R}_{f}=5 \Omega$ e $\phi=60^{\circ}$. Sinais: (a) correntes; (b) saídas do filtro notch; (c) cumulantes e; (d) saídas da rede de localização para faltas F-F.

Os resultados para os Casos 1, 2 e 3 são apresentados na Figura 72, na Figura 73 e na Figura 74, respectivamente. O mesmo módulo de localização é utilizado para as faltas B-C e C-A, sendo realizado apenas o correto chaveamento das entradas quando da classificação dessas faltas. Observa-se que, depois de transcorrido $3 / 4$ do ciclo fundamental, o sistema de localização identifica corretamente as zonas de falta para cada caso de teste. De fato, para o caso 1 tem-se $y_{1}$ ativa indicando Zona 1 , como esperado (Figura 72). Para os casos 2 e 3, tem-se respectivamente a ativação das saídas $y_{2}$ e $y_{3}$, como esperado (Figura 73 e Figura 74). 


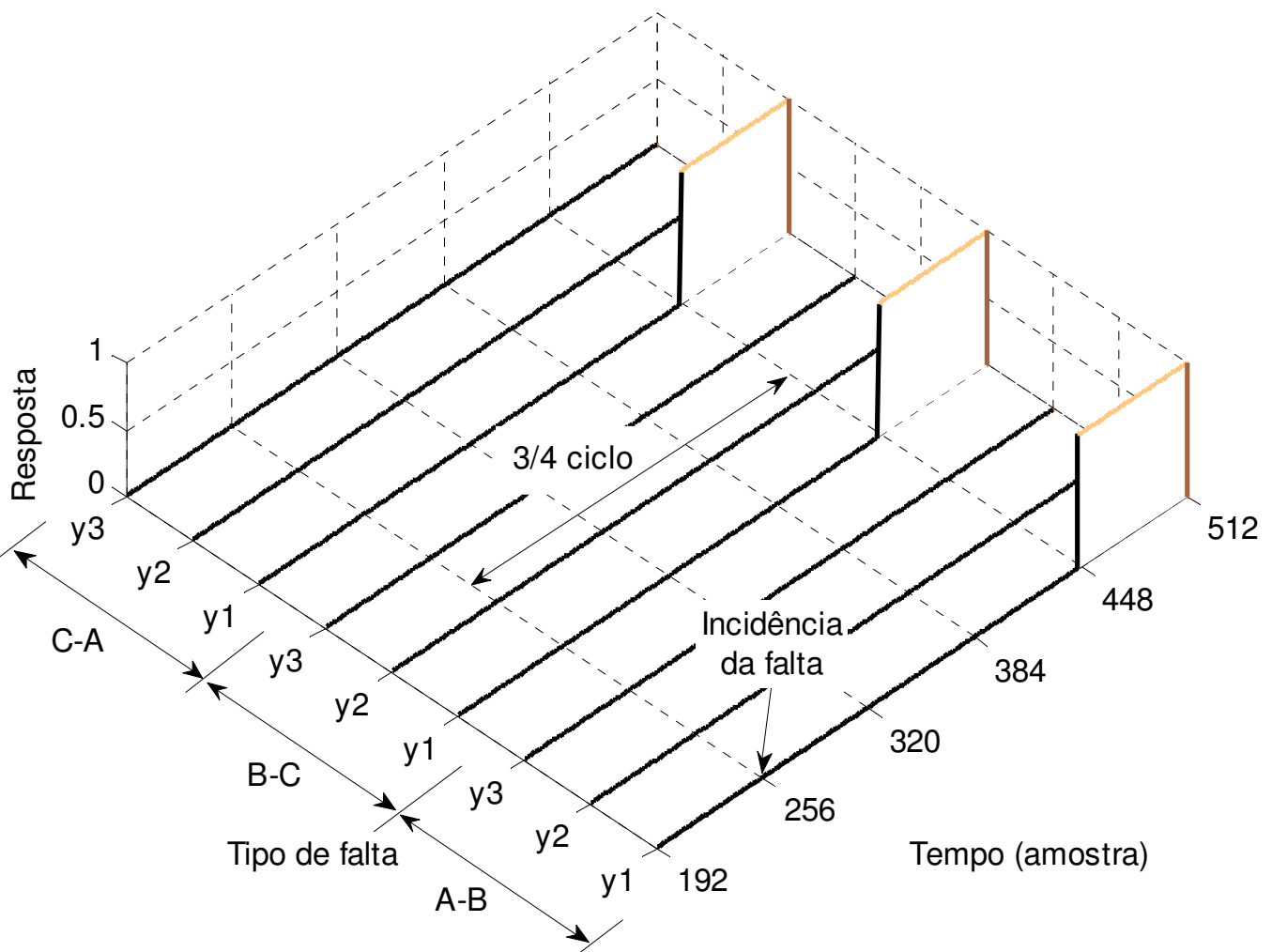

Figura 72. Resultados de localização para simulações de faltas fase-fase na linha LT2 com $d=35 \mathrm{~km}$, $R_{f}=0 \Omega$ e $\phi=30^{\circ}$

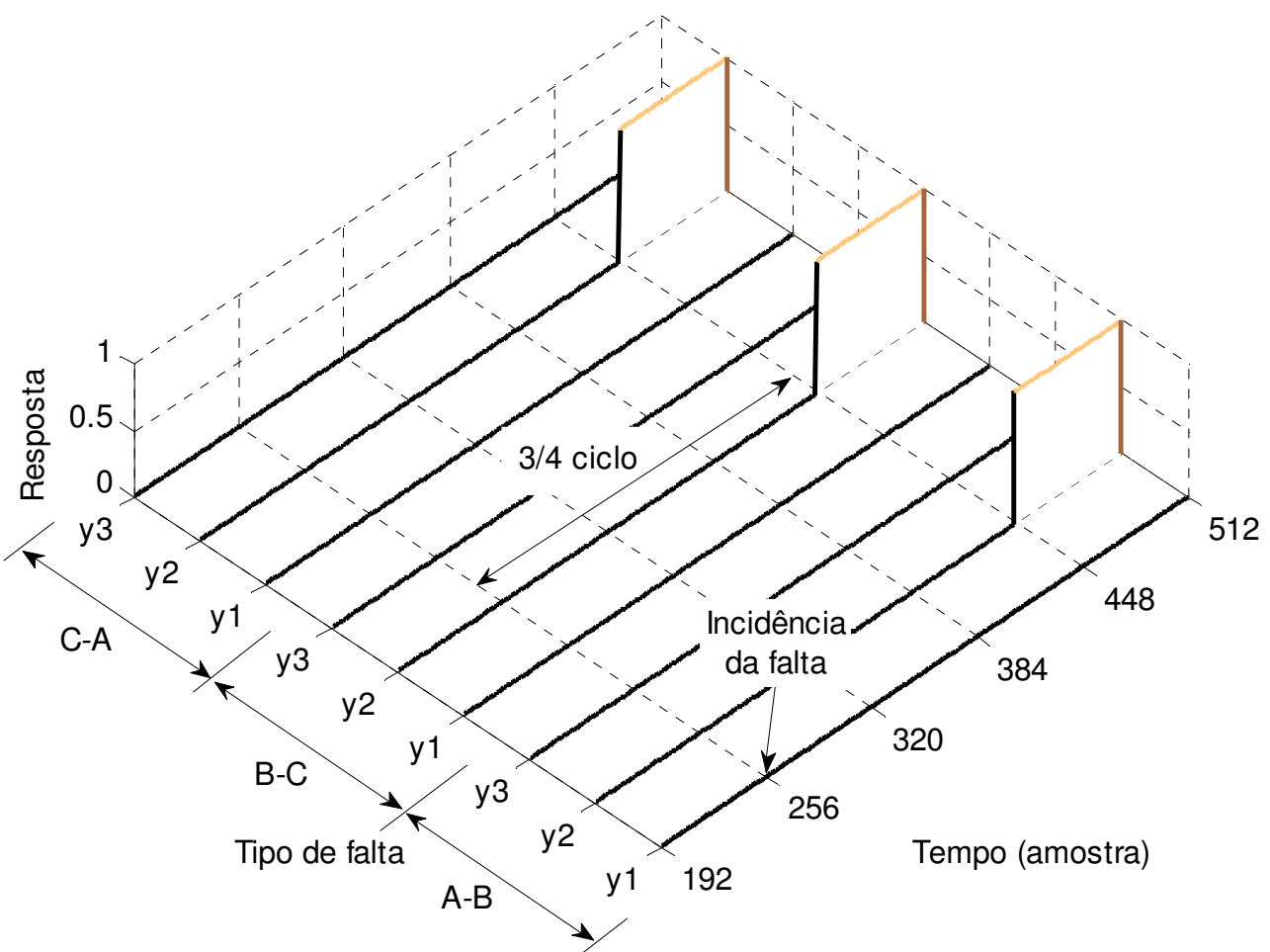

Figura 73. Resultados de localização para simulações de faltas fase-fase na linha LT3 com $d=155$ $\mathrm{km}, R_{f}=2 \Omega$ e $\phi=90^{\circ}$ 


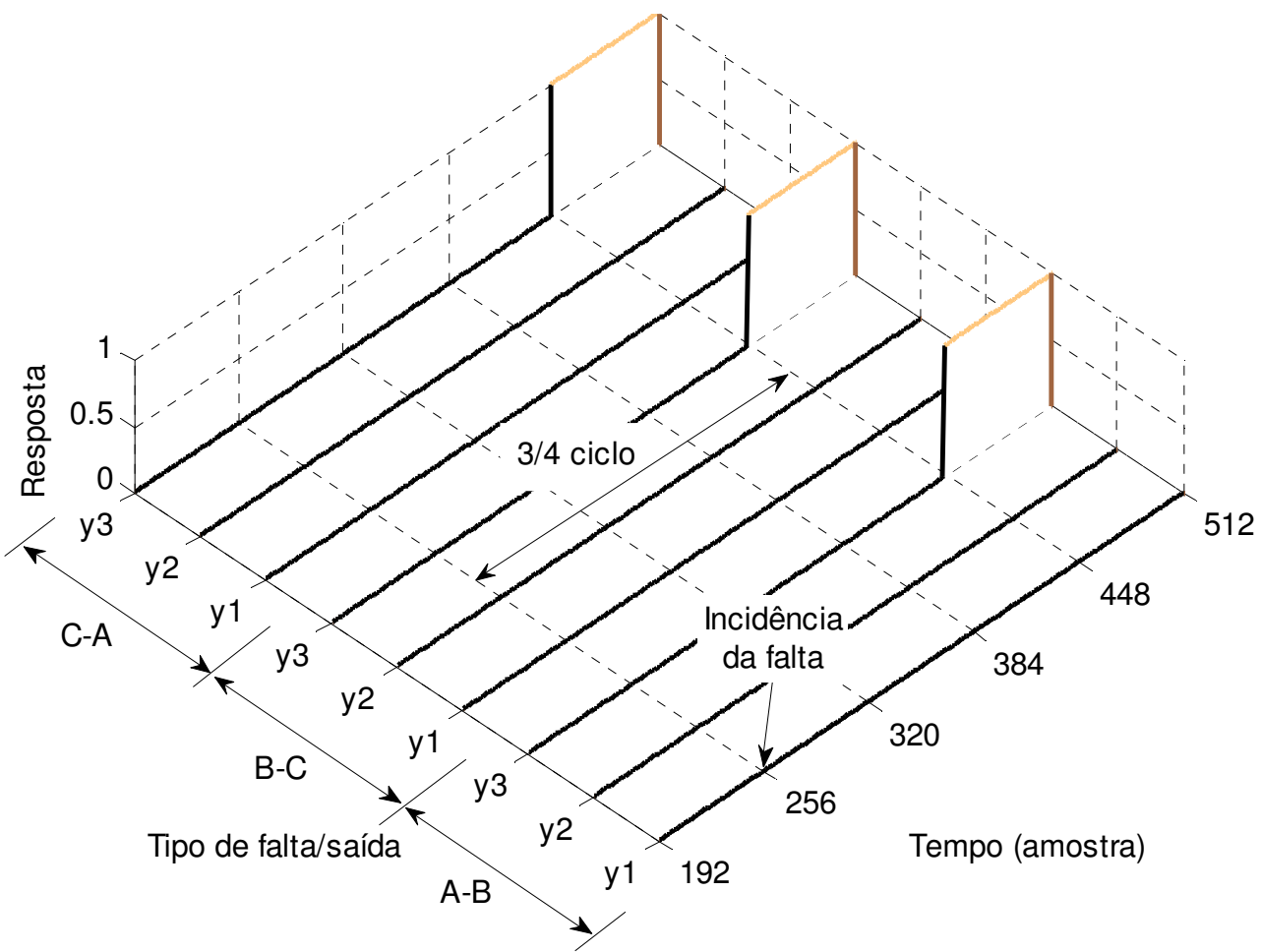

Figura 74. Resultados de localização para simulações de faltas fase-fase na linha LT3 $\operatorname{com} d=\mathbf{2 4 0}$

$$
\mathrm{km}, R_{f}=0,5 \Omega \text { e } \phi=0^{\circ}
$$

\subsubsection{Faltas envolvendo as três fases (F-F-F)}

Finalmente, trata-se, nesta seção, da localização das falta trifásicas. Considerando sinais de corrente da fase A, para as faltas A-B-C, o discriminante de Fisher referentes aos cumulantes de $2^{\mathrm{a}}, 3^{\mathrm{a}}$ e $4^{\mathrm{a}}$ ordens é apresentado na Figura 75 . Nesta figura, observase a maior expressividade de estatísticas de $2^{\mathrm{a}}$ e $4^{\mathrm{a}}$ ordens. Mais especificamente, tem-se como destaque os cumulantes de $2^{\mathrm{a}}$ ordem com lags $\tau=\{5,66,90\}$ e de $4^{\mathrm{a}}$ ordem com lags $\tau=\{25,83\}$.

Tomando um cumulante de $2^{\mathrm{a}}$ ordem por fase, com lag $\tau=66$, na Figura 76 é apresentado o resultado da geração de padrões para o problema de localização de faltas F-F-F. Conforme pode ser observado, os padrões se apresentam em lugares geométricos relativamente distintos para as faltas ocorridas nas diferentes zonas de proteção. De fato, observa-se apenas uma leve sobreposição de classes. 
(a)

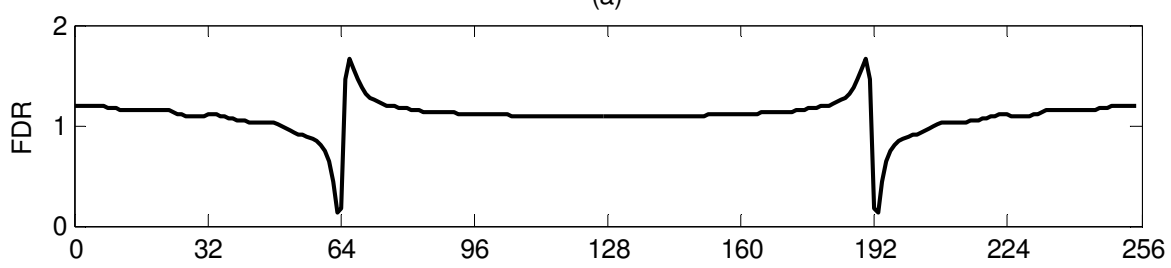

(b)

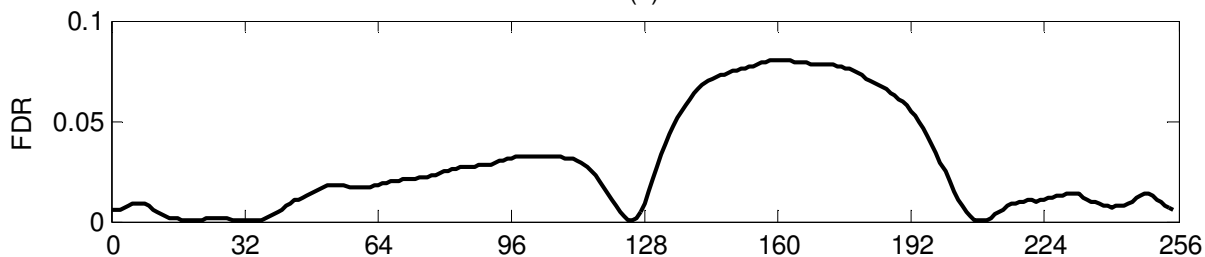

(c)

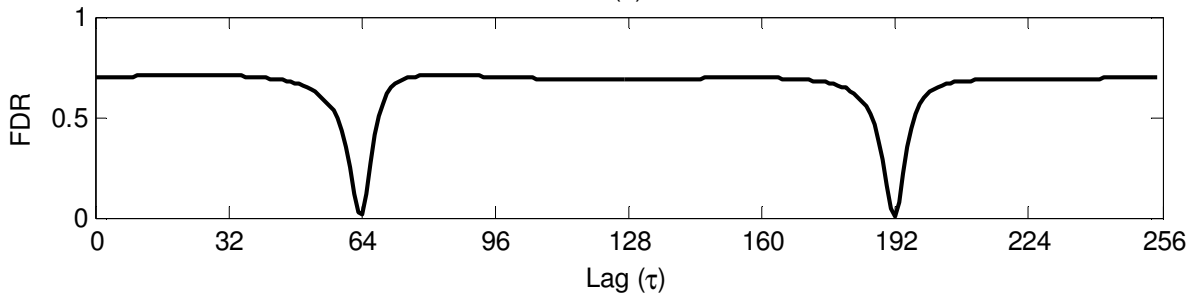

Figura 75. Fisher Discriminant Ratio para o problema de localização de faltas F-F-F: (a) cumulantes de $2^{\mathrm{a}}$ ordem; (b) cumulantes de $3^{\mathrm{a}}$ ordem e; (c) cumulantes de $4^{\mathrm{a}}$ ordem.

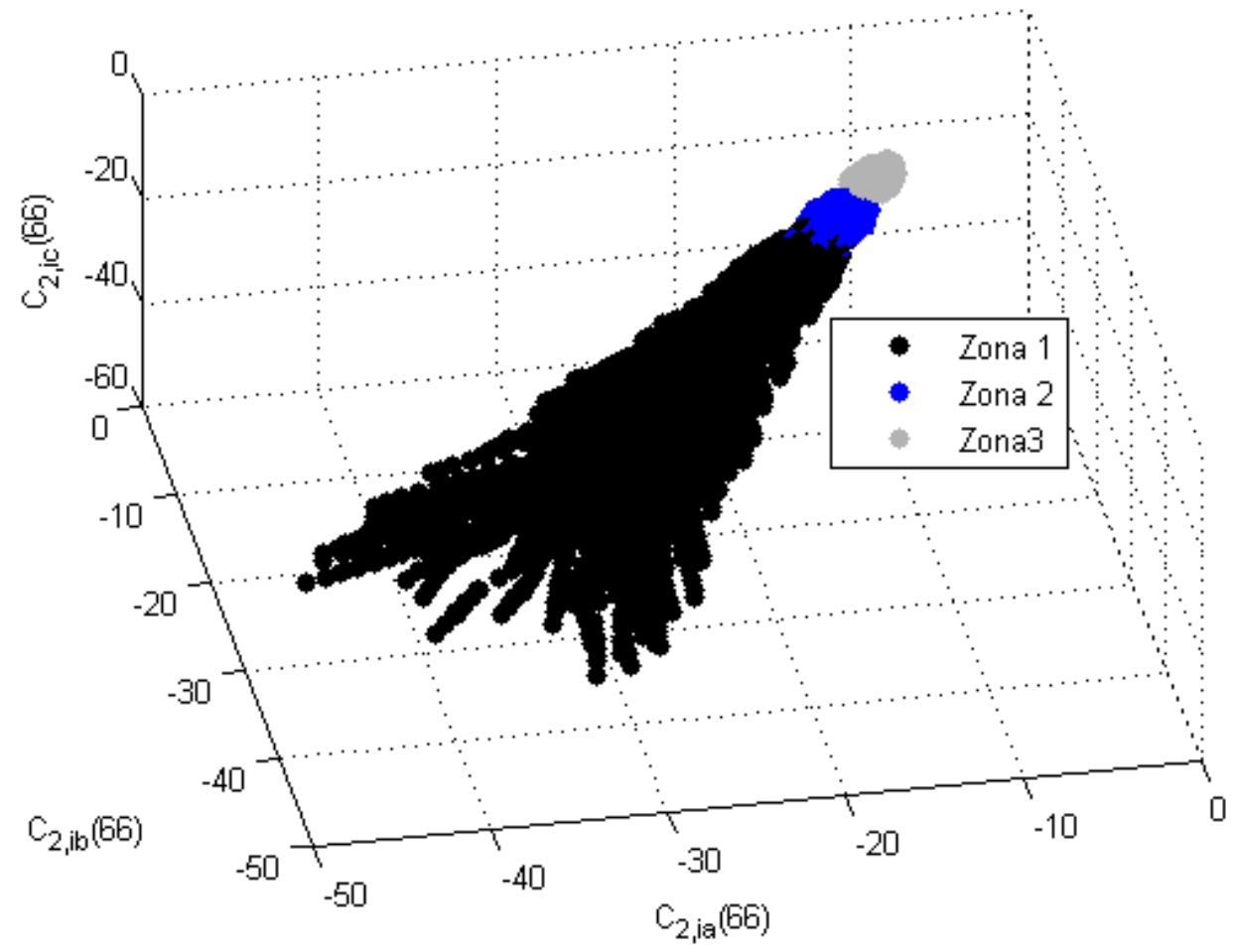

Figura 76. Padrões gerados para solução do problema de localização de faltas do tipo fase-fase-fase. 
Uma rede neural de duas camadas como a da Figura 53, com $N_{1}=40$ neurônios na camada escondida e $N_{2}=3$ neurônios na camada de saída, foi utilizada para a solução do problema de classificação de padrões da Figura 76. O treinamento desta rede foi executado também admitindo-se o máximo de 5000 épocas e visando um EQM mínimo de $1,0 \times 10^{-6}$. O algoritmo de treinamento foi executado pelas 5000 épocas sem que tenha ocorrido a convergência. O valor final do EQM foi de $7,6644 \times 10^{-3}$ e a evolução deste parâmetro é apresentado na Figura 77(a). Também nesta figura, em (b), (c) e (d) têm-se apresentados os valores das saídas $y_{1}, y_{2}$ e $y_{3}$ no processo de validação. Obtevese uma taxa de acerto de $98,68 \%$ neste processo.

Uma falta trifásica foi simulada a $100 \mathrm{~km}$ do relé, com resistência $R_{f}=5 \Omega$ e ângulo de incidência $\phi=60^{\circ}$, para ilustrar a operação do módulo de localização em tempo real. O resultado encontra-se na Figura 78. Em (a) e (b) são mostrados os sinais de corrente e os sinais de erro, respectivamente. Os cumulantes estão dispostos em (c) e, finalmente, em (d) tem-se as saídas do módulo de localização. Em se tratando de uma falta na Zona 1, o módulo indica esta condição corretamente, com a ativação da saída $y_{1}$, após transcorridos 3/4 do instante de incidência/detecção da falta.

Finalmente, três casos distintos de falta são utilizados para testes do módulo de identificação de zonas de faltas para defeitos envolvendo as três fases. Os parâmetros utilizados nestas simulações distinguem-se daqueles utilizados quando do treinamento da RNA e, portanto, fornecem também uma ideia da capacidade de generalização da rede. Os parâmetros utilizados para testes são :

- Caso 1: $\quad$ Linha LT2 com $d=80 \mathrm{~km}, R_{t}=1 \Omega$ e $\phi=90^{\circ}$

- Caso 2: $\quad$ Linha LT2 $\operatorname{com} d=140 \mathrm{~km}, R_{t}=10 \Omega$ e $\phi=120^{\circ}$

- Caso 3: $\quad$ Linha LT3 $\operatorname{com} d=200 \mathrm{~km}, R_{t}=0 \Omega$ e $\phi=0^{\circ}$ 


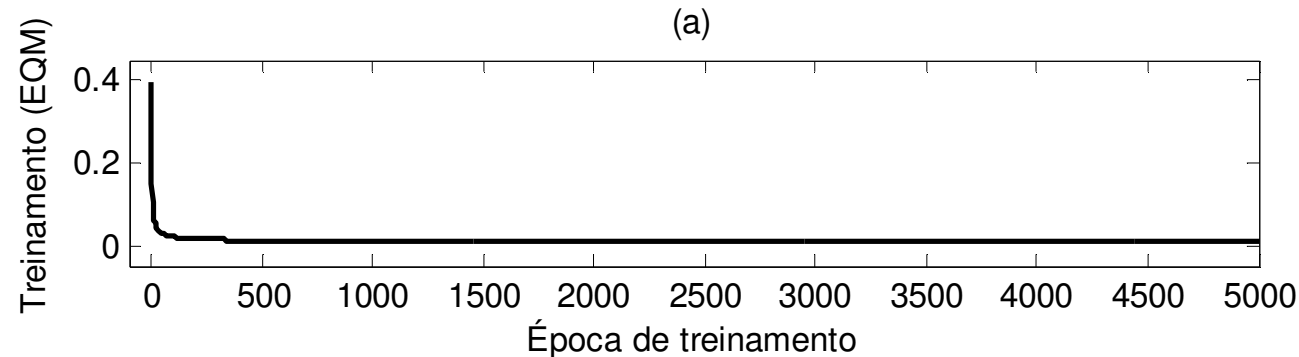

(b)

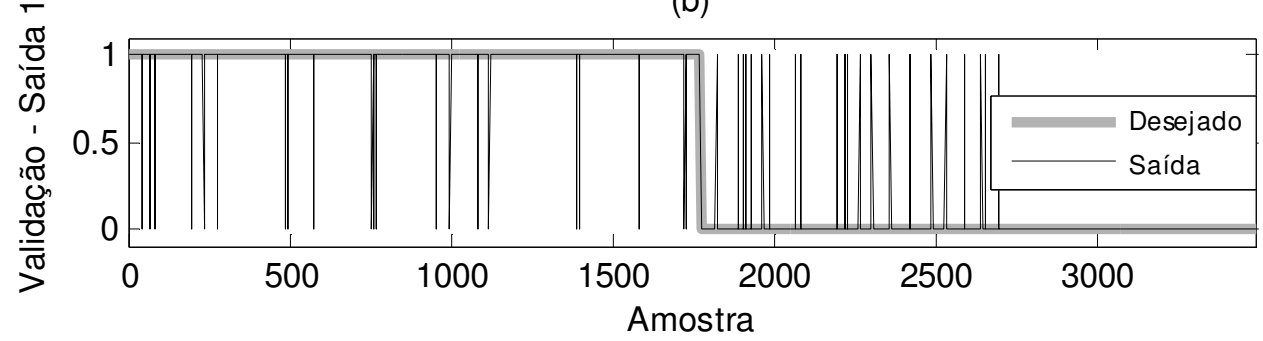

(c)
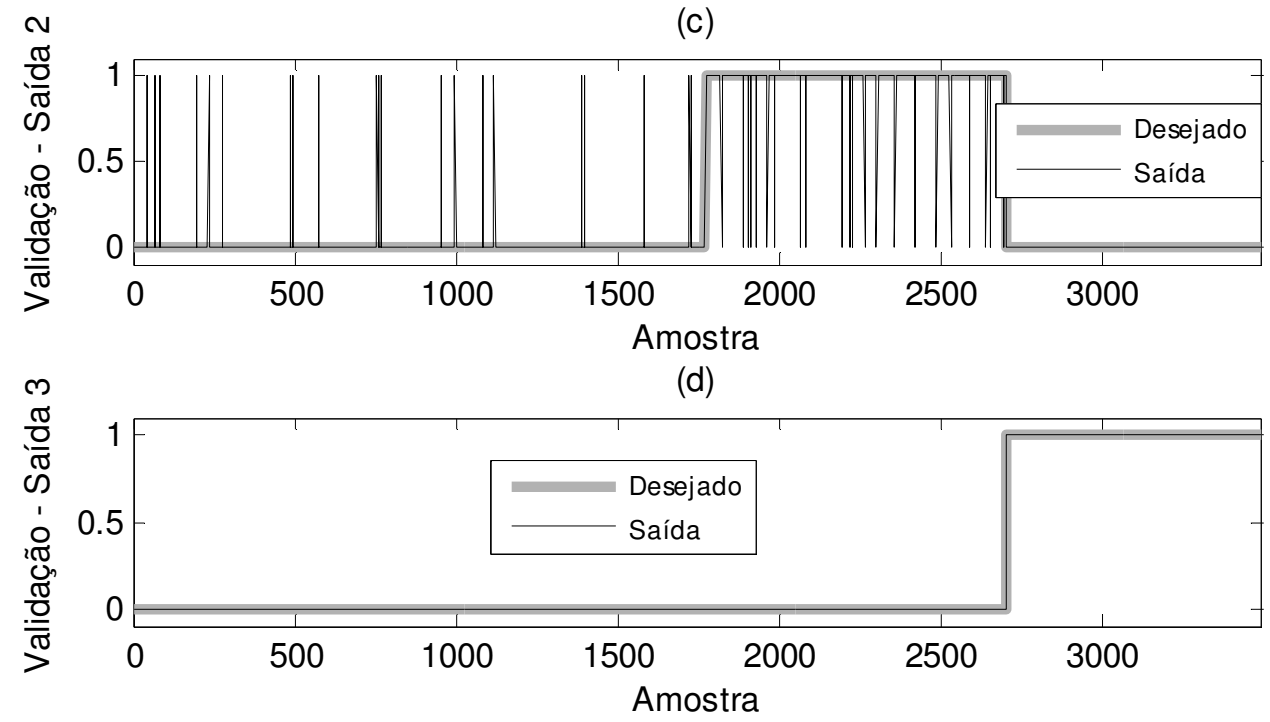

Figura 77. Resultados obtidos para a RNA de localização (faltas do tipo F-F-F): (a) evolução do EQM no treinamento e; validação da rede: (b) saída $y_{1 ;}$ (c) saída $y_{2 ;}$ e (d) saída $y_{3}$.

Os resultados de operação do módulo de localização para as configurações prévias de faltas são apresentados na Figura 79. Verificando a Figura 49, pode-se perceber que os casos 1, 2 e 3 correspondem a faltas nas zonas 1, 2 e 3, respectivamente. O resultado da Figura 79 traduz exatamente a verificação destas condições. De fato, no Caso 1, pode-se verificar a ativação da saída $y_{1}$ depois de decorrido o intervalo de $3 / 4$ do ciclo fundamental a partir do instante de incidência/detecção da falta, na amostra 256. Para os 
casos 2 e 3, têm-se a ativação das saídas $y_{2}$ e $y_{3}$, como esperado. Portanto, verifica-se êxito do localizador de faltas nestas situações testadas.

(a)

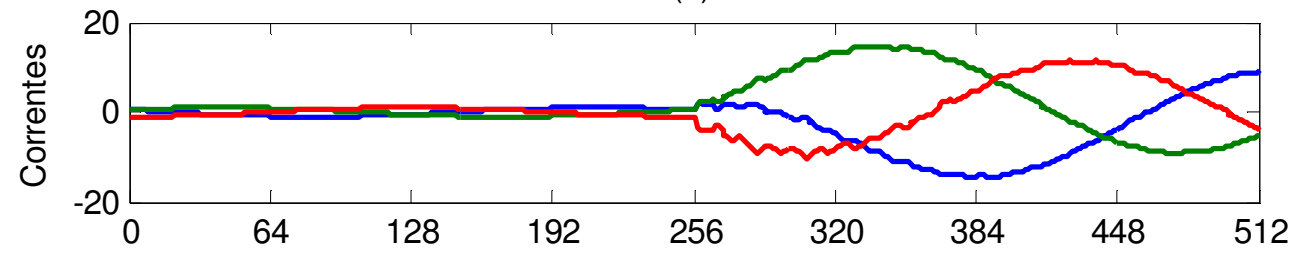

(b)

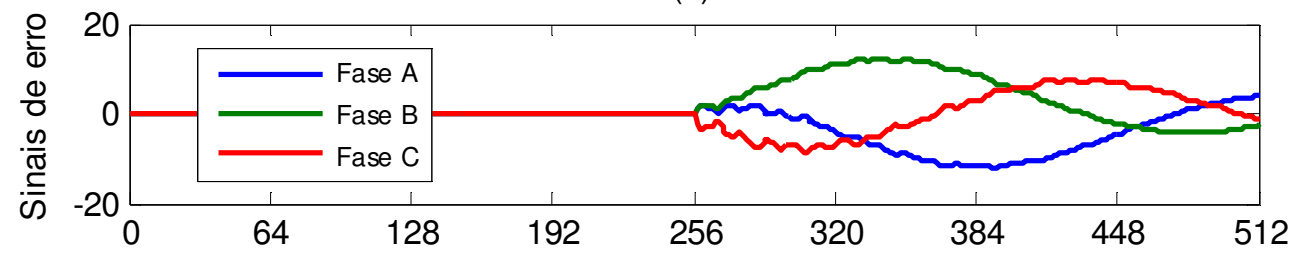

(c)

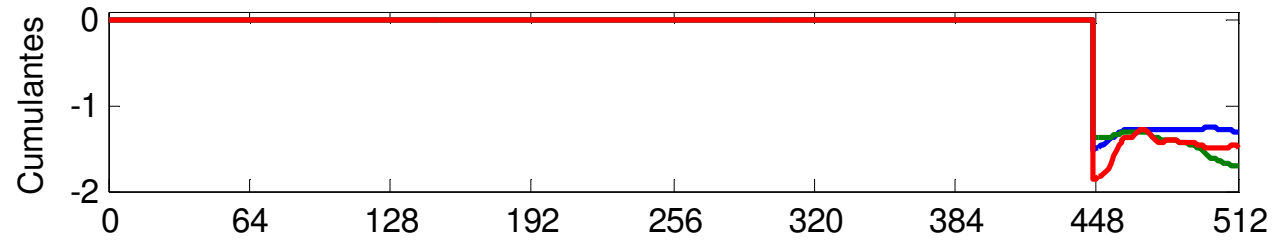

(d)

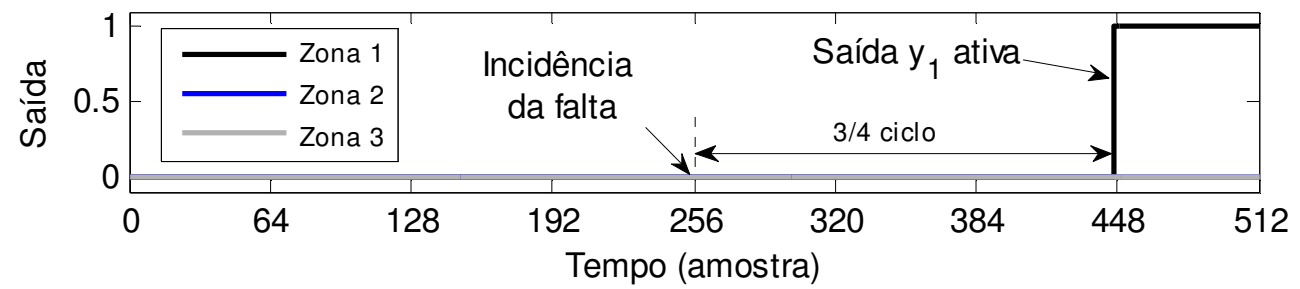

Figura 78. Simulação de falta A-B-C a $100 \mathrm{~km}$ do relé, $\operatorname{com} R_{f}=5 \Omega$ e $\phi=60^{\circ}$. Sinais: (a) correntes; (b) saídas do filtro notch; (c) cumulantes e; (d) saídas da rede de localização para faltas F-F-F. 


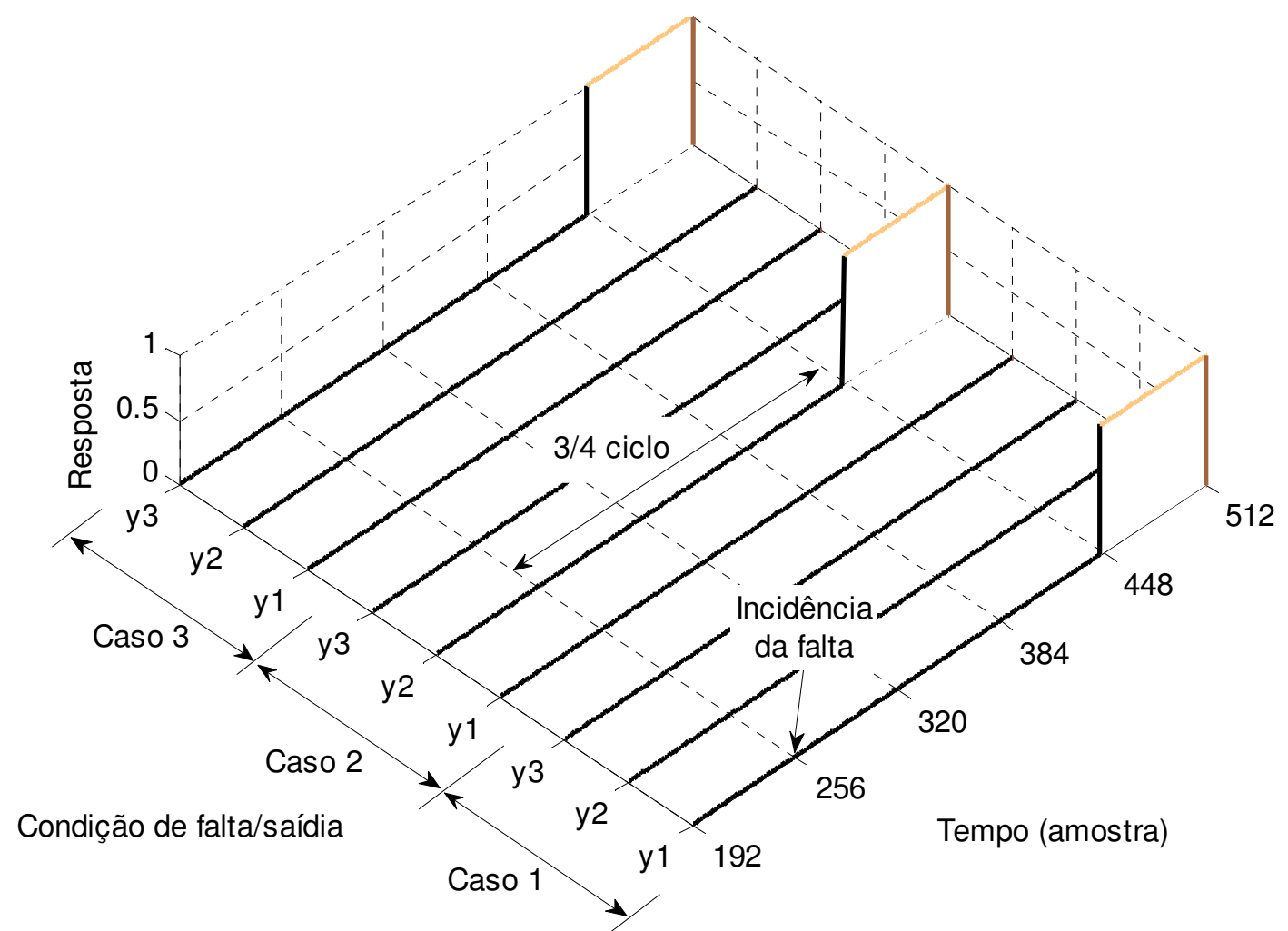

Figura 79. Resultados de localização para simulações de faltas nas linhas LT2 e LT3 referentes aos casos 1,2 e 3 de faltas trifásicas.

\subsection{Esquemático das estruturas de detecção, classificação e localização}

Pode-se resumir as etapas de detecção, classificação e localização abordadas neste capítulo tal como apresentado na Figura 80. Os sinais de erro alimentam os módulos da proteção, com exceção do identificador de participação da terra na falta, que recebe como entrada os sinais de corrente. Pode-se observar nesta figura um resumo de todos os cumulantes necessários para a proteção de distância pelo método proposto. Cabe enfatizar que a representação desta figura para os módulos de localização de faltas F-T, F-F-T e F-F é aplicada às faltas A-T, A-B-T e A-B, respectivamente. Para a localização de faltas envolvendo outras fases, as entradas dos módulos devem ser reordenadas, tal como comentado anteriormente. 

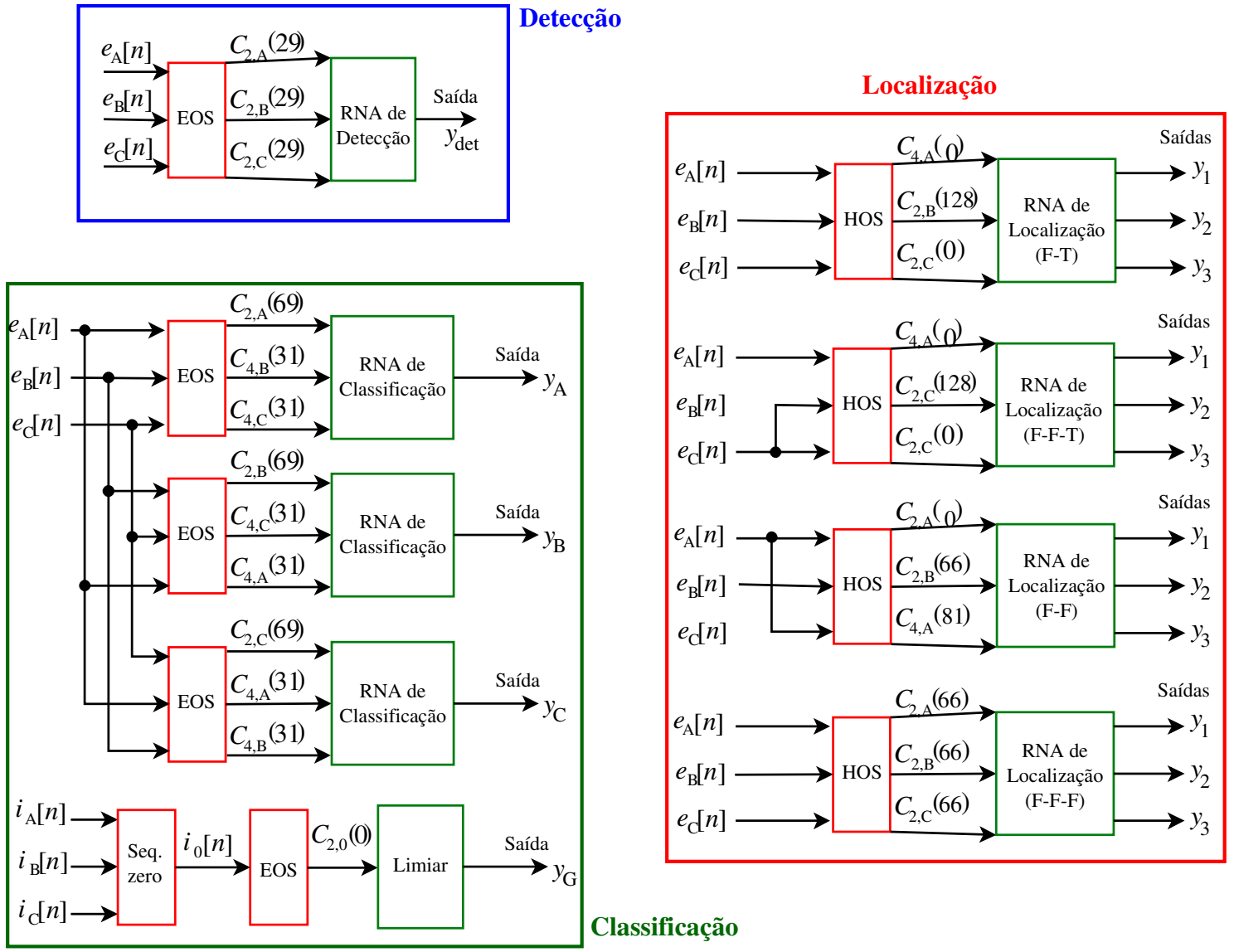

Figura 80. Estruturas das etapas de detecção, classificação e localização.

\subsection{Considerações finais do capítulo}

Neste capítulo foram apresentados detalhadamente os módulos de detecção, classificação e localização de faltas que formam a estrutura de proteção proposta nesta tese. Os módulos foram obtidos com o emprego do discriminante de Fisher para a seleção de variáveis a serem utilizadas como entradas para as redes neurais. Foram apresentados os resultados de treinamento e validação destas redes. Em termos gerais, pode-se afirmar que foram obtidos módulos para a composição de um sistema de proteção adequado para aplicação em linhas de transmissão. De fato, foram obtidas taxas de acerto elevadas na validação das RNAs e os testes iniciais de operação das etapas de proteção indicaram ótima capacidade de generalização. A operação conjunta dos módulos abordados neste capítulo é tratada no Capítulo 6. 


\section{SIMULAÇÃO DE OPERAÇÃO DA PROTEÇÃO DE DISTÂNCIA PROPOSTA}

Neste capítulo, são apresentados os resultados do protótipo de relé desenvolvido, embasado na aplicação de estatísticas de ordem superior e de redes neurais artificiais à proteção de linhas de transmissão. Utilizando os módulos de detecção, classificação e localização apresentados no capítulo anterior, considera-se, a partir deste ponto, a operação conjunta destes módulos provendo o monitoramento do sistema elétrico de potência considerado no estudo. Conforme colocado anteriormente, o universo de estudo desta tese admite a hipótese de que o fenômeno ocorrido no sistema elétrico trata-se de uma falta. O desempenho do sistema de proteção proposto é, portanto, levantado e avaliado.

\subsection{Protótipo de relé desenvolvido}

Um protótipo de relé digital baseado no método proposto foi montado no ambiente Simulink ${ }^{\circledR}$ e engloba todas as funcionalidades dos subsistemas de proteção abordados anteriormente, com o contínuo monitoramento do sistema elétrico de potência que se encontra em operação. A organização funcional deste protótipo está apresentada na Figura 81. Os dados das correntes no barramento E são aplicados ao bloco de pré-processamento. Nesta etapa, ocorrem três operações básicas relatadas na Seção 4.3, relativas ao processo de condicionamento do sinal e resumidas na Figura 82. A primeira etapa consiste na redução dos níveis de corrente, simulando a operação de um TC e dos transformadores representados na Figura 15. Em seguida, ocorre o processo de filtragem anti-aliasing, executado por um filtro passa-baixas Butterworth de $2^{\mathrm{a}}$ ordem com frequência de corte $f_{C}=1000 \mathrm{~Hz}$. Por fim, é realizada a conversão A/D adotando um número $N=12$ bits de tamanho de palavra. 


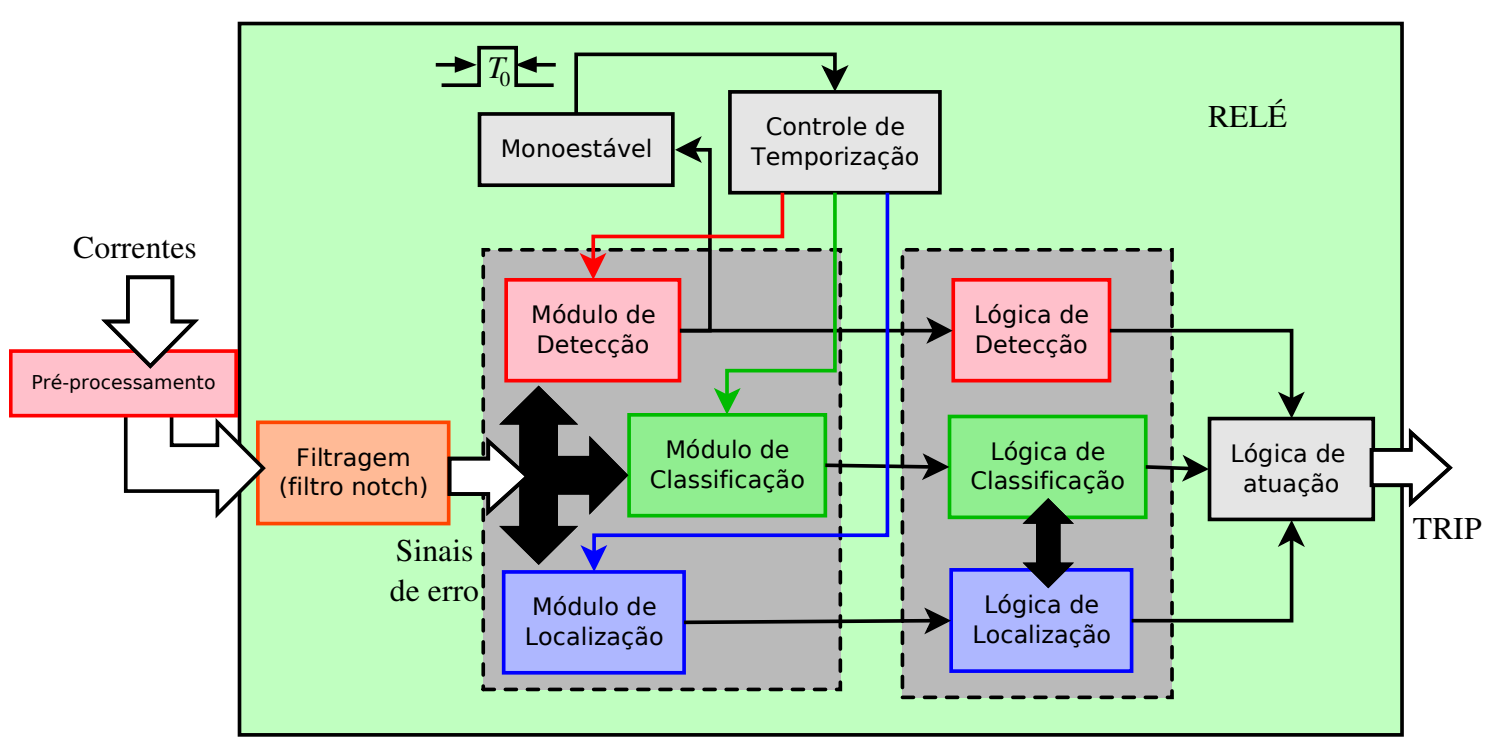

Figura 81. Protótipo de relé digital baseado na metodologia proposta.

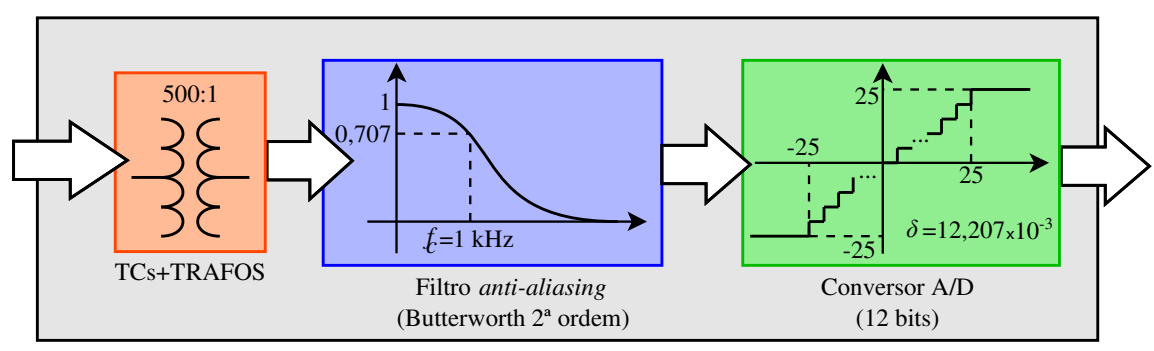

Figura 82. Representação detalhada da etapa de condicionamento de sinais.

O filtro notch consiste na primeira manipulação dos sinais de corrente internamente no modelo de proteção proposto. Quanto aos parâmetros do filtro, relativos a (4.1), foi adotado $\alpha=0,995$ e calculado $\beta=0,9997$, utilizando a expressão $\beta=\cos \left(2 \pi f_{0} / f_{S}\right)[12]$

O módulo de detecção monitora continuamente o estado dos SEP simulado. A ocorrência de uma falta é prontamente detectada por este módulo e, neste caso, ocorre o disparo do monoestável presente no esquema. Este dispositivo é responsável por gerar um pulso que habilita o funcionamento do bloco Controle de Temporização. Este componente é peça chave no esquema proposto e é responsável por fornecer a temporização adequada de cada submódulo do relé - detecção, classificação e 
localização - assim como a sincronização dos mesmos. Em suma, considerando os intervalos de tempo utilizados anteriormente para a geração dos padrões, o controle de temporização deve garantir que cada submódulo opere com os dados para os quais foi projetado.

Desta forma, tem-se a representação dos sinais de habilitação dos subsistemas de proteção apresentado na Figura 83. Como pode ser notado nesta figura, o módulo de detecção permanece em operação no primeiro $1 / 4$ de ciclo logo após a primeira acusação de falta no SEP, sendo desabilitado em seguida. O módulo de classificação é, portanto, acionado, permanecendo em operação durante meio período fundamental. Quando este último é desabilitado, é acionado, por fim, o módulo de localização. A operação deste módulo ocorre no último quarto do primeiro ciclo de regime pós-falta. Durante este período, controlado pelo pulso de saída gerado pelo monoestável, o relé de proteção deve ser capaz de detectar, classificar e localizar a falta ocorrida no sistema elétrico.

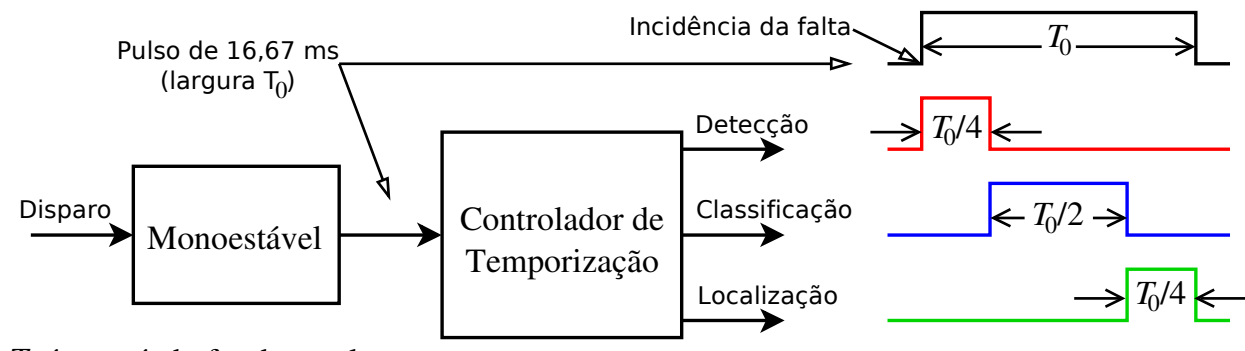

$T_{0}$ é o período fundametal

Figura 83. Representação da operação do controle de temporização do relé proposto.

Prosseguindo, observam-se no protótipo da Figura 81 os blocos denominados de Lógica de Detecção, Lógica de Classificação e Lógica de Localização. Estes blocos efetuam o processamento da saída dos respectivos submódulos e têm por objetivo confirmar uma determinada situação que o sistema de proteção está acusando. De maneira simples, pode-se colocar esses blocos como contadores que são incrementados a cada instante de tempo em que as saídas das RNAS estão ativadas. Desta forma, 
quando os contadores atingem um valor pré-estabelecido, é confirmada aquela informação como sendo válida na representação do estado do SEP em falta. As constantes utilizadas para a validação de um determinado estado indicado pelo relé estão dispostas na Tabela 6-1. Os valores apresentados nesta tabela foram obtidos experimentalmente e representam, na realidade, o número mínimo de amostras em que uma saída deve permanecer ativa para se confirmar o resultado indicado pelo relé. É importante citar que as saídas das RNAs sofrem pós-processamento, de forma a se evitar dúvida sobre o seu estado (ativo/inativo),

$$
y_{\mathrm{pos}}= \begin{cases}0, & \text { se } y<0,5 \\ 1, & \text { se } y \geq 0,5\end{cases}
$$

Um caso especial de lógica de validação diz respeito à classificação de faltas. Observou-se com os experimentos a necessidade da consideração de um caso particular para classificação de faltas trifásicas. Para estas faltas, foi verificada a possibilidade de ocorrer de os contadores não atingirem o valor determinado na Tabela 6-1. Entretanto, observa-se que o valor final destes contadores serem sempre superiores a $100 \mathrm{e}$ exibirem praticamente os mesmos valores. Assim, um caso especial deve ser sempre verificado, em adição ao procedimento de comparação com as constantes tabeladas. Esta verificação é detalhada na Tabela 6-2.

Quanto à localização, por se tratar de um módulo com três saídas, adota-se também o caso particular em que o contador de uma das saídas não atinge o valor adotado na Tabela 6-1, mas, em contrapartida, é maior que os contadores das demais saídas. Desta forma, é validada aquela saída como indicadora da zona de ocorrência da falta. Este caso especial de validação da localização é detalhado na Tabela 6-3. Cabe ressaltar que, caso a falta não seja confirmada durante o período reservado à detecção, ou seja, caso o contador da lógica de detecção não atinja o valor especificado na Tabela 6-1, as etapas de classificação e localização não são acionadas. 
Tabela 6-1. Constantes utilizadas para validação das indicações de detecção, classificação e localização do relé proposto.

\begin{tabular}{c|c|c}
\hline \hline Etapa & Contadores & Constantes \\
\hline \hline Detecção & $k_{(\mathrm{det})}$ & $\mathbf{4 5}$ \\
\hline Classificação & $k_{\text {(faseA) }}, k_{(\mathrm{faseB}),} k_{(\mathrm{faseC})}, k_{\text {(terra })}$ & $\mathbf{1 1 5}$ \\
\hline Localização & $k_{\text {(zona) })} k_{(\mathrm{zona}),} k_{\text {(zona3) }}$ & $\mathbf{3 2}$ \\
\hline \hline
\end{tabular}

Tabela 6-2. Caso especial de validação do resultado de classificação.

\begin{tabular}{c|c}
\hline \multicolumn{1}{c}{ Etapa } & \multicolumn{2}{c}{ Regra especial de validação } \\
\hline \hline Classificação & Se $k_{(\text {fase } \mathrm{A})} \approx k_{(\mathrm{fase})} \approx k_{(\mathrm{faseC})} \Rightarrow$ falta trifásica \\
\hline \hline
\end{tabular}

Tabela 6-3. Casos especiais de validação do resultado de localização.

\begin{tabular}{c|l}
\hline \hline \multicolumn{1}{c}{ Etapa } & \multicolumn{2}{c}{ Regra especial de validação } \\
\hline \multirow{3}{*}{ Localização } & Se $k_{\text {(zona1) }} \geq k_{\text {(zona2) }}$ e $k_{\text {(zona1) }} \geq k_{\text {(zona3) }} \Rightarrow$ validação de $y_{1}$ \\
& Se $k_{\text {(zona2) }}>k_{\text {(zona1) }}$ e $k_{\text {(zona2) }} \geq k_{\text {(zona3) }} \Rightarrow$ validação de $y_{2}$ \\
& Se $k_{\text {(zona3) }}>k_{\text {(zona1) }}$ e $k_{\text {(zona3) }}>k_{\text {(zona2) }} \Rightarrow$ validação de $y_{3}$ \\
\hline \hline
\end{tabular}

\subsection{Geração de parâmetros de simulação}

Os testes de operação são divididos por linha de transmissão e por zona. Isto é, são efetuados experimentos na linha LT2, inicialmente na Zona 1 e, posteriormente, na Zona 2. O mesmo se aplica à linha de transmissão LT3, com faltas sendo realizadas inicialmente na Zona 2 e, em seguida, na Zona 3. Considera-se um número total de experimentos $E=1000$ em cada zona de proteção de cada linha.

A geração dos parâmetros de faltas nos experimentos possui caráter aleatório. O objetivo deste procedimento é a realização dos testes em uma ampla gama de possibilidades, para melhor caracterizar o desempenho dos sistemas de proteção. Desta maneira, fazendo uso de distribuições de probabilidade uniformes, são determinados os parâmetros distância, resistência e ângulo de incidência da falta, tal como representado na Figura 84 através dos gráficos de função de densidade de probabilidade $(f d p)$. 


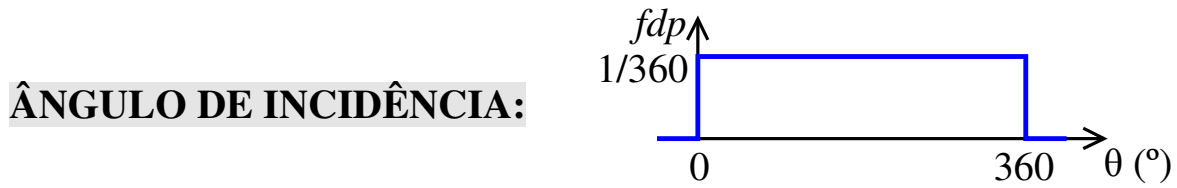

RESISTÊNCIA:
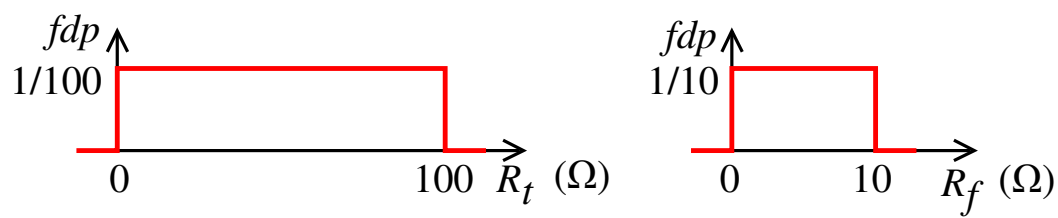

DISTÂNCIA:

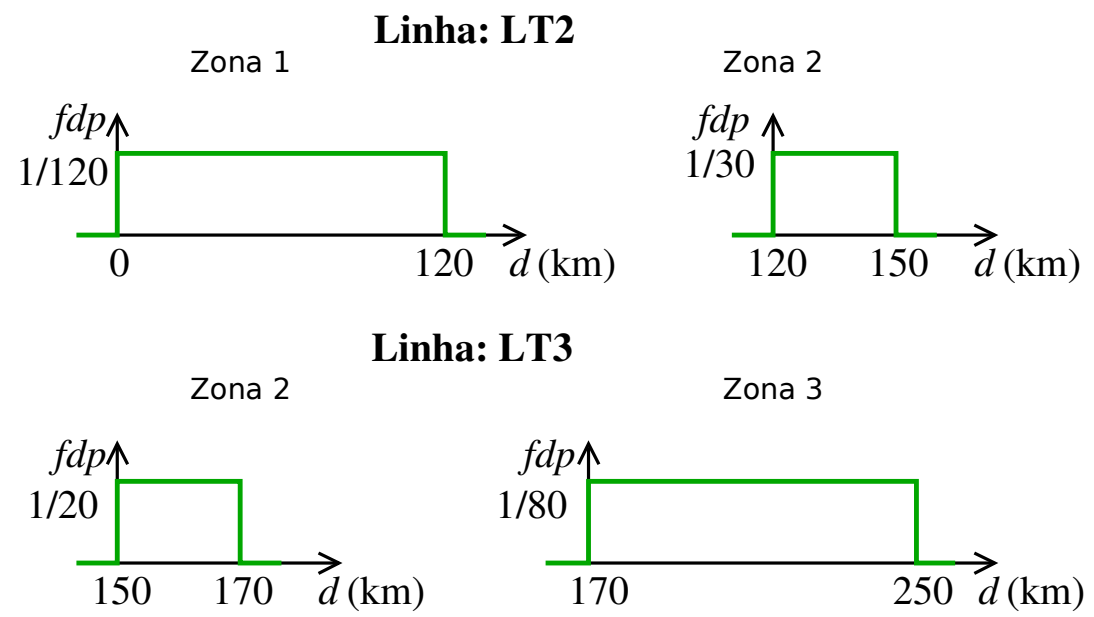

Figura 84. Distribuições de probabilidades para geração dos parâmetros de faltas.

\subsection{Aspectos relacionados à direcionalidade da falta e à comparação de resultados}

Como colocado anteriormente no Capítulo 4, neste trabalho optou-se pela utilização de uma metodologia simples de verificação de direção da falta, como a relatada em [7]. Consultando o sistema elétrico estudado na Figura 22, é verificada facilmente a necessidade de utilização de uma rotina de direcionalidade de modo a identificar se a falta ocorreu na linha LT1.

Utilizando-se a DFT para extração de fasores, tem-se uma representação na Figura 85 do módulo de direcionalidade utilizado neste trabalho. Conforme demonstrado em 
[7], são duas as possibilidades para o ângulo de defasagem $\theta$ entre a corrente da fase faltosa e a tensão desta mesma fase, tal como apresentado nesta figura.

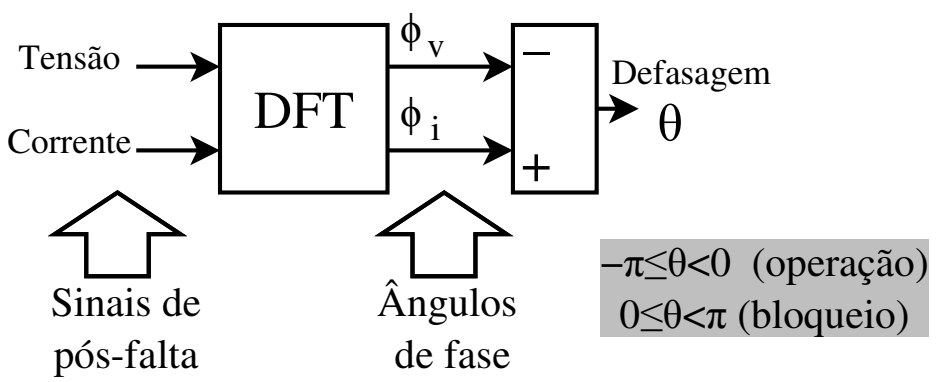

Figura 85. Diagrama funcional da metodologia de direcionalidade.

Pode-se verificar que a metodologia utilizada para a verificação de direção utiliza sinais de tensão. Estes sinais são ditos sinais de polarização em um relé direcional, haja vista que são utilizados como valores de referência na rotina executada pelo relé. Apesar de se poder colocar esta escolha como uma possível desvantagem no método proposto, há de se salientar que a consideração deste procedimento foi meramente visando à simplicidade na implementação. Ademais, no âmbito de simulações computacionais não há desvantagem na utilização deste método, já que o mesmo fornece resultados concisos e não há custos financeiros relacionados à instalação de TPs no modelo computacional.

Em se tratando de uma implementação prática, pode-se considerar, no entanto, métodos de determinação de direcionalidade de faltas que utilizam somente sinais de corrente, tais como os propostos por Pradhan, Routray e Gudipalli [84] ou por Ukil, Deck e Shah [85]. Esta estratégia elimina de fato o uso de TPs e os altos custos financeiros relacionados à aquisição dos mesmos, sem que seja afetado o desempenho da metodologia proposta, exibido e comentado detalhadamente nas seções seguintes.

Nos trabalhos citados no parágrafo anterior, o ponto chave consiste na análise das mudanças de fase ocorridas nos sinais de corrente. Em [84], os autores utilizam na análise de direcionalidade a avaliação dos ângulos de fase das componentes de sequência positiva das correntes. Já em [85], os autores utilizam como variável de 
polarização os sinais de corrente de regime pré-falta e faz-se necessária apenas a detecção de cruzamento por zero para aplicação do algoritmo.

Quanto à direcionalidade da falta, é imperativo afirmar, portanto, que o uso de uma rotina extra não significa desvantagem da metodologia proposta. Apesar de não ser fundamentada no uso de cumulantes e redes neurais, ao se utilizar unicamente sinais de corrente, tem-se um sistema de proteção completo e eficiente.

No que tange à comparação de resultados, a mesma é efetuada nas extensas baterias de testes realizados, com a consideração de um relé tradicional operando segundo as técnicas de detecção, classificação e localização de faltas especificadas na Seção 2.1. Neste processo de comparação, têm-se como válidas duas regras básicas:

1. Avaliação das taxas de acerto das etapas de detecção, classificação e localização para os diferentes tipos de falta, nas zonas de proteção pré-definidas;

2. As taxas de acerto de que trata o item anterior são computadas com o resultado obtido no decorrer do primeiro ciclo de pós-falta, contado a partir da detecção do defeito pelo método em questão.

A regra 1 permite uma avaliação estatística das metodologias, exibindo índices gerais no que tange ao desempenho da metodologia proposta e da metodologia empregada em um relé tradicional. Já a regra 2, consiste no mesmo procedimento adotado por Souza [16], quando comparou a impedância aparente de um relé tradicional, obtida com o uso da DFT, com a impedância aparente obtida com sua metodologia, baseada em algoritmos genéticos.

No presente trabalho, ambas as metodologias possuem também um tempo de processamento máximo permitido igual a um período fundamental para fornecer uma 
resposta para a situação de falta testada. No caso do relé tradicional, por exemplo, a impedância aparente utilizada para avaliação da zona de falta consiste na impedância calculada com a primeira janela completa do regime pós-falta. Este procedimento visa identificar qual metodologia é capaz de fornecer o resultado mais confiável no intervalo de um ciclo completo contado a partir da detecção da falta.

\subsection{Operação da proteção para faltas do tipo F-T}

Os resultados alcançados nesta pesquisa são sumarizados em tabelas para apresentação. No entanto, inicialmente, são apresentados alguns resultados referentes à dinâmica do sistema de operação, tal como detalhado no início da Seção 6. Em especial, são considerados dez experimentos aleatórios e distintos de falta do tipo A-T, cujos parâmetros distância, resistência e incidência são apresentados na Figura 86. Conforme pode ser verificado, estes experimentos são todos correspondentes a faltas na Zona 1 de proteção, conforme definido anteriormente (vide Figura 49).
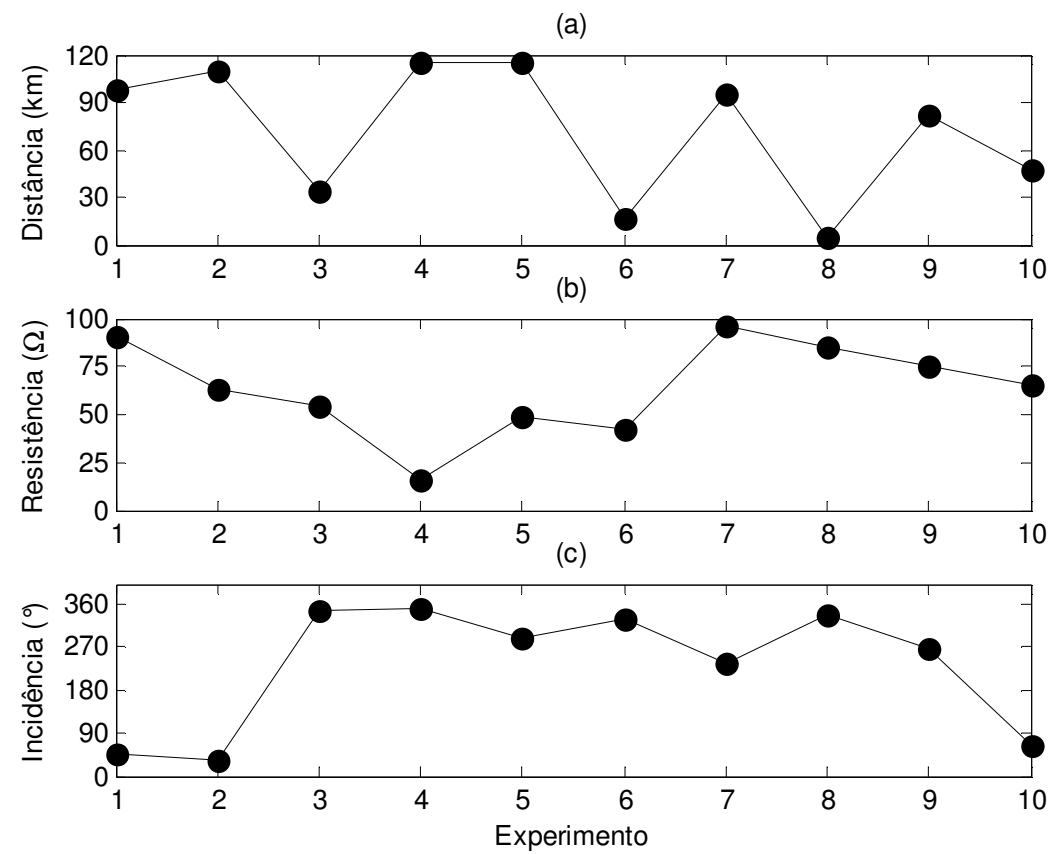

Figura 86. Combinações de simulações referentes a dez experimentos de faltas F-T. 
Os resultados do algoritmo proposto para os dez casos, ou experimentos, de faltas são apresentados na Figura 87. Nesta figura, estão apresentadas as respostas temporais (eixo das abscissas) dos módulos da proteção para todos os casos testados (eixo das ordenadas). A cor preta representa resposta com valor "0" (saída inativa) e a cor branca representa resposta com valor “1” (saída ativa). Tons de cinza representam valores intermediários. A incidência da falta se dá na amostra 256 e o módulo de localização responde prontamente a esta nova condição de operação do SEP. Seguindo a etapa de detecção, a etapa de classificação aponta a participação da fase A e da terra nas faltas. Os módulos de monitoramento das fases B e C apresentam "leves" e breves estados de ativação, os quais não são suficientes para a indicação da participação destas fases no defeito. Por fim, a etapa de localização é ativada. Pode-se verificar que um total de nove experimentos foram corretamente identificados na Zona 1. No entanto, o quinto experimento, com distância próxima a 120 km, foi identificado na Zona 2, o que implica em um erro da metodologia proposta quanto à localização da falta.

Em se tratando do esquema de proteção tradicional, os resultados para os casos testados são apresentados na Figura 88. São apresentadas as respostas temporais das etapas de detecção e classificação. Como no caso anterior, saídas inativas são representadas em preto e saídas ativas são representadas em branco. Valores intermediários se apresentam em tons de cinza. Pode-se verificar facilmente que a detecção da falta ocorre para todos os casos, assim como a identificação do envolvimento da fase A e da terra no defeito. Finalmente, a impedância aparente calculada no término do primeiro ciclo completo pós-falta é representada no plano R-X. Pode-se verificar que, em apenas três casos, ocorre a indicação de Zona 1 para as faltas testadas. Os demais casos, dois na Zona 2 e cinco na Zona 3, constituem erros da metodologia tradicional na localização da falta. 


\section{Detecção}
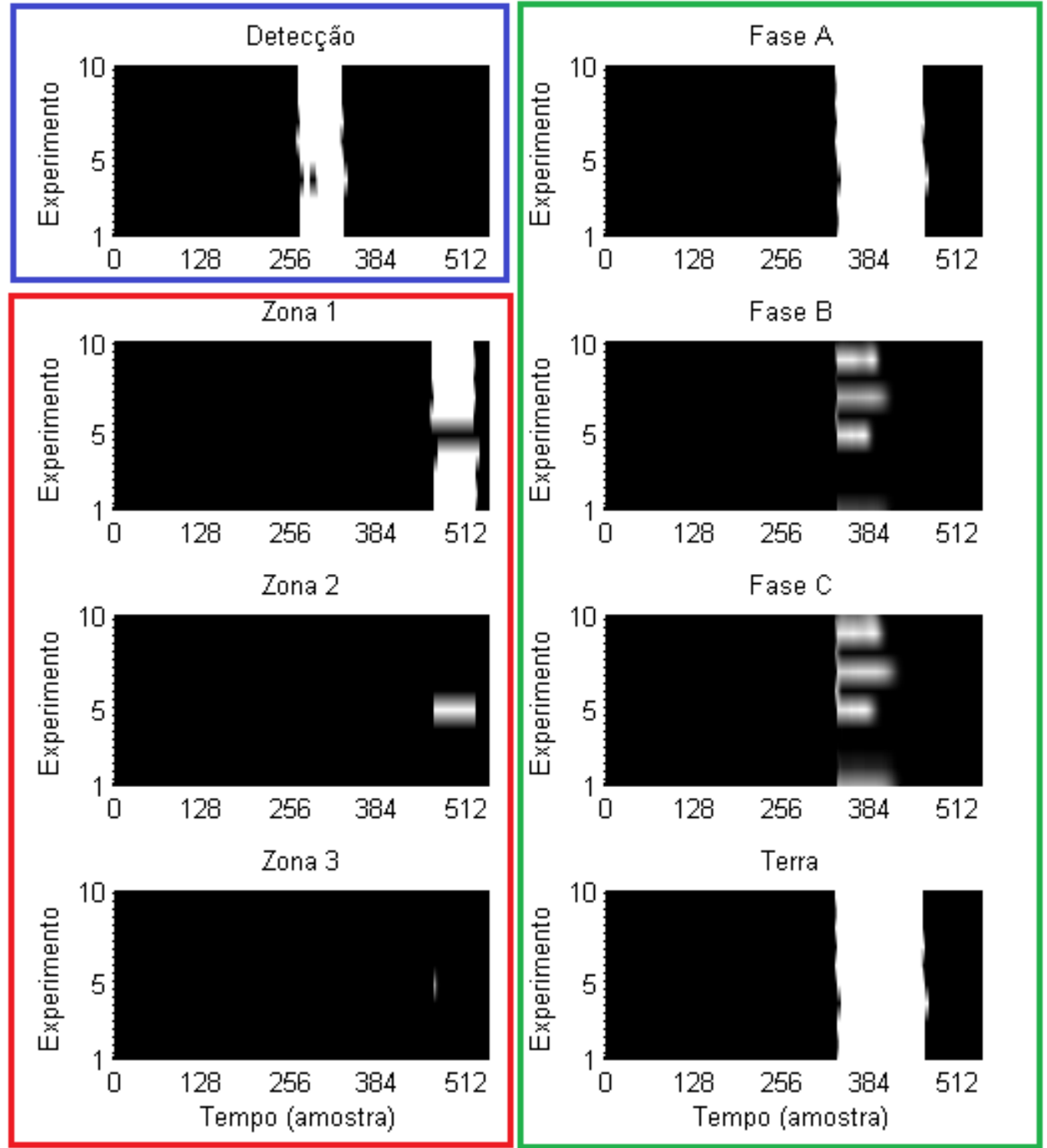

Localização

Classificação

Figura 87. Resultados de operação do sistema de proteção proposto para dez experimentos distintos de faltas F-T: saídas inativas em cor preta e ativas em cor branca 


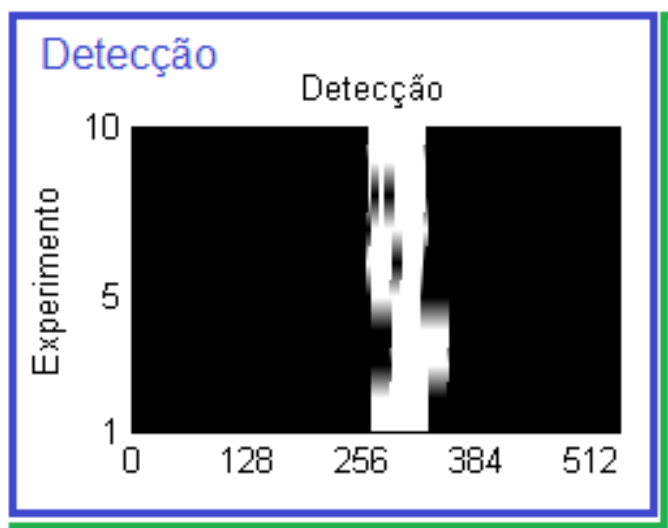

Classificaçẫo - $I_{0}$
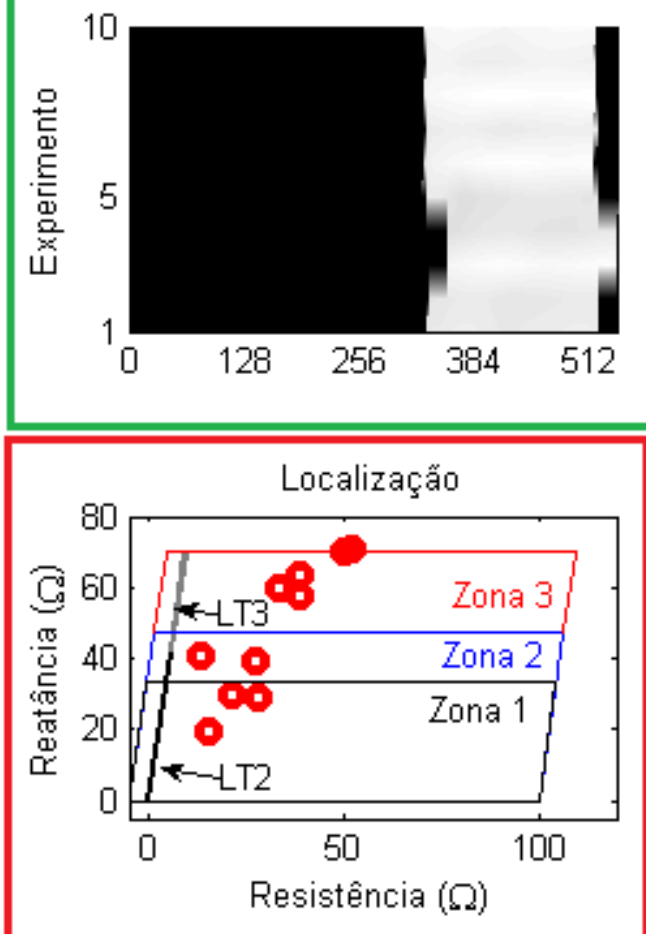

Localização

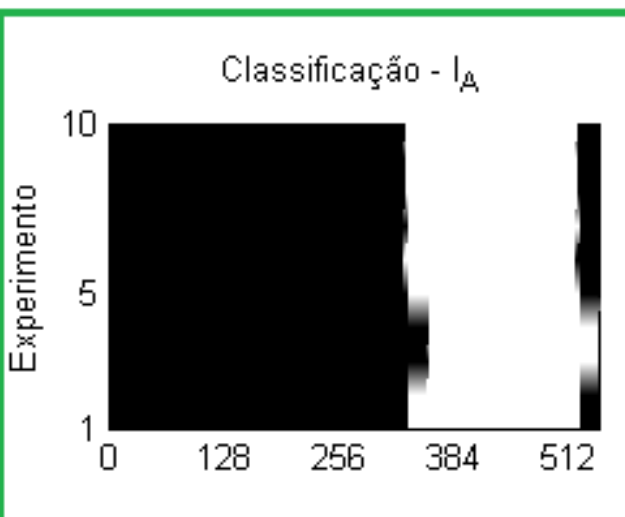

Classificaçẫo - $I_{日}$

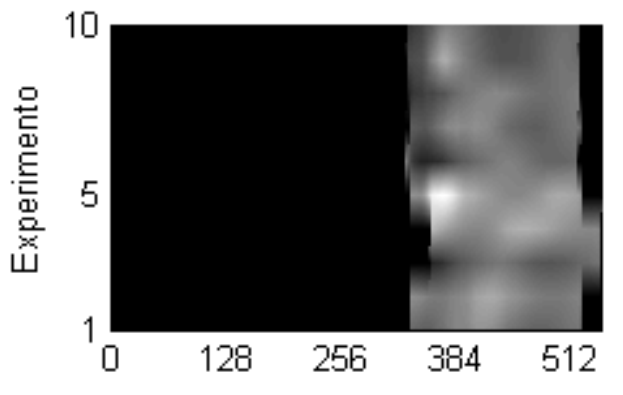

Classificaçẫo $-\mathrm{I}_{\mathrm{C}}$

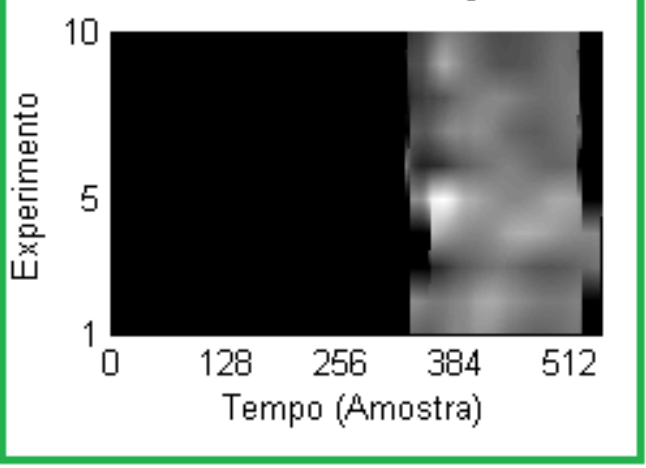

Classificação

Figura 88. Resultados de operação do método de proteção tradicional para dez experimentos distintos de faltas F-T: saídas inativas em cor preta e ativas em cor branca. 
No que se segue, são apresentados os resultados obtidos na operação do sistema de proteção quando da ocorrência de faltas envolvendo uma fase e a terra (F-T). Inicialmente será considerada a linha de transmissão LT2 e, em seguida, a linha LT3.

\subsubsection{Resultados para faltas monofásicas na linha LT2}

\subsubsection{Faltas F-T na Zona 1 de proteção}

Seja considerada inicialmente a ocorrência das faltas na Zona 1. Esta região equivale ao intervalo de 0 a $120 \mathrm{~km}$ em relação ao relé, na linha LT2. Os resultados para estas condições estão dispostos na Tabela 6-4, na Tabela 6-5 e na Tabela 6-6. Do total de 1000 experimentos realizados, as etapas de detecção e classificação foram executadas com taxa de acerto de $100 \%$ para ambas as técnicas analisadas. No que tange à localização, pode-se observar um desempenho amplamente superior da técnica proposta, com EOSs e RNAs, frente à metodologia tradicional de proteção. De fato, aproximadamente $97 \%$ das faltas foram corretamente acusadas na Zona 1, para o relé desenvolvido neste trabalho. O restante foi reconhecido na Zona 2. Em contrapartida, para o relé tradicional, observa-se apenas $40 \%$ das indicações corretas, aproximadamente, no que diz respeito à zona de falta. Situação mais crítica ocorre com a indicação de aproximadamente $30 \%$ das faltas como ocorrendo na Zona 3. Na técnica proposta, nenhuma falta foi acusada nesta zona de proteção. Os resultados demonstram um ligeiro aumento do desempenho da técnica proposta com a inserção do filtro antialiasing e do conversor A/D no processo de medição das correntes no barramento onde se encontra alojado o relé.

Tabela 6-4. Resultados de detecção para faltas F-T na Zona 1, linha LT2.

\begin{tabular}{c|c|c}
\hline \hline \multicolumn{3}{c}{ Detecção } \\
\hline \hline Condições de teste & Metodologia Proposta & Metodologia Tradicional \\
\hline $\begin{array}{c}\text { Sem filtro anti-aliasing } \\
\text { e conversor A/D }\end{array}$ & 1000 & 1000 \\
\hline $\begin{array}{c}\text { Com filtro anti-aliasing } \\
\text { e conversor A/D }\end{array}$ & 1000 & 1000 \\
\hline \hline
\end{tabular}


Tabela 6-5. Resultados de classificação para faltas F-T na Zona 1, linha LT2.

\begin{tabular}{c|c|c|c|c|c|c|c|c}
\hline \hline \multicolumn{7}{c}{ Classificação } \\
\hline \hline \multirow{2}{*}{ Condições de teste } & \multicolumn{7}{c|}{ Metodologia Proposta } & \multicolumn{4}{c}{ Metodologia Tradicional } \\
\cline { 2 - 9 } & Fase A & Fase B & Fase C & Terra & Fase A & Fase B & Fase C & Terra \\
\hline $\begin{array}{c}\text { Sem filtro anti-aliasing } \\
\text { e conversor A/D }\end{array}$ & 1000 & 0 & 0 & 1000 & 1000 & 0 & 0 & 1000 \\
\hline $\begin{array}{c}\text { Com filtro anti-aliasing } \\
\text { e conversor A/D }\end{array}$ & 1000 & 0 & 0 & 1000 & 1000 & 0 & 0 & 1000 \\
\hline \hline
\end{tabular}

Tabela 6-6. Resultados de localização para faltas F-T na Zona 1, linha LT2.

\begin{tabular}{c|c|c|c|c|c|c}
\hline \hline \multicolumn{7}{c}{ Localização } \\
\hline \hline \multirow{2}{*}{ Condições de teste } & \multicolumn{2}{|c}{ Metodologia Proposta } & \multicolumn{2}{c}{ Metodologia Tradicional } \\
\cline { 2 - 7 } & Zona 1 & Zona 2 & Zona 3 & Zona 1 & Zona 2 & Zona 3 \\
\hline $\begin{array}{c}\text { Sem filtro anti-aliasing } \\
\text { e conversor A/D }\end{array}$ & 966 & 34 & 0 & 411 & 292 & 297 \\
\hline $\begin{array}{c}\text { Com filtro anti-aliasing } \\
\text { e conversor A/D }\end{array}$ & 976 & 24 & 0 & 414 & 294 & 292 \\
\hline \hline
\end{tabular}

\subsubsection{Avaliação dos efeitos dos parâmetros de faltas F-T na Zona 1}

A análise realizada nesta Seção consiste em um levantamento de possíveis correlações entre os parâmetros de falta e os erros observados para a metodologia proposta, no que tange à zona primária de proteção.

Conforme pode ser observado na Tabela 6-6, a técnica proposta exibe um total de 34 erros na determinação da zona de falta, quando da não consideração do préprocessamento com filtro anti-aliasing e conversor A/D. Considerando estes casos de falhas, foi realizado o levantamento dos parâmetros das faltas e os mesmos encontramse dispostos na Figura 89(a), (b) e (c). Analisando o parâmetro distância da falta, observa-se uma predominância dos erros para distâncias elevadas em relação ao relé, acima dos $100 \mathrm{~km}$. Ou seja, tratam-se de faltas próximas do limiar entre Zona 1 e Zona 2. O histograma da Figura 90(a), obtido a partir dos dados da Figura 89(a), acusa uma parcela superior a $60 \%$ dos erros ocorrendo acima dos $100 \mathrm{~km}$. Apenas três falhas são associadas a faltas próximas do relé, com distâncias inferiores a $5 \mathrm{~km}$. Notam-se, no 
entanto, elevadas resistências de falta para esses três casos. Quanto ao parâmetro resistência de falta, observa-se na Figura 89(b) a predominância de falhas associadas a resistências de falta superiores a $50 \Omega$. Esta característica resta clara no histograma da Figura 90(b). Analisando o resultado da Figura 89, percebe-se também que, para os casos onde a resistência de falta é inferior a $50 \Omega$, as distâncias são próximas do limite de $120 \mathrm{~km}$ da zona primária do relé. No que tange ao parâmetro ângulo de incidência, através do resultado da Figura 89(c) e do histograma associado, Figura 90(c), pode-se perceber que as falhas na localização ocorrem especialmente para faltas cuja incidência se dá no entorno dos ângulos de $90^{\circ}$ e $270^{\circ}$.

A inserção da etapa de condicionamento de sinais proporcionou redução do número de erros de localização como evidenciado na Tabela 6-6. De fato, nestas condições são verificadas apenas 24 falhas. Os parâmetros das faltas em que foram verificados os erros são apresentados também na Figura 89. Nesta figura, em (d), podese observar um menor índice de variação da distância da falta, se comparado com o resultado de (a). Esta informação fica evidente quando analisado o histograma deste parâmetro, na Figura 90(d). Um único erro de localização ocorreu para uma distância inferior a $100 \mathrm{~km}$, mais precisamente com $d=5,08 \mathrm{~km}$. Trata-se, entretanto, de um caso com uma elevada resistência de falta (aprox. $100 \Omega$ ). No que concerne â resistência de falta, observa-se na Figura 89(e) e no histograma associado, Figura 90(e), uma distribuição mais ampla deste parâmetro. Finalmente, em se tratando do ângulo de incidência da falta, observa-se claramente, analisando a Figura 89(f) e a Figura 90(f), uma associação dos erros de localização às ocorrências de faltas com ângulos nas proximidades de $90^{\circ}$ e $270^{\circ}$. 
Por fim, realiza-se um levantamento da taxa de acerto de localização como função da distância em que a falta ocorre. O resultado é apresentado na Tabela 6-7. Considerando as simulações sem etapa de pré-processamento, cabe salientar que, apesar de os erros de localização estarem associados à proximidade do limiar entre zona primária e secundária, a taxa de acerto da localização para faltas ocorridas no intervalo $114 \leq d<120$ é de $74 \%$. Este intervalo corresponde ao intervalo de incerteza de alcance da Zona 1 , adotado considerando a variação de $\pm 5 \%$ em relação ao limiar de $120 \mathrm{~km}$. No intervalo anterior, com a distância entre 0 e $114 \mathrm{~km}$, o índice de acerto da etapa de localização é de 97,7\%, como apresentado na tabela. Também na Tabela 6-7 são apresentados os resultados obtidos com a etapa de pré-processamento nas simulações. Pode-se obsevar que índice de acerto de localização nas proximidades do relé aumentou para $78 \%$, tendo havido 10 falhas de localização para um total de 46 faltas simuladas neste trecho da linha. Da mesma forma, no intervalo anterior, do relé até o quilômetro 114 da linha LT2, tem-se um incremento no desempenho de localização da falta, passando a figurar um índice de acerto superior a 98\%. Pode-se afirmar, com base neste resultado, que a etapa de condicionamento de sinais permitiu concentrar a probabilidade de ocorrência de erros, para o método proposto, na região de incerteza do alcance da Zona 1, o que representa uma importante e desejada característica para um relé de distância. 
(a)

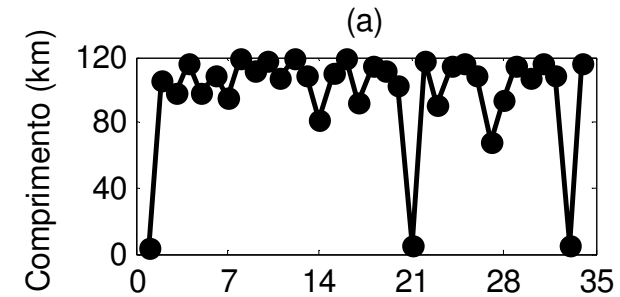

(b)

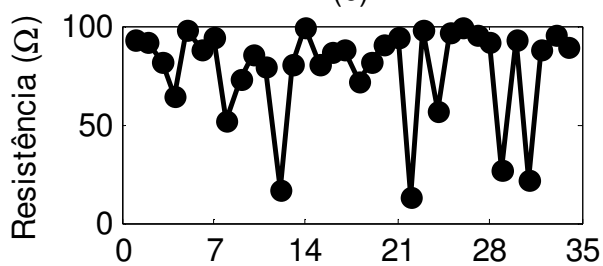

(c)

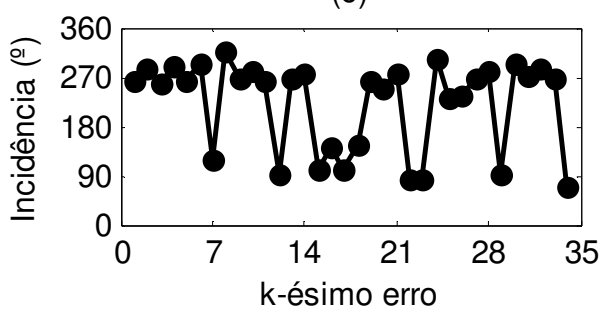

(d)

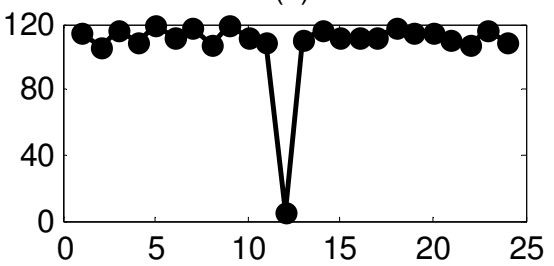

(e)

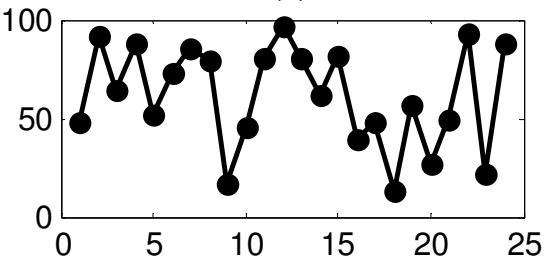

(f)

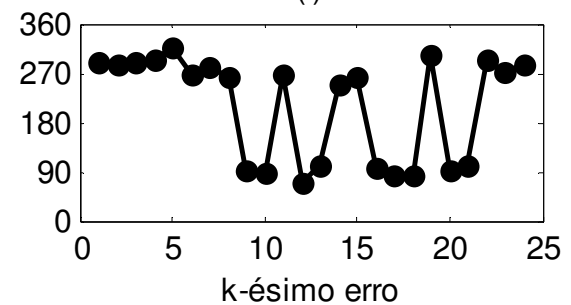

Figura 89. Parâmetros de faltas F-T associados a erros de localização na Zona 1 (LT2): Operação sem pré-processamento em (a), (b) e (c) e com pré-processamento em (d), (e) e (f).
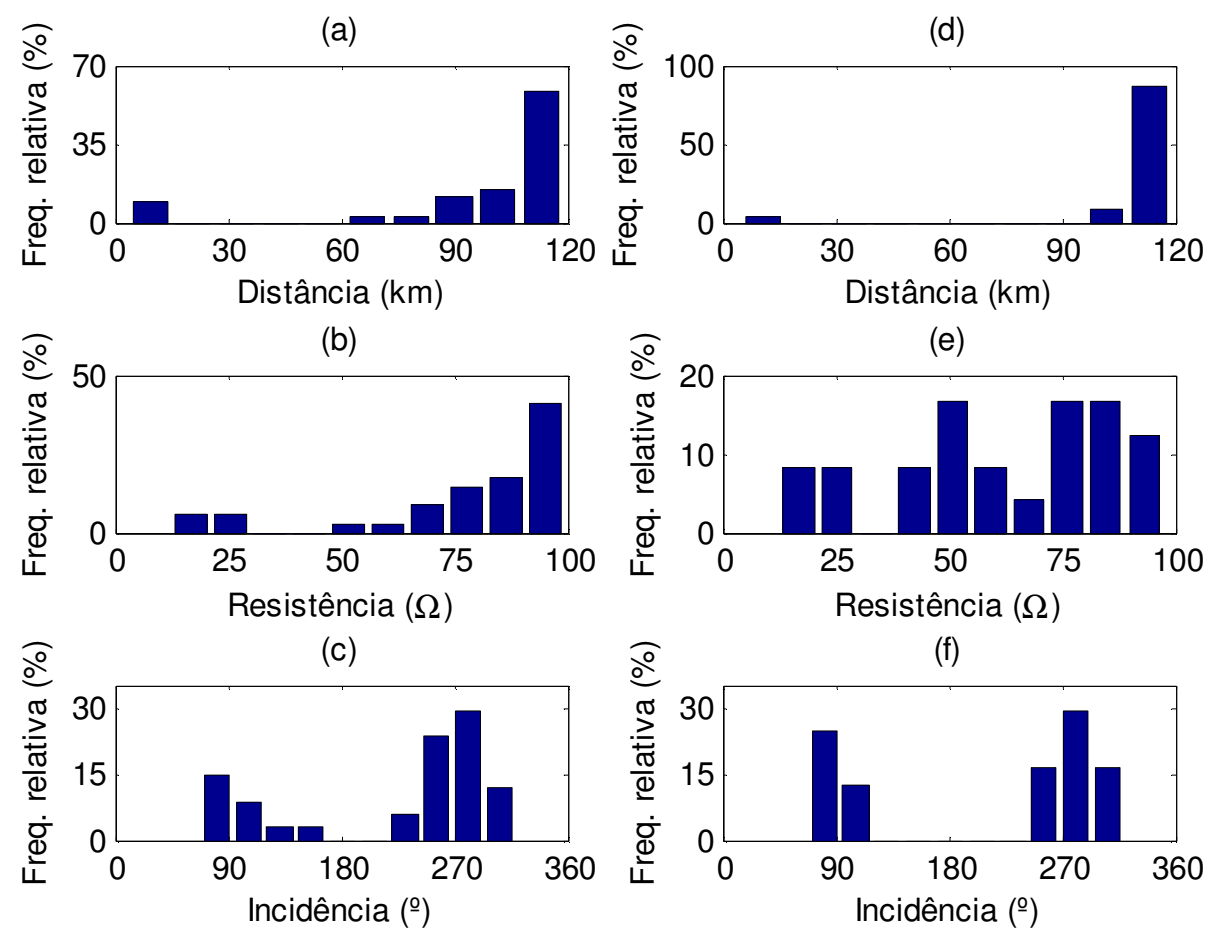

Figura 90. Distribuição dos parâmetros de faltas F-T associados a erros de localização na Zona 1 (LT2): Operação sem pré-processamento em (a), (b) e (c) e com pré-processamento em (d), (e) e (f). 
Tabela 6-7. Taxa de acerto de localização para faltas F-T na Zona 1 (LT2), em função da distância da falta.

\begin{tabular}{c|c|c|c|c}
\hline \hline \multicolumn{5}{|c}{ Localização } \\
\hline \hline Condição de teste & Distância & $\mathbf{N}^{\mathbf{0}}$ de falhas & Total de faltas & Taxa de acerto (\%) \\
\hline $\begin{array}{c}\text { Sem filtro anti-aliasing } \\
\text { e conversor A/D }\end{array}$ & $0 \leq d<114$ & 22 & 954 & $97,7 \%$ \\
\cline { 2 - 5 } & $114 \leq d<120$ & 12 & 46 & $74,0 \%$ \\
\hline $\begin{array}{c}\text { Com filtro anti-aliasing } \\
\text { e conversor A/D }\end{array}$ & $0 \leq d<114$ & 14 & 954 & $98,5 \%$ \\
\cline { 2 - 5 } & $114 \leq d<120$ & 10 & 46 & $78,3 \%$ \\
\hline \hline
\end{tabular}

\subsubsection{Faltas F-T na Zona 2 de proteção}

Considerando a incidência de faltas na porção da linha LT2 equivalente à Zona 2, são apresentados os resultados na Tabela 6-8, na Tabela 6-9 e na Tabela 6-10, respectivamente para as etapas de detecção, classificação e localização. Em se tratando das duas primeiras etapas, assim como no caso das faltas na Zona 1, é observado o acerto das duas metodologias para todos os casos de faltas simulados. Novamente, observa-se superior desempenho do protótipo proposto na etapa de localização. A taxa de acerto obtida com essa metodologia é superior a 90\%, sendo o restante das faltas acusadas na Zona 1. Nenhuma falta foi identificada na Zona 3 e esta se trata de outra vantagem frente ao relé baseado na impedância aparente. Nesta última técnica, apenas cerca de $13 \%$ das faltas foram corretamente localizadas na Zona 2. Todo o restante foi identificado como ocorrendo na Zona 3.

Tabela 6-8. Resultados de detecção para faltas F-T na Zona 2, linha LT2

\begin{tabular}{c|c|c}
\hline \hline \multicolumn{3}{c}{ Detecção } \\
\hline \hline Condições de teste & $\begin{array}{c}\text { Metodologia } \\
\text { Proposta }\end{array}$ & $\begin{array}{c}\text { Metodologia } \\
\text { Tradicional }\end{array}$ \\
\hline $\begin{array}{c}\text { Sem filtro anti-aliasing } \\
\text { e conversor A/D }\end{array}$ & 1000 & 1000 \\
\hline $\begin{array}{c}\text { Com filtro anti-aliasing } \\
\text { e conversor A/D }\end{array}$ & 1000 & 1000 \\
\hline \hline
\end{tabular}


Tabela 6-9. Resultados de classificação para faltas F-T na Zona 2, linha LT2.

\begin{tabular}{c|c|c|c|c|c|c|c|c}
\hline \multicolumn{10}{c}{ Classificação } \\
\hline \hline Condições de teste & \multicolumn{3}{c|}{ Metodologia Proposta } & \multicolumn{4}{c}{ Metodologia Tradicional } \\
\cline { 2 - 9 } & Fase A & Fase B & Fase C & Terra & Fase A & Fase B & Fase C & Terra \\
\hline $\begin{array}{c}\text { Sem filtro anti-aliasing } \\
\text { e conversor A/D }\end{array}$ & 1000 & 0 & 0 & 1000 & 1000 & 0 & 0 & 1000 \\
\hline $\begin{array}{c}\text { Com filtro anti-aliasing } \\
\text { e conversor A/D }\end{array}$ & 1000 & 0 & 0 & 1000 & 1000 & 0 & 0 & 1000 \\
\hline \hline
\end{tabular}

Tabela 6-10. Resultados de localização para faltas F-T na Zona 2, linha LT2.

\begin{tabular}{c|c|c|c|c|c|c}
\hline \hline \multicolumn{7}{c}{ Localização } \\
\hline \multirow{2}{*}{ Condições de teste } & \multicolumn{2}{|c|}{ Metodologia Proposta } & \multicolumn{3}{|c}{ Metodologia Tradicional } \\
\cline { 2 - 7 } & Zona 1 & Zona 2 & Zona 3 & Zona 1 & Zona 2 & Zona 3 \\
\hline $\begin{array}{c}\text { Sem filtro anti-aliasing } \\
\text { e conversor A/D }\end{array}$ & 98 & 902 & 0 & 0 & 129 & 871 \\
\hline $\begin{array}{c}\text { Com filtro anti-aliasing } \\
\text { e conversor A/D }\end{array}$ & 86 & 914 & 0 & 0 & 134 & 866 \\
\hline \hline
\end{tabular}

\subsubsection{Avaliação dos efeitos dos parâmetros de faltas $F$-T na Zona 2}

Conforme apresentado na Tabela 6-10, se considerada a ausência do préprocessamento dos sinais de corrente com filtro anti-aliasing e conversor D/A, 98 faltas são erroneamente indicadas na zona primária, tendo as mesmas ocorrido na zona secundária de proteção. Por outro lado, se considerado o pré-processamento, este número de falhas reduz para 86. Na Figura 91, são apresentados os parâmetros de falta relacionados aos erros de localização nestas duas condições.

Iniciando com a análise dos resultados sem a etapa de condicionamento de sinais, têm-se os parâmetros na Figura 91(a), (b) e (c). Diferentemente da análise de erros ocorridos na Zona 1, não fica clara a relação entre os parâmetros e os erros de localização na Zona 2 por simples inspeção visual. Lançando mão da análise dos histogramas da Figura 92(a), (b) e (c), relativos aos dados da Figura 91, pode-se 
estabelecer alguns importantes comentários. Com relação à distância de ocorrência da falta, percebe-se que os erros da etapa de localização estão correlacionados a distâncias próximas do limiar entre as zonas primária e secundária $(120 \mathrm{~km})$, especialmente para distâncias inferiores a $130 \mathrm{~km}$. A resistência de falta possui uma distribuição bem uniforme no intervalo considerado, de 0 a $100 \Omega$, conforme pode ser verificado na Figura 92(b). No entanto, é superior o número de erros para os casos em que $R_{t}>80 \Omega$. Por fim, com relação ao ângulo de incidência, observa-se especialmente uma associação dos erros aos valores de ângulos no entorno de $0^{\circ}$ e $180^{\circ}$.

A inserção do pré-processamento com filtro anti-aliasing e conversor A/D reduziu em aproximadamente $12 \%$ o número de indicações incorretas da zona de proteção, conforme Tabela 6-10. Na Figura 91(d), (e) e (f) estão dispostos os parâmetros de configuração das faltas equivalentes a estes casos de erro. Percebe-se, nesta figura, em (d), uma maior concentração das distâncias de falta nas proximidades dos $120 \mathrm{~km}$. Esta informação está evidenciada no histograma da Figura 92(a). A análise do parâmetro resistência de falta demonstrou um acúmulo dos casos de erro para resistências de maior valor. De fato, a comparação do histograma da Figura 92(b) com o da Figura 92(e) evidencia um aumento na frequência relativa para resistências superiores a $60 \Omega$. Por fim, os erros de localização estão associados a ângulo de incidência de falta no entorno de $0^{\circ}$ e $180^{\circ}$ (vide Figura 92(f)), como no caso tratado anteriormente. 
(a)

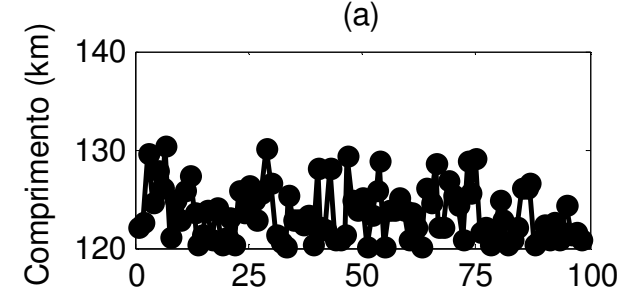

(b)

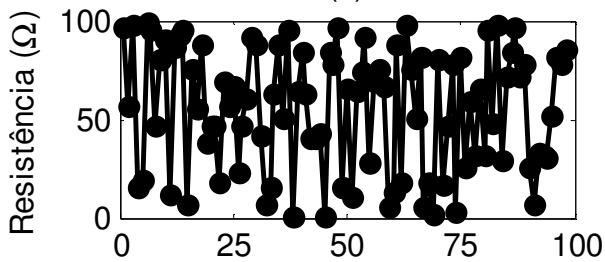

(c)

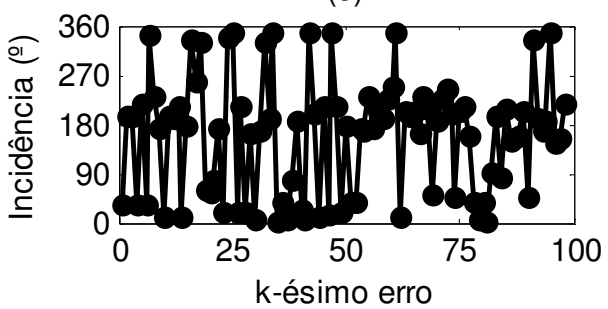

(d)

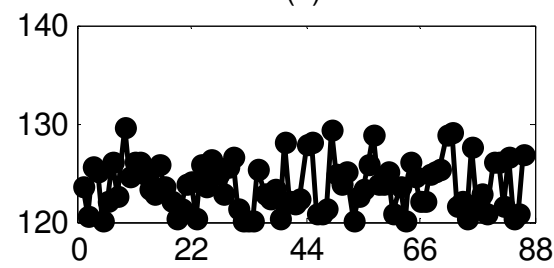

(e)

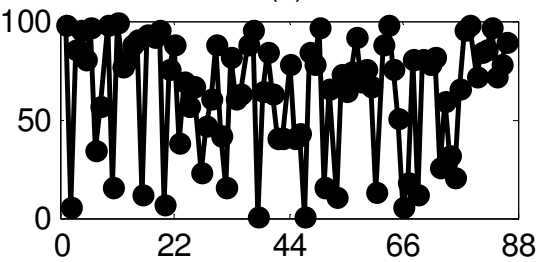

(f)

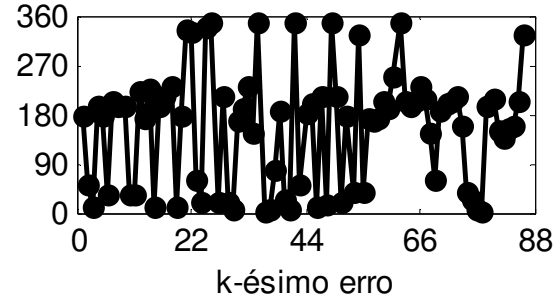

Figura 91. Parâmetros de faltas F-T associados a erros de localização na Zona 2 (LT2): Operação sem pré-processamento em (a), (b) e (c) e com pré-processamento em (d), (e) e (f).

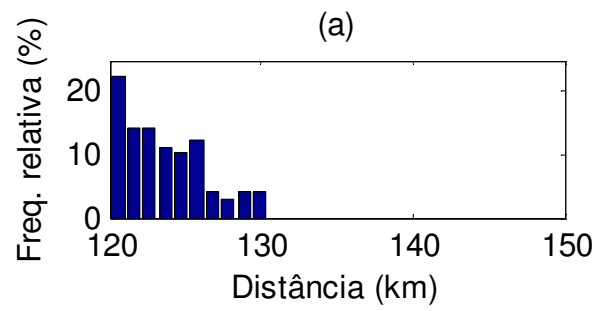

(b)

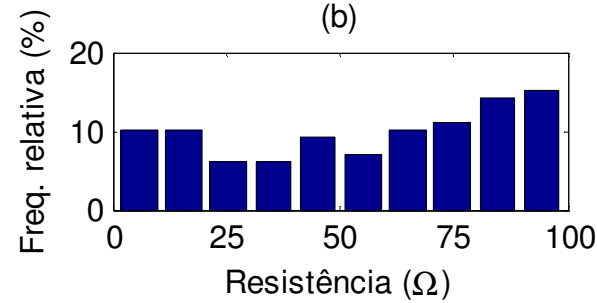

(c)

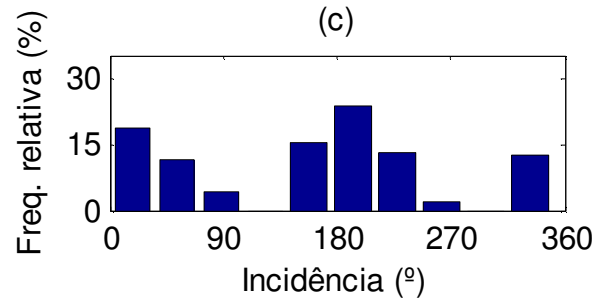

(d)

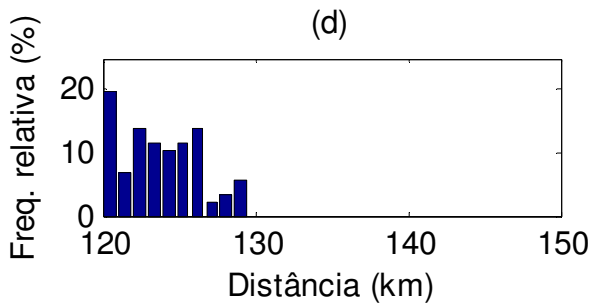

(e)

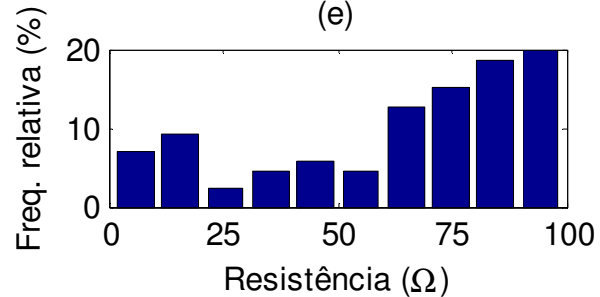

(f)

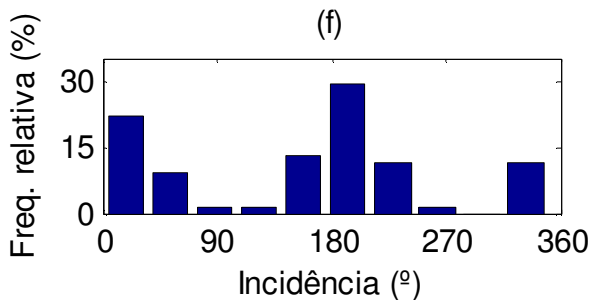

Figura 92. Distribuição dos parâmetros de faltas F-T associados a erros de localização na Zona 2 (LT2): Operação sem pré-processamento em (a), (b) e (c) e com pré-processamento em (d), (e) e (f). 
A Tabela 6-11 sumariza os dados de desempenho geral da etapa de localização para faltas na zona secundária da linha LT2, em função da distância da falta. A primeira informação disponível nesta tabela se refere à operação do sistema sem préprocessamento dos sinais de corrente. Pode-se verificar que, para o intervalo de incerteza padrão de 5\% na zona de alcance, entre 120 e $126 \mathrm{~km}$, a taxa de acerto da zona da falta é da ordem de $63 \%$. No intervalo seguinte, entre 126 e $150 \mathrm{~km}$, verifica-se um índice de acerto no processo de localização de 97,5\%. Considerando o préprocessamento dos sinais de corrente, o índice de acerto nos intervalos de 120 a $126 \mathrm{~km}$ e de 126 a $150 \mathrm{~km}$ atingem, respectivamente, os patamares de $68 \%$ e $97 \%$.

Tabela 6-11. Taxa de acerto de localização para faltas F-T na Zona 2 (LT2), em função da distância da falta.

\begin{tabular}{c|c|c|c|c}
\hline \hline \multicolumn{5}{|c}{ Localização } \\
\hline \hline Condição de teste & Distância & $\mathbf{N}^{\mathbf{0}}$ de falhas & Total de faltas & Taxa de acerto (\%) \\
\hline \multirow{2}{*}{$\begin{array}{c}\text { Sem filtro anti-aliasing } \\
\text { e conversor A/D }\end{array}$} & $120 \leq d<126$ & 78 & 212 & $63,2 \%$ \\
\cline { 2 - 5 } & $126 \leq d<150$ & 20 & 788 & $97,5 \%$ \\
\hline $\begin{array}{c}\text { Com filtro anti-aliasing } \\
\text { e conversor A/D }\end{array}$ & $120 \leq d<126$ & 67 & 210 & $68,1 \%$ \\
\cline { 2 - 5 } & $126 \leq d<150$ & 19 & 790 & 97,6 \\
\hline \hline
\end{tabular}

\subsubsection{Resultados para faltas monofásicas na linha LT3}

\subsubsection{Faltas F-T na Zona 2 de proteção}

Considerando a linha de transmissão LT3, nesta seção, são avaliadas as faltas na zona secundária de proteção. Tendo como referência o barramento $F$, esta região de proteção secundária equivale à porção que vai de 0 a $20 \mathrm{~km}$, conforme pode ser verificado na Figura 49. Tendo como referência o barramento E, pode-se colocar essa região de proteção como o intervalo de distâncias que vai de 150 a 170 km.

Os resultados dos 1000 experimentos de falta realizados nesta porção da linha LT3 são dispostos na Tabela 6-12, na Tabela 6-13 e na Tabela 6-14. Pode-se constatar a 
execução das etapas de detecção e de classificação das faltas, para ambos os métodos, com uma eficiência de $100 \%$. Em se tratando de processo de localização, observa-se desempenho consideravelmente superior da metodologia proposta. Com efeito, o índice de acerto da zona de ocorrência de falta é superior a 97\% para a técnica baseada em EOS e RNA, contrastando com o baixo desempenho, de aproximadamente $20 \%$ de acertos, para a técnica baseada na impedância aparente. Para ambos os métodos, as faltas não indicadas na Zona 2 são indicadas na Zona 3. Desta forma, especialmente para a técnica da impedância aparente, a proteção do SEP fica prejudicada, haja vista que a proteção de retaguarda que o relé deve prover para as faltas nesta porção da linha LT3 fica consideravelmente comprometida. Por fim, cabe salientar que o relé proposto tem o desempenho de localização incrementado com a consideração da etapa de préprocessamento, ou seja, incluindo os filtros passa-baixas anti-aliasing e o conversor A/D para discretização dos sinais de corrente.

Tabela 6-12. Resultados de detecção para faltas F-T na Zona 2, linha LT3.

\begin{tabular}{c|c|c}
\hline \hline \multicolumn{3}{|c}{ Detecção } \\
\hline \hline Condições de teste & $\begin{array}{c}\text { Metodologia } \\
\text { Proposta }\end{array}$ & $\begin{array}{c}\text { Metodologia } \\
\text { Tradicional }\end{array}$ \\
\hline $\begin{array}{c}\text { Sem filtro anti-aliasing } \\
\text { e conversor A/D }\end{array}$ & 1000 & 1000 \\
\hline $\begin{array}{c}\text { Com filtro anti-aliasing } \\
\text { e conversor A/D }\end{array}$ & 1000 & 1000 \\
\hline \hline
\end{tabular}

Tabela 6-13. Resultados de classificação para faltas F-T na Zona 2, linha LT3.

\begin{tabular}{c|c|c|c|c|c|c|c|c}
\hline \hline \multicolumn{7}{c|}{ Classificação } \\
\hline \hline Condições de teste & \multicolumn{7}{|c|}{ Metodologia Proposta } & \multicolumn{3}{c}{ Metodologia Tradicional } \\
\cline { 2 - 9 } & Fase A & Fase B & Fase C & Terra & Fase A & Fase B & Fase C & Terra \\
\hline $\begin{array}{c}\text { Sem filtro anti-aliasing } \\
\text { e conversor A/D }\end{array}$ & 1000 & 0 & 0 & 1000 & 1000 & 0 & 0 & 1000 \\
\hline $\begin{array}{c}\text { Com filtro anti-aliasing } \\
\text { e conversor A/D }\end{array}$ & 1000 & 0 & 0 & 1000 & 1000 & 0 & 0 & 1000 \\
\hline \hline
\end{tabular}


Tabela 6-14. Resultados de localização para faltas F-T na Zona 2, linha LT3.

\begin{tabular}{c|c|c|c|c|c|c}
\hline \hline \multicolumn{7}{c}{ Localização } \\
\hline \hline \multirow{2}{*}{ Condições de teste } & \multicolumn{3}{|c}{ Metodologia Proposta } & \multicolumn{3}{|c}{ Metodologia Tradicional } \\
\cline { 2 - 7 } & Zona 1 & Zona 2 & Zona 3 & Zona 1 & Zona 2 & Zona 3 \\
\hline $\begin{array}{c}\text { Sem filtro anti-aliasing } \\
\text { e conversor A/D }\end{array}$ & 0 & 975 & 25 & 0 & 17 & 983 \\
\hline $\begin{array}{c}\text { Com filtro anti-aliasing } \\
\text { e conversor A/D }\end{array}$ & 0 & 994 & 6 & 0 & 21 & 979 \\
\hline \hline
\end{tabular}

\subsubsection{Avaliação dos efeitos dos parâmetros de faltas F-T na Zona 2}

Os casos simulados associados aos erros de localização do método proposto possuem os parâmetros distância, resistência e ângulo de incidência especificados na Figura 93. Nesta figura, são apresentados os dados relativos às faltas sem o préprocessamento, em (a), (b) e (c), e os dados relativos às faltas com a consideração deste componente, em (d), (e) e (f). Por se tratar de um número baixo de indicações incorretas, as próprias curvas apresentadas nesta figura são utilizadas para se obter algumas conclusões, evitando a geração dos histogramas equivalentes.

Inicialmente, considerando o sistema de proteção sem o filtro anti-aliasing e o conversor A/D, com 25 indicações incorretas de zona de falta, observa-se na Figura 93(a) que as distâncias de ocorrência de falta estão confinadas em um intervalo de $4 \mathrm{~km}$ na linha LT3. Este intervalo vai do quilômetro 16 ao 20, com referência ao barramento F, ou equivalentemente, vai do quilômetro 166 ao 170, com referência ao relé. No tocante à resistência das faltas, observa-se em (b) que há uma distribuição relativamente uniforme deste parâmetro. Finalmente, resta claro em (c) que os erros na localização estão associados às faltas com incidência no entorno dos ângulos de $90^{\circ}$ e $270^{\circ}$. Com a inserção da etapa de condicionamento de sinais (Figura 93(d), (e) e (f)), observa-se, especialmente, que os erros se concentram entre o quilômetro 168 e o quilômetro 170 . 
Adicionalmente, os erros estão associados a resistências de faltas superiores a $50 \Omega$, na sua maioria. Por fim, quanto ao ângulo de incidência é válida a conclusão anterior.

(a)

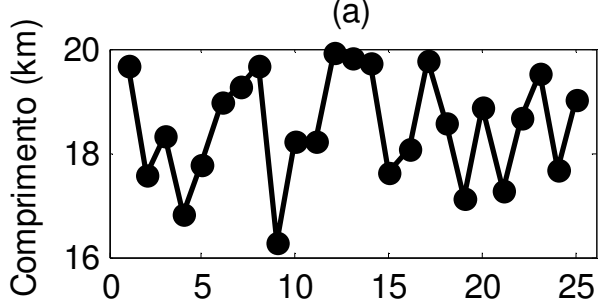

(b)

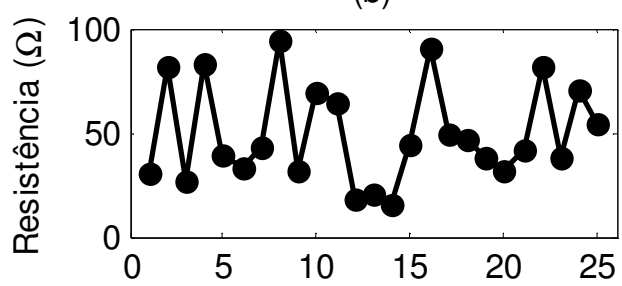

(c)

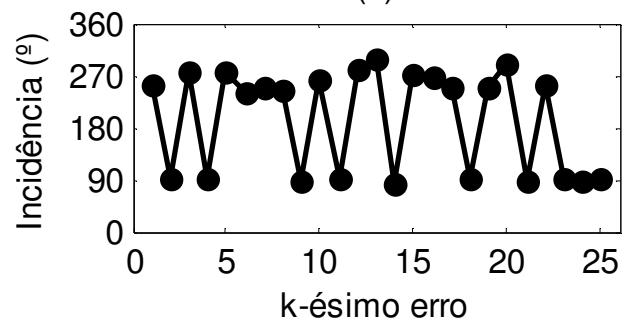

(d)

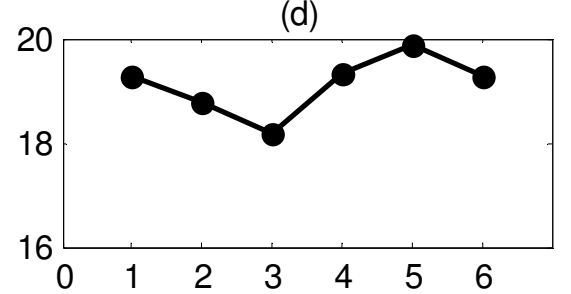

(e)

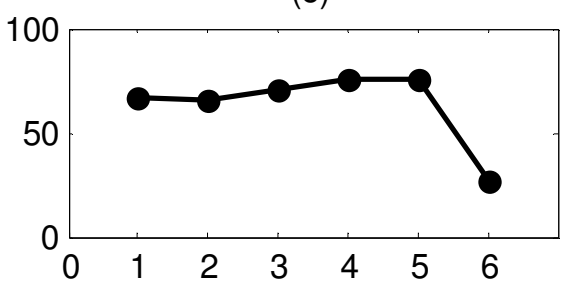

(f)

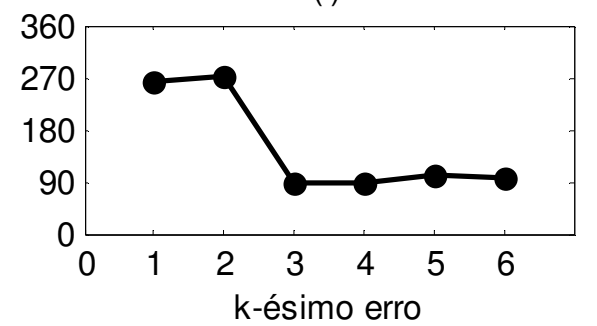

Figura 93. Parâmetros de faltas F-T associados a erros de localização na Zona 2 (LT3): Operação sem pré-processamento em (a), (b) e (c) e com pré-processamento em (d), (e) e (f).

Em termos de desempenho geral da localização, como função da distância de ocorrência da falta, têm-se especificados os dados na Tabela 6-15. No intervalo compreendido entre 150 e 161,5 km tem-se uma taxa de acerto de $100 \%$. No intervalo restante, que equivale à região de incerteza de alcance da Zona 2, de um total de 418 faltas simuladas apenas 25 casos corresponderam a erros de localização. Neste intervalo, tem-se, portanto, uma taxa de acerto de 94,0\%. Considerando a etapa de préprocessamento inserida no sistema de proteção, o desempenho do método proposto é melhorado. Como anteriormente, na porção inicial da linha LT3, de 150 a 161,5 km, o índice de acerto da etapa de localização é de $100 \%$. Em contrapartida, na região 
equivalente ao intervalo dos 161,5 aos $170 \mathrm{~km}$, a etapa de localização do método proposto experimenta um índice de acerto de $98,6 \%$.

Tabela 6-15. Taxa de acerto de localização para faltas F-T na Zona 2 (LT3), em função da distância da falta.

\begin{tabular}{c|c|c|c|c}
\hline \hline \multicolumn{5}{c}{ Localização } \\
\hline Condição de teste & Distância & $\mathbf{N}^{\mathbf{0}}$ de falhas & Total de faltas & Taxa de acerto (\%) \\
\hline Sem filtro anti-aliasing & $150 \leq d<161,5$ & 0 & 582 & $100 \%$ \\
\cline { 2 - 5 } e conversor A/D & $161,5 \leq d<170$ & 25 & 418 & $94,0 \%$ \\
\hline $\begin{array}{c}\text { Com filtro anti-aliasing } \\
\text { e conversor A/D }\end{array}$ & $150 \leq d<161,5$ & 0 & 581 & $100 \%$ \\
\cline { 2 - 5 } & $161,5 \leq d<170$ & 6 & 419 & $98,6 \%$ \\
\hline \hline
\end{tabular}

\subsubsection{Faltas $F-T$ na Zona 3 de proteção}

Finalmente, realiza-se análise para faltas F-T na Zona 3 de proteção, que equivale ao intervalo do quilômetro 20 ao quilômetro 100 da linha LT3 ou, equivalentemente, no intervalo dos 170 aos $250 \mathrm{~km}$ quando a referência tomada é o barramento D, ou o relé.

Os resultados das etapas de detecção, classificação e localização, tanto para o método proposto quanto para a técnica de comparação, são apresentados na Tabela 6-16, na Tabela 6-17 e na Tabela 6-18, respectivamente. As duas primeiras etapas da proteção são executadas por ambas as técnicas sem a constatação de qualquer erro. $\mathrm{Na}$ etapa de localização, a técnica proposta apresenta um índice de desempenho superior a 93\%. Apenas cerca de $6 \%$ das faltas são erroneamente localizadas na Zona 2. A metodologia tradicional tem um índice de acerto de aproximadamente $100 \%$ para este caso. Este é um resultado esperado, haja vista que os índices de acusação de Zona 3 são elevados para esta metodologia, mesmo com as faltas ocorrendo nas zonas primária e secundária. Há de se observar que a inserção do filtro passa-baixas e do conversor A/D reduziu ligeiramente o desempenho da técnica proposta no processo de localização, de $95 \%$ para $93,7 \%$. 
Tabela 6-16. Resultados de deteç̧ão para faltas F-T na Zona 3, linha LT3

\begin{tabular}{c|c|c}
\hline \hline \multicolumn{3}{|c}{ Deteç̧ão } \\
\hline Condições de teste & $\begin{array}{c}\text { Metodologia } \\
\text { Proposta }\end{array}$ & $\begin{array}{c}\text { Metodologia } \\
\text { Tradicional }\end{array}$ \\
\hline $\begin{array}{c}\text { Sem filtro anti-aliasing } \\
\text { e conversor A/D }\end{array}$ & 1000 & 1000 \\
\hline $\begin{array}{c}\text { Com filtro anti-aliasing } \\
\text { e conversor A/D }\end{array}$ & 1000 & 1000 \\
\hline \hline
\end{tabular}

Tabela 6-17. Resultados de classificação para faltas F-T na Zona 3, linha LT3.

\begin{tabular}{c|c|c|c|c|c|c|c|c}
\hline \hline \multicolumn{10}{c}{ Classificação } \\
\hline \hline Condições de teste & \multicolumn{3}{c|}{ Metodologia Proposta } & \multicolumn{4}{c}{ Metodologia Tradicional } \\
\cline { 2 - 9 } & Fase A & Fase B & Fase C & Terra & Fase A & Fase B & Fase C & Terra \\
\hline $\begin{array}{c}\text { Sem filtro anti-aliasing } \\
\text { e conversor A/D }\end{array}$ & 1000 & 0 & 0 & 1000 & 1000 & 0 & 0 & 1000 \\
\hline $\begin{array}{c}\text { Com filtro anti-aliasing } \\
\text { e conversor A/D }\end{array}$ & 1000 & 0 & 0 & 1000 & 1000 & 0 & 0 & 1000 \\
\hline \hline
\end{tabular}

Tabela 6-18. Resultados de localização para faltas F-T na Zona 3, linha LT3.

\begin{tabular}{c|c|c|c|c|c|c}
\hline \hline \multicolumn{7}{c}{ Localização } \\
\hline \hline \multirow{2}{*}{ Condições de teste } & \multicolumn{2}{|c|}{ Metodologia Proposta } & \multicolumn{3}{|c}{ Metodologia Tradicional } \\
\cline { 2 - 7 } & Zona 1 & Zona 2 & Zona 3 & Zona 1 & Zona 2 & Zona 3 \\
\hline $\begin{array}{c}\text { Sem filtro anti-aliasing } \\
\text { e conversor A/D }\end{array}$ & 0 & 50 & 950 & 0 & 0 & 1000 \\
\hline $\begin{array}{c}\text { Com filtro anti-aliasing } \\
\text { e conversor A/D }\end{array}$ & 0 & 63 & 937 & 0 & 3 & 997 \\
\hline \hline
\end{tabular}

\subsubsection{Avaliação dos efeitos dos parâmetros de faltas F-T na Zona 3}

Os parâmetros de simulação das faltas nas quais houve acusação incorreta da zona são apresentados na Figura 94. Nesta figura, em (a), (b) e (c), tem-se a distância, a resistência e o ângulo de incidência, respectivamente, para os 50 casos de erro equivalentes à operação sem filtragem e conversão A/D. Já os parâmetros relativos aos 63 casos de erro equivalentes à operação com etapa de condicionamento de sinal são 
apresentados em (d), (e) e (f). Dado o alto número de indicações incorretas, nesta análise, faz-se uso dos histogramas referentes à Figura 94, apresentados na Figura 95.

Considerando, inicialmente, a operação sem pré-processamento, observa-se uma concentração dos erros para distâncias no intervalo de 20 a 30 km. Esta informação fica evidente com a análise da Figura 94(a) associada com a análise da Figura 95(a). Na Figura 95(b), especialmente, pode-se perceber que os casos de erro ocorrem para toda a faixa de variação de resistências de falta. Por fim, no que tange à incidência da falta, observa-se na análise conjunta da Figura 94(c) com a Figura 95(c) que a ocorrência dos erros de localização está associada aos ângulos nos arredores de $0^{\circ}$ e $180^{\circ}$.

Quando da operação do sistema com filtragem anti-aliasing e processo de conversão A/D, percebe-se um aumento no intervalo das distâncias equivalentes aos erros de localização. Esta informação está estampada na Figura 95(d), em comparação com a Figura 95(a). No tocante ao parâmetro resistência de falta, não fica claro um padrão de associação deste parâmetro aos erros de localização. Em contrapartida, em se tratando da incidência da falta, percebe-se também uma associação das indicações incorretas do localizador com os ângulos de incidência no entorno de $0^{\circ}$ e $180^{\circ}$.

A análise quantitativa do desempenho da localização para a Zona 3 de proteção, em função da distância da falta, encontra-se disponível na Tabela 6-19. Os desempenhos com e sem a consideração do filtro anti-aliasing e do conversor A/D são aproximadamente similares. Nos $8,5 \mathrm{~km}$ correspondentes à região de incerteza do alcance da proteção, tem-se uma taxa de acerto máxima de 54,3\%. Entretanto, cumpre enfatizar que o índice de desempenho para faltas ocorridas na porção restante da linha, de 178,5 a $250 \mathrm{~km}$, exibe um valor mínimo de $99 \%$. 
(a)

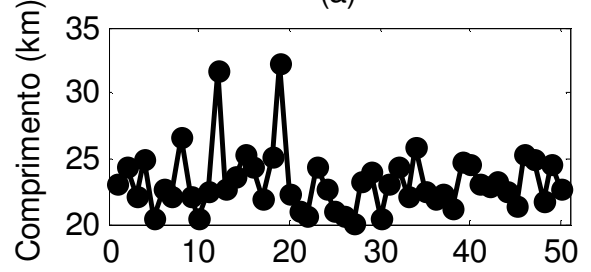

(b)

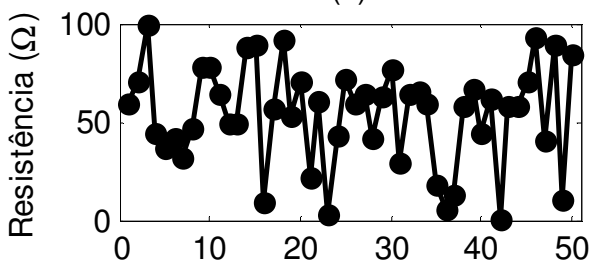

(c)

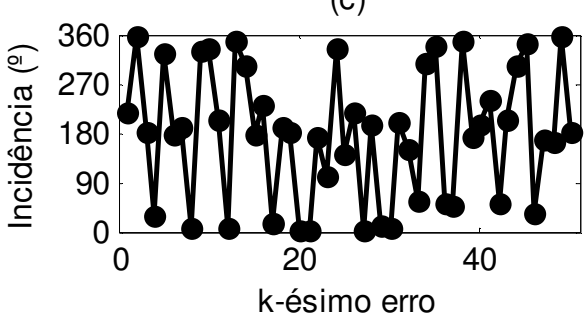

(d)

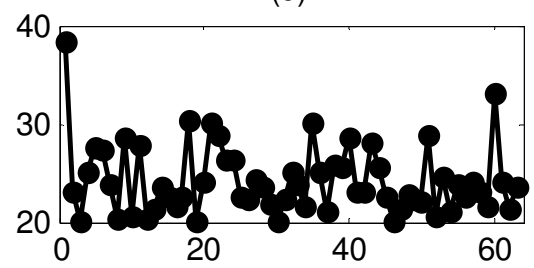

(e)

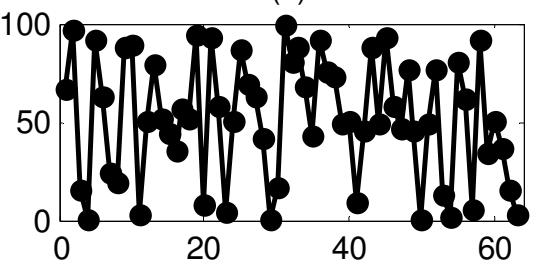

(f)

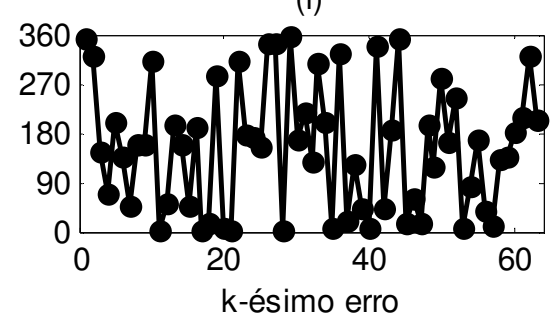

Figura 94. Parâmetros de faltas F-T associados a erros de localização na Zona 3 (LT3): Operação sem pré-processamento em (a), (b) e (c) e com pré-processamento em (d), (e) e (f).

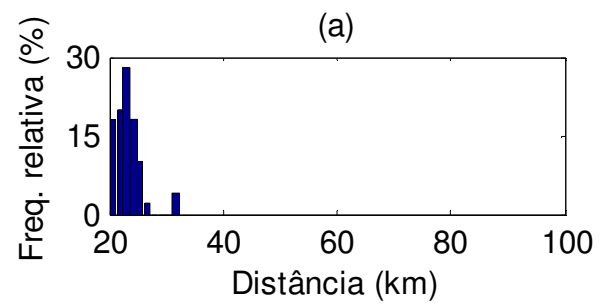

(b)

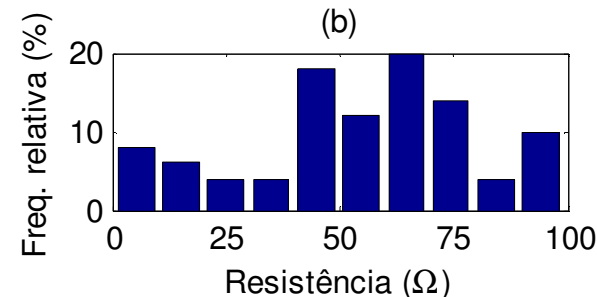

(c)

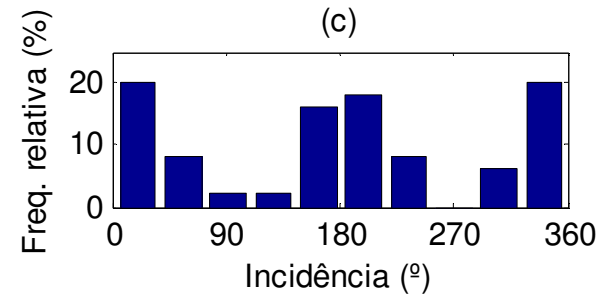

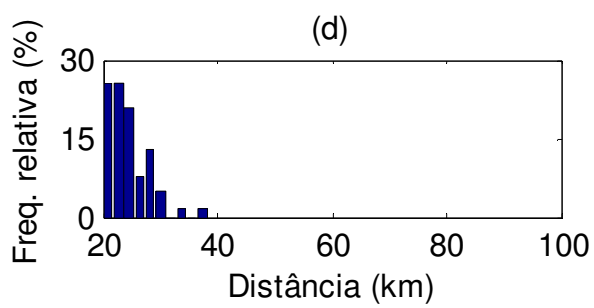

(e)

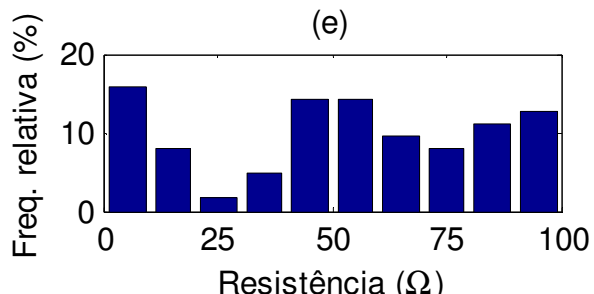

(f)

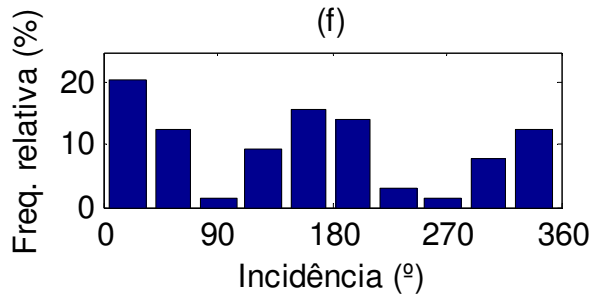

Figura 95. Distribuição dos parâmetros de faltas F-T associados a erros de localização na Zona 3 (LT3): Operação sem pré-processamento em (a), (b) e (c) e com pré-processamento em (d), (e) e (f). 
Tabela 6-19. Taxa de acerto de localização para faltas F-T na Zona 3 (LT3), em função da distância da falta.

\begin{tabular}{c|c|c|c|c}
\hline \hline \multicolumn{5}{c}{ Localização } \\
\hline \hline Condição de teste & Distância & $\mathbf{N}^{\mathbf{0}}$ de falhas & Total de faltas & Taxa de acerto (\%) \\
\hline $\begin{array}{c}\text { Sem filtro anti-aliasing } \\
\text { e conversor A/D }\end{array}$ & $170 \leq d<178,5$ & 48 & 105 & $54,3 \%$ \\
\cline { 2 - 5 } & $178,5 \leq d<250$ & 2 & 895 & $99,8 \%$ \\
\hline $\begin{array}{c}\text { Com filtro anti-aliasing } \\
\text { e conversor A/D }\end{array}$ & $170 \leq d<178,5$ & 54 & 104 & $48,1 \%$ \\
\cline { 2 - 5 } & $178,5 \leq d<250$ & 9 & 896 & $99,0 \%$ \\
\hline \hline
\end{tabular}

\subsubsection{Resumo da avaliação de desempenho para faltas F-T}

Os resultados apresentados e discutidos detalhadamente nas Seções 6.4.1 e 6.4.2, referentes à operação da proteção para faltas do tipo fase-terra, são resumidos na Figura 96. Considera-se, neste resumo, somente o desempenho de operação com etapa de préprocessamento inserida nas simulações, haja vista que uma implementação prática emprega obrigatoriamente os componentes desta etapa.

Na Figura 96, pode-se realizar uma comparação direta das taxas de acerto de localização de faltas relativas ao método proposto, em (a), com as taxas de acerto relativas ao método da impedância aparente, em (b). Considerando os índices por zona de proteção, observa-se ampla superioridade do método baseado em EOS e RNA, com taxa de acerto mínima superior a $93 \%$ na Zona 3. Em compensação, a localização baseada na metodologia da impedância aparente apresenta apenas 7,8\% de acerto para faltas ocorridas na Zona 2. Nesta figura, também estão disponíveis os índices de acerto relativos a intervalos da linha de transmissão, as quais foram obtidas considerando as regiões de incerteza da zona de proteção. Observa-se ampla vantagem da metodologia proposta comparando-a com a metodologia tradicional. Com efeito, nas regiões fora dos intervalos de incerteza, tem-se verificada taxa de acerto mínima superior a $98 \%$ do algoritmo proposto. Contrastando com este índice tem-se a taxa de acerto do método tradicional de apenas 7,7\%, no intervalo compreendido entre o quilômetro 126 e o quilômetro 161,5. 

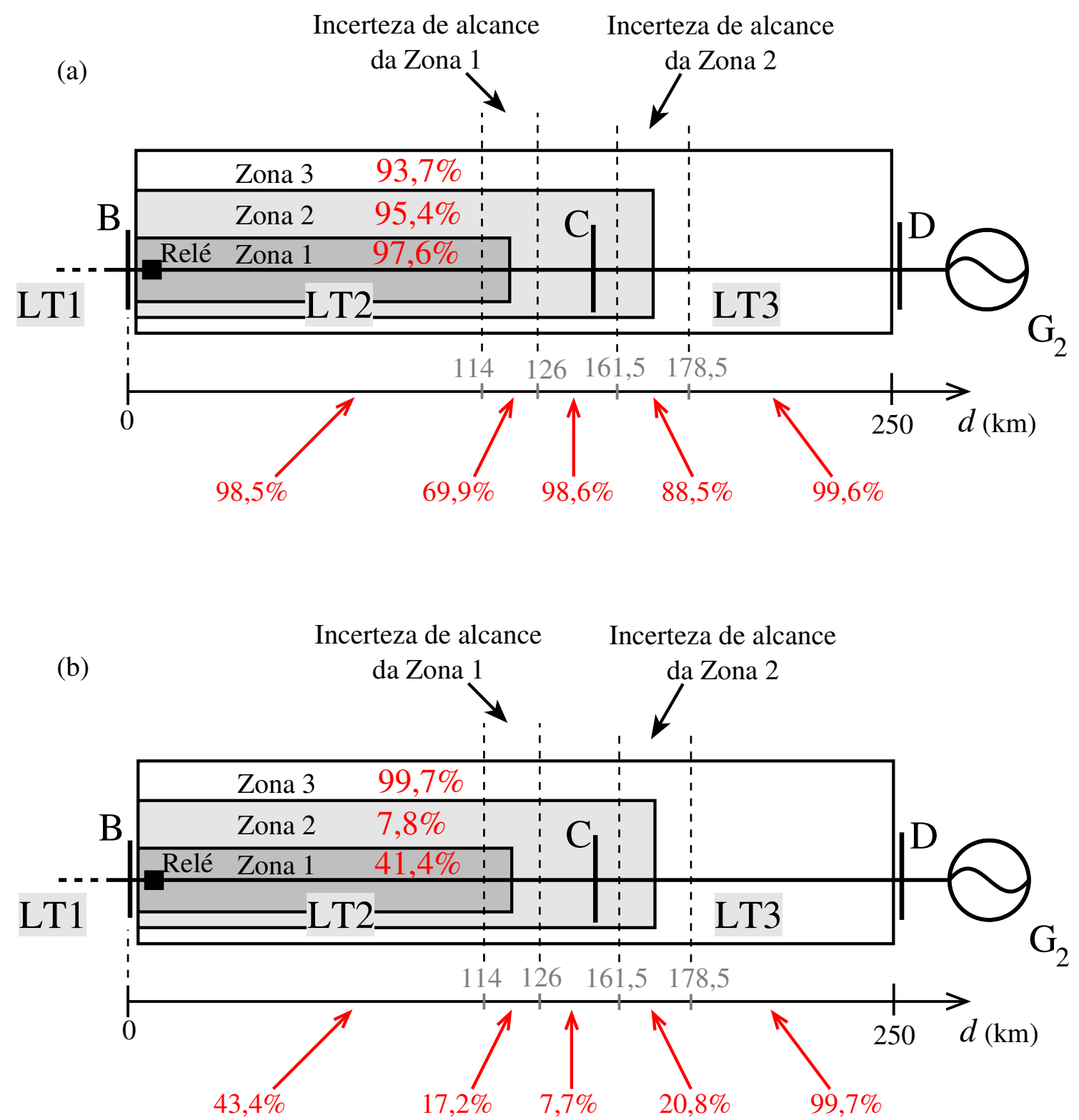

Figura 96. Resumo do resultado de localização (taxa de acerto) para faltas F-T: (a) metodologia proposta e; (b) metodologia tradicional.

O baixo desempenho relacionado à metodologia tradicional, para faltas monofásicas, pode ser compreendido com a análise da Figura 97. No gráfico R-X desta figura, é apresentado o lugar geométrico das impedâncias calculadas para os 1000 experimentos de faltas referentes à zona primária. Percebe-se claramente, neste caso, que o ajuste de Zona 1 deve ser realizado de forma a cobrir uma porção maior de $80 \%$ para o aumento do índice de acerto do relé tradicional e obtenção de valores 
compatíveis com os divulgados na literatura. Como exemplo, se a zona primária for ajustada de forma a cobrir $100 \%$ da linha protegida, a taxa de acerto de localização do método tradicional, nesta zona, passa a ser de aproximadamente $60 \%$. No entanto, dada a forma geométrica da região ideal de operação (vide [10]), delimitada pelas fronteiras I, II, III e IV, é imperativo afirmar que o ajuste da curva quadrilateral não permite a obtenção de desempenho de localização equivalente ao do método proposto nesta tese.

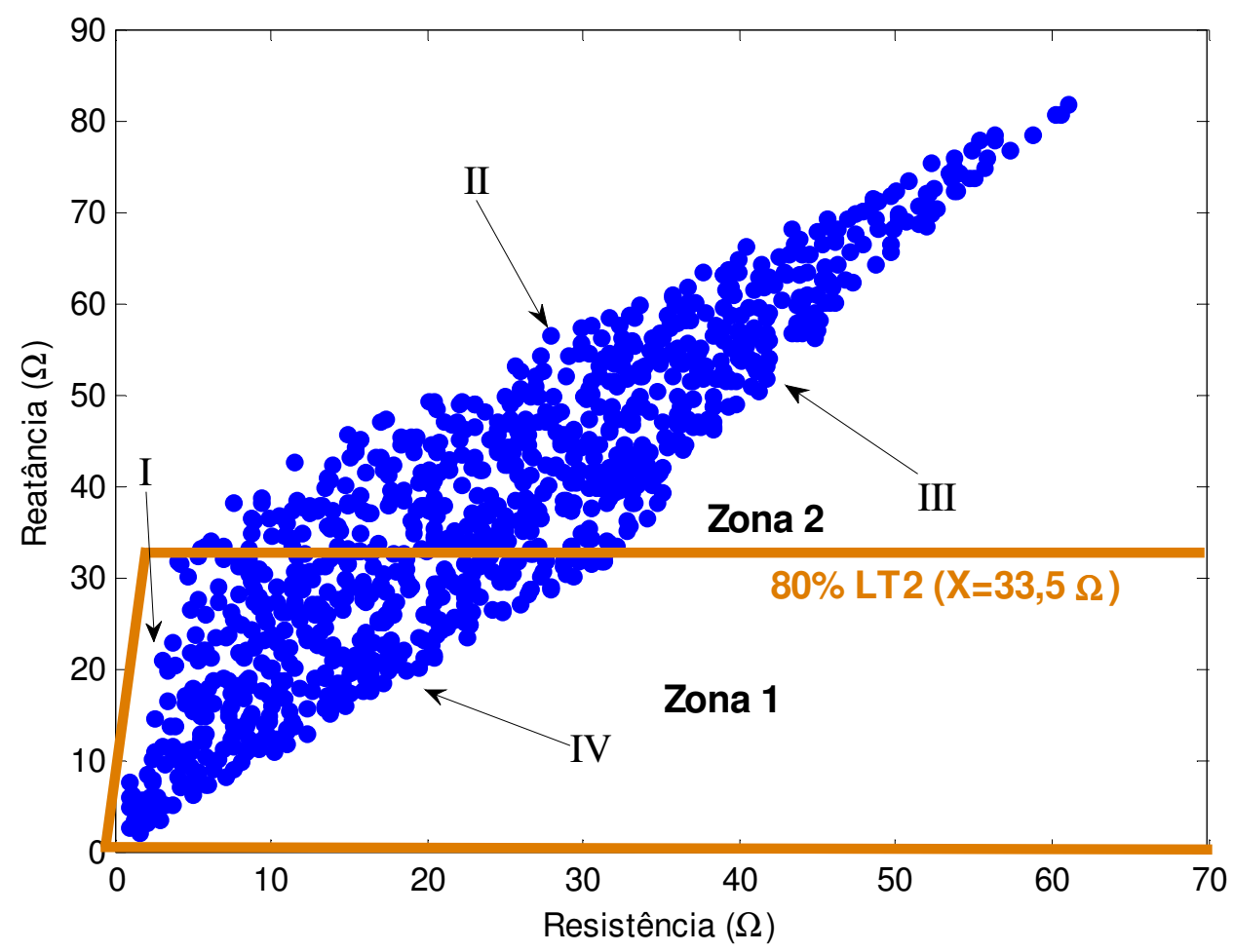

Figura 97. Lugar geométrico das impedâncias referentes às faltas monofásicas na zona 1.

\subsection{Operação da proteção para faltas do tipo F-F-T}

Os resultados referentes às faltas envolvendo duas fases mais a terra são apresentados nesta Seção. Mais especificamente, considera-se uma bateria de testes executada para faltas A-B-T, sendo abordadas inicialmente as faltas na linha LT2 e, posteriormente, na linha LT3. Na operação da proteção para este tipo de falta, é considerado também um total de 1000 experimentos, tal como anteriormente. 


\subsubsection{Resultados para faltas bifásicas com terra na linha LT2}

\subsubsection{Faltas F-F-T na Zona 1 de proteção}

Os resultados para o intervalo compreendido entre 0 e $120 \mathrm{~km}$ na linha LT2 são apresentados na Tabela 6-20, na Tabela 6-21 e na Tabela 6-22. Pode-se verificar nas duas primeiras tabelas, equivalentes às etapas de detecção e classificação, índices de acerto de $100 \%$ para ambas as metodologias.

Tabela 6-20. Resultados de detecção para faltas F-F-T na Zona 1, linha LT2

\begin{tabular}{c|c|c}
\hline \hline \multicolumn{3}{c}{ Detecção } \\
\hline \hline Condições de teste & $\begin{array}{c}\text { Metodologia } \\
\text { Proposta }\end{array}$ & $\begin{array}{c}\text { Metodologia } \\
\text { Tradicional }\end{array}$ \\
\hline $\begin{array}{c}\text { Sem filtro anti-aliasing } \\
\text { e conversor A/D }\end{array}$ & 1000 & 1000 \\
\hline $\begin{array}{c}\text { Com filtro anti-aliasing } \\
\text { e conversor A/D }\end{array}$ & 1000 & 1000 \\
\hline \hline
\end{tabular}

Tabela 6-21. Resultados de classificação para faltas F-F-T na Zona 1, linha LT2.

\begin{tabular}{c|c|c|c|c|c|c|c|c}
\hline \hline \multicolumn{7}{c|}{ Classificação } \\
\hline \hline \multirow{2}{*}{ Condições de teste } & \multicolumn{3}{c|}{ Metodologia Proposta } & \multicolumn{4}{c}{ Metodologia Tradicional } \\
\cline { 2 - 9 } & Fase A & Fase B & Fase C & Terra & Fase A & Fase B & Fase C & Terra \\
\hline $\begin{array}{c}\text { Sem filtro anti-aliasing } \\
\text { e conversor A/D }\end{array}$ & 1000 & 1000 & 0 & 1000 & 1000 & 1000 & 0 & 1000 \\
\hline $\begin{array}{c}\text { Com filtro anti-aliasing } \\
\text { e conversor A/D }\end{array}$ & 1000 & 1000 & 0 & 1000 & 1000 & 1000 & 0 & 1000 \\
\hline \hline
\end{tabular}

Tabela 6-22. Resultados de localização para faltas F-F-T na Zona 1, linha LT2.

\begin{tabular}{c|c|c|c|c|c|c}
\hline \hline \multicolumn{7}{c}{ Localização } \\
\hline \hline \multirow{2}{*}{ Condições de teste } & \multicolumn{2}{|c|}{ Metodologia Proposta } & \multicolumn{3}{|c}{ Metodologia Tradicional } \\
\cline { 2 - 7 } Zona 1 & Zona 2 & Zona 3 & Zona 1 & Zona 2 & Zona 3 \\
\hline $\begin{array}{c}\text { Sem filtro anti-aliasing } \\
\text { e conversor A/D }\end{array}$ & 997 & 3 & 0 & 993 & 7 & 0 \\
\hline $\begin{array}{c}\text { Com filtro anti-aliasing } \\
\text { e conversor A/D }\end{array}$ & 982 & 18 & 0 & 997 & 3 & 0 \\
\hline \hline
\end{tabular}

Na análise da Tabela 6-22, pode-se constatar índices de desempenho no patamar dos $99 \%$ para ambas as técnicas. Apenas para a técnica proposta, com a consideração da 
etapa de pré-processamento, tem-se um desempenho ligeiramente superior a $98 \%$ na identificação da zona primária de proteção. Nestes tipos de falta, o curto-circuito entre as fases gera correntes elevadas e o acréscimo do número de erros, de 3 para 18, pode estar relacionada à saturação nos conversores $\mathrm{A} / \mathrm{D}$, principalmente. Por fim, resta salientar que todas as faltas não identificadas na zona de proteção correta, a Zona 1, são indicadas na zona subsequente, a Zona 2. Não há nenhuma acusação de Zona 3, para as faltas simuladas na zona primária. Em termos gerais, pode-se colocar como ligeiramente superior o desempenho do relé tradicional, baseado na análise da impedância aparente, frente à abordagem do método proposto, baseado em EOS e RNAs.

\subsubsection{Avaliação dos efeitos dos parâmetros de faltas F-F-T na Zona 1}

Os parâmetros distância, resistência e ângulo de incidência, para os casos de erro de localização observados na metodologia proposta, são especificados na Figura 98. Nesta figura, em (a), (b) e (c) tem-se os parâmetros equivalentes aos três casos de erro com operação sem filtros anti-aliasing e conversor A/D. Considerando a inserção desses componentes no sistema, têm-se os parâmetros equivalentes aos dezoito casos de erro apresentados nesta figura, em (d), (e) e (f). Por se tratar de um número reduzido de erros, preferiu-se não gerar os histogramas equivalentes.

De uma consulta simples à Figura 98, pode-se verificar que as faltas ocorrem para um vasto conjunto de valores de resistência de falta. Quanto ao ângulo de incidência das faltas, resta claro que o estabelecimento de um padrão relacionado aos casos de erro é difícil de ser obtido, dada a variação deste parâmetro. Entretanto, a avaliação aqui realizada se resume a observar mais pormenorizadamente a associação entre os casos de erro e o parâmetro distância de falta. Da inspeção desta figura, pode-se estabelecer uma correlação dos erros com distâncias elevadas de falta em relação ao relé, ou seja, nas proximidades do limiar (120 km) entre zona primária e secundária. 
Em termos quantitativos, a relação entre os erros de localização e a distância de ocorrência das faltas está disposta na Tabela 6-23. Pode-se observar, nesta tabela, que a taxa de acerto mínima na localização da falta é ainda superior a 99\%, para o intervalo de 0 a 114 km. Na região de incerteza da zona de proteção primária, dos 114 aos 120 km, observa-se índice de acerto de 96\%. Quando inserido o pré-processamento dos sinais elétricos, percebe-se uma redução deste índice para $67,4 \%$.

(a)

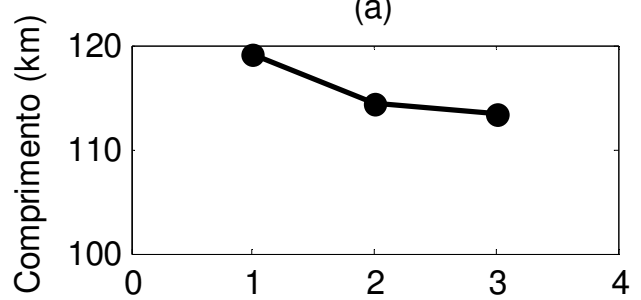

(b)

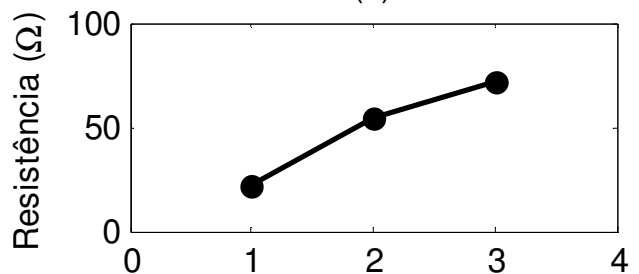

(c)

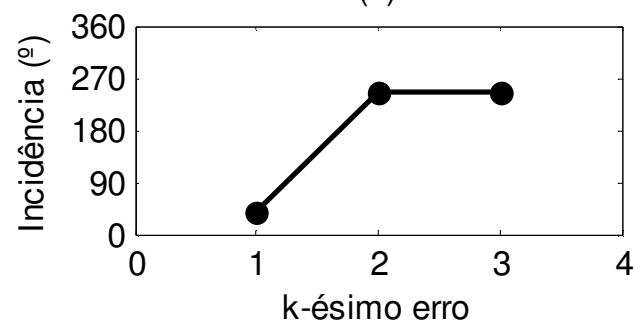

(d)

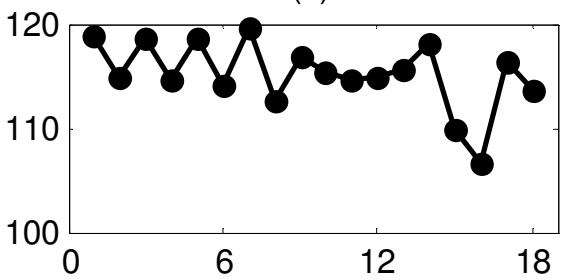

(e)

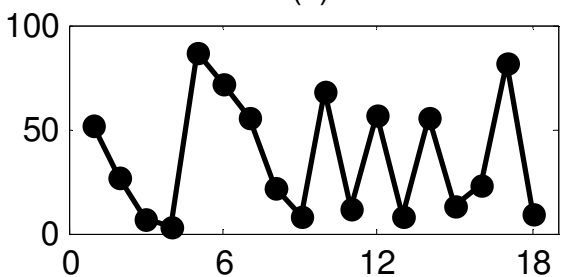

(f)

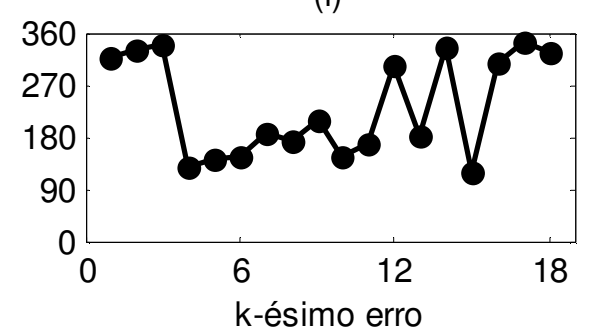

Figura 98. Parâmetros de faltas F-F-T associados a erros de localização na Zona 1 (LT2): Operação sem pré-processamento em (a), (b) e (c) e com pré-processamento em (d), (e) e (f).

Tabela 6-23. Taxa de acerto de localização para faltas F-F-T na Zona 1 (LT2), em função da distância da falta.

\begin{tabular}{c|c|c|c|c}
\hline \hline \multicolumn{5}{c}{ Localização } \\
\hline \hline Condição de teste & Distância & $\mathbf{N}^{\mathbf{0}}$ de falhas & Total de faltas & Taxa de acerto (\%) \\
\hline $\begin{array}{c}\text { Sem filtro anti-aliasing } \\
\text { e conversor A/D }\end{array}$ & $0 \leq d<114$ & 1 & 950 & $99,9 \%$ \\
\cline { 2 - 5 } & $114 \leq d<120$ & 2 & 50 & $96 \%$ \\
\hline $\begin{array}{c}\text { Com filtro anti-aliasing } \\
\text { e conversor A/D }\end{array}$ & $0 \leq d<114$ & 4 & 957 & $99,6 \%$ \\
\cline { 2 - 5 } & $114 \leq d<120$ & 14 & 43 & $67,4 \%$ \\
\hline \hline
\end{tabular}




\subsubsection{Faltas F-F-T na Zona 2 de proteção}

Em se tratando da porção da linha LT2 equivalente ao trecho da zona secundária, ou seja, entre 120 e 150 km, os resultados de detecção, classificação e localização são apresentados, respectivamente, na Tabela 6-24, na Tabela 6-25 e na

Tabela 6-26. Novamente, tem-se índice de acerto de 100\% para as duas primeiras etapas da proteção de distância, tanto na metodologia proposta quanto na metodologia tradicional. Na etapa de localização, têm-se verificadas para ambas as metodologias indicações de zona de proteção incorreta. Em todos os erros verificados, as faltas ocorridas na zona secundária foram indicadas na zona primária de proteção. O método da impedância aparente apresenta um índice de acerto médio de 78,4\% na localização. Em oposição, verifica-se um aumento do índice de acerto da técnica baseada em cumulantes quando da inserção do pré-processamento dos sinais de corrente, passando do nível de $76 \%$ para consideráveis $85,7 \%$.

Tabela 6-24. Resultados de detecção para faltas F-F-T na Zona 2, linha LT2

\begin{tabular}{c|c|c}
\hline \hline \multicolumn{3}{|c}{ Detecção } \\
\hline \hline Condições de teste & $\begin{array}{c}\text { Metodologia } \\
\text { Proposta }\end{array}$ & $\begin{array}{c}\text { Metodologia } \\
\text { Tradicional }\end{array}$ \\
\hline $\begin{array}{c}\text { Sem filtro anti-aliasing } \\
\text { e conversor A/D }\end{array}$ & 1000 & 1000 \\
\hline $\begin{array}{c}\text { Com filtro anti-aliasing } \\
\text { e conversor A/D }\end{array}$ & 1000 & 1000 \\
\hline \hline
\end{tabular}

Tabela 6-25. Resultados de classificação para faltas F-F-T na Zona 2, linha LT2.

\begin{tabular}{c|c|c|c|c|c|c|c|c}
\hline \hline \multicolumn{10}{c|}{ Classificação } \\
\hline \hline Condições de teste & \multicolumn{3}{|c|}{ Metodologia Proposta } & \multicolumn{4}{c}{ Metodologia Tradicional } \\
\cline { 2 - 9 } & Fase A & Fase B & Fase C & Terra & Fase A & Fase B & Fase C & Terra \\
\hline $\begin{array}{c}\text { Sem filtro anti-aliasing } \\
\text { e conversor A/D }\end{array}$ & 1000 & 1000 & 0 & 1000 & 1000 & 1000 & 0 & 1000 \\
\hline $\begin{array}{c}\text { Com filtro anti-aliasing } \\
\text { e conversor A/D }\end{array}$ & 1000 & 1000 & 0 & 1000 & 1000 & 1000 & 0 & 1000 \\
\hline \hline
\end{tabular}


Tabela 6-26. Resultados de localização para faltas F-F-T na Zona 2, linha LT2.

\begin{tabular}{c|c|c|c|c|c|c}
\hline \hline \multicolumn{7}{|c}{ Localização } \\
\hline \hline \multirow{2}{*}{ Condições de teste } & \multicolumn{2}{|c|}{ Metodologia Proposta } & \multicolumn{3}{|c}{ Metodologia Tradicional } \\
\cline { 2 - 7 } & Zona 1 & Zona 2 & Zona 3 & Zona 1 & Zona 2 & Zona 3 \\
\hline $\begin{array}{c}\text { Sem filtro anti-aliasing } \\
\text { e conversor A/D }\end{array}$ & 239 & 761 & 0 & 214 & 786 & 0 \\
\hline $\begin{array}{c}\text { Com filtro anti-aliasing } \\
\text { e conversor A/D }\end{array}$ & 143 & 857 & 0 & 218 & 782 & 0 \\
\hline \hline
\end{tabular}

\subsubsection{Avaliação dos efeitos dos parâmetros de faltas F-F-T na Zona 2}

Os erros de localização da metodologia proposta são detalhados nesta Seção, com a exibição, na Figura 99, dos parâmetros da falta equivalentes aos 239 erros da operação sem pré-processamento, em (a), (b) e (c), e aos 143 erros da operação com filtros antialiasing e conversores A/D, em (d), (e) e (f).

De início, na Figura 99, observa-se uma associação das falhas às faltas cujas distâncias estão nas proximidades dos $120 \mathrm{~km}$, limiar entre as zonas primária e secundária. Este é um resultado esperado e esta conclusão fica clara quando analisados os histogramas da Figura 100(a) e (d). No tocante à resistência de faltas, resta claro, da análise da Figura 100(b) e (e), um acúmulo deste parâmetro na região entre os $50 \Omega$ e os $100 \Omega$, especialmente para a operação sem filtragem anti-aliasing e conversão A/D. No que tange ao ângulo de incidência, observa-se que as falhas da localização ocorreram especialmente para os valores contidos nos intervalos de 0 a $90^{\circ}$ e de 180 a $270^{\circ}$.

Seguindo a metodologia de análise adotada previamente, de caráter quantitativo, na Tabela 6-27 estão dispostos índices de acerto do módulo de localização proposto em função da distância de ocorrência da falta. Em se tratando da região de incerteza do alcance do relé, entre o quilômetro 120 e o quilômetro 126, observa-se que o índice de acerto é de apenas 30\%, para a operação sem pré-processamento. No entanto, com a 
inserção dos módulos de pré-processamento, este índice de acerto é consideravelmente aumentado, passando para $60 \%$. Considerando o intervalo subsequente, de 126 a 150 km, observa-se uma taxa de acerto média de aproximadamente 90\%. Em uma análise conjunta dos parâmetros distância e resistência, observou-se que os erros ocorridos para distâncias acima dos 140 km estão associados a altos valores de resistências de falta, próximas dos $100 \Omega$.

(a)

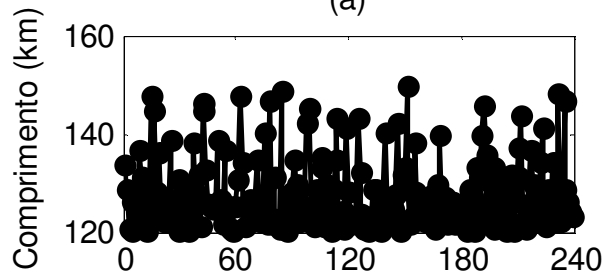

(b)

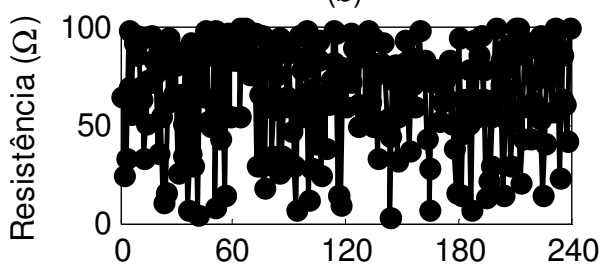

(c)

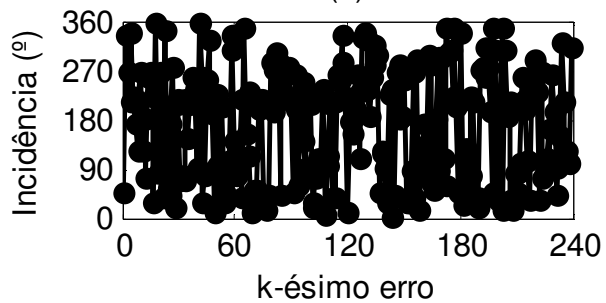

(d)

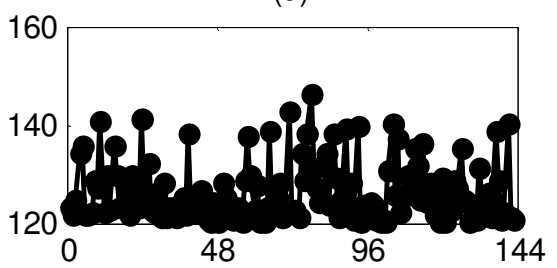

(e)

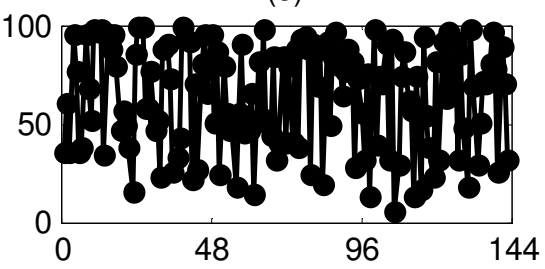

(f)

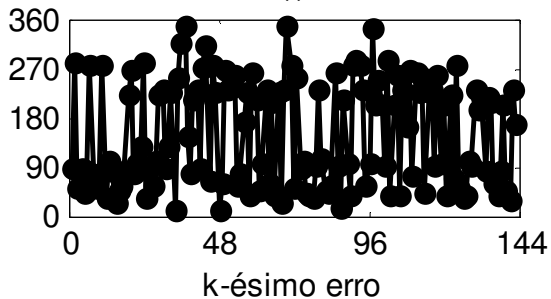

Figura 99. Parâmetros de faltas F-F-T associados a erros de localização na Zona 2 (LT2): Operação sem pré-processamento em (a), (b) e (c) e com pré-processamento em (d), (e) e (f). 

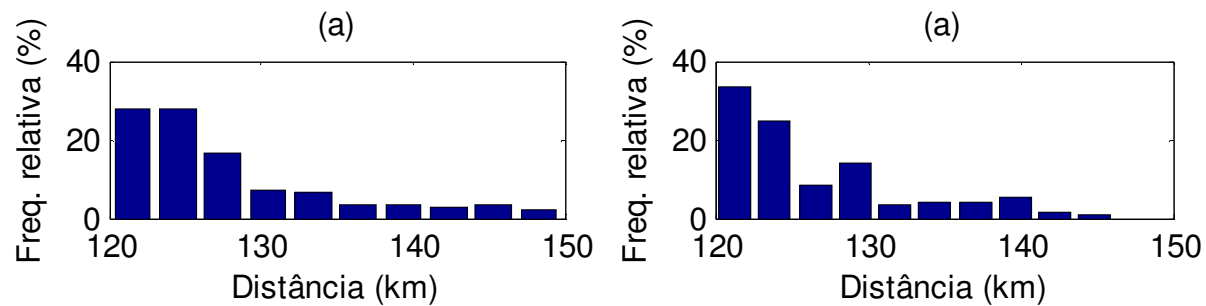

(b)
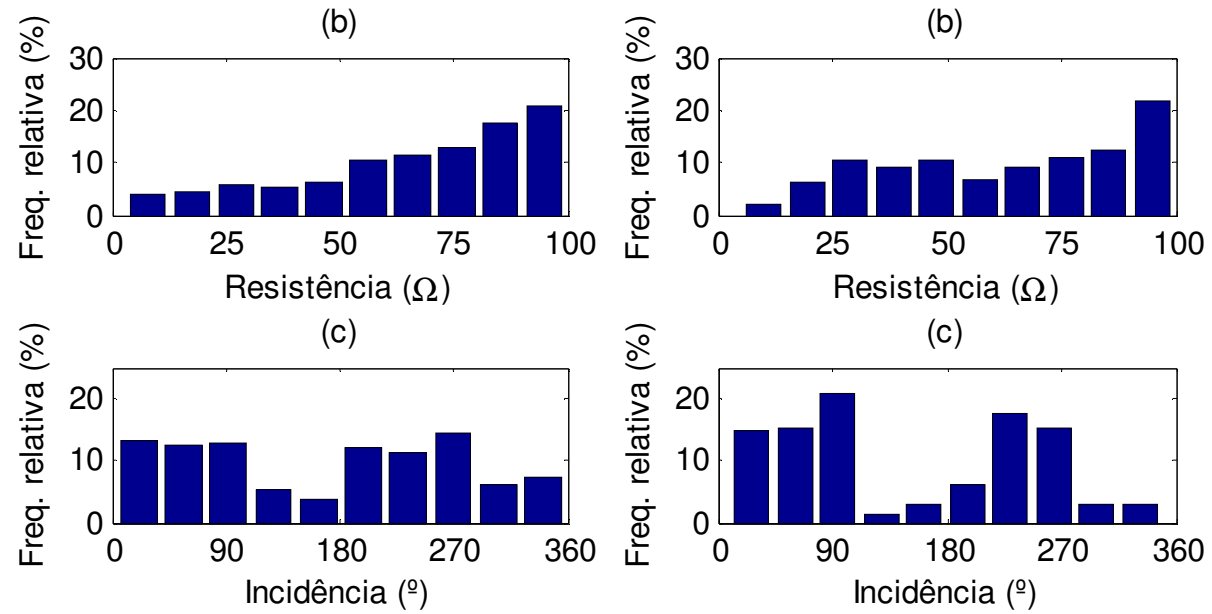

Figura 100. Distribuição dos parâmetros de falta F-F-T associados a erros de localização na Zona 2 (LT2): Operação sem pré-processamento em (a), (b) e (c) e com pré-processamento em (d), (e) e (f).

Tabela 6-27. Taxa de acerto de localização para faltas F-F-T na Zona 2 (LT2), em função da distância da falta.

\begin{tabular}{c|c|c|c|c}
\hline \hline \multicolumn{5}{|c}{ Localização } \\
\hline \hline Condição de teste & Distância & $\mathbf{N}^{\mathbf{0}}$ de falhas & Total de faltas & Taxa de acerto (\%) \\
\hline \multirow{2}{*}{$\begin{array}{c}\text { Sem filtro anti-aliasing } \\
\text { e conversor A/D }\end{array}$} & $120 \leq d<126$ & 133 & 188 & $29,3 \%$ \\
\cline { 2 - 5 } & $126 \leq d<150$ & 106 & 812 & $86,9 \%$ \\
\hline $\begin{array}{c}\text { Com filtro anti-aliasing } \\
\text { e conversor A/D }\end{array}$ & $120 \leq d<126$ & 86 & 215 & $60,0 \%$ \\
\cline { 2 - 5 } & $126 \leq d<150$ & 57 & 785 & $92,7 \%$ \\
\hline \hline
\end{tabular}

\subsubsection{Resultados para faltas bifásicas com terra na linha LT3}

\subsubsection{Faltas $\boldsymbol{F - F - T}$ na Zona 2 de proteção}

Considerando o trecho de $20 \mathrm{~km}$ da linha LT3 pertencente à zona secundária, os resultados gerais de operação dos sistemas de proteção são apresentados na Tabela 6-28, na Tabela 6-29 e na Tabela 6-30. Novamente, é considerado um total de 1000 experimentos aleatórios de falta. As etapas de detecção e classificação são executadas 
pelo algoritmo proposto e pela metodologia tradicional sem a verificação de erros. Considerando a etapa de localização, verifica-se desempenho superior do método baseado em EOSs e RNA. De fato, a taxa de acerto mínima do método proposto é de 99,3\% quando da operação sem pré-processamento. Neste caso, apenas 7 faltas são erroneamente acusadas na zona primária. $\mathrm{O}$ índice de acerto da técnica baseada na impedância aparente é de aproximadamente 90\%. No entanto, o tipo de erro de identificação da zona de falta é diferente. Nesta última técnica, as faltas acusadas fora da Zona 2 são acusadas integralmente na Zona 3.

Tabela 6-28. Resultados de detecção para faltas F-F-T na Zona 2, linha LT3

\begin{tabular}{c|c|c}
\hline \hline \multicolumn{3}{|c}{ Detecção } \\
\hline \hline Condições de teste & $\begin{array}{c}\text { Metodologia } \\
\text { Proposta }\end{array}$ & $\begin{array}{c}\text { Metodologia } \\
\text { Tradicional }\end{array}$ \\
\hline $\begin{array}{c}\text { Sem filtro anti-aliasing } \\
\text { e conversor A/D }\end{array}$ & 1000 & 1000 \\
\hline $\begin{array}{c}\text { Com filtro anti-aliasing } \\
\text { e conversor A/D }\end{array}$ & 1000 & 1000 \\
\hline \hline
\end{tabular}

Tabela 6-29. Resultados de classificação para faltas F-F-T na Zona 2, linha LT3.

\begin{tabular}{c|c|c|c|c|c|c|c|c}
\hline \hline \multicolumn{10}{c|}{ Classificação } \\
\hline \hline Condições de teste & \multicolumn{3}{|c|}{ Metodologia Proposta } & \multicolumn{4}{c}{ Metodologia Tradicional } \\
\cline { 2 - 9 } & Fase A & Fase B & Fase C & Terra & Fase A & Fase B & Fase C & Terra \\
\hline $\begin{array}{c}\text { Sem filtro anti-aliasing } \\
\text { e conversor A/D }\end{array}$ & 1000 & 1000 & 0 & 1000 & 1000 & 1000 & 0 & 1000 \\
\hline $\begin{array}{c}\text { Com filtro anti-aliasing } \\
\text { e conversor A/D }\end{array}$ & 1000 & 1000 & 0 & 1000 & 1000 & 1000 & 0 & 1000 \\
\hline \hline
\end{tabular}

Tabela 6-30. Resultados de localização para faltas F-F-T na Zona 2, linha LT3.

\begin{tabular}{c|c|c|c|c|c|c}
\hline \hline \multicolumn{7}{c}{ Localização } \\
\hline \hline \multirow{2}{*}{ Condições de teste } & \multicolumn{3}{|c}{ Metodologia Proposta } & \multicolumn{3}{|c}{ Metodologia Tradicional } \\
\cline { 2 - 7 } & Zona 1 & Zona 2 & Zona 3 & Zona 1 & Zona 2 & Zona 3 \\
\hline $\begin{array}{c}\text { Sem filtro anti-aliasing } \\
\text { e conversor A/D }\end{array}$ & 7 & 993 & 0 & 0 & 905 & 95 \\
\hline $\begin{array}{c}\text { Com filtro anti-aliasing } \\
\text { e conversor A/D }\end{array}$ & 0 & 1000 & 0 & 0 & 916 & 84 \\
\hline \hline
\end{tabular}




\subsubsection{Avaliação dos efeitos dos parâmetros de faltas F-F-T na Zona 2}

Os parâmetros relativos aos 7 casos de erro na identificação da zona da falta pela técnica proposta são apresentados na Figura 101. Desta figura, sem que seja necessária a confecção de histogramas, pode-se estabelecer algumas conclusões. Em especial, tem-se a relação dos erros com a baixa distância da falta. Com efeito, da Figura 101(a) observase que todas as falhas do localizador aconteceram para distâncias inferiores a $10 \mathrm{~km}$. Outrossim, têm-se associadas e estes baixos valores de distância de faltas altos valores para as resistências das mesmas. Conforme Figura 101(b), as falhas ocorrem especialmente para resistências no intervalo entre $80 \Omega$ e $100 \Omega$. Com relação ao ângulo de incidência, não fica clara a identificação de um padrão entre este parâmetro e os erros de localização.

Avaliação quantitativa entre os erros de localização e a distância de falta é disposta na Tabela 6-31. Nesta tabela, observa-se que na região de incerteza da zona de proteção, de 161,5 a $170 \mathrm{~km}$, todas as faltas foram corretamente identificadas na zona secundária, equivalendo a uma taxa de acerto de $100 \%$. No intervalo anterior, que vai de 150 a $161,5 \mathrm{~km}$, foram verificadas as 7 falhas, para um total de 582 faltas simuladas. Estes resultados são responsáveis por um índice de acerto de 98,8\% nesta região.

Por fim, cabe comentar que, para este tipo de falta, os erros na porção da linha LT3 equivalente à Zona 2 de proteção são diferentes dos erros observados para as faltas monofásicas, analisadas anteriormente, neste mesmo trecho. De fato, para as faltas envolvendo uma fase e a terra, os erros foram observados na região de incerteza na fronteira entre a Zona 2 e a Zona 3 de proteção. 
(a)

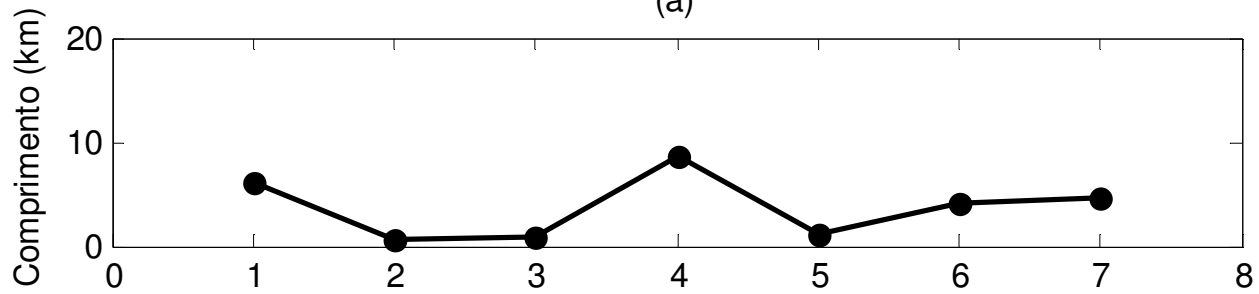

(b)

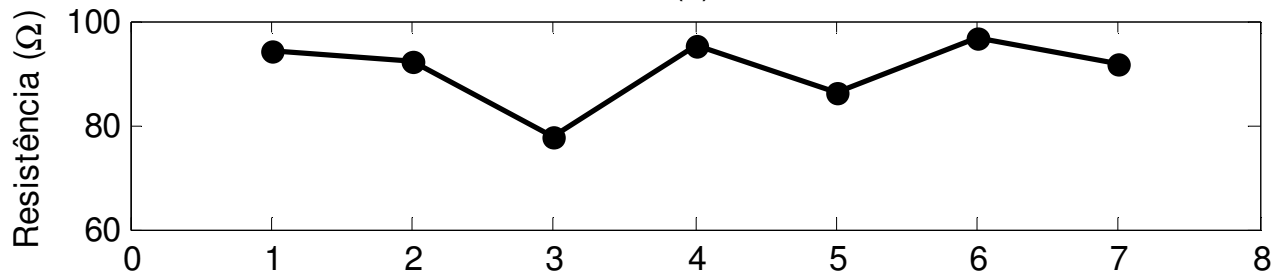

(c)

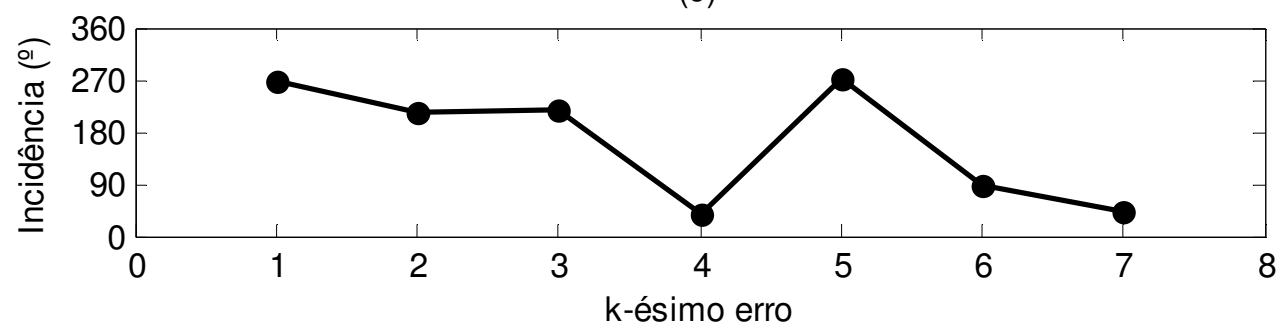

Figura 101. Parâmetros de faltas F-F-T associados a erros de localização na Zona 2 (LT3): Operação sem pré-processamento em (a), (b) e (c) e com pré-processamento em (d), (e) e (f).

Tabela 6-31. Taxa de acerto de localização para faltas F-F-T na Zona 2 (LT3), em função da distância da falta.

\begin{tabular}{c|c|c|c|c}
\hline \multicolumn{5}{c}{ Localização } \\
\hline \hline Condição de teste & Distância & $\mathbf{N}^{\mathbf{0}}$ de falhas & Total de faltas & Taxa de acerto (\%) \\
\hline Sem filtro anti-aliasing & $150 \leq d<161,5$ & 7 & 582 & $98,8 \%$ \\
\cline { 2 - 5 } e conversor A/D & $161,5 \leq d<170$ & 0 & 418 & $100 \%$ \\
\hline \hline
\end{tabular}

\subsubsection{Faltas $F-F-T$ na Zona 3 de proteção}

Por fim, considerando o trecho de $80 \mathrm{~km}$ da linha LT3 equivalente à Zona 3 (de 20 a 100 km em relação ao barramento F), têm-se os resultados das etapas de detecção, classificação e localização especificadas, respectivamente, na Tabela 6-32, na Tabela 6-33 e na Tabela 6-34. De maneira similar aos resultados já exibidos, as etapas de detecção e classificação são executadas sem a ocorrência de erros. Na etapa de localização, são conferidos erros tanto por parte do algoritmo proposto quanto por parte 
do algoritmo baseado na impedância aparente. Este último apresentou, por sinal, desempenho ligeiramente superior ao do método baseado em cumulantes, com uma taxa de acertos média de aproximadamente $86 \%$. Ademais, as indicações incorretas da zona de proteção ocorrem inteiramente com a indicação da Zona 2 no lugar da Zona 3. O método baseado em EOSs e RNA exibiu uma taxa de acerto média de aproximadamente $82 \%$ e foi verificado que a inserção da etapa de pré-processamento equivaleu ao índice de desempenho mais baixo.

Tabela 6-32. Resultados de detecção para faltas F-F-T na Zona 3, linha LT3

\begin{tabular}{c|c|c}
\hline \hline \multicolumn{3}{|c}{ Detecção } \\
\hline Condições de teste & $\begin{array}{c}\text { Metodologia } \\
\text { Proposta }\end{array}$ & $\begin{array}{c}\text { Metodologia } \\
\text { Tradicional }\end{array}$ \\
\hline $\begin{array}{c}\text { Sem filtro anti-aliasing } \\
\text { e conversor A/D }\end{array}$ & 1000 & 1000 \\
\hline $\begin{array}{c}\text { Com filtro anti-aliasing } \\
\text { e conversor A/D }\end{array}$ & 1000 & 1000 \\
\hline \hline
\end{tabular}

Tabela 6-33. Resultados de classificação para faltas F-F-T na Zona 3, linha LT3.

\begin{tabular}{c|c|c|c|c|c|c|c|c}
\hline \hline \multicolumn{7}{c|}{ Classificação } \\
\hline \hline Condições de teste & \multicolumn{3}{|c|}{ Metodologia Proposta } & \multicolumn{3}{c}{ Metodologia Tradicional } \\
\cline { 2 - 9 } & Fase A & Fase B & Fase C & Terra & Fase A & Fase B & Fase C & Terra \\
\hline $\begin{array}{c}\text { Sem filtro anti-aliasing } \\
\text { e conversor A/D }\end{array}$ & 1000 & 1000 & 0 & 1000 & 1000 & 1000 & 0 & 1000 \\
\hline $\begin{array}{c}\text { Com filtro anti-aliasing } \\
\text { e conversor A/D }\end{array}$ & 1000 & 1000 & 0 & 1000 & 1000 & 1000 & 0 & 1000 \\
\hline \hline
\end{tabular}

Tabela 6-34. Resultados de localização para faltas F-F-T na Zona 3, linha LT3.

\begin{tabular}{c|c|c|c|c|c|c}
\hline \hline \multicolumn{7}{c}{ Localização } \\
\hline \hline \multirow{2}{*}{ Condições de teste } & \multicolumn{2}{|c}{ Metodologia Proposta } & \multicolumn{3}{|c}{ Metodologia Tradicional } \\
\cline { 2 - 7 } Zona 1 & Zona 2 & Zona 3 & Zona 1 & Zona 2 & Zona 3 \\
\hline $\begin{array}{c}\text { Sem filtro anti-aliasing } \\
\text { e conversor A/D }\end{array}$ & 1 & 165 & 834 & 0 & 137 & 863 \\
\hline $\begin{array}{c}\text { Com filtro anti-aliasing } \\
\text { e conversor A/D }\end{array}$ & 0 & 188 & 812 & 0 & 141 & 859 \\
\hline \hline
\end{tabular}




\subsubsection{Avaliação dos efeitos dos parâmetros de faltas F-F-T na Zona 3}

Os casos de simulação correspondentes aos erros apresentados na Tabela 6-34 são avaliados nesta Seção. Na Figura 102, têm-se em (a), (b) e (c) os parâmetros de faltas equivalentes aos 166 casos de indicação incorreta obtidos na operação da proteção sem pré-processamento. Nesta mesma figura, em (d), (e) e (f) têm-se os parâmetros dos erros associados à operação com filtro anti-aliasing e conversor A/D.

Na análise do parâmetro distância, verifica-se uma maior concentração deste parâmetro no intervalo entre 20 e 40 km (170 a 190 km em relação ao relé), ou seja, no trecho de início da Zona 3. Esta informação fica clara quando analisados os histogramas da Figura 103(a) e (d), equivalentes aos dados da Figura 102(a) e (d), respectivamente. $\mathrm{Na}$ análise destas duas figuras, no tocante à resistência de faltas, percebe-se também, claramente, uma correlação dos erros de localização com as resistências de valores mais elevados, entre 50 e $100 \Omega$. Por fim, com relação ao ângulo de incidência de falta, percebe-se um maior índice de erros associados à incidência das faltas nos intervalos de $0^{\circ}$ a $90^{\circ}$ e de $180^{\circ}$ a $270^{\circ}$.

Quantitativamente, o desempenho do localizador é levantado e especificado na Tabela 6-35, como função da distância onde foi simulada a falta. Na região de incerteza do alcance da proteção, de 170 a $178,5 \mathrm{~km}$, tem-se um índice de acerto da zona de proteção de aproximadamente $19,2 \%$ que se reduz para $12,2 \%$ quando da utilização da etapa de pré-processamento. Em contrapartida, na porção restante da linha, de 178,5 a $250 \mathrm{~km}$, esta taxa de acerto alcança o patamar dos $90 \%$. 
(a)

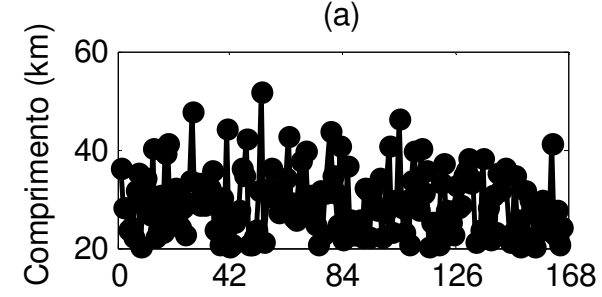

(b)

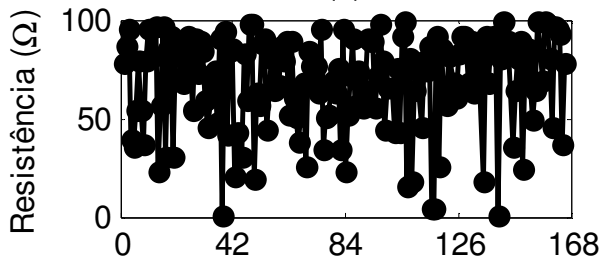

(c)

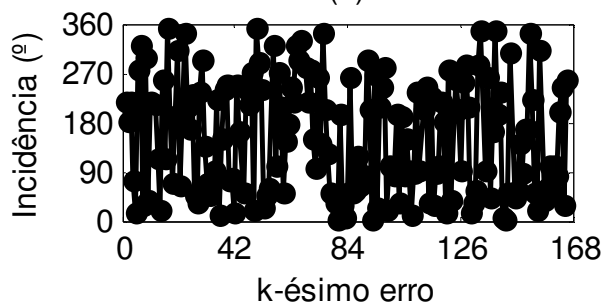

(d)

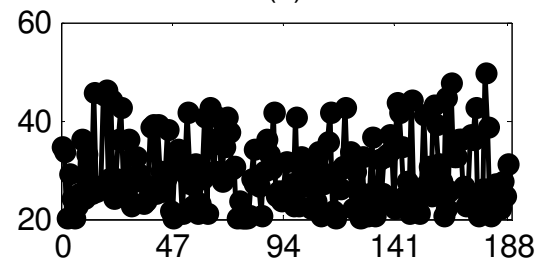

(e)

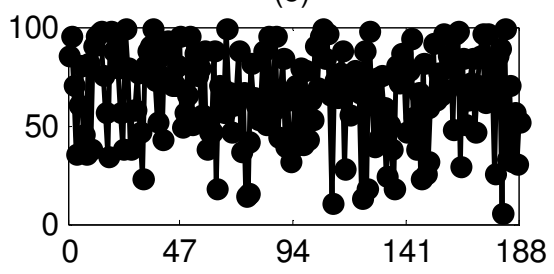

(f)

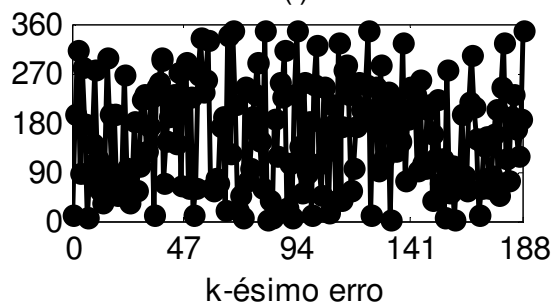

Figura 102. Parâmetros de faltas F-F-T associados a erros de localização na Zona 3 (LT3):

Operação sem pré-processamento em (a), (b) e (c) e com pré-processamento em (d), (e) e (f).

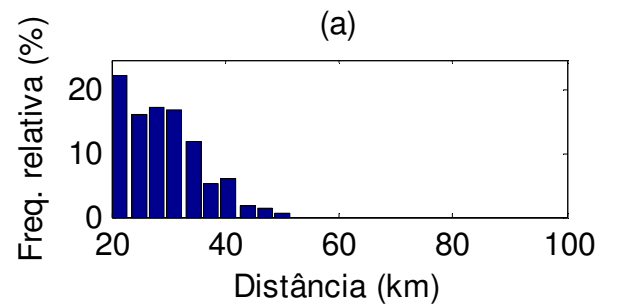

(b)

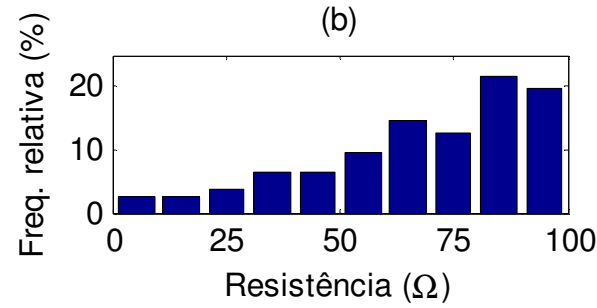

(c)

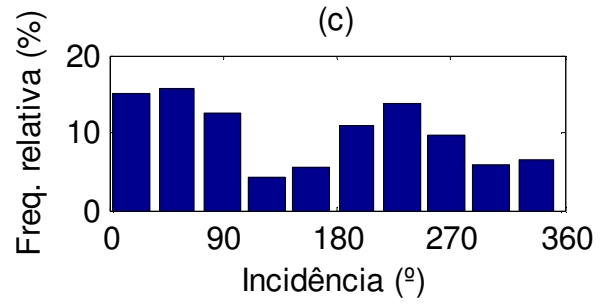

(d)

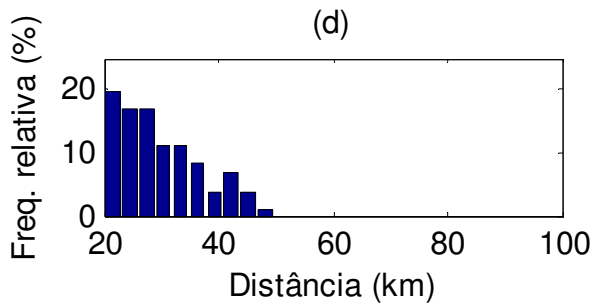

(e)

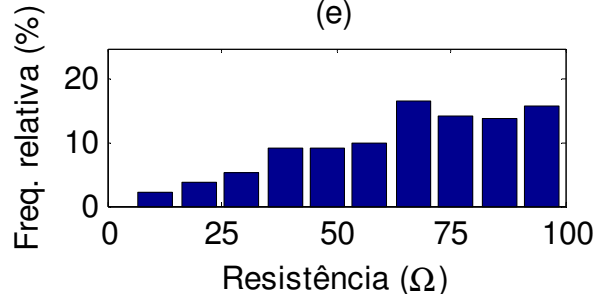

(f)

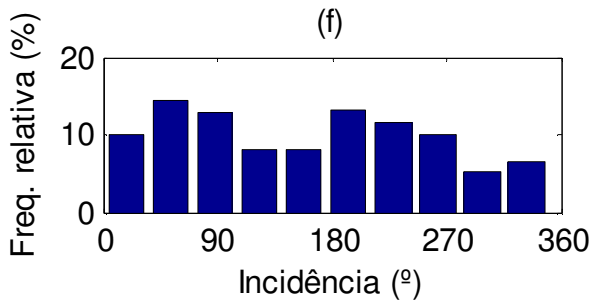

Figura 103. Distribuição de parâmetros de faltas F-F-T associados a erros de localização na Zona 3 (LT3): Operação sem pré-processamento em (a), (b) e (c) e com pré-processamento em (d), (e) e (f). 
Tabela 6-35. Taxa de acerto de localização para faltas F-F-T na Zona 3 (LT3), em função da distância da falta.

\begin{tabular}{c|c|c|c|c}
\hline \hline \multicolumn{5}{c}{ Localização } \\
\hline \hline Condição de teste & Distância & $\mathbf{N}^{\circ}$ de falhas & Total de faltas & Taxa de acerto (\%) \\
\hline $\begin{array}{c}\text { Sem filtro anti-aliasing } \\
\text { e conversor A/D }\end{array}$ & $170 \leq d<178,5$ & 84 & 104 & $18,4 \%$ \\
\cline { 2 - 5 } & $178,5 \leq d<250$ & 82 & 897 & $90,9 \%$ \\
\hline $\begin{array}{c}\text { Com filtro anti-aliasing } \\
\text { e conversor A/D }\end{array}$ & $170 \leq d<178,5$ & 101 & 115 & $12,2 \%$ \\
\cline { 2 - 5 } & $178,5 \leq d<250$ & 87 & 885 & $90,2 \%$ \\
\hline \hline
\end{tabular}

\subsubsection{Resumo da avaliação de desempenho para faltas F-F-T}

Os resultados de operação do sistema de proteção para faltas envolvendo duas fases e a terra é sumarizado na Figura 104, considerando a inserção do préprocessamento com filtro anti-aliasing e conversor A/D. Nesta figura, são apresentadas as taxas de acerto na etapa de localização equivalentes aos resultados do método proposto, em (a), e da metodologia tradicional baseada na impedância aparente, em (b).

Como pode ser verificado, no que tange ao desempenho por zona de falta, é factível afirmar que há uma equivalência nos resultados de ambas as metodologias. A técnica baseada em cumulantes e RNAs apresenta superioridade para faltas na Zona 2 ao passo que a metodologia tradicional se sobressai na identificação de faltas na Zona 3 , especialmente - na Zona 1 , a diferença de desempenho é de apenas 1,5\%, com vantagem do relé baseado na impedância aparente. Nas regiões exclusas às zonas de incerteza de alcance, têm-se desempenhos similares para as técnicas comparadas, com taxa de acerto sempre superior ao índice de 90\%. A metodologia proposta apresenta baixo desempenho apenas no trecho de incerteza de alcance da Zona 1, onde o índice de acerto não atingiu os $65 \%$. Nas demais regiões de incerteza, têm-se taxas de acerto sempre superiores ou iguais a $60 \%$ para ambos os métodos. 


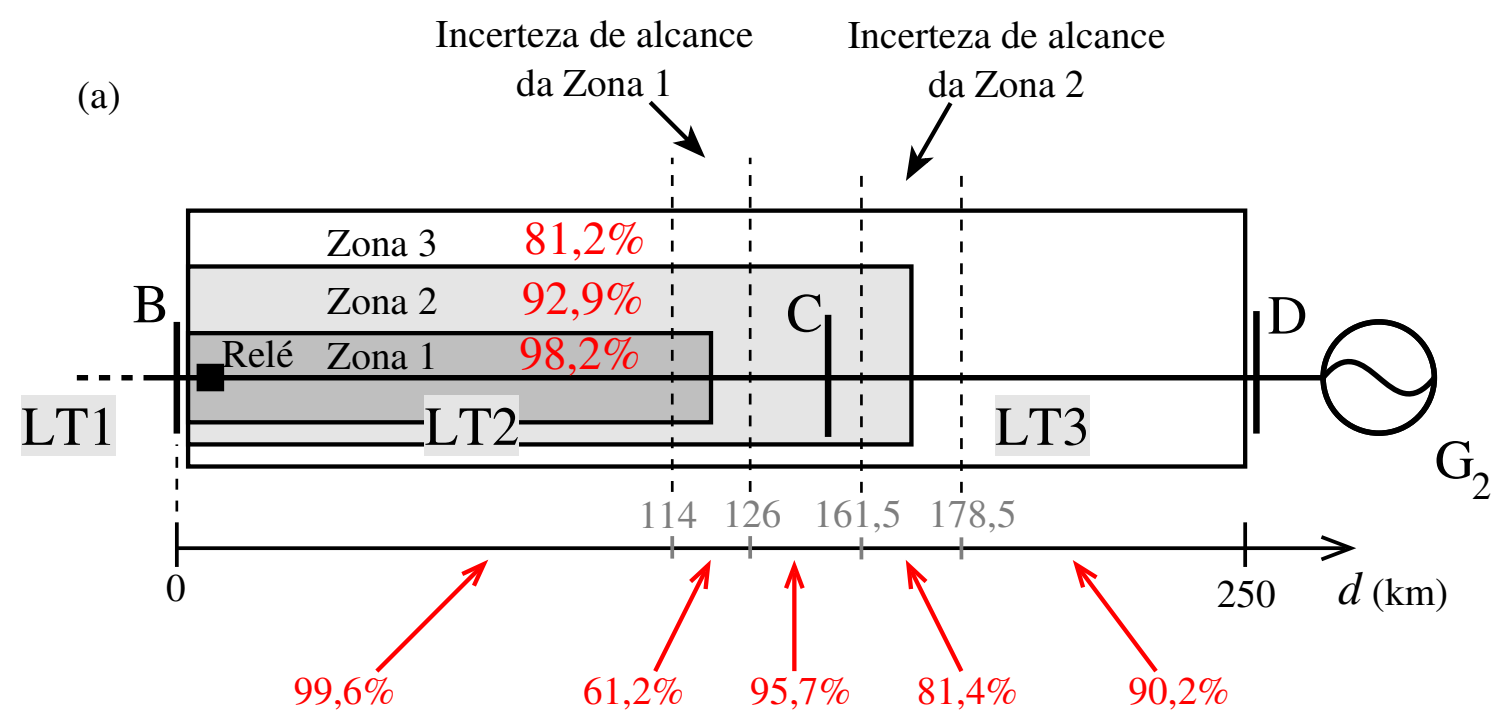

(b)

Incerteza de alcance Incerteza de alcance

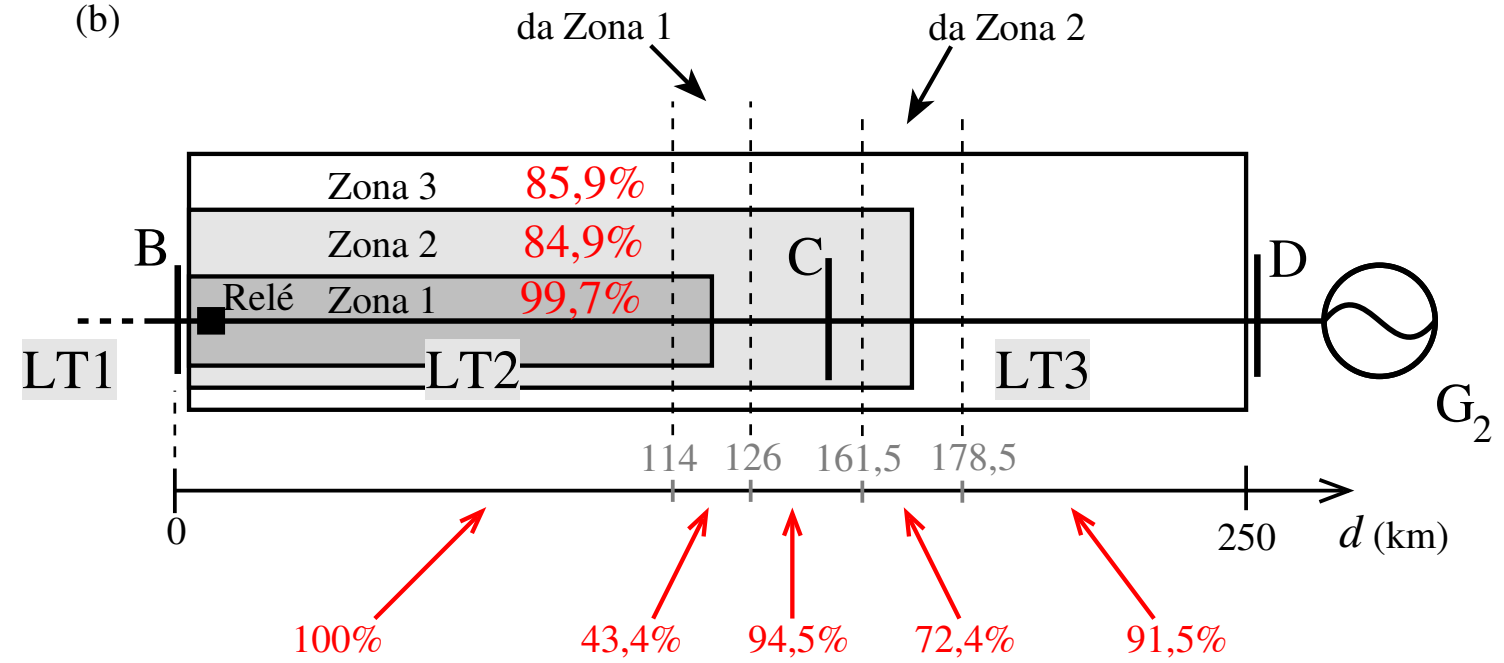

Figura 104. Resumo do resultado de localização (taxa de acerto) para faltas F-F-T: (a) metodologia proposta e; (b) metodologia tradicional.

\subsection{Operação da proteção para faltas do tipo F-F}

\subsubsection{Resultados para faltas bifásicas na linha LT2}

\subsubsection{Faltas F-F na Zona 1 de proteção}

Os resultados obtidos para faltas envolvendo duas fases, na porção equivalente à Zona 1 da linha LT2, são apresentadas na Tabela 6-36 (detecção), Tabela 6-37 (classificação) e na Tabela 6-38 (localização). Conforme demonstrado, não são 
verificados erros no processo de detecção e de classificação por parte de ambas as metodologias. No tocante à localização, observa-se superioridade do método baseado em impedância aparente, apresentando um número máximo de três faltas identificadas erroneamente na Zona 2, quando da utilização da etapa de pré-processamento. Apesar de inferior, a metodologia proposta apresenta ainda um elevado índice de acerto na localização da falta, superior a $96 \%$. Há de se destacar que nenhuma falta foi identificada na Zona 3.

Tabela 6-36. Resultados de detecção para faltas F-F na Zona 1, linha LT2

\begin{tabular}{c|c|c}
\hline \hline \multicolumn{3}{|c}{ Detecção } \\
\hline \hline Condições de teste & $\begin{array}{c}\text { Metodologia } \\
\text { Proposta }\end{array}$ & $\begin{array}{c}\text { Metodologia } \\
\text { Tradicional }\end{array}$ \\
\hline $\begin{array}{c}\text { Sem filtro anti-aliasing } \\
\text { e conversor A/D }\end{array}$ & 1000 & 1000 \\
\hline $\begin{array}{c}\text { Com filtro anti-aliasing } \\
\text { e conversor A/D }\end{array}$ & 1000 & 1000 \\
\hline \hline
\end{tabular}

Tabela 6-37. Resultados de classificação para faltas F-F na Zona 1, linha LT2.

\begin{tabular}{c|c|c|c|c|c|c|c|c}
\hline \hline \multicolumn{10}{c|}{ Classificação } \\
\hline \hline \multirow{2}{*}{ Condições de teste } & \multicolumn{3}{c|}{ Metodologia Proposta } & \multicolumn{4}{c}{ Metodologia Tradicional } \\
\cline { 2 - 9 } & Fase A & Fase B & Fase C & Terra & Fase A & Fase B & Fase C & Terra \\
\hline $\begin{array}{c}\text { Sem filtro anti-aliasing } \\
\text { e conversor A/D }\end{array}$ & 1000 & 1000 & 0 & 0 & 1000 & 1000 & 0 & 0 \\
\hline $\begin{array}{c}\text { Com filtro anti-aliasing } \\
\text { e conversor A/D }\end{array}$ & 1000 & 1000 & 0 & 0 & 1000 & 1000 & 0 & 0 \\
\hline \hline
\end{tabular}

Tabela 6-38. Resultados de localização para faltas F-F na Zona 1, linha LT2.

\begin{tabular}{c|c|c|c|c|c|c}
\hline \hline \multicolumn{7}{c}{ Localização } \\
\hline \hline \multirow{2}{*}{ Condições de teste } & \multicolumn{2}{c}{ Metodologia Proposta } & \multicolumn{3}{|c}{ Metodologia Tradicional } \\
\cline { 2 - 7 } Zona 1 & Zona 2 & Zona 3 & Zona 1 & Zona 2 & Zona 3 \\
\hline $\begin{array}{c}\text { Sem filtro anti-aliasing } \\
\text { e conversor A/D }\end{array}$ & 961 & 39 & 0 & 999 & 1 & 0 \\
\hline $\begin{array}{c}\text { Com filtro anti-aliasing } \\
\text { e conversor A/D }\end{array}$ & 966 & 34 & 0 & 997 & 3 & 0 \\
\hline \hline
\end{tabular}




\subsubsection{Avaliação dos efeitos dos parâmetros de faltas F-F na Zona 1}

Os dados de faltas relativos aos casos onde foram verificados erros de localização pela metodologia desenvolvida estão dispostos na Figura 105. Nesta figura, em (a), (b) e (c), têm-se os parâmetros equivalentes aos trinta e nove casos de erro com operação sem pré-processamento. Com a inserção desta etapa no sistema, têm-se os parâmetros equivalentes aos trinta e quatro casos de erro apresentados nesta figura, em (d), (e) e (f).

A partir de uma consulta rápida à Figura 105, pode-se constatar que as faltas ocorrem predominantemente em distâncias próximas à fronteira entre Zona 1 e Zona 2. Esta informação fica clara quando da análise dos histogramas da Figura 106(a) e (d), relativos aos dados de distância da Figura 105(a) e (d). Quanto ao parâmetro resistência de falta, verificando a Figura 105(b) e (e), e os histogramas associados da Figura 106, pode-se identificar uma ligação dos casos de erro a resistências de falta mais elevadas. Finalmente, considerando o ângulo de incidência pode-se constatar que os erros de localização ocorrem praticamente em todo o intervalo de 0 a $360^{\circ}$, sem um padrão claramente visível, como constatado em casos anteriores. Com efeito, para esta conclusão, basta observar os histogramas da Figura 106(c) e (f).

Quantitativamente, uma análise da relação entre os erros de localização e a distância de ocorrência das faltas está disposta na Tabela 6-39. Pode-se constatar nesta tabela, que a taxa de acerto mínima na localização da falta é igual ou superior a 98\%, para o intervalo de 0 a $114 \mathrm{~km}$. Na região de incerteza da zona de proteção primária, dos 114 aos 120 km, observa-se índice de acerto no entorno de 55\%. 


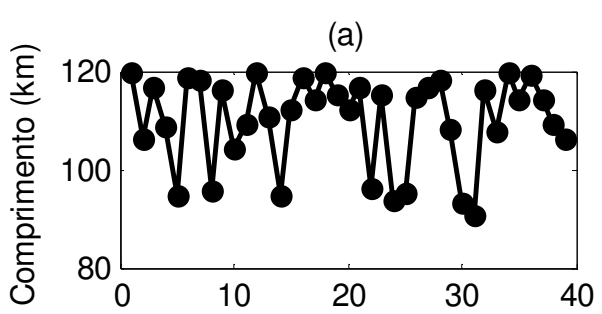

(b)

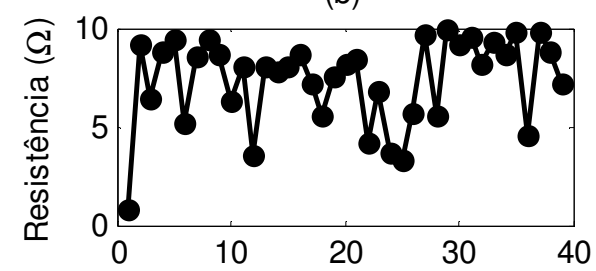

(c)

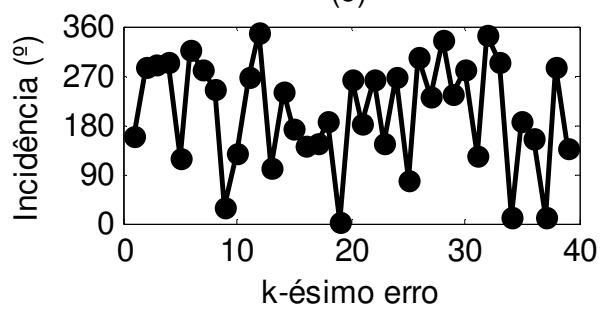

(d)

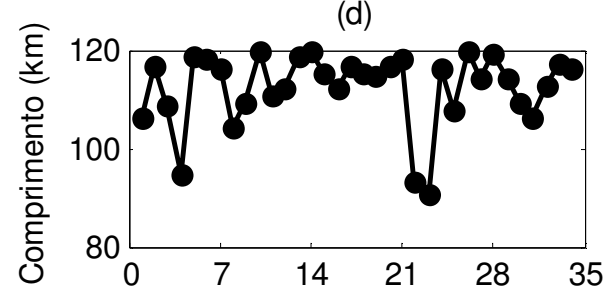

(e)

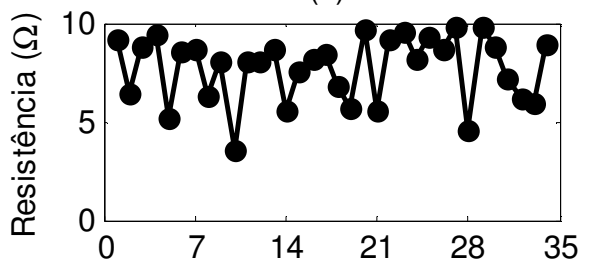

(f)

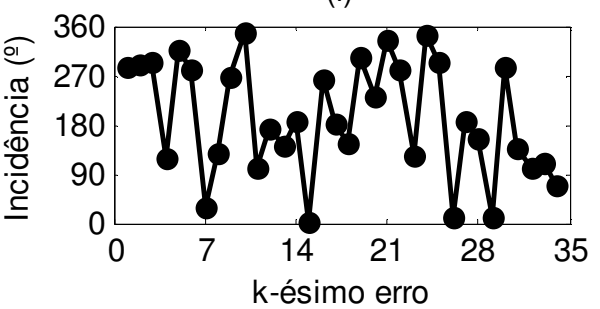

Figura 105. Parâmetros de faltas F-F associados a erros de localização na Zona 1 (LT2): Operação sem pré-processamento em (a), (b) e (c) e com pré-processamento em (d), (e) e (f).
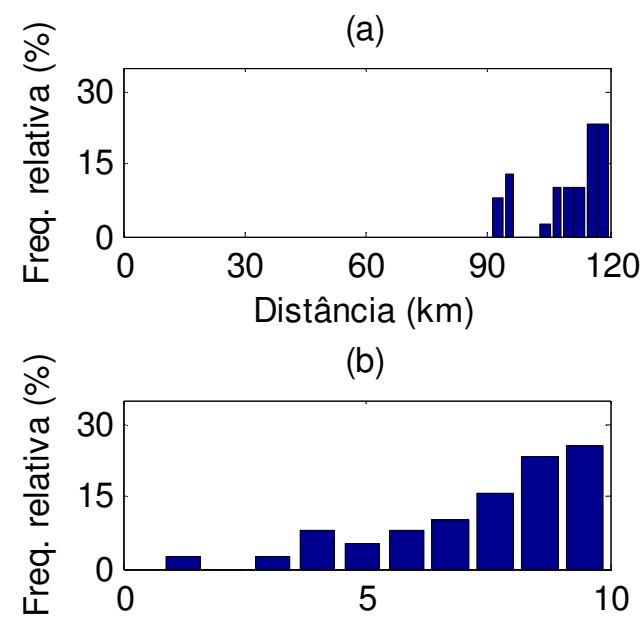

Resistência $(\Omega)$

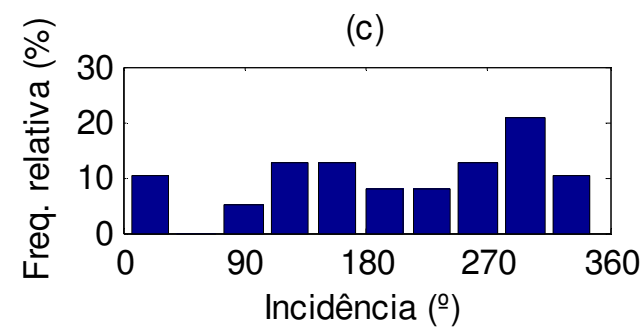

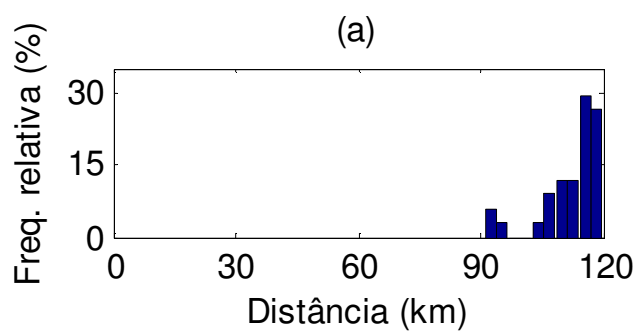

(b)

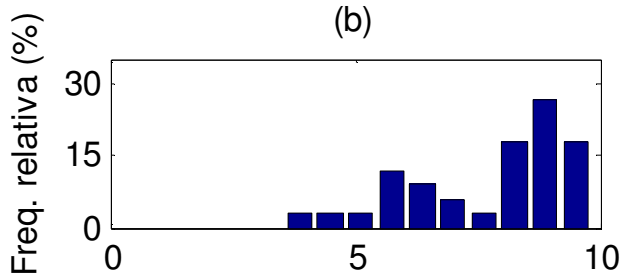

Resistência $(\Omega)$

(c)

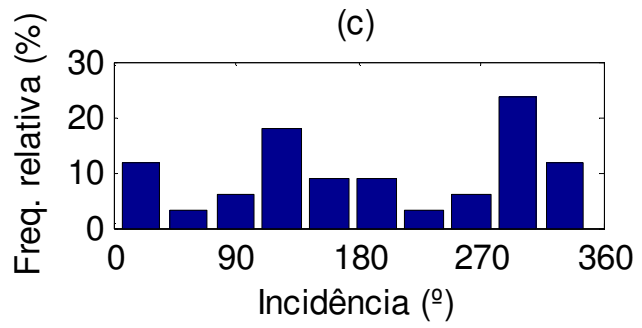

Figura 106. Distribuição dos parâmetros de faltas F-F associados a erros de localização na Zona 1 (LT2): Operação sem pré-processamento em (a), (b) e (c) e com pré-processamento em (d), (e) e (f). 
Tabela 6-39. Taxa de acerto de localização para faltas F-F na Zona 1 (LT2), em função da distância da falta.

\begin{tabular}{c|c|c|c|c}
\hline \hline \multicolumn{5}{|c}{ Localização } \\
\hline \hline Condição de teste & Distância & $\mathbf{N}^{\mathbf{0}}$ de falhas & Total de faltas & Taxa de acerto (\%) \\
\hline $\begin{array}{c}\text { Sem filtro anti-aliasing } \\
\text { e conversor A/D }\end{array}$ & $0 \leq d<114$ & 19 & 956 & $98,0 \%$ \\
\cline { 2 - 5 } & $114 \leq d<120$ & 20 & 44 & $54,5 \%$ \\
\hline $\begin{array}{c}\text { Com filtro anti-aliasing } \\
\text { e conversor A/D }\end{array}$ & $0 \leq d<114$ & 14 & 955 & $98,5 \%$ \\
\cline { 2 - 5 } & $114 \leq d<120$ & 20 & 45 & $55,6 \%$ \\
\hline \hline
\end{tabular}

\subsubsection{Faltas F-F na Zona 2 de proteção}

Na porção da linha LT2, referente à Zona 2 de proteção, têm-se os resultados de operação da proteção dispostos na Tabela 6-40, na Tabela 6-41 e na Tabela 6-42. Verifica-se nas duas primeiras que a detecção e a classificação das faltas é executada com sucesso, tanto por parte do algoritmo proposto quanto da técnica tradicional. No que tange à localização, verifica-se na Tabela 6-42 ampla superioridade da técnica baseada em EOS e RNA. Com efeito, $98 \%$ das faltas foram identificadas corretamente na Zona 2 pela técnica proposta com a etapa de pré-processamento inserida no sistema. Este índice contrasta com o baixo índice de 57,2\% apresentado pela técnica da impedância aparente.

Tabela 6-40. Resultados de detecção para faltas F-F na Zona 2, linha LT2

\begin{tabular}{c|c|c}
\hline \hline \multicolumn{3}{|c}{ Detecção } \\
\hline \hline Condições de teste & $\begin{array}{c}\text { Metodologia } \\
\text { Proposta }\end{array}$ & $\begin{array}{c}\text { Metodologia } \\
\text { Tradicional }\end{array}$ \\
\hline $\begin{array}{c}\text { Sem filtro anti-aliasing } \\
\text { e conversor A/D }\end{array}$ & 1000 & 1000 \\
\hline $\begin{array}{c}\text { Com filtro anti-aliasing } \\
\text { e conversor A/D }\end{array}$ & 1000 & 1000 \\
\hline \hline
\end{tabular}

Tabela 6-41. Resultados de classificação para faltas F-F na Zona 2, linha LT2.

\begin{tabular}{c|c|c|c|c|c|c|c|c}
\hline \hline \multicolumn{10}{c|}{ Classificação } \\
\hline \hline \multirow{2}{*}{ Condições de teste } & \multicolumn{3}{|c|}{ Metodologia Proposta } & \multicolumn{3}{c}{ Metodologia Tradicional } \\
\cline { 2 - 9 } & Fase A & Fase B & Fase C & Terra & Fase A & Fase B & Fase C & Terra \\
\hline $\begin{array}{c}\text { Sem filtro anti-aliasing } \\
\text { e conversor A/D }\end{array}$ & 1000 & 1000 & 0 & 0 & 1000 & 1000 & 0 & 0 \\
\hline $\begin{array}{c}\text { Com filtro anti-aliasing } \\
\text { e conversor A/D }\end{array}$ & 1000 & 1000 & 0 & 0 & 1000 & 1000 & 0 & 0 \\
\hline \hline
\end{tabular}


Tabela 6-42. Resultados de localização para faltas F-F na Zona 2, linha LT2.

\begin{tabular}{c|c|c|c|c|c|c|}
\hline \hline \multicolumn{7}{|c}{ Localização } \\
\hline \multirow{2}{*}{ Condições de teste } & \multicolumn{2}{|c|}{ Metodologia Proposta } & \multicolumn{3}{|c}{ Metodologia Tradicional } \\
\cline { 2 - 7 } Zona 1 & Zona 2 & Zona 3 & Zona 1 & Zona 2 & Zona 3 \\
\hline $\begin{array}{c}\text { Sem filtro anti-aliasing } \\
\text { e conversor A/D }\end{array}$ & 0 & 995 & 5 & 432 & 568 & 0 \\
\hline $\begin{array}{c}\text { Com filtro anti-aliasing } \\
\text { e conversor A/D }\end{array}$ & 16 & 980 & 4 & 428 & 572 & 0 \\
\hline \hline
\end{tabular}

\subsubsection{Avaliação dos efeitos dos parâmetros de faltas F-F na Zona 2}

Os parâmetros de falta relativos aos experimentos onde se constatou erro de localização são apresentados na Figura 107. Por se tratar de um número reduzido de erros, esta análise abre mão da geração de histogramas.

Considerando os cinco casos de erro relativos à operação sem filtragem e conversão A/D, pode-se constatar na análise da Figura 107(a) que a distância de falta é sempre superior a $130 \mathrm{~km}$. Ademais, nesta figura, em (b), verifica-se claramente uma associação dos erros à resistência de falta mais elevadas consideradas nas simulações, próximas aos $10 \Omega$. Estas são as associações mais visíveis a uma rápida análise. Se considerada a inserção da etapa de pré-processamento, pode-se verificar que os erros estão associados a distâncias próximas do limiar entre a Zona 1 e a Zona 2 para os dezesseis casos de erro relativos à identificação de Zona 1. A resistência de falta associada a estes casos é sempre inferior a $5 \Omega$. Outros quatro erros, referentes à indicação de Zona 3, estão associados a distâncias próximas do limite da linha LT2 e a resistências de faltas elevadas.

Por fim, em termos quantitativos, o índice de acerto da localização na região de incerteza de alcance - de 120 a 126 km - é de 92,5\%, no mínimo. Fora desta região, no restante do trecho da linha LT2, verifica-se o índice de acerto sempre superior a 99\%. Estes dados estão apresentados na Tabela 6-43. 
(a)

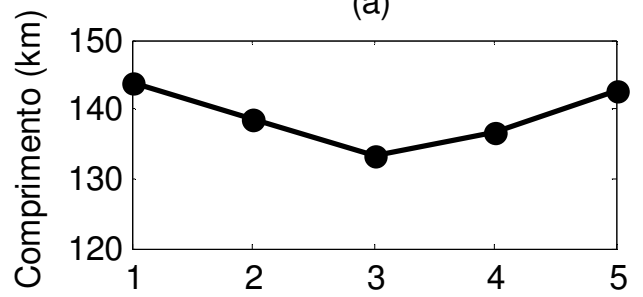

(b)

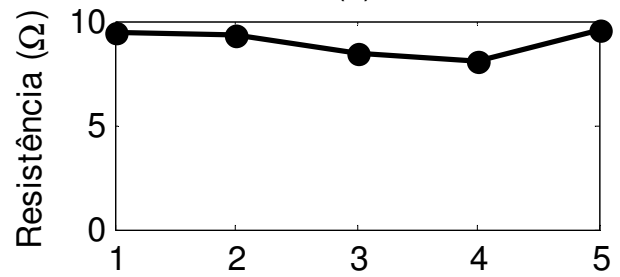

(c)

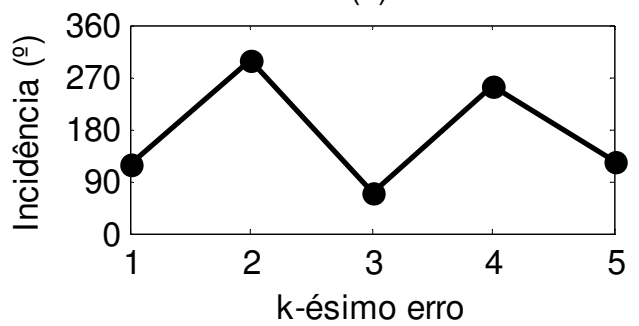

(d)

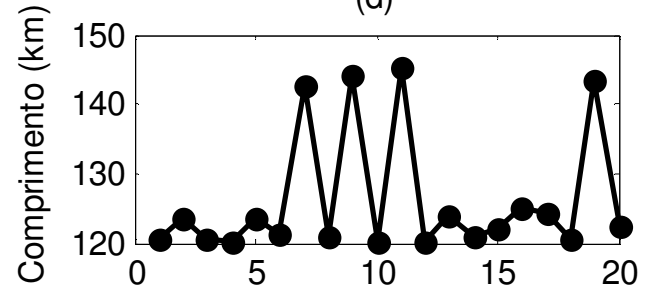

(e)

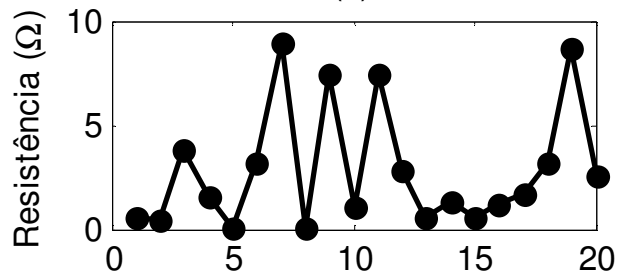

(f)

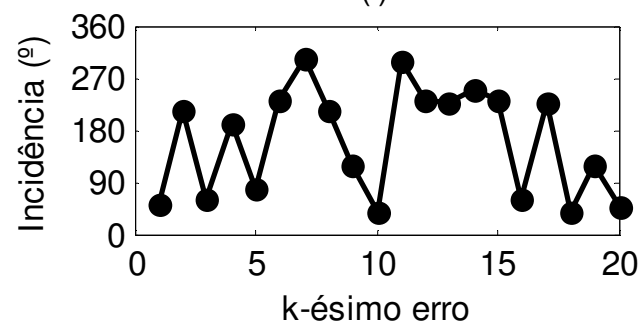

Figura 107. Parâmetros de faltas F-F associados a erros de localização na Zona 2 (LT2): Operação sem pré-processamento em (a), (b) e (c) e com pré-processamento em (d), (e) e (f).

Tabela 6-43. Taxa de acerto de localização para faltas F-F na Zona 2 (LT2), em função da distância da falta.

\begin{tabular}{c|c|c|c|c}
\hline \hline \multicolumn{5}{c}{ Localização } \\
\hline \hline Condição de teste & Distância & $\mathbf{N}^{\mathbf{0}}$ de falhas & Total de faltas & Taxa de acerto (\%) \\
\hline Sem filtro anti-aliasing & $120 \leq d<126$ & 0 & 190 & $100 \%$ \\
\cline { 2 - 5 } e conversor A/D & $126 \leq d<150$ & 5 & 810 & $99,4 \%$ \\
\hline Com filtro anti-aliasing & $120 \leq d<126$ & 16 & 210 & $92,4 \%$ \\
\cline { 2 - 5 } e conversor A/D & $126 \leq d<150$ & 4 & 790 & $99,5 \%$ \\
\hline \hline
\end{tabular}

\subsubsection{Resultados para faltas bifásicas na linha LT3}

\subsubsection{Faltas F-F na Zona 2 de proteção}

No trecho da linha LT3 referente à Zona 2 de proteção, os resultados dos 1000 experimentos de operação da proteção são apresentados na Tabela 6-44, na Tabela 6-45 e na Tabela 6-46. As etapas de detecção e classificação são executadas por ambas as 
metodologias sem a incidência de erros, como demonstrado nas duas primeiras tabelas. Já a etapa de localização é realizada de maneira distinta pelo método proposto e pela técnica tradicional. Em termos gerais, o desempenho do método baseado na impedância aparente é superior, com uma taxa de acerto de localização de aproximadamente $95 \%$ quando da operação com etapa de pré-processamento. Nesta condição, a técnica proposta apresenta taxa de acerto de $86,3 \%$. Em todos os erros de localização da metodologia proposta ocorre a indicação da Zona 3 no lugar da Zona 2. Em oposição, a técnica baseada na impedância aparente apresenta alguns poucos erros referentes à indicação da Zona 1 de proteção, além da indicação da Zona 3.

Tabela 6-44. Resultados de detecção para faltas F-F na Zona 2, linha LT3

\begin{tabular}{c|c|c}
\hline \hline \multicolumn{3}{c}{ Detecção } \\
\hline Condições de teste & $\begin{array}{c}\text { Metodologia } \\
\text { Proposta }\end{array}$ & $\begin{array}{c}\text { Metodologia } \\
\text { Tradicional }\end{array}$ \\
\hline $\begin{array}{c}\text { Sem filtro anti-aliasing } \\
\text { e conversor A/D }\end{array}$ & 1000 & 1000 \\
\hline $\begin{array}{c}\text { Com filtro anti-aliasing } \\
\text { e conversor A/D }\end{array}$ & 1000 & 1000 \\
\hline \hline
\end{tabular}

Tabela 6-45. Resultados de classificação para faltas F-F na Zona 2, linha LT3

\begin{tabular}{c|c|c|c|c|c|c|c|c}
\hline \hline \multicolumn{10}{c|}{ Classificação } \\
\hline \hline Condições de teste & \multicolumn{3}{|c|}{ Metodologia Proposta } & \multicolumn{4}{c}{ Metodologia Tradicional } \\
\cline { 2 - 9 } & Fase A & Fase B & Fase C & Terra & Fase A & Fase B & Fase C & Terra \\
\hline $\begin{array}{c}\text { Sem filtro anti-aliasing } \\
\text { e conversor A/D }\end{array}$ & 1000 & 1000 & 0 & 0 & 1000 & 1000 & 0 & 0 \\
\hline $\begin{array}{c}\text { Com filtro anti-aliasing } \\
\text { e conversor A/D }\end{array}$ & 1000 & 1000 & 0 & 0 & 1000 & 1000 & 0 & 0 \\
\hline \hline
\end{tabular}

Tabela 6-46. Resultados de localização para faltas F-F na Zona 2, linha LT3.

\begin{tabular}{c|c|c|c|c|c|c}
\hline \hline \multicolumn{7}{c}{ Localização } \\
\hline \hline \multirow{2}{*}{ Condições de teste } & \multicolumn{2}{|c|}{ Metodologia Proposta } & \multicolumn{3}{|c}{ Metodologia Tradicional } \\
\cline { 2 - 7 } Zona 1 & Zona 2 & Zona 3 & Zona 1 & Zona 2 & Zona 3 \\
\hline $\begin{array}{c}\text { Sem filtro anti-aliasing } \\
\text { e conversor A/D }\end{array}$ & 0 & 902 & 98 & 5 & 949 & 46 \\
\hline $\begin{array}{c}\text { Com filtro anti-aliasing } \\
\text { e conversor A/D }\end{array}$ & 0 & 863 & 137 & 9 & 955 & 36 \\
\hline \hline
\end{tabular}




\subsubsection{Avaliação dos efeitos dos parâmetros de faltas F-F na Zona 2}

Os parâmetros distância, resistência e ângulo de incidência, referentes aos casos onde se verificou erro de localização pelo método proposto, são especificados na Figura 108. Nesta figura, são apresentados os dados relativos às faltas sem a etapa de condicionamento dos sinais de corrente, em (a), (b) e (c), e os dados relativos às faltas com a consideração deste componente, em (d), (e) e (f).

Inicialmente, considerando o parâmetro distância, percebe-se uma concentração deste parâmetro nas proximidades do limiar entre Zona 2 e Zona 3. Esta informação também fica evidente quando da análise dos histogramas da Figura 109(a) e (d), referentes aos dados da Figura 108(a) e (d). Em seguida, em termos do parâmetro resistência de falta, percebe-se uma associação entre os erros e resistências de valores mais elevados, próximos de $10 \Omega$. Os histogramas da Figura 109(b) e (e) também permitem verificar com clareza esta característica. Finalmente, com relação ao parâmetro ângulo de incidência da falta, apesar da ocorrência de erros para todo o intervalo possível deste parâmetro, observa-se uma concentração dos erros em valores entre $90^{\circ}$ e $120^{\circ}$ e entre $270^{\circ}$ e $300^{\circ}$.

Análise quantitativa de desempenho em função do parâmetro distância de falta encontra-se disposta na Tabela 6-47. Observa-se que, na região de incerteza de alcance, compreendida entre os quilômetros 161,5 e 170, o número de falhas máximo é de 112 para um total de 424 faltas simuladas no trecho. Isto equivale a um índice de acerto mínimo da metodologia proposta de $73,6 \%$, quando da operação com módulo de préprocessamento. Na porção restante da linha, entre o barramento F e o quilômetro 161,5, o número de falhas é significativamente menor, sendo alcançado um índice de acerto superior a $95 \%$. 
(a)

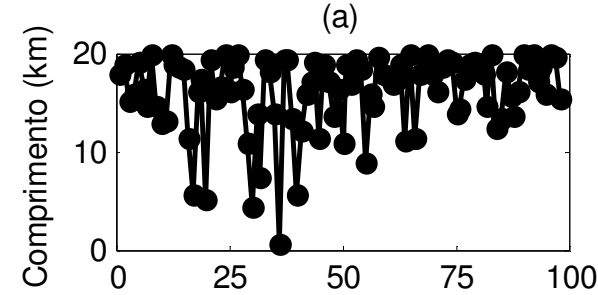

(b)

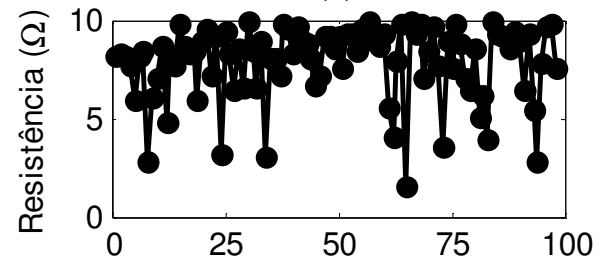

(c)

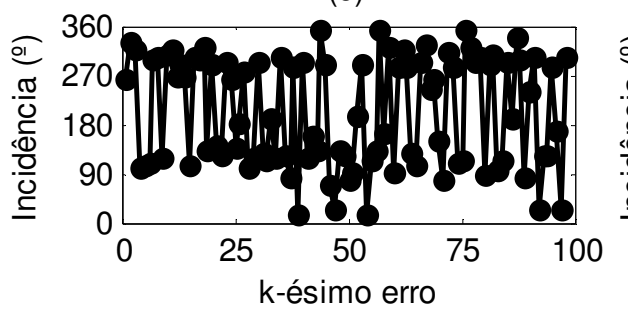

(d)

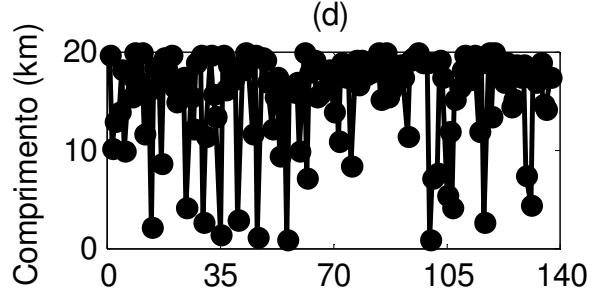

(e)

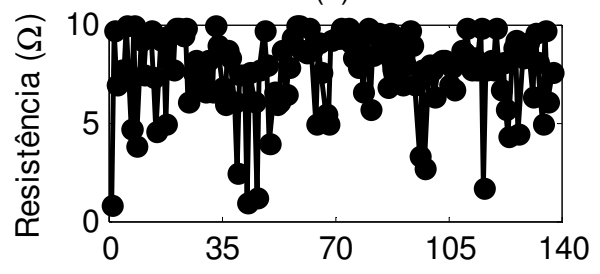

(f)

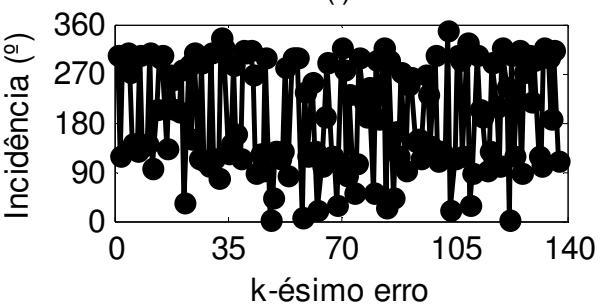

Figura 108. Parâmetros de faltas F-F associados a erros de localização na Zona 2 (LT3): Operação sem pré-processamento em (a), (b) e (c) e com pré-processamento em (d), (e) e (f).
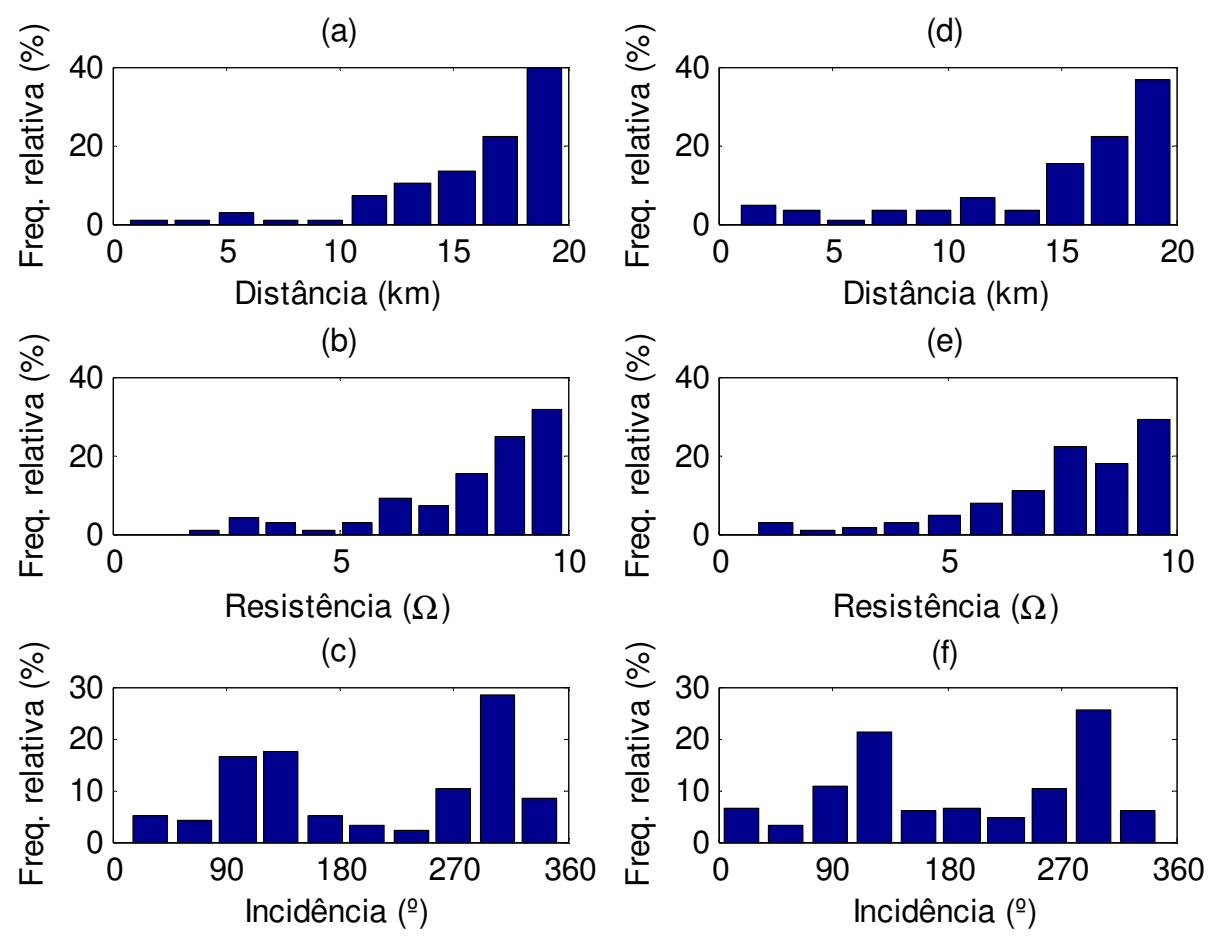

Resistência $(\Omega)$

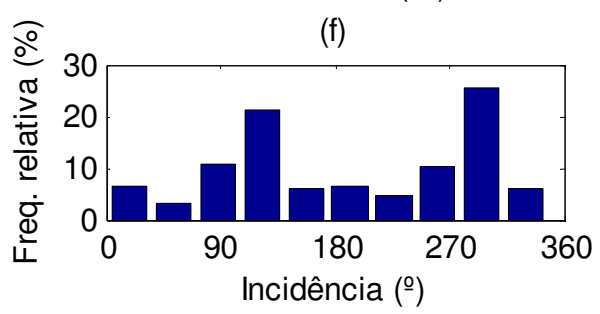

Figura 109. Distribuição dos parâmetros de faltas F-F associados a erros de localização na Zona 2 (LT3): Operação sem pré-processamento em (a), (b) e (c) e com pré-processamento em (d), (e) e (f). 
Tabela 6-47. Taxa de acerto de localização para faltas F-F na Zona 2 (LT3), em função da distância da falta.

\begin{tabular}{c|c|c|c|c}
\hline \multicolumn{5}{c}{ Localização } \\
\hline Condição de teste & Distância & $\mathbf{N}^{\mathbf{0}}$ de falhas & Total de faltas & Taxa de acerto (\%) \\
\hline Sem filtro anti-aliasing & $150 \leq d<161,5$ & 13 & 591 & $97,8 \%$ \\
\cline { 2 - 5 } e conversor A/D & $161,5 \leq d<170$ & 85 & 409 & $79,2 \%$ \\
\hline Com filtro anti-aliasing & $150 \leq d<161,5$ & 25 & 576 & $95,7 \%$ \\
\cline { 2 - 5 } e conversor A/D & $161,5 \leq d<170$ & 112 & 424 & $73,6 \%$ \\
\hline \hline
\end{tabular}

\subsubsection{Faltas $F-F$ na Zona 3 de proteção}

Finalmente, completando a análise de faltas envolvendo duas fases, sem a participação da terra, tem-se como trecho analisado o intervalo da linha LT3 equivalente à Zona 3 de proteção. Os resultados obtidos são apresentados na Tabela 6-48, na Tabela 6-49 e na Tabela 6-50. Da mesma forma que em todos os casos anteriores, tem-se verificado êxito das etapas de detecção e classificação tanto pela metodologia proposta quanto pela metodologia tradicional. A análise da etapa de localização demonstra desempenho superior do método baseado em estatísticas de ordem superior. De fato, conforme dados da Tabela 6-50, o índice de acerto deste método é superior a 97\%. Considerando a operação com filtro anti-aliasing e conversor A/D, por exemplo, do total de 1000 experimentos um montante de 976 foram identificados corretamente na Zona 3 de proteção. A metodologia tradicional baseada na impedância aparente exibe um índice de desempenho bem inferior ao do algoritmo proposto, permanecendo o mesmo levemente acima do patamar dos $75 \%$.

Tabela 6-48. Resultados de detecção para faltas F-F na Zona 3, linha LT3

\begin{tabular}{c|c|c}
\hline \hline \multicolumn{3}{c}{ Detecção } \\
\hline \hline Condições de teste & $\begin{array}{c}\text { Metodologia } \\
\text { Proposta }\end{array}$ & $\begin{array}{c}\text { Metodologia } \\
\text { Tradicional }\end{array}$ \\
\hline $\begin{array}{c}\text { Sem filtro anti-aliasing } \\
\text { e conversor A/D }\end{array}$ & 1000 & 1000 \\
\hline $\begin{array}{c}\text { Com filtro anti-aliasing } \\
\text { e conversor A/D }\end{array}$ & 1000 & 1000 \\
\hline \hline
\end{tabular}


Tabela 6-49. Resultados de classificação para faltas F-F na Zona 3, linha LT3

\begin{tabular}{c|c|c|c|c|c|c|c|c}
\hline \hline \multicolumn{10}{c|}{ Classificação } \\
\hline \hline \multirow{2}{*}{ Condições de teste } & \multicolumn{3}{c|}{ Metodologia Proposta } & \multicolumn{4}{c}{ Metodologia Tradicional } \\
\cline { 2 - 9 } & Fase A & Fase B & Fase C & Terra & Fase A & Fase B & Fase C & Terra \\
\hline $\begin{array}{c}\text { Sem filtro anti-aliasing } \\
\text { e conversor A/D }\end{array}$ & 1000 & 1000 & 0 & 0 & 1000 & 1000 & 0 & 0 \\
\hline $\begin{array}{c}\text { Com filtro anti-aliasing } \\
\text { e conversor A/D }\end{array}$ & 1000 & 1000 & 0 & 0 & 1000 & 1000 & 0 & 0 \\
\hline \hline
\end{tabular}

Tabela 6-50. Resultados de localização para faltas F-F na Zona 3, linha LT3

\begin{tabular}{c|c|c|c|c|c|c}
\hline \hline \multicolumn{7}{c}{ Localização } \\
\hline \hline \multirow{2}{*}{ Condições de teste } & \multicolumn{2}{|c}{ Metodologia Proposta } & \multicolumn{2}{|c}{ Metodologia Tradicional } \\
\cline { 2 - 7 } & Zona 1 & Zona 2 & Zona 3 & Zona 1 & Zona 2 & Zona 3 \\
\hline $\begin{array}{c}\text { Sem filtro anti-aliasing } \\
\text { e conversor A/D }\end{array}$ & 0 & 29 & 971 & 0 & 249 & 751 \\
\hline $\begin{array}{c}\text { Com filtro anti-aliasing } \\
\text { e conversor A/D }\end{array}$ & 0 & 24 & 976 & 0 & 241 & 759 \\
\hline \hline
\end{tabular}

\subsubsection{Avaliação dos efeitos dos parâmetros de faltas F-F na Zona 3}

Os parâmetros das faltas onde se verificou erro do sistema de localização proposto são apresentados na Figura 110 para análise. Nesta figura, estão dispostos os dados relativos aos vinte e nove erros de operação sem o pré-processamento, em (a), (b) e (c), e os dados relativos aos vinte e quatro erros de operação com o pré-processamento incluído, em (d), (e) e (f). Não são apresentados histogramas nesta análise.

$\mathrm{Na}$ análise do parâmetro distância, observa-se na Figura 110(a) e (d) ampla predominância de ocorrências de erros para as proximidades do limiar entre Zona 2 e Zona 3. De fato, a grande maioria dos erros acontece no início do trecho da Zona 3, entre 20 e $25 \mathrm{~km}$ ou, equivalentemente, entre os quilômetros 170 e 175 em relação ao relé. Na Figura 110(b) e (e), observa-se uma associação dos erros de localização a resistências de faltas mais baixas, especialmente inferiores a $5 \Omega$. Por fim, no tocante ao ângulo de incidência de falta, observa-se a ocorrência de erros para os ângulos no entorno de $0^{\circ}$ e de $180^{\circ}$, especialmente quando da consideração da etapa de préprocessamento inserida nas simulações (Figura 110(f)). 
(a)

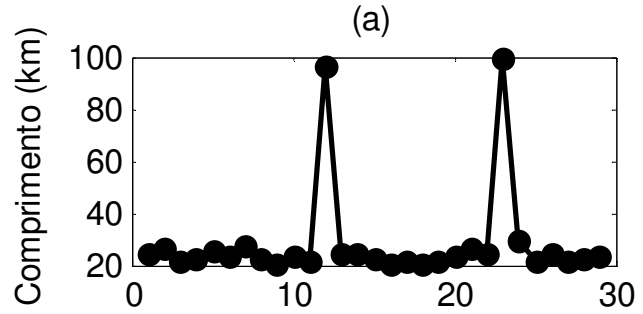

(b)

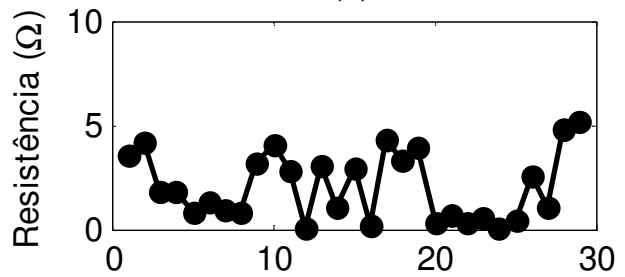

(c)

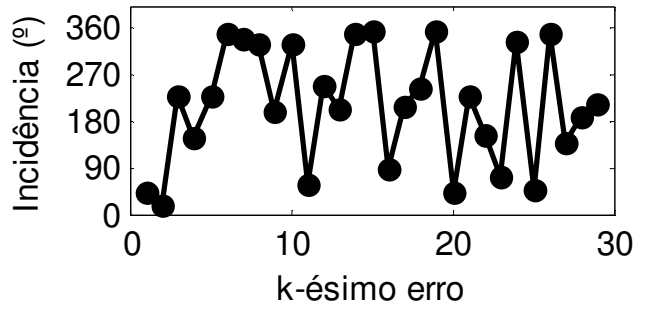

(d)

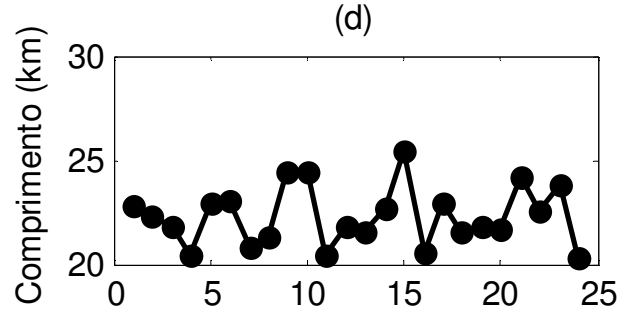

(e)

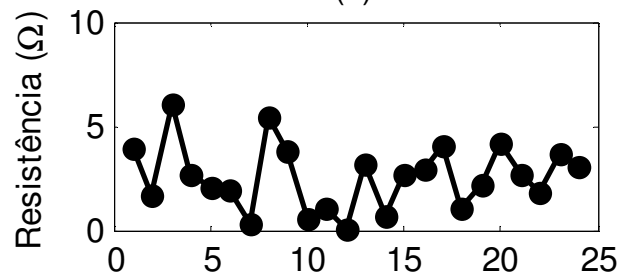

(f)

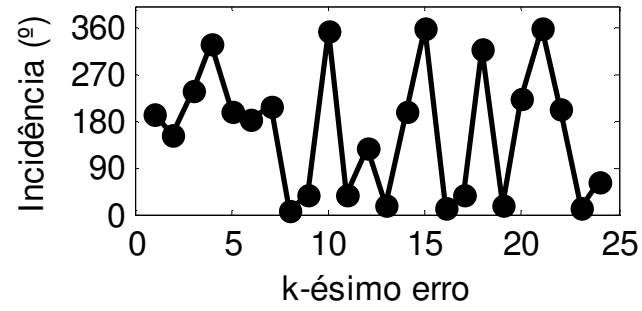

Figura 110. Parâmetros de faltas F-F associados a erros de localização na Zona 3 (LT3): Operação sem pré-processamento em (a), (b) e (c) e com pré-processamento em (d), (e) e (f).

Em termos quantitativos, a técnica proposta apresenta índice de acerto de localização de $100 \%$ para a região compreendida entre o quilômetro 178,5 e o quilômetro 250. Este dado é apresentado na Tabela 6-51. Também, nesta tabela, pode-se verificar que o índice de acerto na região de incerteza de alcance na Zona 3, no intervalo entre 170 e $178,5 \mathrm{~km}$ assume um valor mínimo superior a $74 \%$.

Tabela 6-51. Taxa de acerto de localização para faltas F-F na Zona 3 (LT3), em função da distância da falta.

\begin{tabular}{c|c|c|c|c}
\hline \hline \multicolumn{5}{c}{ Localização } \\
\hline \hline Condição de teste & Distância & $\mathbf{N}^{\mathbf{0}}$ de falhas & Total de faltas & Taxa de acerto (\%) \\
\hline Sem filtro anti-aliasing & $170 \leq d<178,5$ & 26 & 113 & $77,0 \%$ \\
\cline { 2 - 5 } e conversor A/D & $178,5 \leq d<250$ & 3 & 887 & $99,7 \%$ \\
\hline $\begin{array}{c}\text { Com filtro anti-aliasing } \\
\text { e conversor A/D }\end{array}$ & $170 \leq d<178,5$ & 24 & 93 & $74,2 \%$ \\
\cline { 2 - 5 } & $178,5 \leq d<250$ & 0 & 907 & $100 \%$ \\
\hline \hline
\end{tabular}




\subsubsection{Resumo da avaliação de desempenho para faltas F-F}

Da análise pormenorizada, realizada anteriormente nas seções 6.6.1 e 6.6.2, podese obter o desempenho geral da proteção de distância em função das distâncias, tal como apresentado na Figura 111. Nesta figura, em (a), têm-se as taxas de acerto de localização relativas à metodologia proposta ao passo que, em (b), têm-se as taxas de acerto relativas à metodologia da impedância aparente.

No que tange ao desempenho por zona de proteção, pode-se verificar desempenho mais regular da metodologia baseada em estatísticas de ordem superior. Apesar de a taxa de acerto na Zona 1 ser superior para o relé tradicional, a técnica proposta apresenta índices de acerto sempre superiores a 92\% nas três zonas. Em contrapartida, na metodologia tradicional, o índice de acerto na Zona 3, por exemplo, sequer atinge o patamar dos $80 \%$.

Considerando as regiões de incerteza de alcance, a metodologia tradicional tem o pior desempenho no trecho relativo à transição da Zona 1 para a Zona 2. com um índice de acerto de apenas 36,9\%. A metodologia tradicional, no entanto, na região de incerteza de alcance da Zona 1, apresenta desempenho superior ao da metodologia tradicional, com índice de acerto de localização superior a 85\%. 

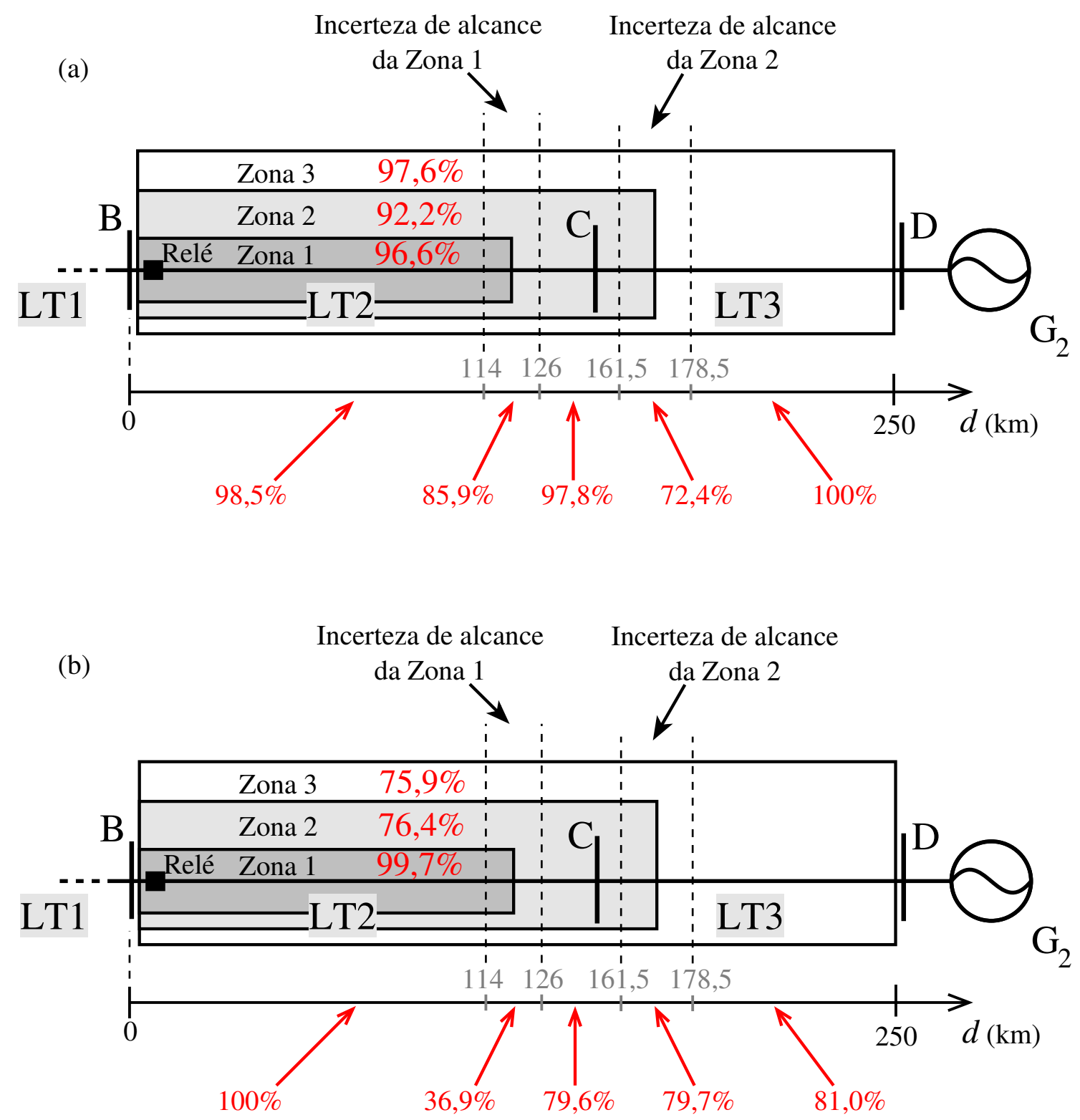

Figura 111. Resumo do resultado de localização (taxa de acerto) para faltas F-F: (a) metodologia proposta e; (b) metodologia tradicional.

\subsection{Operação da proteção para faltas do tipo F-F-F}

\subsubsection{Resultados para faltas trifásicas na linha LT2}

\subsubsection{Faltas F-F-F na Zona 1 de proteção}

Considerando a região da linha LT2 equivalente à zona de proteção primária, os resultados de operação equivalentes aos 1000 experimentos aleatórios são apresentados na Tabela 6-52, na Tabela 6-53 e na Tabela 6-54. As etapas de detecção e classificação são realizadas com índice de acerto de $100 \%$ para ambas as metodologias, como 
explicitado nas duas primeiras tabelas. Já na etapa de localização, na Tabela 6-54, podese verificar desempenho superior da técnica tradicional frente à metodologia proposta. De fato, o algoritmo baseado em EOS identifica erroneamente 17 faltas na Zona 2 quando da operação com filtro anti-aliasing e conversor A/D, por exemplo. Apesar deste erro, deve-se salientar que o índice de acerto é ainda elevado, sendo superior a 98\%. Ademais, nenhuma falta é erroneamente localizada na Zona 3.

Tabela 6-52. Resultados de detecção para faltas F-F-F na Zona 1, linha LT2

\begin{tabular}{c|c|c}
\hline \hline \multicolumn{3}{|c}{ Detecção } \\
\hline \hline Condições de teste & $\begin{array}{c}\text { Metodologia } \\
\text { Proposta }\end{array}$ & $\begin{array}{c}\text { Metodologia } \\
\text { Tradicional }\end{array}$ \\
\hline $\begin{array}{c}\text { Sem filtro anti-aliasing } \\
\text { e conversor A/D }\end{array}$ & 1000 & 1000 \\
\hline $\begin{array}{c}\text { Com filtro anti-aliasing } \\
\text { e conversor A/D }\end{array}$ & 1000 & 1000 \\
\hline \hline
\end{tabular}

Tabela 6-53. Resultados de classificação para faltas F-F-F na Zona 1, linha LT2.

\begin{tabular}{c|c|c|c|c|c|c|c|c}
\hline \hline \multicolumn{7}{c|}{ Classificação } \\
\hline \hline \multirow{2}{*}{ Condições de teste } & \multicolumn{3}{c|}{ Metodologia Proposta } & \multicolumn{4}{c}{ Metodologia Tradicional } \\
\cline { 2 - 9 } & Fase A & Fase B & Fase C & Terra & Fase A & Fase B & Fase C & Terra \\
\hline $\begin{array}{c}\text { Sem filtro anti-aliasing } \\
\text { e conversor A/D }\end{array}$ & 1000 & 1000 & 1000 & 0 & 1000 & 1000 & 1000 & 0 \\
\hline $\begin{array}{c}\text { Com filtro anti-aliasing } \\
\text { e conversor A/D }\end{array}$ & 1000 & 1000 & 1000 & 0 & 1000 & 1000 & 1000 & 0 \\
\hline \hline
\end{tabular}

Tabela 6-54. Resultados de localização para faltas F-F-F na Zona 1, linha LT2.

\begin{tabular}{c|c|c|c|c|c|c}
\hline \hline \multicolumn{7}{c}{ Localização } \\
\hline \hline \multirow{2}{*}{ Condições de teste } & \multicolumn{2}{|c|}{ Metodologia Proposta } & \multicolumn{3}{|c}{ Metodologia Tradicional } \\
\cline { 2 - 7 } Zona 1 & Zona 2 & Zona 3 & Zona 1 & Zona 2 & Zona 3 \\
\hline $\begin{array}{c}\text { Sem filtro anti-aliasing } \\
\text { e conversor A/D }\end{array}$ & 988 & 12 & 0 & 1000 & 0 & 0 \\
\hline $\begin{array}{c}\text { Com filtro anti-aliasing } \\
\text { e conversor A/D }\end{array}$ & 983 & 17 & 0 & 1000 & 0 & 0 \\
\hline \hline
\end{tabular}

\subsubsection{Avaliação dos efeitos dos parâmetros de faltas F-F-F na Zona 1}

Considerando as simulações com ocorrência de erros de localização, na Figura 112, são apresentados os parâmetros de falta para a operação sem pré-processamento, 
em (a), (b) e (c), e com pré-processamento, em (d), (e) e (f). Para ambos os casos, podese perceber que, no tocante ao parâmetro distância de falta, é claramente visível uma associação dos erros às distâncias próximas à fronteira com a zona secundária de proteção, ou seja, próximas de $120 \mathrm{~km}$. Adicionalmente, pode-se perceber nesta figura, uma relação entre os erros e simulações com elevadas resistências de faltas, próximas do valor máximo considerado de $10 \Omega$. Quanto ao parâmetro fase, não se encontra claro um padrão associado aos erros de localização. Por se tratar de poucos casos de erro, não foram gerados os histogramas dos dados da Figura 112.

(a)

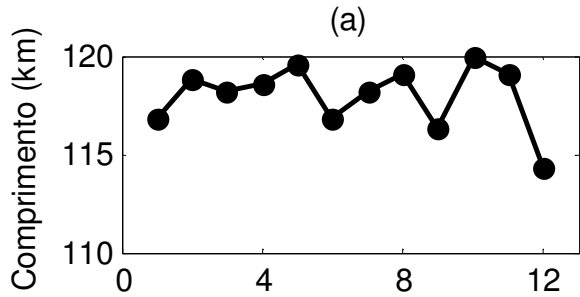

(b)

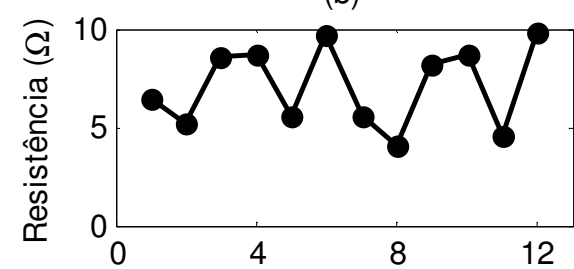

(c)

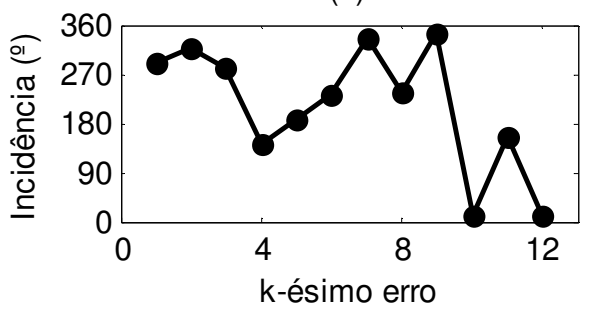

(d)

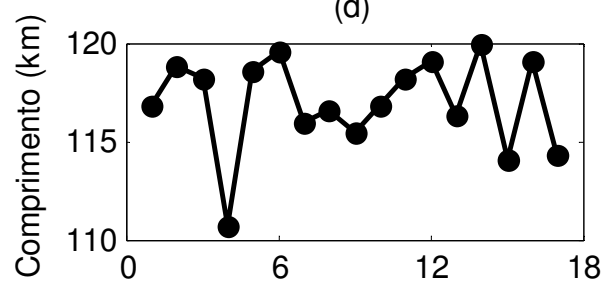

(e)

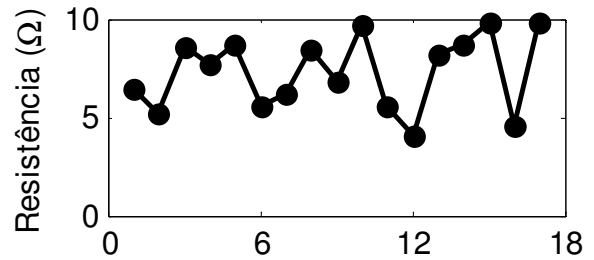

(f)

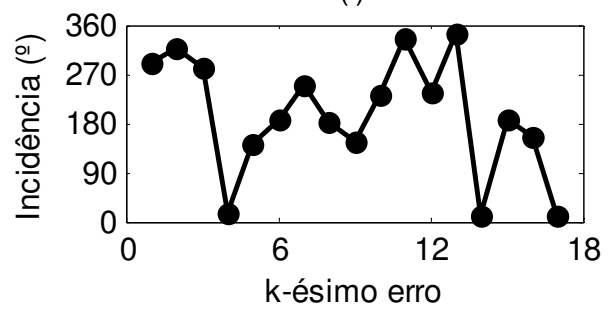

Figura 112. Parâmetros de faltas F-F-F associados a erros de localização na Zona 1 (LT2): Operação sem pré-processamento em (a), (b) e (c) e com pré-processamento em (d), (e) e (f).

Em se tratando do parâmetro distância, especialmente, uma análise quantitativa de erros é apresentada na Tabela 6-55. Pode-se observar, por exemplo, que no intervalo entre o relé e o quilômetro 114 não foi verificada nenhuma falha de localização para a operação sem módulo de pré-processamento. Com este módulo presente, apenas um 
erro de localização foi verificado de um total de 954 faltas simuladas neste intervalo. Já na região próxima à fronteira com a Zona 2, equivalente à região de incerteza de alcance da Zona 1, entre os quilômetros 114 e 120, são verificados 16 erros para um total de 46 faltas simuladas. Esta proporção representa um considerável índice de acerto, igual a $65,2 \%$, neste intervalo.

Tabela 6-55. Taxa de acerto de localização para faltas F-F-F na Zona 1 (LT2), em função da distância da falta.

\begin{tabular}{c|c|c|c|c}
\hline \multicolumn{5}{c}{ Localização } \\
\hline \hline Condição de teste & Distância & $\mathbf{N}^{\mathbf{0}}$ de falhas & Total de faltas & Taxa de acerto (\%) \\
\hline \multirow{2}{*}{$\begin{array}{c}\text { Sem filtro anti-aliasing } \\
\text { e conversor A/D }\end{array}$} & $0 \leq d<114$ & 0 & 957 & $100 \%$ \\
\cline { 2 - 5 } & $114 \leq d<120$ & 12 & 43 & $72,1 \%$ \\
\hline $\begin{array}{c}\text { Com filtro anti-aliasing } \\
\text { e conversor A/D }\end{array}$ & $0 \leq d<114$ & 1 & 954 & $99,9 \%$ \\
\cline { 2 - 5 } & $114 \leq d<120$ & 16 & 46 & $65,2 \%$ \\
\hline \hline
\end{tabular}

\subsubsection{Faltas F-F-F na Zona 2 de proteção}

Os resultados para faltas ocorridas na porção da linha LT2 equivalente à zona secundária de proteção são apresentados na Tabela 6-56, na Tabela 6-57 e na Tabela 6-58. Resta claro da análise das duas primeiras, que as etapas de detecção e classificação são executadas com sucesso. Considerando a localização, da Tabela 6-58, pode-se verificar desempenho nitidamente superior da técnica proposta. De fato, considerando a operação com filtro anti-aliasing e conversão A/D, por exemplo, do total de 1000 experimentos, têm-se 901 acertos da técnica baseada em EOSs e RNAs contra apenas 570 acertos da metodologia tradicional baseada na impedância aparente.

Tabela 6-56. Resultados de detecção para faltas F-F-F na Zona 2, linha LT2

\begin{tabular}{c|c|c}
\hline \hline \multicolumn{3}{c}{ Detecção } \\
\hline \hline Condições de teste & Metodologia Proposta & Metodologia Tradicional \\
\hline $\begin{array}{c}\text { Sem filtro anti-aliasing } \\
\text { e conversor A/D }\end{array}$ & 1000 & 1000 \\
\hline $\begin{array}{c}\text { Com filtro anti-aliasing } \\
\text { e conversor A/D }\end{array}$ & 1000 & 1000 \\
\hline \hline
\end{tabular}


Tabela 6-57. Resultados de classificação para faltas F-F-F na Zona 2, linha LT2.

\begin{tabular}{c|c|c|c|c|c|c|c|c}
\hline \hline \multicolumn{7}{c|}{ Classificação } \\
\hline \hline \multirow{2}{*}{ Condições de teste } & \multicolumn{3}{|c|}{ Metodologia Proposta } & \multicolumn{4}{c}{ Metodologia Tradicional } \\
\cline { 2 - 9 } & Fase A & Fase B & Fase C & Terra & Fase A & Fase B & Fase C & Terra \\
\hline $\begin{array}{c}\text { Sem filtro anti-aliasing } \\
\text { e conversor A/D }\end{array}$ & 1000 & 1000 & 1000 & 0 & 1000 & 1000 & 1000 & 0 \\
\hline $\begin{array}{c}\text { Com filtro anti-aliasing } \\
\text { e conversor A/D }\end{array}$ & 1000 & 1000 & 1000 & 0 & 1000 & 1000 & 1000 & 0 \\
\hline \hline
\end{tabular}

Tabela 6-58. Resultados de localização para faltas F-F-F na Zona 2, linha LT2.

\begin{tabular}{c|c|c|c|c|c|c}
\hline \hline \multicolumn{7}{c}{ Localização } \\
\hline \multirow{2}{*}{$\begin{array}{c}\text { Condições de } \\
\text { teste }\end{array}$} & \multicolumn{2}{c}{ Metodologia Proposta } & \multicolumn{3}{|c}{ Metodologia Tradicional } \\
\cline { 2 - 7 } Zona 1 & Zona 2 & Zona 3 & Zona 1 & Zona 2 & Zona 3 \\
\hline $\begin{array}{c}\text { Sem filtro anti-aliasing } \\
\text { e conversor A/D }\end{array}$ & 50 & 950 & 0 & 421 & 579 & 0 \\
\hline $\begin{array}{c}\text { Com filtro anti-aliasing } \\
\text { e conversor A/D }\end{array}$ & 99 & 901 & 0 & 430 & 570 & 0 \\
\hline \hline
\end{tabular}

\subsubsection{Avaliação dos efeitos dos parâmetros de faltas F-F-F na Zona 2}

Os parâmetros de faltas dos casos de erro de localização são apresentados na Figura 113 para análise. Nesta figura, em (a), (b) e (c), têm-se os parâmetros referentes aos 50 erros quando da operação sem pré-processamento. Já em (d), (e) e (f) são exibidos os parâmetros referentes aos 99 erros verificados quando da operação com préprocessamento.

Quanto ao parâmetro resistência de falta, percebe-se facilmente que os erros estão correlacionados às distâncias próximas ao limiar com a Zona 1 de proteção. Esta característica se torna visível também quando da análise dos histogramas da Figura 114(a) e (d), referentes aos dados da Figura 113(a) e (d). No que concerne o parâmetro resistência de falta, observa-se que os erros ocorrem para faltas com baixas resistências, especialmente inferiores a $5 \Omega$. Os histogramas da Figura 114(b) e (e) permitem confirmar facilmente esta afirmativa. Por fim, em se tratando do parâmetro incidência 
da falta, percebe-se, especialmente, pela análise dos histogramas da Figura 114(c) e (f), que não há uma correlação clara com os casos de erro.

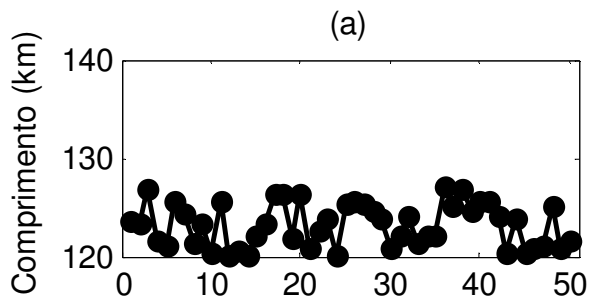

(b)

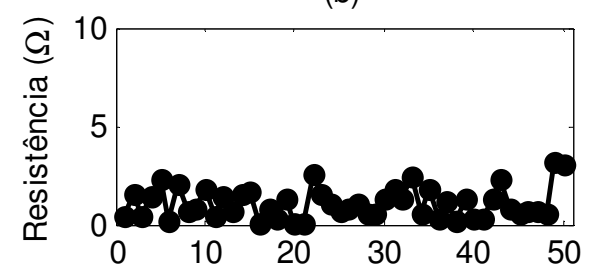

(c)

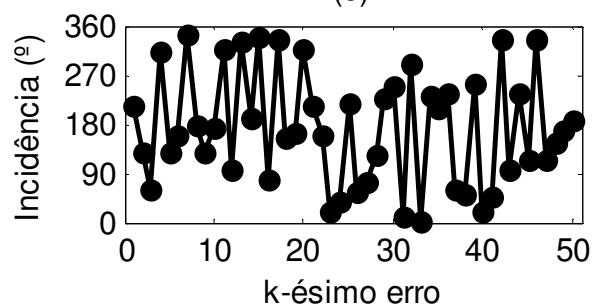

(d)

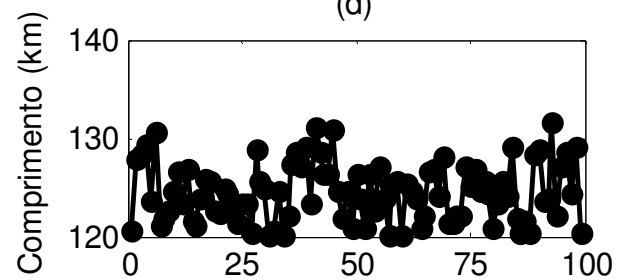

(e)

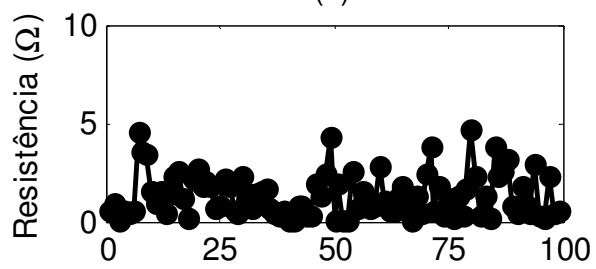

(f)

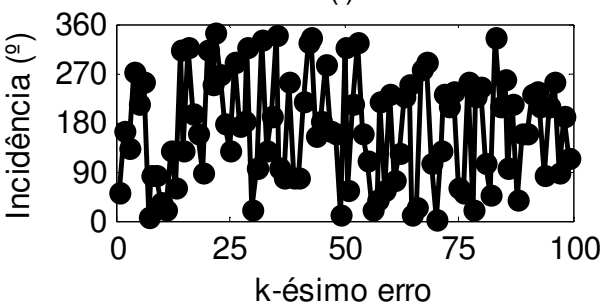

Figura 113. Parâmetros de faltas F-F-F associados a erros de localização na Zona 2 (LT2):

Operação sem pré-processamento em (a), (b) e (c) e com pré-processamento em (d), (e) e (f).

O desempenho da localização é disposto em termos quantitativos, como função da distância de falta, na Tabela 6-59. Considerando o sistema com etapa de filtragem e conversão A/D, verifica-se no intervalo de incerteza de alcance, de 120 a $126 \mathrm{~km}$, um total de 68 erros de localização para 210 faltas simuladas. Estes números implicam em uma taxa de acerto superior a $67 \%$. Já na região externa à faixa de incerteza, o índice de acerto supera o nível dos 95\%, tanto na operação com pré-processamento quanto na operação sem esta etapa. 

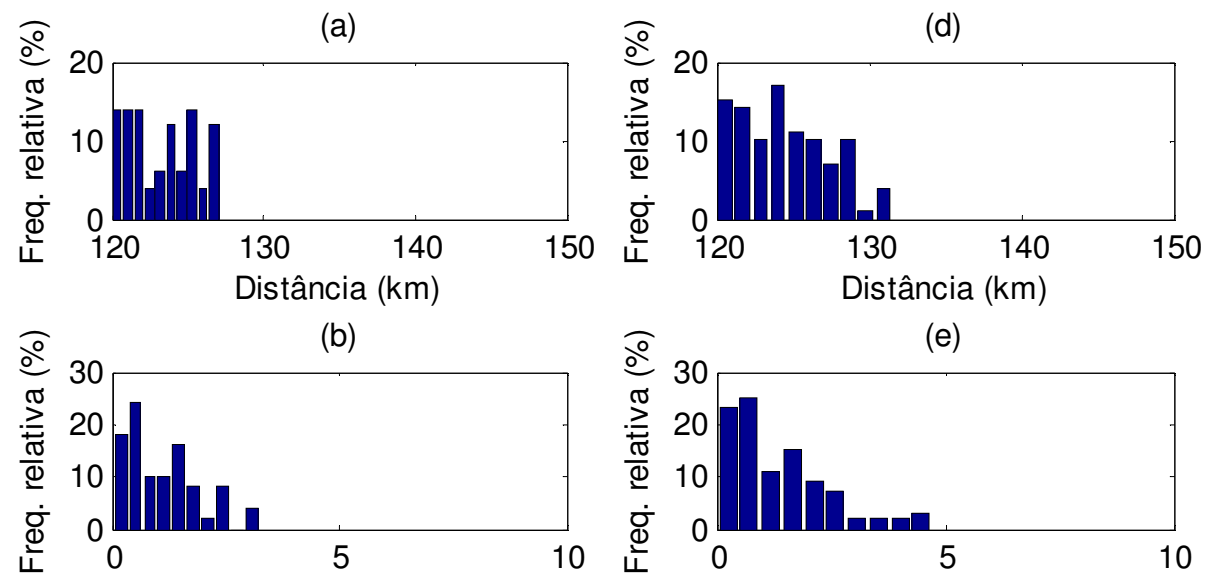

Resistência $(\Omega)$

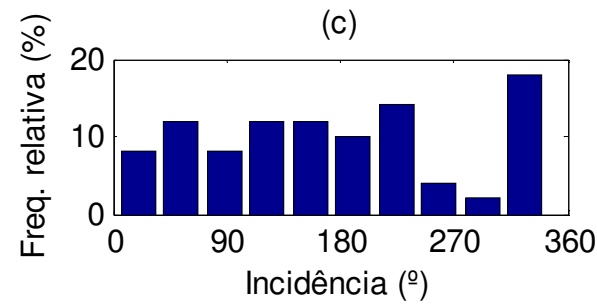

Resistência $(\Omega)$

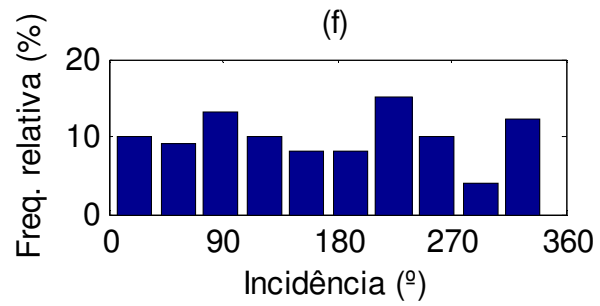

Figura 114. Distribuição dos parâmetros de faltas F-F-F associados a erros de localização na Zona 2 (LT2): Operação sem pré-processamento em (a), (b) e (c) e com pré-processamento em (d), (e) e (f).

Tabela 6-59. Taxa de acerto de localização para faltas F-F-F na Zona 2 (LT2), em função da distância da falta.

\begin{tabular}{c|c|c|c|c}
\hline \hline \multicolumn{5}{c}{ Localização } \\
\hline \hline Condição de teste & Distância & $\mathbf{N}^{\mathbf{0}}$ de falhas & Total de faltas & Taxa de acerto (\%) \\
\hline $\begin{array}{c}\text { Sem filtro anti-aliasing } \\
\text { e conversor A/D }\end{array}$ & $120 \leq d<126$ & 44 & 215 & $79,5 \%$ \\
\cline { 2 - 5 } & $126 \leq d<150$ & 6 & 785 & $99,2 \%$ \\
\hline $\begin{array}{c}\text { Com filtro anti-aliasing } \\
\text { e conversor A/D }\end{array}$ & $120 \leq d<126$ & 68 & 210 & $67,6 \%$ \\
\cline { 2 - 5 } & $126 \leq d<150$ & 31 & 790 & $96,1 \%$ \\
\hline \hline
\end{tabular}

\subsubsection{Resultados para faltas trifásicas na linha LT3}

\subsubsection{Faltas F-F-F na Zona 2 de proteção}

Os resultados de operação para faltas na porção inicial de $20 \mathrm{~km}$ da linha LT3, equivalente à zona secundária de proteção, estão dispostos na Tabela 6-60, na Tabela 6-61 e na Tabela 6-62. 
Como anteriormente, não são verificados erros de detecção e localização, para ambas as metodologias. Na etapa de localização, detalhada na Tabela 6-62, verifica-se desempenho levemente superior da metodologia proposta frente à técnica tradicional. Se for considerada a operação com filtros anti-aliasing e conversores A/D, pode-se afirmar que os desempenhos são similares. De fato, tem-se um total de acertos de 961 referentes à técnica baseada em EOS contra 955 referentes à técnica da impedância aparente para o total de 1000 experimentos realizados.

Tabela 6-60. Resultados de detecção para faltas F-F-F na Zona 2, linha LT3

\begin{tabular}{c|c|c}
\hline \hline \multicolumn{3}{|c}{ Detecção } \\
\hline \hline Condições de teste & $\begin{array}{c}\text { Metodologia } \\
\text { Proposta }\end{array}$ & $\begin{array}{c}\text { Metodologia } \\
\text { Tradicional }\end{array}$ \\
\hline $\begin{array}{c}\text { Sem filtro anti-aliasing } \\
\text { e conversor A/D }\end{array}$ & 1000 & 1000 \\
\hline $\begin{array}{c}\text { Com filtro anti-aliasing } \\
\text { e conversor A/D }\end{array}$ & 1000 & 1000 \\
\hline \hline
\end{tabular}

Tabela 6-61. Resultados de classificação para faltas F-F-F na Zona 2, linha LT3

\begin{tabular}{c|c|c|c|c|c|c|c|c}
\hline \hline \multicolumn{10}{c|}{ Classificação } \\
\hline \hline Condições de teste & \multicolumn{3}{|c|}{ Metodologia Proposta } & \multicolumn{4}{c}{ Metodologia Tradicional } \\
\cline { 2 - 9 } & Fase A & Fase B & Fase C & Terra & Fase A & Fase B & Fase C & Terra \\
\hline $\begin{array}{c}\text { Sem filtro anti-aliasing } \\
\text { e conversor A/D }\end{array}$ & 1000 & 1000 & 1000 & 0 & 1000 & 1000 & 1000 & 0 \\
\hline $\begin{array}{c}\text { Com filtro anti-aliasing } \\
\text { e conversor A/D }\end{array}$ & 1000 & 1000 & 1000 & 0 & 1000 & 1000 & 1000 & 0 \\
\hline \hline
\end{tabular}

Tabela 6-62. Resultados de localização para faltas F-F-F na Zona 2, linha LT3.

\begin{tabular}{c|c|c|c|c|c|c}
\hline \hline \multicolumn{7}{c}{ Localização } \\
\hline \hline \multirow{2}{*}{ Condições de teste } & \multicolumn{2}{|c}{ Metodologia Proposta } & \multicolumn{2}{|c}{ Metodologia Tradicional } \\
\cline { 2 - 7 } & Zona 1 & Zona 2 & Zona 3 & Zona 1 & Zona 2 & Zona 3 \\
\hline $\begin{array}{c}\text { Sem filtro anti-aliasing } \\
\text { e conversor A/D }\end{array}$ & 0 & 982 & 18 & 3 & 952 & 45 \\
\hline $\begin{array}{c}\text { Com filtro anti-aliasing } \\
\text { e conversor A/D }\end{array}$ & 0 & 961 & 39 & 6 & 955 & 39 \\
\hline \hline
\end{tabular}




\subsubsection{Avaliação dos efeitos dos parâmetros de faltas F-F-F na Zona 2}

Os parâmetros referentes às simulações onde foram constatados erros de localização são novamente analisados. Eles se encontram relacionados na Figura 115. Nesta figura, em (a), (b) e (c) estão dispostos os parâmetros referentes aos 18 casos de erro quando da operação sem filtros anti-aliasing e conversão A/D. Quando da inserção do módulo de condicionamento, têm-se os parâmetros exibidos em (d), (e) e (f).

Os dados da Figura 115 são analisados sem a necessidade de construção de histogramas. Pode-se perceber, facilmente, a correlação das faltas com distâncias próximas ao limite da Zona 2 com a Zona 3. De fato, a maioria das falhas de localização ocorre para distâncias superiores a $17 \mathrm{~km}$ ou, equivalentemente, entre os quilômetros 167 e 170. Em se tratando do parâmetro resistência, resta claro da análise da Figura 115(b) e (e) que as falhas estão associadas a resistências de faltas elevadas, especialmente acima dos $7 \Omega$. A análise do parâmetro ângulo de incidência não permite estabelecer conclusões diretas.

Quantitativamente, tem-se que entre o quilômetro 0 e o quilômetro 11,5 da linha LT3 - equivalentemente, entre os quilômetros 150 e 161,5 em relação ao relé - nenhum erro de localização é identificado. Este dado se encontra disponível na Tabela 6-63. Também nesta tabela pode-se verificar o índice de acerto referente à região de incerteza de alcance da Zona 2, entre os quilômetros 161,5 e 170. Observa-se que o pior caso ocorre quando da operação com pré-processamento. No entanto, este caso ainda equivale a um elevado índice, superior aos $90 \%$. 

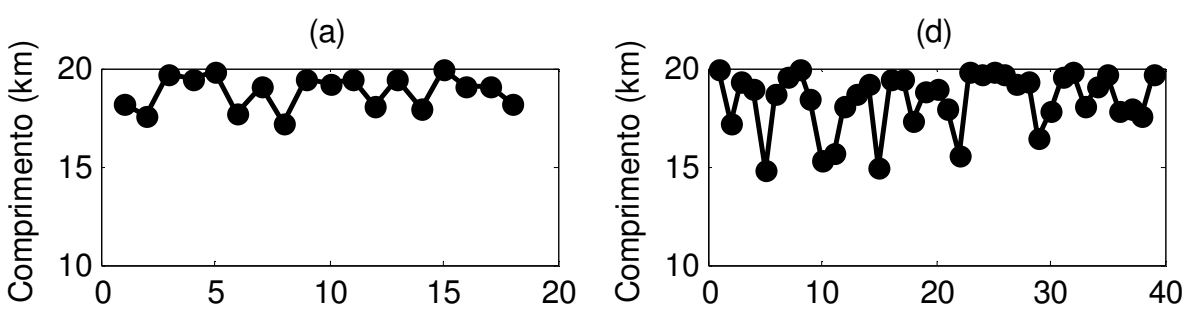

(b)
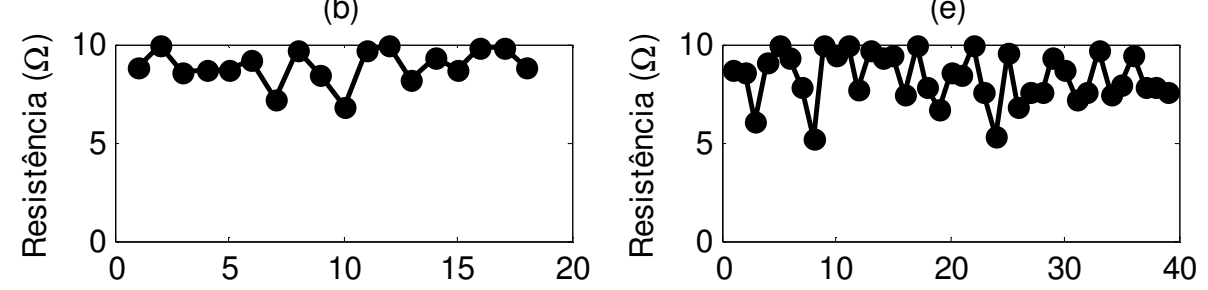

(c)

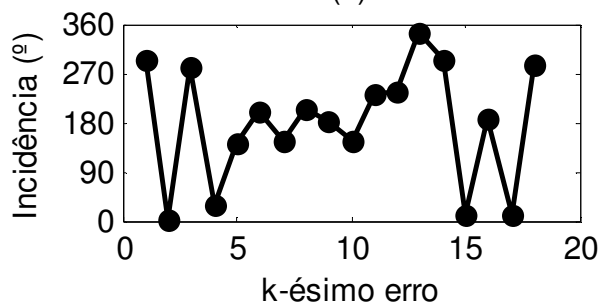

(f)

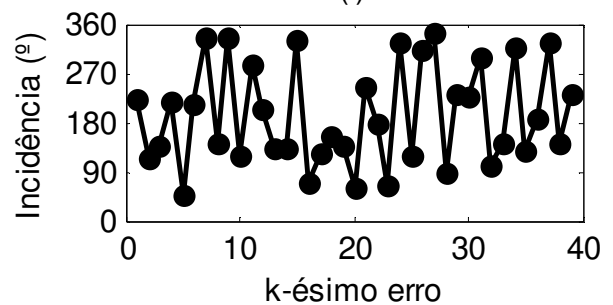

Figura 115. Parâmetros de faltas F-F-F associados a erros de localização na Zona 2 (LT3): Operação sem pré-processamento em (a), (b) e (c) e com pré-processamento em (d), (e) e (f).

Tabela 6-63. Taxa de acerto de localização para faltas F-F-F na Zona 2 (LT3), em função da distância da falta.

\begin{tabular}{c|c|c|c|c}
\hline \hline \multicolumn{5}{c}{ Localização } \\
\hline \hline Condição de teste & Distância & $\mathbf{N}^{\mathbf{0}}$ de falhas & Total de faltas & Taxa de acerto (\%) \\
\hline Sem filtro anti-aliasing & $150 \leq d<161,5$ & 0 & 567 & $100 \%$ \\
\cline { 2 - 5 } e conversor A/D & $161,5 \leq d<170$ & 18 & 433 & $95,8 \%$ \\
\hline Com filtro anti-aliasing & $150 \leq d<161,5$ & 0 & 581 & $100 \%$ \\
\cline { 2 - 5 } e conversor A/D & $161,5 \leq d<170$ & 39 & 419 & $90,7 \%$ \\
\hline \hline
\end{tabular}

\subsubsection{Faltas F-F-F na Zona 3 de proteção}

Finalmente, analisa-se os resultados de faltas aplicadas na região da linha LT3 equivalente à Zona 3 de proteção. Estes resultados encontram-se relacionados na Tabela 6-64, na Tabela 6-65 e na Tabela 6-66. Quanto à detecção, resultado exibido na Tabela 6-64, e à classificação, resultado exibido na Tabela 6-65, verifica-se novamente a 
execução das etapas sem a ocorrência de falhas. Os resultados de localização, no entanto, demonstram superioridade da metodologia proposta frente à técnica de comparação. De fato, considere a operação com pré-processamento, por exemplo. Neste caso, de um total de 1000 experimentos, 948 são identificados corretamente na Zona 3 pelo técnica baseada em EOSs e RNAs ao passo que, pela metodologia baseada na impedância aparente, são identificadas corretamente apenas 741 faltas.

Tabela 6-64. Resultados de detecção para faltas F-F-F na Zona 3, linha LT3

\begin{tabular}{c|c|c}
\hline \hline \multicolumn{3}{|c}{ Detecção } \\
\hline \hline Condições de teste & $\begin{array}{c}\text { Metodologia } \\
\text { Proposta }\end{array}$ & $\begin{array}{c}\text { Metodologia } \\
\text { Tradicional }\end{array}$ \\
\hline $\begin{array}{c}\text { Sem filtro anti-aliasing } \\
\text { e conversor A/D }\end{array}$ & 1000 & 1000 \\
\hline $\begin{array}{c}\text { Com filtro anti-aliasing } \\
\text { e conversor A/D }\end{array}$ & 1000 & 1000 \\
\hline \hline
\end{tabular}

Tabela 6-65. Resultados de classificação para faltas F-F-F na Zona 3, linha LT3

\begin{tabular}{c|c|c|c|c|c|c|c|c}
\hline \hline \multicolumn{10}{c|}{ Classificação } \\
\hline \hline Condições de teste & \multicolumn{3}{|c|}{ Metodologia Proposta } & \multicolumn{4}{c}{ Metodologia Tradicional } \\
\cline { 2 - 9 } & Fase A & Fase B & Fase C & Terra & Fase A & Fase B & Fase C & Terra \\
\hline $\begin{array}{c}\text { Sem filtro anti-aliasing } \\
\text { e conversor A/D }\end{array}$ & 1000 & 1000 & 1000 & 0 & 1000 & 1000 & 1000 & 0 \\
\hline $\begin{array}{c}\text { Com filtro anti-aliasing } \\
\text { e conversor A/D }\end{array}$ & 1000 & 1000 & 1000 & 0 & 1000 & 1000 & 1000 & 0 \\
\hline \hline
\end{tabular}

Tabela 6-66. Resultados de localização para faltas F-F-F na Zona 3, linha LT3

\begin{tabular}{c|c|c|c|c|c|c}
\hline \hline \multicolumn{7}{c}{ Localização } \\
\hline \hline \multirow{2}{*}{ Condições de teste } & \multicolumn{2}{|c|}{ Metodologia Proposta } & \multicolumn{3}{|c}{ Metodologia Tradicional } \\
\cline { 2 - 7 } Zona 1 & Zona 2 & Zona 3 & Zona 1 & Zona 2 & Zona 3 \\
\hline $\begin{array}{c}\text { Sem filtro anti-aliasing } \\
\text { e conversor A/D }\end{array}$ & 0 & 37 & 963 & 0 & 245 & 755 \\
\hline $\begin{array}{c}\text { Com filtro anti-aliasing } \\
\text { e conversor A/D }\end{array}$ & 0 & 52 & 948 & 0 & 259 & 741 \\
\hline \hline
\end{tabular}




\subsubsection{Avaliação dos efeitos dos parâmetros de faltas F-F-F na Zona 3}

Tomando os casos de erro de localização na Zona 3, têm-se na Figura 116 os parâmetros relativos às faltas simuladas. Nesta figura, em (a), (b) e (c) são exibidos os parâmetros de falta dos 37 casos de erro relativos à operação sem filtragem e conversão A/D. Na mesma figura, em (d), (e) e (f), são exibidos os parâmetros quando da operação com estes componentes.

No que tange ao parâmetro distância da falta, observa-se que os erros são verificados para distâncias próximas do limiar entre a Zona 2 e a Zona 3. De fato, verificando os histogramas da Figura 117(a) e (d) observa-se que a grande maioria de erros ocorreu para distâncias inferiores a $30 \mathrm{~km}$ ou, equivalentemente, na região entre 170 e $180 \mathrm{~km}$ a partir do relé. Outra característica visível no resultado apresentado na Figura 116 diz respeito ao parâmetro resistência de falta. Verifica-se, também, analisando os histogramas da Figura 117(b) e (e), que os erros são correlacionados a baixas resistências de faltas, especialmente inferiores a $5 \Omega$. Quanto ao ângulo de incidência, verifica-se uma distribuição relativamente uniforme dos erros ao longo de todo intervalo de $0^{\circ}$ a $360^{\circ}$, especialmente quando da operação com pré-processamento.

Levando-se em consideração o parâmetro distância de falta, na Tabela 6-67, é apresentada uma análise quantitativa dos resultados para o trecho de linha estudado. No início da Zona 3 na linha LT3, entre os quilômetros 170 e 178,5, é verificada uma taxa de acerto de localização mínima de 58,5\%, para operação com pré-processamento dos sinais elétricos. Esta região faz parte da região de incerteza de alcance da Zona 2. Na porção restante da linha LT3, que vai do quilômetro 178,5 ao quilômetro 250, o índice de acerto aumenta bruscamente para 99,1\%. Nesta região, de um total de 894 faltas simuladas, apenas 8 foram identificadas erroneamente na Zona 2. 

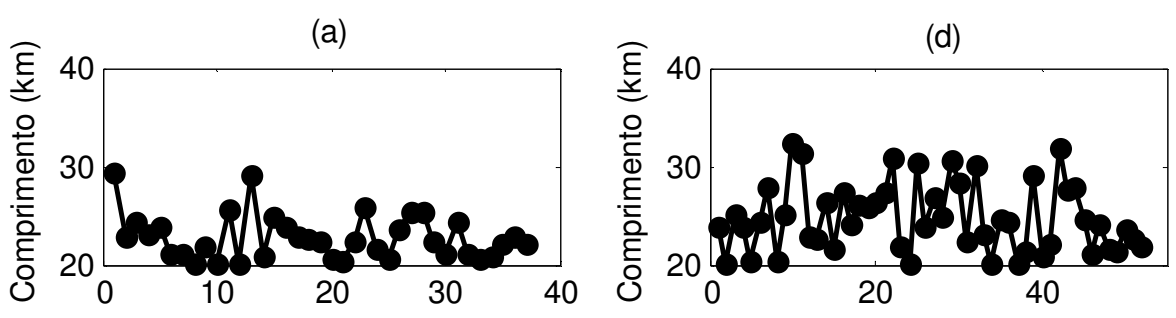

(b)

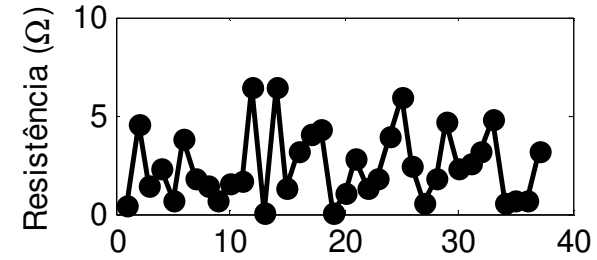

(e)

(c)
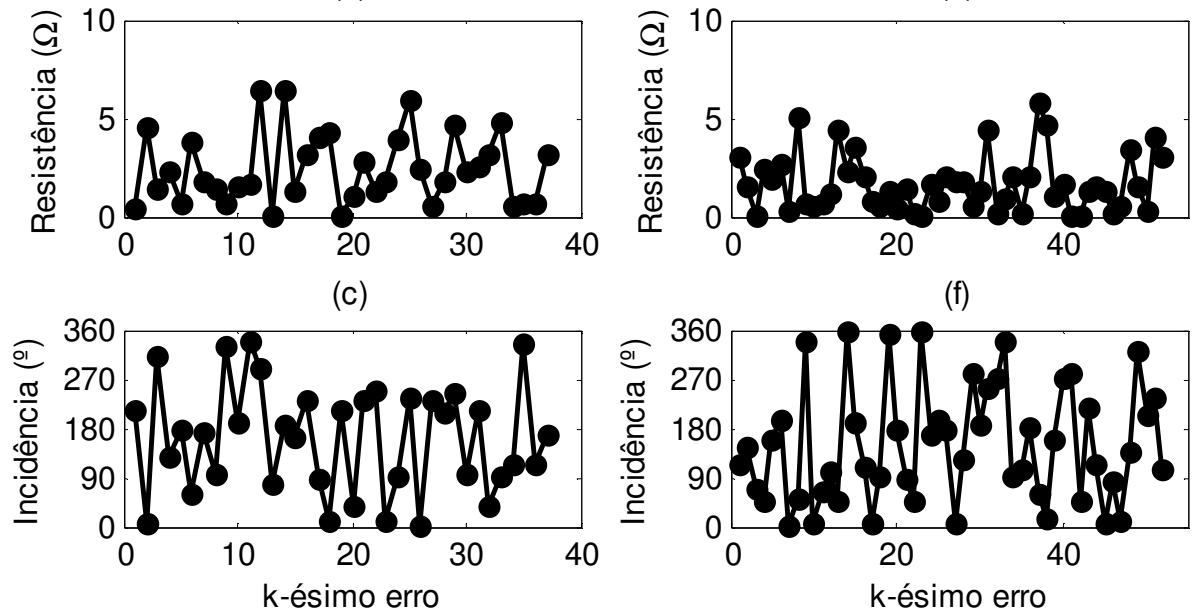

(f)

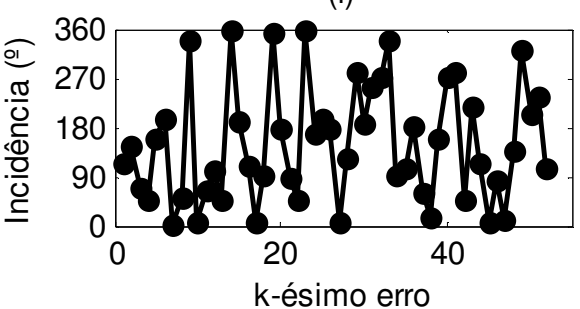

Figura 116. Parâmetros de faltas F-F-F associados a erros de localização na Zona 3 (LT3):

Operação sem pré-processamento em (a), (b) e (c) e com pré-processamento em (d), (e) e (f).

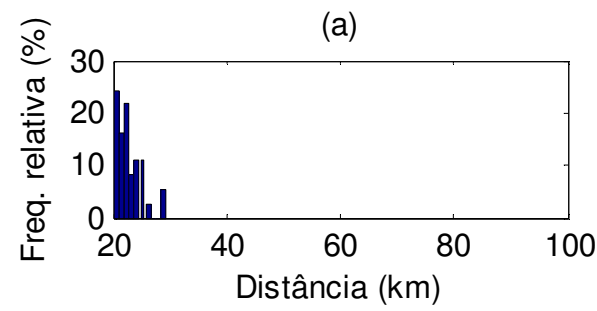

(b)

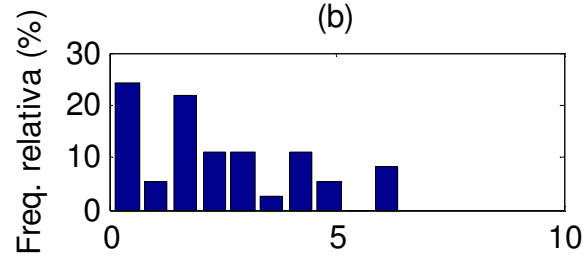

Resistência $(\Omega)$

(c)

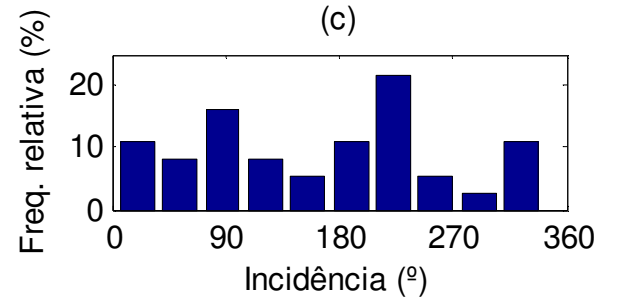

(d)

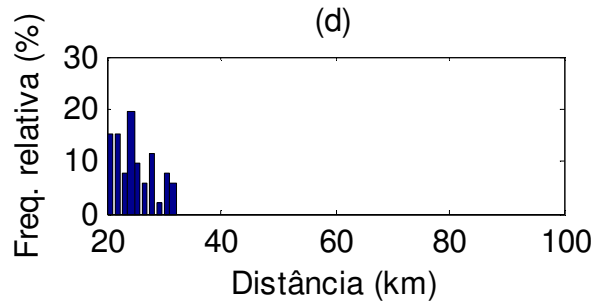

(e)

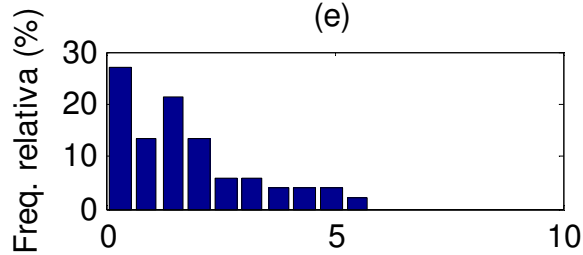

Resistência $(\Omega)$

(f)

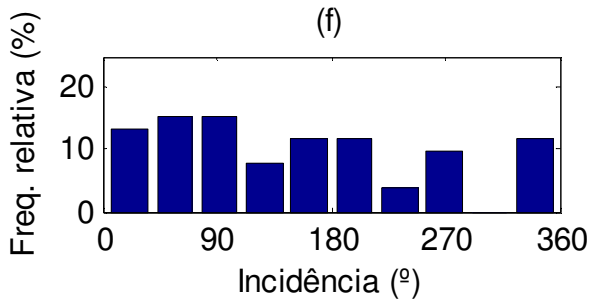

Figura 117. Distribuição dos parâmetros de faltas F-F-F associados a erros de localização na Zona 3 (LT3): Operação sem pré-processamento em (a), (b) e (c) e com pré-processamento em (d), (e) e (f). 
Tabela 6-67. Taxa de acerto de localização para faltas F-F-F na Zona 3 (LT3), em função da distância da falta.

\begin{tabular}{c|c|c|c|c}
\hline \multicolumn{5}{|c}{ Localização } \\
\hline \hline Condição de teste & Distância & $\mathbf{N}^{0}$ de falhas & Total de faltas & Taxa de acerto (\%) \\
\hline $\begin{array}{c}\text { Sem filtro anti-aliasing } \\
\text { e conversor A/D }\end{array}$ & $170 \leq d<178,5$ & 35 & 113 & $69,0 \%$ \\
\cline { 2 - 5 } & $178,5 \leq d<250$ & 2 & 887 & $99,8 \%$ \\
\hline $\begin{array}{c}\text { Com filtro anti-aliasing } \\
\text { e conversor A/D }\end{array}$ & $170 \leq d<178,5$ & 44 & 106 & $58,5 \%$ \\
\cline { 2 - 5 } & $178,5 \leq d<250$ & 8 & 894 & $99,1 \%$ \\
\hline \hline
\end{tabular}

\subsubsection{Resumo da avaliação de desempenho para faltas F-F-F}

A operação do sistema de proteção, no que tange ao desempenho de localização, pode ser resumida tal como apresentado na Figura 118, para faltas trifásicas. Nesta figura, em (a) tem-se o desempenho do algoritmo proposto e em (c) do algoritmo tradicional utilizado para comparação. Considerando o desempenho por zonas de falta, apesar de a metodologia baseada na impedância aparente apresentar um maior índice de acerto na Zona 1, pode-se concluir que a técnica proposta possui um desempenho superior, haja vista as taxas de acerto obtidas nas zonas 2 e 3.

Nas regiões de incerteza de alcance, a taxa de acerto mínima da metodologia baseada em cumulantes é 67,2\%, na região de transição entre as linhas LT1 e LT2. Neste mesmo trecho, a técnica tradicional usada para comparação tem desempenho de apenas $37,1 \%$ de acerto. Na região de incerteza de alcance relativa à Zona 2, apesar do aumento da taxa de acerto do método da impedância aparente, a metodologia proposta exibe índice superior, com taxa de acerto próxima dos $85 \%$. Nos trechos externos às regiões de incerteza, observa-se desempenho mais regular da metodologia proposta, com índice de acerto mínimo de 97,7\%. 

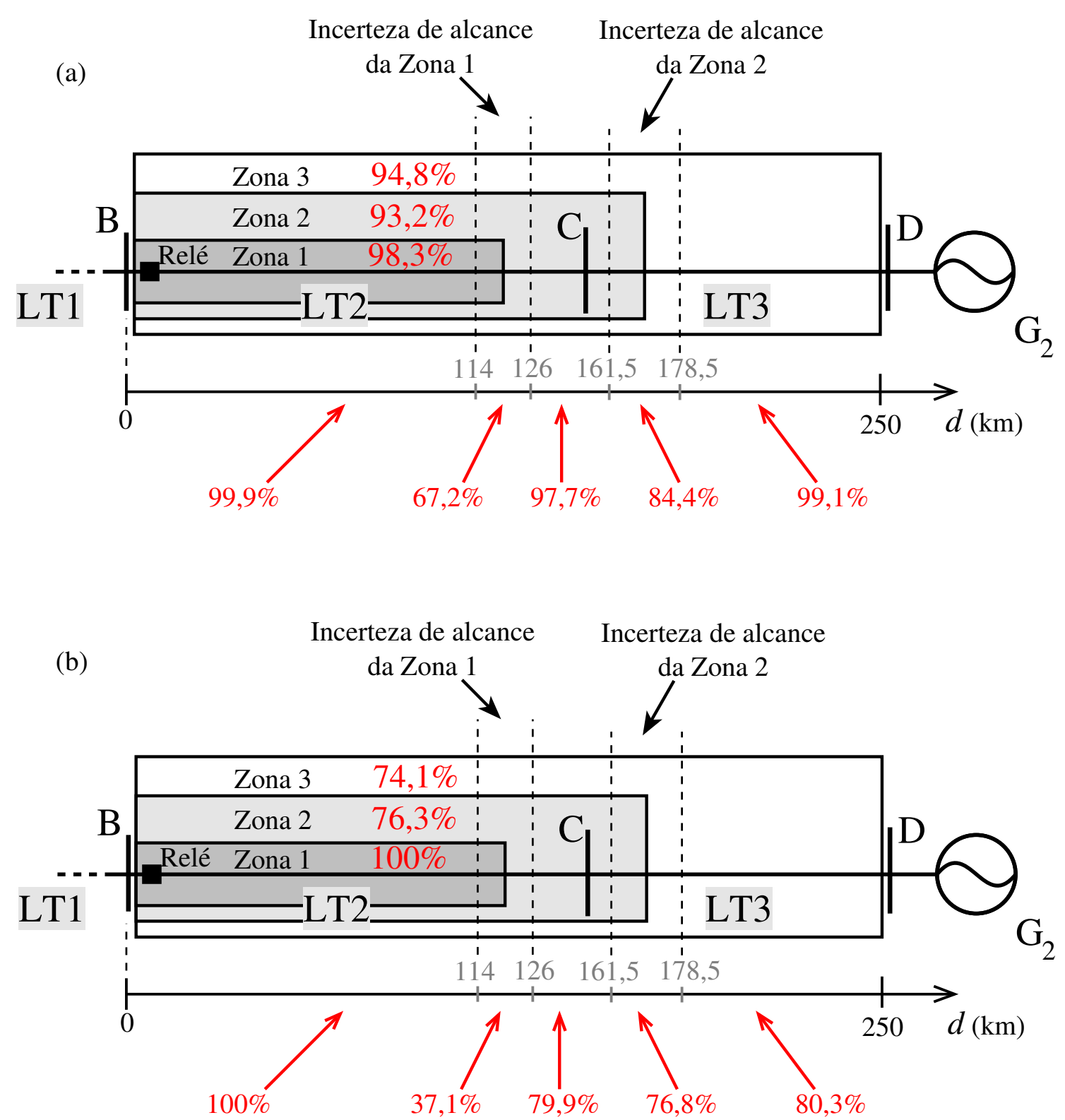

Figura 118. Resumo do resultado de localização (taxa de acerto) para faltas F-F-F: (a) metodologia proposta e; (b) metodologia tradicional.

\subsection{Considerações finais do capítulo}

Neste capítulo foi apresentada a estrutura proposta para um relé de proteção de LTs baseado em cumulantes e redes neurais artificiais. Foram realizadas extensas baterias de testes e o desempenho da metodologia proposta foi comparado com o desempenho de um relé tradicional baseado na impedância aparente. Especialmente 
para faltas monofásicas, observou-se ampla superioridade do algoritmo proposto nesta tese. Para os demais tipos de falta, observou-se que os índices de acerto de localização referentes ao relé tradicional são levemente superiores ao do método proposto para faltas na Zona 1. No entanto, nas demais zonas de proteção o desempenho da técnica proposta normalmente se sobressai. Os erros de localização do algoritmo baseado em cumulantes foram analisados e foram relacionados aos parâmetros da falta. Como exemplo, foi verificado que os erros de localização da Zona 1 normalmente ocorrem para distâncias de faltas bem próximas ao limite desta com a zona secundária. Essa análise se mostra importante, haja vista que pode guiar um novo processo de geração de padrões e treinamento de redes neurais visando à diminuição de erros. 


\section{CONSIDERAÇÕES FINAIS}

\subsection{Conclusões}

O presente trabalho abordou a proteção de distância de linhas de transmissão como um problema de classificação de padrões, de forma a prover soluções para as etapas de detecção, classificação e localização de faltas. Foram empregadas as estatísticas de ordem superior para a extração de características de sinais de corrente, unicamente, de modo a formar classes de padrões representativas do problema abordado. Para a identificação dos padrões, considerando as classes obtidas, foram empregadas redes neurais artificiais com arquitetura perceptron multicamadas. A técnica obtida possui relevância na área da proteção, conforme evidenciado pelos comentários conclusivos enunciados no que se segue.

Os resultados, apresentados inicialmente no Capítulo 5, dizem respeito à obtenção de combinações de cumulantes para geração de padrões representativos das classes envolvidas em cada etapa da proteção de distância. A aplicação do discriminante linear de Fisher como ferramenta de seleção de EOS se mostrou adequada para este objetivo, haja vista que impôs simplicidade no processo e as classes de dados obtidas foram separadas com sucesso pelas redes neurais empregadas. Apesar de ter sido observada uma pequena sobreposição de classes, o desempenho geral de validação das redes foi muito satisfatório, sendo a taxa de acerto mínima obtida superior a 98\%.

A montagem de um protótipo de relé foi permitida através da junção dos módulos de detecção, classificação e localização que passam a operar segundo um controlador de temporização. Este protótipo permitiu aplicar faltas no SEP, com variadas condições de distância, resistência e ângulo de incidência, simulando a operação da proteção. As baterias de testes realizadas demonstraram que os resultados obtidos com a nova 
metodologia implicam em melhorias da proteção de distância de linhas de transmissão, comparando o desempenho do método com o desempenho do método da impedância aparente, comumente empregado para este fim.

Considerando os tipos de faltas simuladas na etapa de operação do sistema de proteção, tem-se como destaque o desempenho do relé proposto na proteção do SEP quando da incidência de faltas envolvendo uma fase e a terra (F-T). De fato, o método proposto provê índice de acerto mínimo na localização superior a 93\%, sendo superior a 97\% para faltas ocorridas na Zona 1 de proteção. Nesta mesma zona, a taxa de acerto exibida pela metodologia baseada na impedância aparente é de apenas 41,4\%. É imperativo afirmar, no entanto, que o índice de acerto do método tradicional deve sofrer um aumento quando da consideração de mais amostras de regime pós-falta. No entanto, o objetivo, neste trabalho, foi a obtenção de um método que alie confiabilidade à rapidez, como evidenciado na Seção 6.3.

Ainda no tocante aos resultados de operação, para faltas do tipo F-F-T, apesar de a taxa de acerto de localização na Zona 3 ser menor para a metodologia proposta, a mesma ultrapassa o patamar dos 80\%. Adicionalmente, na Zona 2 tem-se índice de acerto $8 \%$ superior ao do relé tradicional, atingindo os $92,9 \%$ de eficiência. O relé baseado na análise da impedância aparente se sobressai na localização de faltas F-F-T na Zona 1. Para faltas envolvendo duas fases, sem a terra, a metodologia proposta obteve taxa de acerto superior aos $92 \%$ nas três zonas de proteção. Em oposição, o relé tradicional exibiu índices de aproximadamente $76 \%$ apenas, nas zonas 2 e 3 . Finalmente, para faltas trifásicas, o método baseado em EOS e RNA apresentou índice de acerto superior a $93 \%$ nas três zonas. Em contrapartida, o relé tradicional obteve índices na casa dos $70 \%$ para as zonas 2 e 3, apesar de ter exibido índice de acerto de $100 \%$ na zona 1. 
O emprego das redes neurais artificiais desempenha um papel importante no sistema de proteção proposto. Além da utilização de uma das suas características mais imponentes, de discriminação de padrões, outro aspecto a ser ressaltado é o auto-ajuste que é proporcionado à proteção. $\mathrm{O}$ uso de RNAs tende a diminuir a quantidade de ajustes manuais de limiares por parte dos engenheiros de proteção e este fator caracteriza um aspecto interessante para diminuição de erros. Isto, obviamente, se o conjunto de dados utilizado no desenvolvimento do esquema for representativo o suficiente para "mostrar" à rede o comportamento a ser modelado. Há de se salientar, no entanto, que a aplicação de um esquema de proteção baseado em redes neurais em SEPs com características distintas requererá certamente um novo processo de treinamento e validação.

O emprego de estatísticas de ordem superior mostrou-se adequado para o processamento dos sinais, provendo especialmente imunidade a ruído. Ademais, o uso de janela de tamanho reduzido na etapa de detecção permitiu que esta etapa fosse executada com rapidez e confiabilidade, como esperado. A utilização dos sinais de corrente para o cálculo destas estatísticas permitiu também a obtenção de um sistema de proteção que lide adequadamente com a presença de componentes de corrente CC de decaimento exponencial. Outro aspecto que pode ser considerado como melhorado diz respeito à ausência de transitórios de filtros digitais para estimação fasorial, já que os mesmos não estão presentes na técnica proposta.

Por fim, cabe salientar novamente a obtenção de uma nova metodologia baseada somente em sinais de corrente. Esta característica impõe, no mínimo, uma importante vantagem frente às demais técnicas: a ausência da necessidade do uso de transformadores de potencial. Apesar de ter sido utilizada uma rotina que emprega tensões e correntes para a determinação da direcionalidade de falta, pode-se agregar à 
metodologia proposta uma rotina de direcionalidade baseada em sinais de corrente apenas, tal como abordado anteriormente. Assim, obter-se-á uma técnica de proteção de linhas de transmissão baseada inteiramente em sinais de corrente.

\subsection{Propostas para trabalhos futuros}

Nesta seção, são delineadas algumas propostas vislumbradas para a continuidade das pesquisas no tema abordado neste trabalho. Estas propostas visam, especialmente, melhorias de desempenho e ampliação das aplicações de cumulantes em proteção. As sugestões são enumeradas como se segue.

- Inicialmente, destaca-se como importante sugestão a simulação de SEPs com modelos de frequência variante como o JMARTI. Apesar de resultados preliminares excelentes [86] na detecção de faltas com EOSs e RNAs para SEPs operando em frequências diferentes da nominal, as simulações com modelo de frequência variante certamente contribuem para a obtenção de um sistema de proteção mais adequado para operação prática em campo;

- Outras sugestões importantes no sentido de se obter um sistema de proteção altamente preparado para a operação em campo diz respeito à consideração de outras condições de simulações, tais como rejeição de cargas, oscilações de potência, energização de transformadores, etc. Um último, mas não menos importante aspecto a ser considerado diz respeito ao uso de TCs "práticos", visando à obtenção de esquemas de proteção imunes à saturação inerentes a estes dispositivos.

- Uma outra investigação sugerida consiste na verificação da aplicação dos cumulantes em sinais de corrente para verificação da direcionalidade da 
falta obtendo-se, assim, um sistema de proteção baseado inteiramente nesta ferramenta. Da mesma forma, propõe-se a aplicação de cumulantes para estimação da distância de ocorrência da falta, utilizando redes neurais para aproximação funcional em substituição à classificação de padrões.

- A utilização de ferramentas mais poderosas que o discriminante linear de Fisher para seleção de parâmetros é também vislumbrada. De fato, a metodologia empregada neste trabalho, apesar de ter levado a combinações de parâmetros adequados para a proteção, pode não ter selecionado os melhores cumulantes. Desta forma, espera-se obter combinações de cumulantes mais adequadas para a solução dos problemas. Ademais, pode-se investigar a utilização de um número maior de parâmetros para as representações de classes.

- Finalmente, verificada a eficiência da metodologia proposta, é recomendada e colocada como sugestão a investigação da aplicação de estatísticas de ordem superior na proteção de outros componentes de SEPs, tais como transformadores de potência, por exemplo. 


\section{REFERÊNCIAS BIBLIOGRÁFICAS}

[1] STEVEnSON JR., W. D. Elementos de Análise de Sistemas de Potência, São Paulo: McGraw-Hill, 1974. 861 p.

[2] CAMARGO, C. B. Gerenciamento pelo lado da demanda: metodologia para identificação do potencial de conservação de energia elétrica de consumidores residenciais. 1996. Tese (Doutorado em Eng. de Produção), Universidade Federal de Santa Catarina, Florianópolis, 1996.

[3] AGÊNCIA NACIONAL DE ENERGIA ELÉTRICA, Atlas da Energia Elétrica do Brasil. $3^{\mathrm{a}}$ ed. 2008. Disponível em: <http://www.aneel.gov.br/ arquivos/PDF/atlas3ed.pdf > . Acesso em: 27 de julho 2012.

[4] JORGE, D. C.; COURY, D. V.; CARVAlHO, A. C. P. L. F. Localização de faltas em linhas de transmissão utilizando reconhecimento de padrões. In: IV BRAZILIAN CONFERENCE ON NEURAL NETWORKS, 1999, São José dos Campos, Proceedings... pp. 61-66.

[5] JORGE D. C, Redes neurais artificiais aplicadas à proteção de sistemas elétricos de potência. 1997. 104 f. Dissertação (Mestrado em Eng. Elétrica), Escola de Engenharia de São Carlos, Universidade de São Paulo , São Carlos, 1997.

[6] WADHWA, C. L. Electrical Power Systems. $4^{\text {a }}$ ed. Nova Delhi, India: New Age International Publishers, 2005. 890 p.

[7] PHADKE, A. G.; THORP, J. S. Computer relaying for power systems, Reino Unido: John Wiley and Sons, 1988. 326 p.

[8] CAMINHA, A. C. Introdução à Proteção dos Sistemas Elétricos de Potência, São Paulo: Edgar Blücher, 1977. 212 p.

[9] COURY, D. V.; OLESKOVICZ, M.; GIOVAnINI R., Proteção Digital de Sistemas Elétricos de Potência: dos relés eletromecânicos aos microprocessadores inteligentes. São Carlos: EESC-USP. 2007. 378 p.

[10] LI, K. K., LAI, L. L. Ideal operating region of digital distance relay under high resistance earth fault. Electric Power Systems Research, v. 43, p. 215-219, 1997.

[11] MARQUES, C. A. G. Técnica de detecção de distúrbios para o monitoramente da qualidade da energia. 2007. 103 f. Dissertação (Mestrado em Eng. Eléttrica), Universidade Federal de Juiz de Fora, Juiz de Fora, 2007.

[12] MITRA, S. K. Digital Signal Processing: A Computer-based Approach, $3^{\text {rd }}$ ed. Nova Delhi, Tata McGraw-Hill, 2006. 972 p.

[13] SMITH, S. W. The scientist and engineer's guide to digital signal Processing. $2^{\mathrm{a}}$ ed. San Diego, CA-EUA: California Technical Publishing, 1999, 650 p.

[14] MOHANTY, S. R.; PRADHAN, A. K.; ROUTRAY A. A cumulative sum-based fault detector for power system relaying application. IEEE Transactions on Power Delivery, v. 23, n. 1, p. 79-86, 2008. 
[15] MACÊDO, R. A., COURY, D. V. Um esquema complete para proteção rápida de linhas de transmissão com o uso de equações diferenciais. Revista SBA Controle \& Automação, v. 14, n. 2, p. 176-186, 2003.

[16] SOUZA, S. A. Algoritmos genéticos aplicados à proteção e à estimação de harmônicos em sistemas elétricos de potência. 2008. 214 f. Tese (Doutorado em Eng. Elétrica), Universidade de São Paulo, São Paulo, 2008.

[17] MUNDAY, P. J.; LUCKETT, R. G.; MURRAY, B. E. A substation based computer for control and protection. IEE Conference Publication, vol. 1, p. 291299, 1975.

[18] BROOKS JR., A. W. "Distance relaying using least-square estimates of voltage current and impedance." In: IEEE POWER INDUSTRY COMPUTER APPLICATION CONFERENCE, 1977, Proceedings... p. 394-402.

[19] SACHDEV, M. S.; BERIBEAU, M. A. A new algorithm for digital impedance relays. IEEE Transactions on Power Apparatus and Systems, vol. PAS-98, n. 6, p. 2232-2240, 1979.

[20] ALFUHAID, A. S.; EL-SAYED, M. A. A recursive lest-squares digital distance relaying of transmission lines. IEEE Transactions on Power Delivery, vol. 14, n. 4, p. 1257-1262, 1999.

[21] PHADKE, A. G.; HLIBKA, T.; IBRAHIM, M. A digital computer system for EHV substation: analysis and field tests. IEEE Transactions on Power Apparatus and Systems, vol. PAS-95, n. 1, p. 291-301, 1976.

[22] PHADKE, A. G.; THORP, J. S.; ADAMIAK, M. G. A new measurement technique for tracking voltage phasors, local system frequency and rate of change of frequency. IEEE Transactions on Power Apparatus and Systems, vol. PAS102, n. 5, pp. 1025-1033, 1983.

[23] EICHHORN, K. F.; LOBOS, T. Recursive real-time calculation of basic waveforms of signals. IEE Proceedings C - Generation, Transmission and Distribution, vol. 138, n. 6, p. 469-470, 1991.

[24] COOLEY, J. W. How the FFT gained acceptance. IEEE Signal Processing Magazine, vol. 9, p. 10-13, 1992.

[25] EICHHORN, K. F.; LADNIAK, L.; LOBOS, T. Algorithms for digital distance protection with improved transient behavior. In: JOINT INTERNATION POWER “ATHENS POWER TECH" CONFERENCE, 1993, Atenas - Grécia, Proceedings... p. 290-294.

[26] YU, S.-LI.; GU, J.-C. Removal of decaying DC in current and voltage signals using a modified Fourier filter algorithm. IEEE Transactions on Power Delivery, vol. 16, n. 3, p. 372-379, 2001.

[27] WANG, M.; SUN, Y. A practical, precise method for frequency tracking and phasor estimation. IEEE Transactions on Power Delivery, vol. 19, n. 4, p. 15471552, 2004.

[28] CHEN, C. S.; LIU, C. W.; JIANG. J. A. Application of combined adaptive Fourier filtering technique and fault detector to fast distance protection. IEEE Transactions Power on Delivery, vol. 21, n. 2, p. 619-626, 2006. 
[29] GIRGIS, A. A.; BROWN, G. R. Application of Kalman filtering in computer relaying. IEEE Transactions on Power Apparatus and Systems, vol. PAS-100, n. 7, p. 3387-3397, 1981.

[30] GIRGIS, A. A. A new Kalman filtering based digital distance relaying. IEEE Transactions on Power Apparatus and Systems, vol. PAS-101, n. 9, p. 34713479, 1982.

[31] GIRGIS, A. A.; BROWN, G. R. Adaptive Kalman Filtering in Computer Relaying - Fault Classification Using Voltage Models. IEEE Transactions on Power Apparatus and Systems, vol. PAS-104, n. 5, p. 1168-1174, 1985.

[32] PRADAN, A. K.; ROUTRAY, A.; SETHI, D. Voltage phasor estimation using complex linear Kalman Filter. In: $8^{\text {th }}$ IEE INTERNATIONAL CONFERENCE ON DEVELOPMENTS IN POWER SYSTEM PROTECTION, 2004, Amsterdã Holanda, Proceedings... p. 24-27.

[33] KHAPARDE, S. A.; KALE, P. B.; AGARWAL, S. H. Application of artificial neural network in protective relaying of transmission lines. In: FIRST INTERNATIONAL FORUM ON APPLICATIONS OF NEURAL NETWORKS TO POWER SYSTEMS, 1991, Seattle - EUA, Proceedings... p. 122-125.

[34] SAKAGUCHI, T. A statistical decision theoretic approach to digital relaying. IEEE Transactions on Power Apparatus and Systems, vol. PAS-99 (5), p. 1918-1926, 1980

[35] CHAKRAVARTHY, S. K.; NAYAR, C. V.; ACHUTHAN, N. R. Applying pattern recognition in distance relaying - part 1: Concepts. IEE Proceedings C Generation, Transmission and Distribution, v. 139, n. 4, p. 301-305.

[36] DALSTEIN, T. E; KULICHE, B. Neural network approach to fault classification for high speed protective relaying. IEEE Transactions on Power Delivery, vol.10, n. 2, p. 1002-1011, 1995.

[37] JONGEPIER, A. G.; VAN DER SLUIS, L. Adaptive distance protection of double-circuits lines using ANN. IEEE Transactions on Power Delivery, vol. 12, n. 1, p. 97-105, 1997.

[38] COURY, D. V.; JORGE, D. C. Artificial neural network approach to distance protection of transmission lines. IEEE Transactions on Power Delivery, v. 11, n. 1, p. 102-108, 1998.

[39] OLESKOVICZ , M.; COURY, D. V.; AGGARWAL, R. K. Redes neurais artificiais aplicadas à classificação rápida de faltas em sistemas elétricos de potência. Revista SBA: Controle \& Automação, v. 11, n. 3, p. 160-168, 2000.

[40] OSMAN, A.H.; ABDELAZIM, T.; MALIK, O. P. Transmission line distance relaying using on-line trained neural networks. IEEE Transactions on Power Delivery, v. 20, n. 2, p. 1257-1264, 2005.

[41] ZHANG, N.; KEZUNOVIC, M. Transmission line boundary protection using wavelet transform and neural network. IEEE Transactions on Power Delivery, v. 22, n. 2, p. 859-869, 2007.

[42] DUTTA, A. A.; KADU, A. N., (2010). Pattern recognition methods for detecting fault in EHV transmission lines. In: II INTERNATION CONFERENCE ON 
MECHANICAL AND ELECTRICAL TECHNOLOGY, 2010, Singapura, 2010 $2^{\text {nd }}$ ICMET. p. 24-27.

[43] RANJBAR, A. M.; CORY, B. J. An improved method for the digital protection of high voltage transmission lines. IEEE Transactions on Power Apparatus and Systems, v. PAS-94, n. 2, p. 544-550, 1975.

[44] AKKE, M. A.; THORP, J. S. Some improvements in the three-phase differential equation algorithm for fast transmission line protection. IEEE Transactions on Power Delivery, vol. 13, n. 1, p. 66-72, 1998.

[45] CROSSlEY, A.; MACLAREN, P. G. Distance Protection Based on Travelling Waves. IEEE Transactions on Power Apparatus and Systems, v. PAS-102, n. 9, p. 2971-2983, 1983.

[46] DUTTA, K.; GUPTA, P. B. D. Microprocessor-based UHS relaying for distance protection using advanced generation signal processing. IEEE Transactions on Power Delivery, v. 7, n. 3, p. 1121-1127, 1992.

[47] OSMAN, A. H.; MALIK, O. P. Transmission line distance protection based on wavelet transform. IEEE Transactions on Power Delivery, v. 19, n. 2, p. 515524, 2004.

[48] LIANG, F.; JEYASURYA, B. Transmission line distance protection using wavelet transform algorithm. IEEE Transactions on Power Delivery, v. 19, n. 2, pp. 545-553, 2004.

[49] GRCAR, B.; RITONJA, J.; POLAJZER, B.; STANKOVIC, A. M. Estimation methods using dynamic phasors for numerical distance protection. IET Generation, Transmission \& Distribution, v. 2, n. 3, p. 433-443, 2008.

[50] YU, C.-S. A discrete Fourier transform-based adaptive mimic phasor estimator for distance relaying applications. IEEE Transactions on Power Delivery, v. 21, n. 4, p. 1836-1846, 2006.

[51] CHO, Y. S.; LEE, C. K.; JANG, G.; LEE, H. J. An innovative decaying DC component estimation algorithm for digital relaying. IEEE Transactions on Power Delivery, v. 24, n. 1, p. 73-78, 2009.

[52] COURY, D. V.; OLESKOVICZ, M.; SOUZA, S. A. Algoritmos genéticos aplicados a uma rápida proteção de distância de linhas de transmissão. Revista SBA Controle \& Automação, vol. 22, n. 4, p. 334-344, 2011.

[53] PRADHAN, A. K.; ROUTRAY, A.; BISWAL, B. Higher order statistics-fuzzy integrated scheme for fault classification of a series-compensated transmission line. IEEE Transactions on Power Delivery, v. 19, n. 2, p. 891-893, 2004.

[54] GIANNAKIS, G. B.; TSATSANIS, M. K. Signal detection and classification using matched filtering and higher order statistics. IEEE Transactions on Acoustics, Speech and Signal Processing, v. 38, n. 7, p. 1284-1296, 1990.

[55] COLONNESE, S.; SCARANO, G. Transient signal detection using higher order moments. IEEE Transactions on Signal Processing, v. 47, n. 2, p. 515-520, 1999. 
[56] BOASHASH, B. Time-Frequency Signal Analysis: methods and applications, Melbourne: Longman Cheshire Pry Limited, 1992. 547 p.

[57] NIKIAS, C. L.; MENDEL, J. M. Signal processing with higher-order spectra. IEEE Signal Processing Magazine, v. 10, n. 3, p. 10-37, 1993.

[58] MENDEL, J. M. Tutorial on higher-order statistics (Spectra) in signal processing and system theory: theoretical results and some applications. Proceedings of the IEEE, v. 79, n. 3, p. 278-305, 1991.

[59] RIBEIRO, M. V.; MARQUES, C. A. G.; DUQUE, C. A.; CERQUEIRA, A. S.; PEREIRA, J. L. R. Detection of disturbances in voltage signals for Power quality analysis using HOS. EURASIP Journal on Advances in Signal Processing, v. 2007, n. 1, 2007.

[60] GEREK, Ö. N.; ECE, D. G. Power quality event analysis using higher order cumulants and quadratic classifiers. IEEE Transactions on Power Delivery, v. 21, n. 2, p. 883-889, 2006.

[61] FERREIRA, D. D.; CERQUEIRA, A. S.; DUQUE, C. A.; RIBEIRO, M. V. "HOS-based method for classification of power quality disturbances," Electronics Letters, v. 45, n. 3, p. 183-185, 2009.

[62] SILVA, I. N.; SPATTI, D. H.; FLAUZINO R. A. Redes Neurais Artificiais para engenharias e ciências aplicadas. São Paulo: Artliber, 2010. 399 p.

[63] HAYKIN, S. Neural Networks: A Comprehensive Foundation, New Jersey: Prentice-Hall, 1999. 696 p.

[64] MCCULLOCH, W. S.; PITTS, W. A logical calculus of the ideas immanent in nervous activity. Bulletin of Mathematical Biophysics, v. 5, p. 115-113, 1943.

[65] HEBB, D. O. The organization of behavior: a neuropsychological theory. New York, USA: Wiley, 1949. 335 p.

[66] ROSENBLATT, F. The perceptron: a probabilistic model for information storage and organization in the brain. Psychological Review, v. 65, n. 6, p. 368-408, 1958.

[67] WIDROW, B.; HOFF, M. E. Adaptive switching circuits. In: IRE WESCON CONVENTION RECORD, Los Angeles - EUA, IRE Wescon Convention Record p. 96-114.

[68] MINSKY, M. L.; PAPERT, S. A. Perceptrons: an introduction to computational geometry. Cambridge, MA, USA: The MIT Press, 1969.

[69] GROSBERG, S. How does a brain build a cognitive code? Psychological Review, v. 87, n. 1, p. 1-51, 1980.

[70] KOHONEN, T. Self-organizing formation of topologically correct feature maps. Biological Cybernetics, v. 43, n. 1, p. 59-69, 1982.

[71] HOPFIELD, J. J. Neural network and physical systems with emergent collective computational abilities. Proceedings of the National Academy of Sciences of the USA, v. 79, n. 8, p. 2554-2558, 1982. 
[72] RUMELHART, D. E.; HINTON, G. E.; WILlIAMS， R. J. Learning Representations by Back-propagation Error. Nature, v. 323, p. 533-536, 1986

[73] GRAF, H. P.; JACKEL, L. D. (1988); Advances in neural network hardware. In: INTERNATIONAL ELECTRON DEVICES MEETING, São Francisco - EUA, Electron Devices Meeting, 1988 IEDM'88 Technical Digest., International, p. 766-769, 1988.

[74] THEODORIDIS, S.; KOUTROUMBAS, K. Pattern Recognition. $2^{\mathrm{a}}$ ed. San Diego - EUA: Academic Press, 2003. 681 p.

[75] CANDAN, K. S.; SAPINO, M. L. Data management for multimedia retrieval. New York - EUA: Cambridge University Press, 2010. 473 p.

[76] MIRA, J.; ÁlvareZ, J. R. (Ed.) Computional methods in neural modeling. Berlim: Springer-Verlag, 2003. 773 p.

[77] DINIZ, P. S. R.; SILVA, E. A. B.; NETTO, S. L. Processamento Digital de Sinais: Projeto e análise de sistemas. Porto Alegre, Bookman, 2004. 590p.

[78] SEDRA, A. S.; SMITH, K. C. Microeletrônica, 4a ed. São Paulo, Makron Books, 2000. $1270 \mathrm{p}$.

[79] TOCCI, R. J.; WIDMER, N. S. Sistemas Digitais: princípios e aplicações. $8^{\mathrm{a}}$ ed. São Paulo, Prentice Hall, 2003. 755 p.

[80] IEE - POWER SYSTEM PROTECTION. Volume 4: Digital protection and signaling. Edited by The Electricity Training Association, IEE Institution of Electrical Engineers, United Kingdom.

[81] SILVA, M. Localização de faltas em linhas de transmissão utilizando a teoria de ondas viajantes e transformada wavelet. 2003. $231 \mathrm{f}$. Dissertação (Mestrado em Eng. Elétrica), Universidade de São Paulo, São Carlos, 2003.

[82] VALINS, T. F. Relé digital de distância baseado na teoria de ondas viajantes e transformada wavelet. 2005. 143 f. Dissertação (Mestrado em Eng. Elétrica), Universidade de São Paulo, São Carlos, 2005.

[83] EUROPEAN EMTP-ATP USERS GROUP. Alternative Transients Program Rule Book. 1987.

[84] PRADHAN, A. K.; ROUTRAY, A.; GUDIPALLI, S. M. Fault direction estimation in radial distribution system using phase change in sequence current, IEEE Transactions on Power Delivery. v. 22, n. 4, p. 2065-2071, 2009.

[85] UKIL, A.; DECK, B.; SHAH, V. H. Current-only directional overcurrent protection distribution automation: challenges and solutions. IEEE Transactions on Smart Grid, v. 3, n. 4, p. 1687-1694, 2012.

[86] CARVAlHO, J. R.; COURY, D. V.; OliVEIRA, D. L. S.; DUQUE, C. A. Um Novo Método de Detecção Rápida de Faltas em Linhas de Transmissão Utilizando Redes Neurais Artificiais e Cumulantes. In: SIMPÓSIO BRASILEIRO DE AUTOMAÇÃO INTELIGENTE (SBAI), 10., 2011, São João Del Rei - MG. Anais... São João Del Rei: UFSJ, 2011. 


\section{APÊNDICE A - PUBLICAÇÕES RELATIVAS À PESQUISA}

Encontram-se listados abaixo artigos científicos elaborados, relacionados ao trabalho desenvolvido nesta pesquisa de doutorado e apresentados em eventos científicos ou submetidos a periódicos de relevância acadêmica.

\section{A.1 CONGRESSOS:}

CARVAlHO, J. R., COURY, D. V., DUQUE, C. A., JORGE, D. C. Development of Detection and Classification Stages for a New Distance Protection Approach Based on Cumulants and Neural Networks. Apresentado no IEEE PES General Meeting, de 24 a 28 de Julho, Detroit, EUA.

CARVAlHO, J. R., COURY, D. V., OlIVEIRA, D. L. S., DUQUE, C. A. Um Novo Método de Detecção Rápida de Faltas em Linhas de Transmissão Utilizando Redes Neurais Artificiais e Cumulantes. Apresentado no X Simpósio Brasileiro de Automação Inteligente (SBAI), de 18 a 21 de setembro de 2011, São João Del Rei MG, Brasil.

\section{A.2 PERIÓDICOS:}

CARVAlHO, J. R., COURY, D. V., DUQUE, C. A., PAULA, B. F. A New Protection of Transmission Lines using Cumulants and Artificial Neural Networks. $\underline{\text { Aceito }}$ para publicação no periódico Journal of Control, Automation and Electrical Systems. 